\title{
LIVING IN-BETWEEN \\ THE PHENOMENOLOGY OF THE CORRIDIC SPACE
}

\author{
by \\ Arnab Ghosh \\ Bachelor of Architecture, SSAA, GGSIPU, India \\ 2016 \\ A thesis \\ presented to Ryerson University \\ in partial fulfillment of the \\ requirements for the degree of \\ Master of Architecture \\ in the Program of \\ Architecture
}

Toronto, Ontario, Canada 2019

(C) Arnab Ghosh 2019 


\section{AUTHOR'S DECLARATION}

I hereby declare that I am the sole author of this thesis. This is a true copy of the thesis, including any required final revisions, as accepted by my examiners.

I authorize Ryerson University to lend this thesis to other institutions or individuals for the purpose of scholarly research.

I further authorize Ryerson University to reproduce this thesis by photocopying or by other means, in total or in part, at the request of other institutions or individuals for the purpose of scholarly research.

I understand that my thesis may be made electronically available to the public. 
Living In-Between

Arnab Ghosh

Master of Architecture 2019

Ryerson University

\section{Abstract}

The ubiquitous corridor in contemporary multi-storied buildings, evince a strong liminal presence as a threshold space. Albeit its passivity, such a space exhibit a potential for playing a determining role in how the social forces shape the structure of community in such systems. The aim of the thesis is to extrude the liminal aspect of a corridor through a phenomenological investigation and determine a new threshold dialectics; the 'corridic place'. The idea of the corridic place is to introduce a new perspective of social dialectics, place-building etc. and recompose the notion of dwelling in a threshold space. By giving material and expression to the dynamism of human dwelling, the corridic place transcends the physical and psychological constraints of a corridor and generates a transformative space conducive to community building. 
Living In-Between 


\section{Acknowledgement}

The completion of this thesis is indebted to a distinguished few:

\section{Dr. Kendra Schank Smith}

For our insightful conversations and her invaluable contribution in the development of the project

\section{Dr. June Komisar}

For her unwavering enthusiasm and contribution in developing the project.

\section{Arthur Wrigglesworth and John Cirka}

For their critical insight and posing the necessary and difficult questions at every milestone.

\section{My family}

For their unfailing support. 
Living In-Between 
Dedicated to my beloved parents 


\section{Table of Contents}

Author's declaration $\quad$ ii

Abstract iii

Acknowledgement $\quad \mathrm{v}$

Dedication vii

List of Figures $x$

List of Appendices xvii

$\begin{array}{ll}0.1 \text { Living In-Between: An introduction } & 1\end{array}$

1.0

$\begin{array}{ll}\text { 1.1 The Birth of the Domestic Corridor } & 7\end{array}$

1.2 The liminal Existence: Rituals and the Built environment 14

1.2.1 Liminality: Definition and Significance 14

1.2.2 The Liminal Entity at Threshold 15

Drawing Parallels from understanding of liminality by Arnold Van Gennep and Victor Turner

$\begin{array}{ll}1.2 .3 \text { Communitas } & 20\end{array}$

2.0

2.1 Textures of the Corridic Place 23

2.1.1 The dialectics of Social Space 24

2.1.2 Domination and Appropriation 26

$\begin{array}{ll}2.1 .3 \text { Place Building } & 30\end{array}$

$\begin{array}{ll}2.1 .4 \text { Placeless-ness } & 31\end{array}$

2.2 Creating Humanistic Topographies in a Corridic Place 34

2.3 Hapticity in a Corridic Place 36

2.3.1 Fragile Ontology of a corridic place 37

2.3.2 The Aesthetic ideal in an Imperfect Space 40 
3.0

3.1 Language of the Corridic Place 43

3.1.1 Street-scaping 43

3.1.2 Porch in Be-twixt $\quad 52$

$\begin{array}{ll}3.1 .3 \text { Architecture of Change } & 60\end{array}$

3.2 Threshold transitions in a Corridic Space 66

3.2.1 The enfilade of the senses 67

3.2.2 Importance of the threshold 68

$\begin{array}{ll}\text { 3.2.3 The Spatial Delimiters } & 70\end{array}$

3.2.3.1 Arcades/ Colonnades and change in Architectural 72 sclae, weight

3.2.3.2 Ramps and Architectural Promenades $\quad 74$

4.0

4.1 Corridic Iterations of Thresholds and Movement Spaces: Constructing Atmospheres

5.0

5.1 The Case for Co-Housing

6.0

$\begin{array}{ll}\text { 6.1 The Corridic Model } & 97\end{array}$

6.1.1 Site, Location and Approach 97

6.1.2 The Corridic House 118

$\begin{array}{llr}\text { 6.2 Corridic Speculations } & 138\end{array}$

$\begin{array}{ll}\text { Appendices } & 141\end{array}$

$\begin{array}{lr}\text { Bibliography } & 148\end{array}$ 


\section{List of Figures}

Fig 1: The liminal residential corridor. 'Time' and 'matter' out of place

Source: Arnab Ghosh

Fig 2: Thresholds like doors and windows are playgrounds for human interiority.

1. Office in Small City. Painting by Edward Hopper.

Source: Edward Hopper-Biography, paintings and Quotes.

https://www.edwardhopper.net/office-in-a-small-city.jsp

2. Young Man at his window. Painting by Gustave Caillebotte

Source: Gustave Caillebotte's Urban Intimacy.

https://www.dailyartmagazine.com/gustave-caillebottes-urban-intimacy/

3. Woman at the window. Painting by Caspar David Friedrich

Source: Casper David Friedrich, The complete works.

https://www.caspardavidfriedrich.org/Woman-At-A-Window-1822.html

4. Hotel by a railroad. Painting by Edward Hopper

Source: Edward Hopper, Complete works

https://www.wikiart.org/en/edward-hopper/hotel-by-a-railroad

Fig 3: Transition from andito to passagio, Palazzo Ducale, Italy

Source: Plan of the ground floor of the Palazzo Ducale. Venetian Art https://library.bc.edu/venetianart/exhibits/show/d--palazzo-ducale/item/589

Fig 4: Vasari Corridor

Source: The Museums of Florence http://www.museumsinflorence.com/musei/corridoio_vasariano.html

Fig 5: Enfilade House Plan, Chateau de Vaux-le-Vicomte

Source: Plan of the ground floor engraved by Jean Marot https://en.wikipedia.org/wiki/Vaux-le-Vicomte

Fig 6 : Emergence of the residential corridor

1. $18^{\text {th }}$ century Blenheim Palace.

Source: https://in.pinterest.com/pin/522839837972227927/?1p=true

2. $19^{\text {th }}$ century Parisian apartment plan.

Source: http://eraallstarproperties.com/19th-century-floor-plans/

3. $20^{\text {th }}$ century Pre-WW1 apartment plan.

Source: https://mentalfloss.com/article/58390/10-elaborate-floor-plans-pre-world-wari-new-york-city-apartments

Fig 7: Deconstruction and dissolution of the passive corridor.

Source: Arnab Ghosh 
Fig 8: Spatialisation. A textured multi-layered association of objects that come into being as an expression of inhabitation

Source: Arnab Ghosh

Fig 9: Material and haptic sequences we encounter when we stroll through an urban space that has emerged organically.

Source: Arnab Ghosh

Fig 10: Sequential construction of a house through experience and sensations.

Source: Arnab Ghosh

Fig 11: De-constructing the dwelling space

Source: Arnab Ghosh

Fig 12: Haptic Mapping of a Corridic Space

Source: Arnab Ghosh

Fig 13: Ambient episode

Source: Arnab Ghosh

Fig 14: The imperfect ideal of the corridic place

Source: Arnab Ghosh

\section{0}

Fig 15:Motor-centric city

Top- emergence of the street as a space for auto-centric movement and diminishing pedestrian sensitivity

Source: Delivery trucks jamming West 37th Street, NYC, 1945 |

Photo by Al Aumuleer. New York World Telegram \& Sun Collection, Library of Congress

https://www.pps.org/article/reimagining-our-streets-as-places-from-transitroutes-to-community-roots

Bottom- Urban Machine. Parallel can be drawn between the street and the utilitarian consolidation of the building corridor

Source: Harvey Wiley Corbett Style Cities of Tomorrow http://artcontrarian.blogspot.com/2014/04/harvey-wiley-corbett-style-citiesof.html

Fig 16: Aranya Housing layout, B.V. Doshi.

Source: Indore,India, Aranya Housing project https://www.architectureindevelopment.org/project.php?id=401

Fig 17: Aranya Housing Street. Miniature drawing by B.V.Doshi.

Source: http://web.mit.edu/incrementalhousing/articlesPhotographs/pdfs/ aranya-3-Details1146.pdf

Fig 18: Kyojima District, Japan

Source: Photo by ogino.taro. https://www.flickr.com/photos/ogitaro/ 
Fig 19: Organisation of living spaces in Moriyama house

Source: https://www.moma.org/collection/works/181232

Fig 20: Street-scaping the residential corridor

Source: Arnab Ghosh

Fig 21: Street dialectics of a corridic space in a residential system

Source: Arnab Ghosh

Fig 22: From portico to porch. Mediating the indoor-outdoor dynamics

Source:Etching by James Stuart (1713-1788) and Nicholas Revett (1720-1804)

The Antiquities of Athens, Volume 1 (1762)

http://sites.middlebury.edu/untouchedbytime/the-early-travelers/

2. Loggia in a Renaissance villa

Source:The loggia of the Capitanio of Vicenza

https://www.venicemyway.org/testimonianze-di-lepanto-nello-stat

3. The porch in a Victorian house

Source:https://fanvid-recs.com/architectural-plans-printing/architectural-plans-printing -and-1873-print-cottage-architectural-design-floor-plans/

Fig 23: Hybridization of the Victorian porch and the African Shotgun houses consolidated into the dialectics of the American porch

1. Traditional Caille house, An African predecessor to Shotgun houses

Source: http://www.newsouthassoc.com/springfield/arch3.html

2. Shotgun houses built by African immigrants in America

Source: http://northbysouth.kenyon.edu/2002/Space/shot2.htm

3. Late $19^{\text {th }}$-Early $20^{\text {th }}$ century domestic porch in America

Source: https://www.brickandbeamdetroit.com/resources/preserving-historic -wood-porches

Fig 24: De-constructing Visual and Physical proximity for layered interaction

Source: Arnab Ghosh

Fig 25: Propinquity principles in a corridic configuration in a residential space

Source: Arnab Ghosh

Fig 26: Gucklhupf House. Spatial play

Source: http://architectuul.com/architect/hans-peter-worndl

Fig 27: Naked House, Mobility

Source: Naked House / Shigeru Ban. http://archeyes.com/naked-house-shigeru-ban/ 
Fig 28: Flexible spatial delineations articulate adaptable programmatic spaces in a corridic space

Source: Arnab Ghosh

Fig 29: Fluid spatial delineation in a corridic space. Plugging/ Un-plugging program

Source: Arnab Ghosh

Fig 30: Fun Palace for Joan Littlewood project, Cedric Price

Source: Fun Palace for Joan Littlewood Project, Stratford East, London, England (Perspective) 1959-1961

https://www.moma.org/collection/works/842

Fig 31: Taking inspiration from the Fun Palace project, the corridic space employs a framework of "plugging and unplugging" adaptable programmatic spaces in its threshold configurations

Source: Arnab Ghosh

Fig 32: 1. Sequential space in a typical Roman house.

Source: https://jhmrad.com/7-best-photo-of-floor-plan-of-a-roman-villa-ideas/ancientroman-house-atrium-plan-typical-home-plans/

2. Japanese house section showing layered transition

Source: Japanese Homes and their suroundings. https://www.kellscraft.com/Japanese Homes/JapaneseHomesCh03.html

Fig 33: 1. Arcades/Colonnades and change in architectural weight and scale

Source: (left) Renaissance colonnade courtyard of Ca'Granada. https://www.dezeen. com/2018/04/16/peter-pichler-wooden-pyramid-pavilion-milan-design-week/ (right)Burlington Arcade. http://www.thesimplyrefined.com/londons-arcades/

Source: 2. Ramps and architectural promenades (left) Vila Savoye Ramp. Photo by Monceau. https://www.flickr.com/photos/ monceau/7645289926/in/photostream/

(right) Centrosoyus, Moscow by Le Corbusier. http://architectuul.com/archi -tecture/centrosoyus-building

Fig 34: Threshold conditions analysis in an arcade/colonnade

Source: Arnab Ghosh

Fig 35: Exaggerating seperate-ness by inserting unique interstitial spatial configurations

Source: Arnab Ghosh

Fig 36a:Study diagram: Compression and Decompression in corridic space

Source: Arnab Ghosh

Fig 36b:Constructing atmospheres: Compression and Decompression in corridic space

Source: Arnab Ghosh 
Fig 37a:Study diagram: Ramps and shift in Architectural weight and Mass

Source: Arnab Ghosh

Fig 37b:Constructing atmospheres: Ramps and shift in Architectural weight and Mass

Source: Arnab Ghosh

Fig 38a:Study diagram: Spatial layers in a corridic promenade

Source: Arnab Ghosh

Fig 38b:Constructing atmospheres: Spatial depth in a corridic promenade

Source: Arnab Ghosh

Fig 39a:Study diagram: Spatial delimiters mediating indoor-outdoor dialectics and creating different threshold variations in a corridic space

Source: Arnab Ghosh

Fig 39b:Constructing atmospheres: Creating conditions for experiential snippets and moments of pause through the interplay of spatial delimiters

Source: Arnab Ghosh

Fig 40: Corridic model in a closed system.

Source: Arnab Ghosh

Fig 41: Baugruppen model: Spreefeld housing, Berlin.

Source: https://www.archdaily.com/587590/coop-housing-project-at-the-riv -er-spreefeld-carpaneto-architekten-fatkoehl-architekten-bararchitekten

Fig 42: Baugruppen model: Spreefeld housing, Berlin.

Source: https://www.archdaily.com/587590/coop-housing-project-at-the-riv -er-spreefeld-carpaneto-architekten-fatkoehl-architekten-bararchitekten

Fig 43: Baugruppen model: R50, Berlin.

Source: https://www.archdaily.com/593154/r50-nil-cohousing-ifau-und-jesko-fezer-heide-and-von-beckerath/

\section{0}

Fig 44: The site at the threshold of two different housing conditions

Source: Arnab Ghosh

Fig 45: Site edge conditions

Source: Arnab Ghosh

Fig 45: Site edge conditions

Source: Arnab Ghosh

Fig 46: Context study

Source: MAPS-DATA DESIGN. Jonathan Critchley. http://jonathancritchley.ca 
Fig 47: Context study. pedestian dnsity and magnets

Source: Arnab Ghosh

Fig 48: Shifting pedestrian footprint within the site by creating an urban park.

Source: Arnab Ghosh

Fig 49: Aerial view of proposd model

Source: Arnab Ghosh

Fig 50: Site schematics

Source: Arnab Ghosh

Fig 51: Threshold 1-Green buffer

Source: Arnab Ghosh

Fig 52a: Transitioning from Green buffer to building

Source: Arnab Ghosh

Fig 52b: Transitioning from Green buffer to building

Source: Arnab Ghosh

Fig 53: View from the allotment garden space.

Source: Arnab Ghosh

Fig 54: Threshold 2 - ramped entrances

Source: Arnab Ghosh

Fig 55: Ramped entrances to the building

Source: Arnab Ghosh

Fig 56: Elevation

Source: Arnab Ghosh

Fig 57: Episodic Architecture

Source: Arnab Ghosh

Fig 58: Play of surfaces

Source: Arnab Ghosh

Fig 59: Eclectic composition of the Dwelling enclaves

Source: Arnab Ghosh

Fig 60: Threshold 3- The Spine

Source: Arnab Ghosh

Fig 61: Section through The Spine in enclave 1 and 2

Source: Arnab Ghosh 
Fig 62: Section through enclave 2

Source: Arnab Ghosh

Fig 63: View A. The spatial layering and play of levels through the corridic spine.

Source: Arnab Ghosh

Fig 64: View B,C,D. Material and spatial transition in the spine

Source: Arnab Ghosh

Fig 65: Threshold 4- The Promenade

Source: Arnab Ghosh

Fig 66: Play of levels of the corridic Promenade

Source: Arnab Ghosh

Fig 67: Play of levels, movement and appropriating a corridic promenade

Source: Arnab Ghosh

Fig 68: Large Openings create vistas and connect visual spaces across different levels in the promenade

Source: Arnab Ghosh

Fig 69: Ontology of ramps in the promenade

Source: Arnab Ghosh

Fig 70: Enclave 3 ramp diagram

Source: Arnab Ghosh

Fig 71: Organization of dwelling units around flexible corridic promenade space in enclave 2

Source: Arnab Ghosh

Fig 72: Organization of dwelling units around flexible corridic promenade space in enclave 1

Source: Arnab Ghosh

Fig 73: Flexibility of the interstitial space in a corridic promenade facilitates different spatial configurations.

Source: Arnab Ghosh

Fig 74a: Architecture of change

Source: Arnab Ghosh

Fig 74b: Architecture of change

Source: Arnab Ghosh

Fig 74c: Architecture of change

Source: Arnab Ghosh 


\section{List of Appendices}

appendix $A$

A1. Heirarchy in shared space

142

Source: Arnab Ghosh

appendix b

B1. Building section AA'- Organisation of private, corridic and public spaces Source: Arnab Ghosh

B2. Building section BB'- Organisation of private, corridic and public spaces Source: Arnab Ghosh

B3. Building section CC'- Organisation of private, corridic and public spaces Source: Arnab Ghosh 
Living In-Between 


\subsection{Living In-Between: An introduction}

This thesis is an investigation into the understanding of the spaces in-between and the inhabitants' lived experiences of liminal dwelling spaces. It is intended to draw attention to the relationship between architecture and social behavior that exists in the liminal spaces. The thesis aims to explore how the threshold spaces may influence and construct a particular nature of contemporary sociality in contrast to the dominant spaces that surround them. Corridors, the Oxford definition of which is a long passage in a building from which doors lead to rooms, has become such a ubiquitous architectural element that it is taken at face value as a purely utilitarian concept in the organization and construction of dwelling spaces. It is indeed, first and foremost, a functional space intended to organize movement and services around dwelling spaces, but from a phenomenological perspective, it is also a liminal space which we inhabit on a daily basis albeit momentarily. Corridors have a substantial physical presence in the everyday culture of any institution or commercial space. It is a space scrutinized as a remnant of a past-design trend that was a part of a divisive, hierarchical organization of space. With the open-plan office, indoor street, forum and atrium displacing them in a new design for 'openness', it is continuously brought into question in the re-arrangement of meaning in a spatial organization (Hurdley, 2017). This thesis extends that question into the residential sphere. A sense of ambiguity marks the liminality of the corridor in a residential space. Therein lies its potential for study from a phenomenological point of view that could help expand the architectural discourse surrounding it. It has the potential to be studied as a space that transcends its functional definition as a more meaningful space that is constructed and re-constructed by the lived 
experiences of the inhabitants. It can be argued that when such liminal spaces are constructed by the inhabitants as vital and meaningful to their everyday lived experiences, they have the potential to transcend their ambiguous qualities as meaningful transitory dwelling spaces.

From a liminal perspective, poised between public and private; open and closed; movement and stasis; the pragmatic and the eerie, corridors are "time and "matter out of place" (Hurdley, 2010) (fig. 1). They can be viewed as more than a passive architectural feature. It is a complex threshold space with an etymology deeply rooted in varied historical contexts where architecture has influenced and shaped social forces. It can also be considered as an outcome of various social forces coalescing to influence the architecture of the respective era. Therefore, in order to look beyond the functional definition, and grasp its liminality, it becomes imperative to study the context in which such threshold space was conceived and the evolution of such spaces as the fabric of the society changed. In modernity, the embodied origin of the corridor space has fallen out of architectural memory and social linguistics but has retained its physical presence as a passive space. 

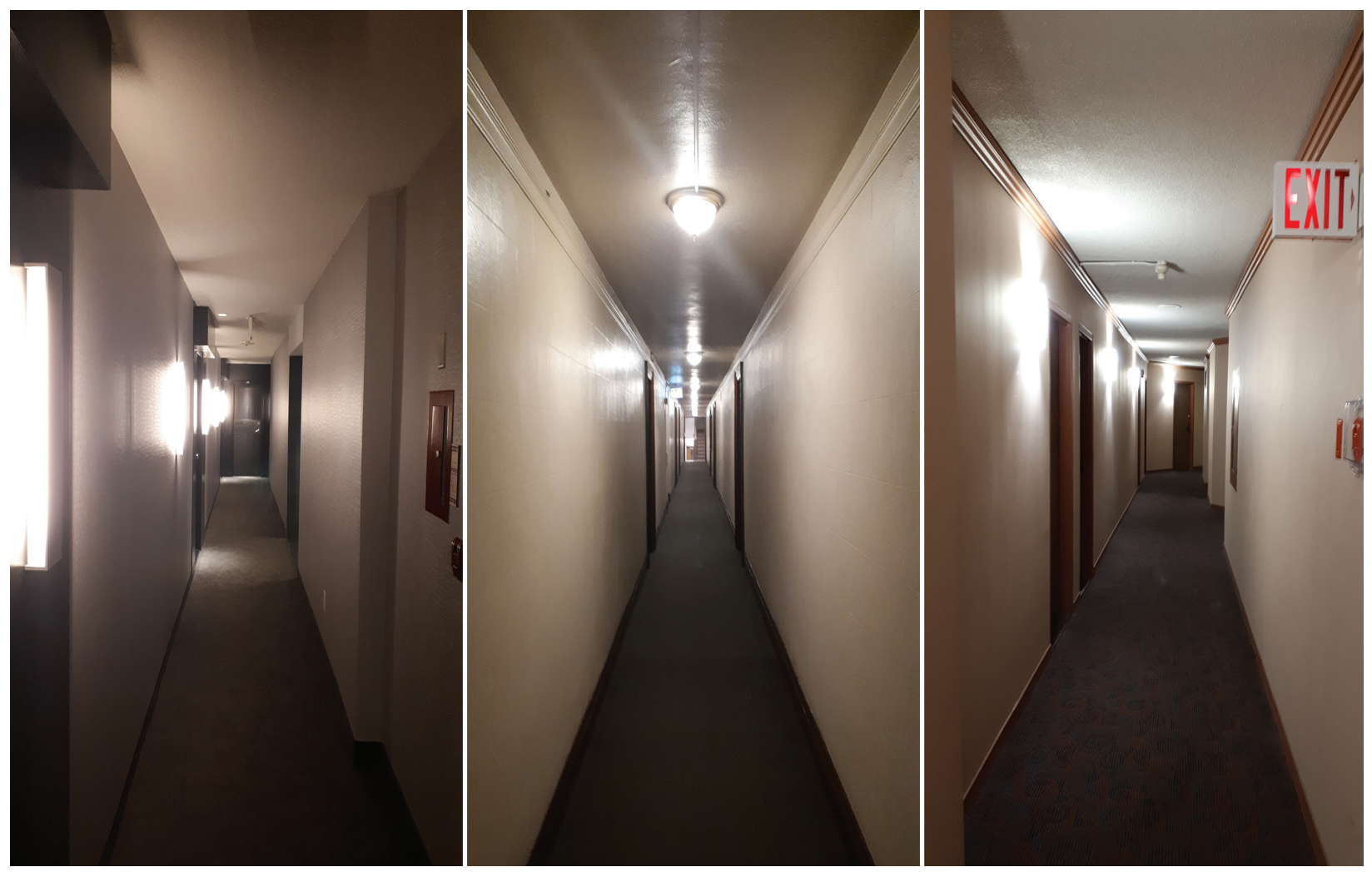

fig 1. The liminal residential corridor.

This thesis aims to introduce a perspective that an inhabitant experi'Time' and 'matter' out of place

ences liminal characteristics in such a threshold space, a space that cuts one out of the natural order of life between dominant social spaces and reconstitutes them into a new order. An inhabitant lives' or 'exists' in space through rituals, movements, routines, and actions: a regularity that is framed by contemporary spatial conventions. This understanding is confined to dominant spaces of existence and extending it over to the liminal threshold spaces offers a holistic understanding of an inhabitants' lived experience in a dwelling space. Carl Jung argues that there is a need to accord space, time and place for 'liminal feeling' and that there is a lack when it comes to providing a ritual space in our lives (Bly, 1990). The corridor as a threshold space provides a fertile ground for such ritualistic existence. Lived experiences in dwelling is not only about the dominant spaces, but also encompasses the transitory spaces of existence, the discreet spaces that lie in-between. 
Wassily Kandinsky gives a profound account of such transformation of lived experience,

"The street may be observed through the window pane, causing its noises to become diminished, its movements ghostly, and the street itself, seen through the transparent but hard and firm pane, to appear as a separate organism, pulsating "out there." Or one can open the door: one can emerge from one's isolation, immerse oneself in this organism, actively involve oneself in it and experience its pulsating life with all one's senses. Sound, with its constantly changing frequencies and rhythms, weaves itself around the individual, spiraling to a crescendo and suddenly falling away as if lamed". (Welten, 2016)

The transformation occurs in the aforementioned excerpt over or through a threshold space. Whether the action involves opening a door, a window, or walking down a passageway to the exit, it can be argued that the observer undergoes a liminal transformation between two dominant modes of existence. This dialectic of the inside and outside played through the threshold space constitute the phenomenology of dwelling. One of the key notions of Gaston Bachelard's The Poetics of Space is; in order to grasp the intimacies of dwelling, a dwelling space (a house, in his case) is needed to be looked at as a phenomenological object, where living is a sequence of reflective experiences which culminates into both sensory unity and complexity as the inhabitant moves from one space to another (Bachelard, 1969). Thresholds like doors and windows are playgrounds for human reflections and interiority (fig2). Although corridors as a significant threshold space is not mentioned in Bachelard's account, its passive existence in-between dominant spaces in modern dwelling begs the question whether a phenomenological investigation can make prominent its potentiality to be considered as an active space for interiority and inter-subjectivity. Investigating into the liminal experiences of the inhabitant in such threshold spaces can help create a tabula rasa for restructuring the spatial conventions that influence social interactions outlining community development in multi-story dwelling spaces. 

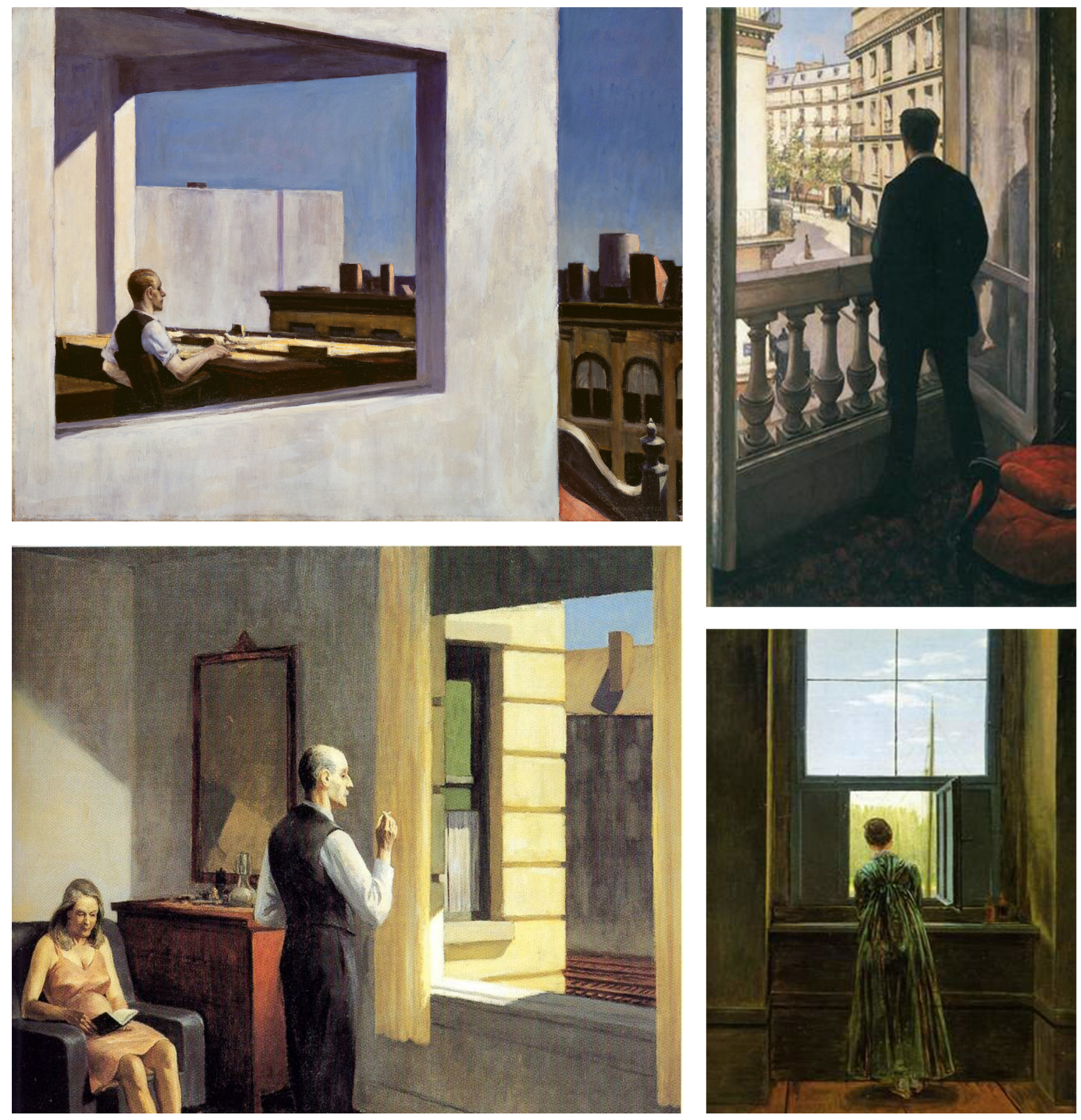

fig 2. Thresholds like doors and windows are playgrounds for human interiority. (Clockwise from top left)1. Office in Small City. Painting by Edward Hopper.

2. Young Man at his window. Painting by Gustave Caillebotte

3. Woman at the window. Painting by Caspar David Friedrich

4. Hotel by a railroad. Painting by Edward Hopper 
Living In-Between 


\section{0}

\subsection{The Birth of the Domestic Corridor}

$\mathbf{B}_{\text {efore taking the architectural investigation beyond the passivity of }}$ the corridor space, it is important to discuss its domestic etymology in a varied historical context to understand the conception of the threshold space. The corridor space is not a recent architectural invention. It is a space that had a strong influence in shaping the fabric of civilized society and establish social hierarchies. The nature of its influence is debated between different schools of thought. Some critics look at the space as a radical break, or a cause out of the blue rather than arising as a product of evolutionary development in architectural design stemming from basic human need. Robin Evans's critique revolves around the instrumentality of the corridor in changing the society that esteemed social interaction to a society built around principles of privacy and personal segregation. Simultaneously, others focused on how the corridor brought forth a new dimension of social interaction in the cultural, religious, and political sphere and introduced new power dynamics. For this thesis, the theoretical investigation will be focused on the corridor's domestic influence. 


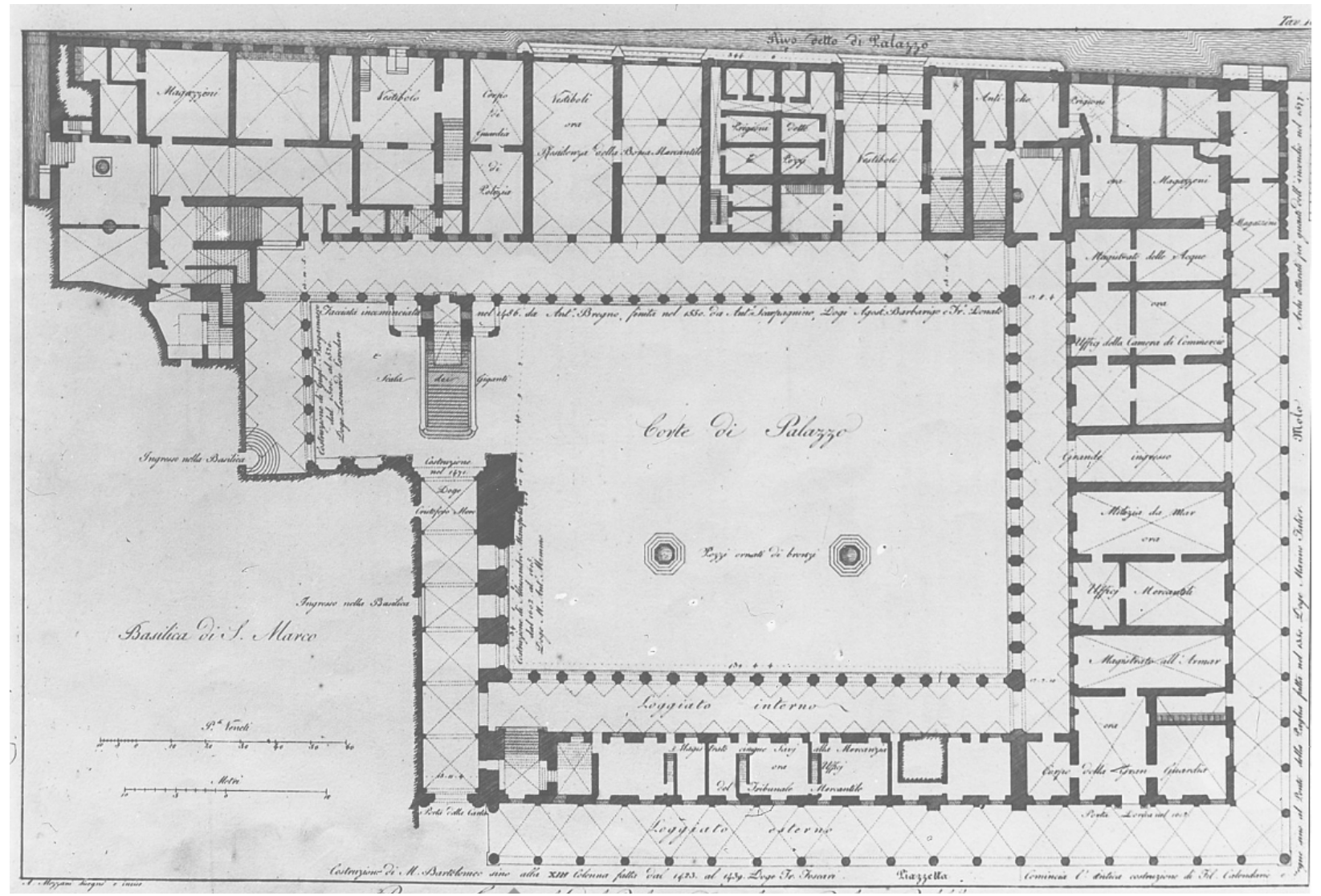

fig 3. Transition from andito to passagio in 17 th century Palazzo Ducale in Italy. the typical mode of transition into a building
In the domestic realm, corridors did not make an appearance until the mid-16th-century architectural dialogue in Europe. The erstwhile usage of the word 'corridor' did not refer to a physical space but a messenger. With the increasing dominance of the French culture, the word got replaced by the term 'courier,' but by then the word 'corridor' was already imprinted on architectural language, primarily to spaces in fortifications in-between bastions for the rapid communication of the troops (Jarzombeck, 2010). In castles, villas, the corridor was introduced as a secret passage-way for the concealed movement of the aristocrats in times of an emergency (fig 4). In palaces or large buildings, the corridors did not function as a primary circulation element. In an Italian palazzo, the main access to the building happened through the andito (entrance hall) that led to a camminata (walking place) or a passagio (gallery around a courtyard space) (Jarzombeck, 2010) (fig 3). 

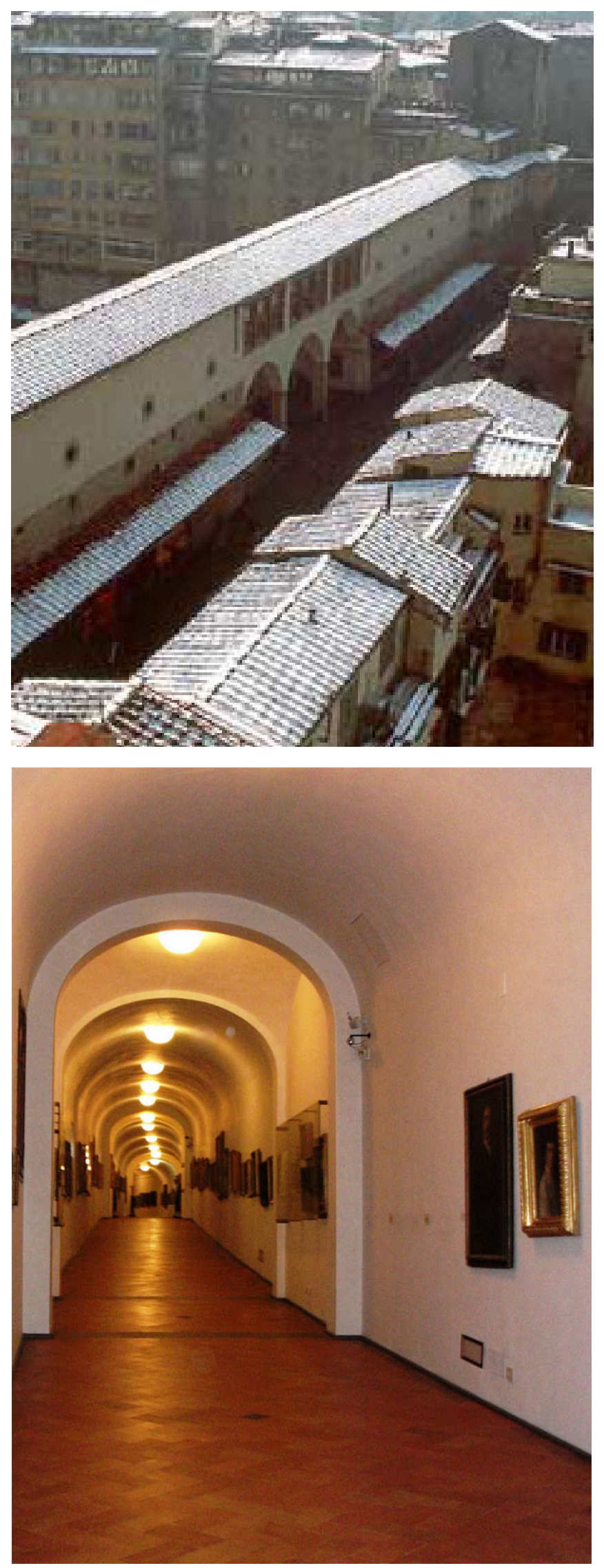

fig 4. Vasari Corridor in 16th century Florence, Italy. A concealed mode of movement used by the Medici family members to transverse between the place of residence at Pitti Palace and work place of the Grand Duke 
Similar organization was prominent in most European cultures. The interlocking thoroughfare of the dominant living spaces (enfilade) was the preferred method of circulation for the aristocrats (fig 5). The corridor was first introduced in the French and the Italian culture for the sole purpose of facilitating the movement of couriers from the outside world to the master of the house. The emergence of the domestic corridor in the 16th-17th century was linked to symbols of power and social status, emphasizing the importance of the master of the house (Jarzombeck, 2010). Middle of the 17th century, corridors emerged as a threshold space, bridging the exterior street to the depths of the building. Bridging in the sense that it did not internally connect the living spaces of the building as the channel model of circulation was given less preference over the courtyard model or the enfilade model when it came to internal circulation. The French and the Italian architects maintained an anti-corridor approach and gave precedence to the degree of intimacy between dominant living spaces over the spatial alignment of rooms in a residential system. Till the late 19th century, the French emphasized galleries and arcades over corridors despite the aspect of speed and connectivity.

"It was not only inappropriate for a residence but was also a "source of noise for the rooms opening off of it and, therefore, no longer in use except in upper stories of buildings meant for storage or in convents" - Jacques-Francois Blondel, "Corridor" in Encyclopedie

The emergence of the domestic corridor as a prominent architectural element can be traced to the changing social dynamics of the Victorian Age in 17 th century Great Britain.

"While evidently still something of a curiosity, its power was beginning to be recognized, for on the plan was written 'A long Entry through all'." (Evans, 1997) 


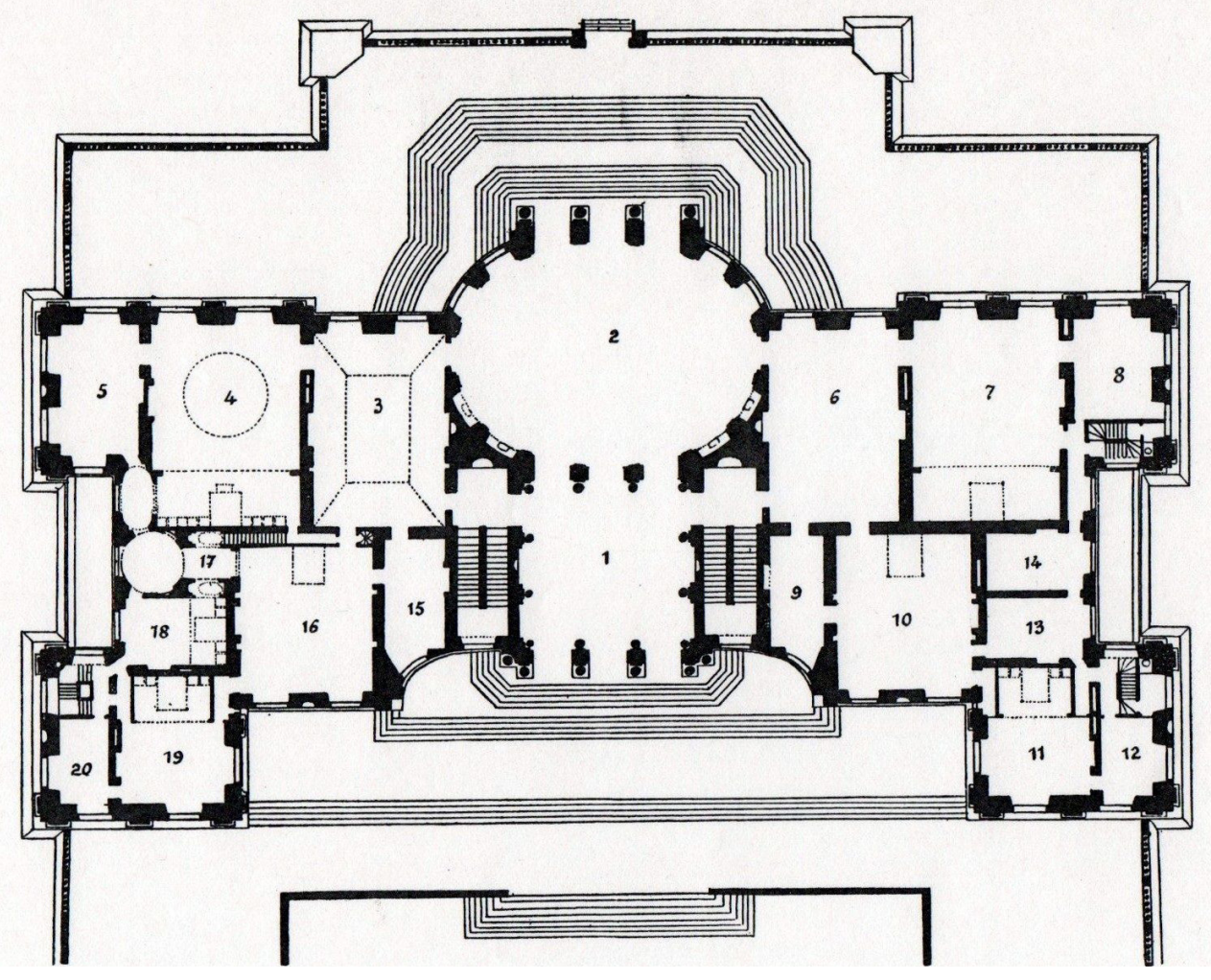

fig 5. Enfilade House Plan, Chateau de Vaux-le-Vicomte

Interconnecting dwelling spaces found precedence over the use of corridors as a standard mode of circulation in residences. 
As a social tool, initially it was introduced in houses built for the aristocrats. With the addition of the main staircase and the back staircase, the corridor space coalesced into a penetrating circulation network linking major interior spaces. It was implemented with the intention of preventing interference due to functional overlap of consecutive rooms. It was also intended to minimize chance interaction between the servant and the master of the house. The corridor ran parallel to the enfilade; a conscious architectural implementation to create social segregation by inscribing a division in thoroughfare where the privileged had direct territorial access whereas it was limited for the unprivileged (Evans, 1997). Eventually, the introduction of the corridor space came to be associated with the creation of two different realities in a domestic system; the inner sanctuary of the inhabited and the de-humanized circulation space. A conscious separation of beauty from utility, delight from commodity and form from function (Evans, 1997). From the viewpoint of social-existential dialectics, the corridor became a tool to distinguish what needs to be exposed and what needs to be preserved in the lived experience of the inhabitant. The introduction of the corridor and the independent access marked a radical change in the social psyche of the inhabitants; "A change of mood concerning the desirability of exposure to company; whether exposure to all in the house, or just to some..." (Evans, 1997). Robin Evans identifies this shift as the introduction of the nascent psychology of 'privacy' where the 'being' of the inhabitant felt not only at risk in the presence of others, but disfigured by them.

The separation of the two realities in the inhabited space witnessed a lack of re-conciliation in the 19th and 20th century and with the advent of the modern period, the systemization of movement and the utilitarian aspect of the corridor gained increasing application. The exponential increase of technological application in architecture of the modern period (introduction of large-scale mechanical ventilation machines) 

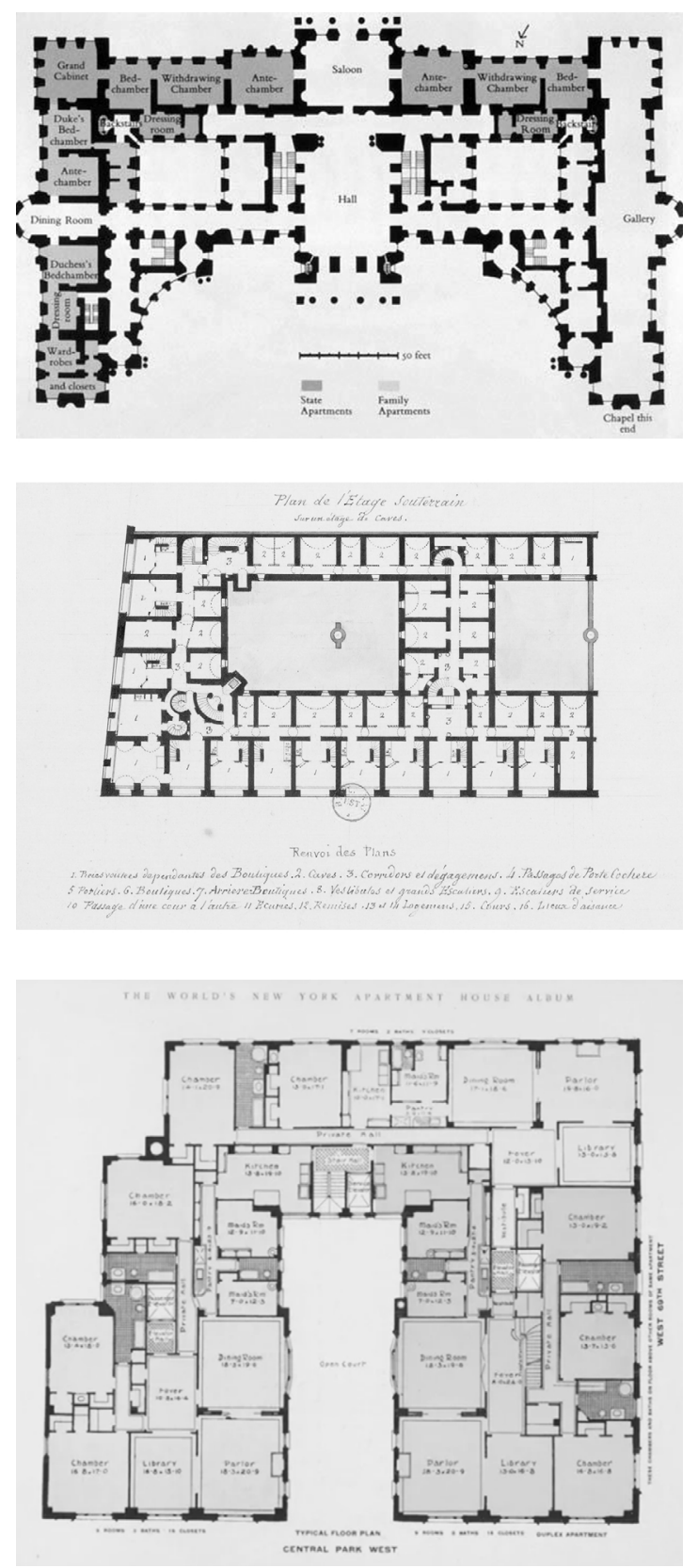

fig 6. Emergence of the residential corridor

(Top to Bottom) $1.18^{\text {th }}$ century Blenheim Palace. Corridors existing parallel to enfilades 2. $19^{\text {th }}$ century Parisian apartment plan.

3. $20^{\text {th }}$ century Pre-WW1 apartment plan. Corridors as the sole mode of movement 
brought about the proliferation of the enclosed ventilated corridor and its advantages were applied to a wide range of residential systems (Jarzombeck, 2010). The primary focus on the utilitarian aspect of speed and convenience pushed the sociological aspect of the threshold space further in the background instead of re-conciliating the threshold space back in the social-existential dialectic of the inhabitant's lived experience

\subsection{The liminal Existence: Rituals and the Built environment}

\subsubsection{Liminality: Definition and Significance}

The objective of the thesis is to employ liminality as a tool in the social and spatial context. The root word limen "is derived from the Latin word for 'threshold', [and] literally means being on the threshold". In both spatial and social context, it refers to an intermediate stage, an inbetween condition of existence in which the liminal entity (inhabitant) has characteristics of what it is between, but at the same time is separate (Alexander, 1991). In the social context, it delineates the psychological state of the liminal entity while in the architectural context it defines the space, inherently ambiguous and transitional between two dominant spaces. This thesis aims to overlap the two meaning and reconstruct the architecture-social behavior relationship existing in the residential corridor. Fred Kotter defines this in-between zone that is the liminal space as "the realm of conscious and unconscious speculation and questioning - the 'zone' where things concrete and ideas are intermingled, taken apart and reassembled - where memory, values, and intentions collide" (Koetter, 1980). From a phenomenological perspective, the understanding of the inhabitant as the liminal entity can influence an approach to architectural design of the corridor as a space that transcends its transitional definition into the transformative. 


\subsubsection{The Liminal Entity at Threshold}

\section{Drawing Parallels from understanding of liminality by Arnold Van Gennep and Victor Turner}

To understand the liminal experience of the inhabitant moving through the threshold spaces, the application of its social and cultural meaning as conceived by the anthropologists Arnold Van Gennep and Victor Turner could help draw principles that could inform the spatial meaning. The term 'liminality' was coined after Van Gennep, and Turner observed the stages of transformation in a ritualistic rite of passage in primitive societies ${ }^{1}$. The thesis intends to draw a parallel by treating the movement of an inhabitant through a corridor in a residential building as a ritualistic procession that exists between two dominant spaces of distinct social influences. In the linear movement from the lobby-stairs/elevators-corridor-room, the inhabitant is viewed upon as a liminal entity moving through a sequence of thresholds, holding distinct meanings that culminate into the entire liminal experience. In applying the thinking of Van Gennep and Turner, these distinct spatial meanings can be de-constructed and restructured to create a transformative space conducive to community building.

In Arnold Van Gennep's The Rites of Passage 'liminality' is expressed as an in-between state of conditions that are characterized by the dislocation of established structures, reversal of hierarchies and uncertainty regarding the future outcomes that exists between two worlds (Van Gennep, 1960). Within these two worlds lie a sequence of transition points that every entity must go through at one point or the other, which Van Gennep asserts outlines the ritualistic living of the entity. The major phases emphasized are separation, transition/

liminality and incorporation where each phase outlines a certain transformation of being in the entity.

1. Birth, puberty, marriage and death are all, in culture, marked by ritualistic ceremonies which, although differing from one another, are universal in essence. While studying the societal and cultural structure of primitive societies, Van Gennep uses the metaphor to describe the ritualistic behavorial and spiritual transition of an individual as ' house divided into rooms and corridors'. A passage occurs when one leaves a stage of life and enters another, and according to the metaphor, the individual 'exist in the threshold while changing rooms'. 
Seperation

Transition
- The separation is the phase described as 'left behind' where the existing routines and practices are separated (Van Gennep, 1960). It's the pre-liminal phase where remnants of the existing social structures are de-constructed. In applying this thinking to spatial experience, the lobby space exists as a semi-public space where the inhabitant walks in from the street level. A certain change in elevation heightens the awareness of separation when the inhabitant climbs the steps at grade to enter the lobby and then enters the elevator. This entire composition acting out in the separation zone can be read as the first transition phase that influence social interactions between inhabitants. Emily Post in Etiquette speaks of the elevator as the first space suggestive of a room where a particular nature of social interaction occurs (Post, 2004). The act of walking into the elevator, holding the door or waiting for the floor and the social interactions surrounding it can be viewed as the first set of liminal experiences that distinguish the inhabitant's being as it is in the exterior spaces of the city from the interior spaces of the building.

- The transition phase according to Van Gennep is marked by symbolic behaviors signifying the detachment of the entity from an earlier state to an ambiguous state where he or she lives outside the normal environment and is brought to reflection in terms of interiority (Van Gennep, 1960). It is the socially unstructured phase, a dislocating space that creates a sort of tabula rasa for the re-structuring of the being of the entity. Applying the thinking to spatial experience, the inhabitant exists in an ambiguous state when walking through the corridor to reach the room. It's a space involving the removal of the social structure existing in the exterior world and the change in the inhabitant's social status. The mundane sequence of closed doors, muffled voices behind stretches of walls separating the dominant spaces from the corridor space, all culminate to create a space of unclassified 
social structure. The inhabitant passing through such an unclassified space finds him or herself in a liminal situation for a period of time. As Gaston Bachelard in The Poetics of Space points out "a door opened is a world revealed" (Bachelard, 1969), the inhabitant finds him or herself traversing between two worlds, a space that is not here or there, as they move through the corridor. The ambiguity of the space and its liminal experience could provide a constructive ground for new modes of social action and reflection on interiority.

Incorporation

- The incorporation is the post liminal phase, or the culmination into the new 'being' according to Van Gennep. It is the action of opening the door and entering one's room. The culmination of the liminal experiences that completely detaches the inhabitant from earlier states of existence. The moment the inhabitant closes the door behind is a brief liminal process by itself; the end of the re-structuring of one's identity where one gains awareness of one's totality and relationship to others.

Does the person enter a room feeling isolated or feeling a part of a bigger community?

The answer to which is determined by the conditions that influence the liminal phase of moving through the corridor. 
Victor Turner builds upon Van Gennep's postulation of the liminal experience, focusing mainly on the transitional phase. According to Turner, liminality, in terms of social structure and time, is an intermediate state of being "in between" in which individuals are striped from their usual identity and their constituting social differences while being on the verge of personal or social transformation (Turner, 1995). Turner equates the liminal experience to a sense of dissolution and abstraction, which is essential to the creation of identity and community. Turner stresses that the scale at which the transition occurs is not as important as the transition itself. A similarity lies in both Van Gennep's and Turner's postulation which is that the post-liminal stage is a function of the liminal stage, the re-structuring of values and identity in a person is greatly dependent upon factors influencing it in its transitional phase. Employing this understanding to architecture or the spatial experience of the liminal inhabitant, the threshold between dominant spaces is important to the experience of the spaces regardless of its program and function. The metaphor of dissolution which Turner applied to the breaking down and re-structuring of a 'being' in order to bring forth a transformation could be applied to the blurring of the architectural elements, reducing spatial conventions into recognized components and recombining those elements to create new spatial meanings (fig 7). Overlaying of recognizable architectural elements leads to an abstraction of spatial conventions and upon entering the space, the re-constituted elements work in a sequence, leading the inhabitant through the building and transforming the ambiguity of the corridor into a space of experience and interiority.

As a result, the architectural space of the corridor can be read as a sequence of transformative threshold spaces that act to change the consciousness of the inhabitant. 


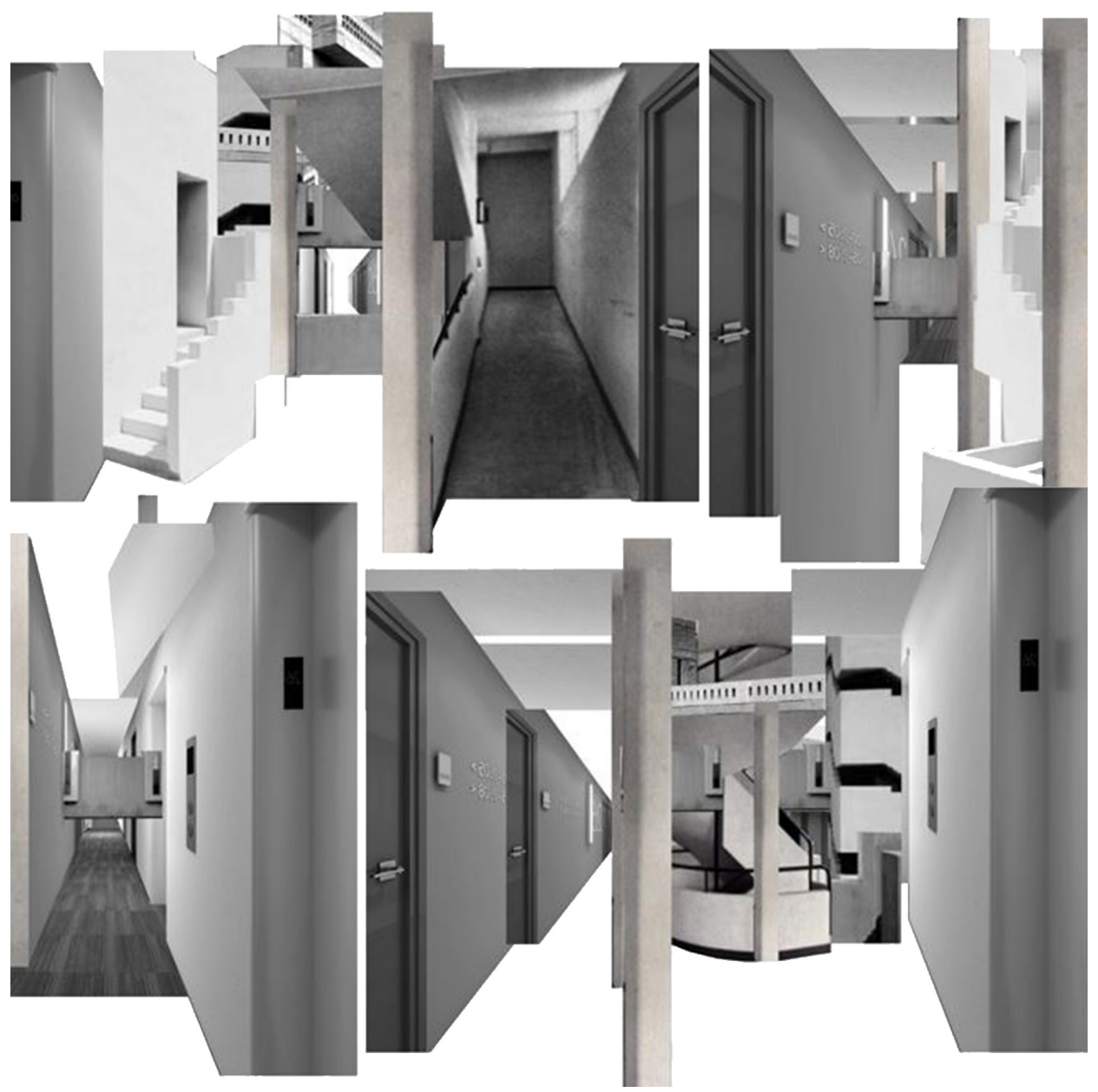

fig 7. Deconstruction and dissolution of the passive corridor.

Can the corridor be an active space for interiority and inter-subjectivity? 


\subsubsection{Communitas}

"It is as though there are here two major "models" for human interrelatedness, juxtaposed and alternating. The first is of society as a structured, differentiated, and often hierarchical system of politico-Legal-economic positions with many types of evaluation, separating men in terms of "more" or "less".... The second, which emerges recognizably in the liminal period, is of society as an unstructured or rudimentarily structured and relatively undifferentiated 'comitatus', community, or even communion of equal individuals...."

(Turner, 1995)

One of the key notion of Turner's postulation of the liminal stage is the communitas. Communitas according to Turner is a relatively structureless society which is based on relations of equality and solidarity and which is opposed to the normative social structure. Communitas gains it meaning through the deconstruction of this normative order (Turner, 1995). The dissolution of structure creates a relaxation in the condition of liminality, further creating an ambiguous space of potentiality in which everyday social experiences can be transformed. The potentiality inherent in liminal space is essentially its transformative nature through which a new understanding of oneself, others, and the space occupied by the two can be grasped. Furthermore, the relaxation of structure allows for encounter between people who are generally isolated from one another (Alexander, 1991). Turner postulates that the liminal stage dissolves and de-emphasizes on pre-existing social structures and creates a tabula rasa of social relations based on common humanity and equality. A transformative space for the phenomenon of communitas to occur can be read as a space associated with nonhierarchical and un-differentiated social relations.

Communitas refers to an unstructured community in which people have a sense of sharing and intimacy that develops among persons who 
experience liminality as a group. One of the many ways in which the phenomenon of communitas is spatially articulated in the architecture of residential spaces is through the design of co-living spaces, shared spaces for amenities that are allocated for the congregation of the inhabitants. Such spaces are designated areas for the sense of community to be established. These are the first spaces where structure is relaxed, flexibility is intended, a space designed for a group of inhabitants express solidarity. The following thesis is aimed at incorporating the phenomenon in an ambiguous space where community is formed not as an outcome of an intent initiated by external agents but as an active choice accommodating the various idiosyncrasies of the inhabitants. Designing the discreet interstitial spaces in-between dominant spaces to be flexible accentuates the transformative potentiality of threshold spaces as well as maintains the soft division between private, semiprivate and communal inhabitation. The lingering ambiguity of the corridor space at the threshold of dominant dwelling spaces provides a fertile ground to explore the possibilities of introducing flexibility and creating a transformative space for the phenomenon of communitas. 
Living In-Between 


\section{0}

\subsection{Textures of the Corridic Place}

In his seminal work 'Building Dwelling Thinking', Martin Heidegger argued that not all buildings are designed for dwelling (Heidegger, 1971). Heidegger's argument highlights the crucial relationship that exists between building and dwelling. The thesis extends the argument to the contemporary discussion surrounding residential systems.

Heidegger hypothesized that various forces in the modern world have also brought about a severance between building and dwelling, exposing an underlying fragmentation in understanding the spatiality of dwelling spaces. Dwelling relates to how we exist, or we live/ inhabit a space. Building is not a mere problem of providing shelter or housing but building as dwelling transcends the functional need for a building (Heidegger, 1971). Dwelling, according to Heidegger, situates the inhabitation of space in a certain relationship with existence that enables the experience of a sense of the present within a community. In order to construct a perspective on the spatial potentiality of corridic spaces, the thesis aims to investigate the phenomenological construction of a dwelling space by studying the forces behind social spaces, place building, humanistic topographies and haptic architecture. 


\subsubsection{The dialectics of Social Space}

The historical account on corridic spaces mentioned previously in this thesis offers a glimpse of how the mechanism of space has been actively responsible for molding the way a society perceives its essence. The French philosopher Henri Lefebvre gives a compelling account on the forces that construct a social space. In the 'Production of Space' Lefebvre points out how in the past, after the alienation from natural space, 'social space' was created and was increasingly connected to conditioning social relations, that in its urban environment, it led to an overall estrangement from the organic spaces people created in accordance with their naturally developing environment over time (Lefebvre, 1991). For Lefebvre, social space is a product continually being constructed (a work) by a set of relations or social processes as they interrelate with each other. He gives space an active agency, a multilayered fabric of connections that are continually produced and re-produced (Schmid, Milgrom, \& Kipfer, 2008). Furthermore, the constitutive capacity accorded by Lefebvre to social space is reflective of Heidegger's definition of dwelling as a collective experience of a mutual sense of the present, forged by a known historical past and predicted future. Social space, as defined by Lefebvre is a collectively produced process which by virtue of being the outcome of past actions, enables fresh actions to occur, while suggesting others and prohibiting yet others (Schmid, Milgrom, \& Kipfer, 2008).

"Social Space is not a thing among other things, nor a product among other products: rather it subsumes things produced, and encompasses their interrelationships in their coexistence and simultaneity - their (relative) order and/or (relative) disorder. It is the outcome of a sequence and set of operations, and thus cannot be -reduced to the rank of a simple object” (Lefebvre, 1991) 
Lefebvre equates the concepts of social space as a 'spatialisation', a textured, multi-layered, fluctuating set of relations between objects in a field (fig 8). A plurality is accorded to social space where a set of spatialisations are interacting with other spatialisations, interpenetrating, superimposing one another. To stress the fluid nature of this 'spatialisation', Lefebvre draws analogies from the hydrodynamics of waves; great movements, vast rhythms, colliding and interfering with one another (Schmid, Milgrom, \& Kipfer, 2008). The spatialisation of social space gravitates away from the classical definition of space as a container we walk through and build things upon to an idea of superimposed layers or an 'assemblage'.

Social space is a material and mental process that has a constitutive effect in spatial practices and experiences of the space (Lefebvre, 1991). To better illustrate, we could take a closer look at a contemporary layout of a dwelling system. Common sense would enable the reading of the spatial dialogue of the building as a system of rigid structures with equally rigid functions assigned to each spatial structure. But in fact, this could also be read holistically as a living system, marked by spatial practices, a nexus of interactions and spatial movements that replaces the immobile image of a dwelling system by a complex of mobilities, a nexus of interpenetrating spatialities. Therefore, it could also be read as a machine analogous to an active body. Such a space is both lived immediately at a concrete level as well at a multilayered, processual abstract level. 


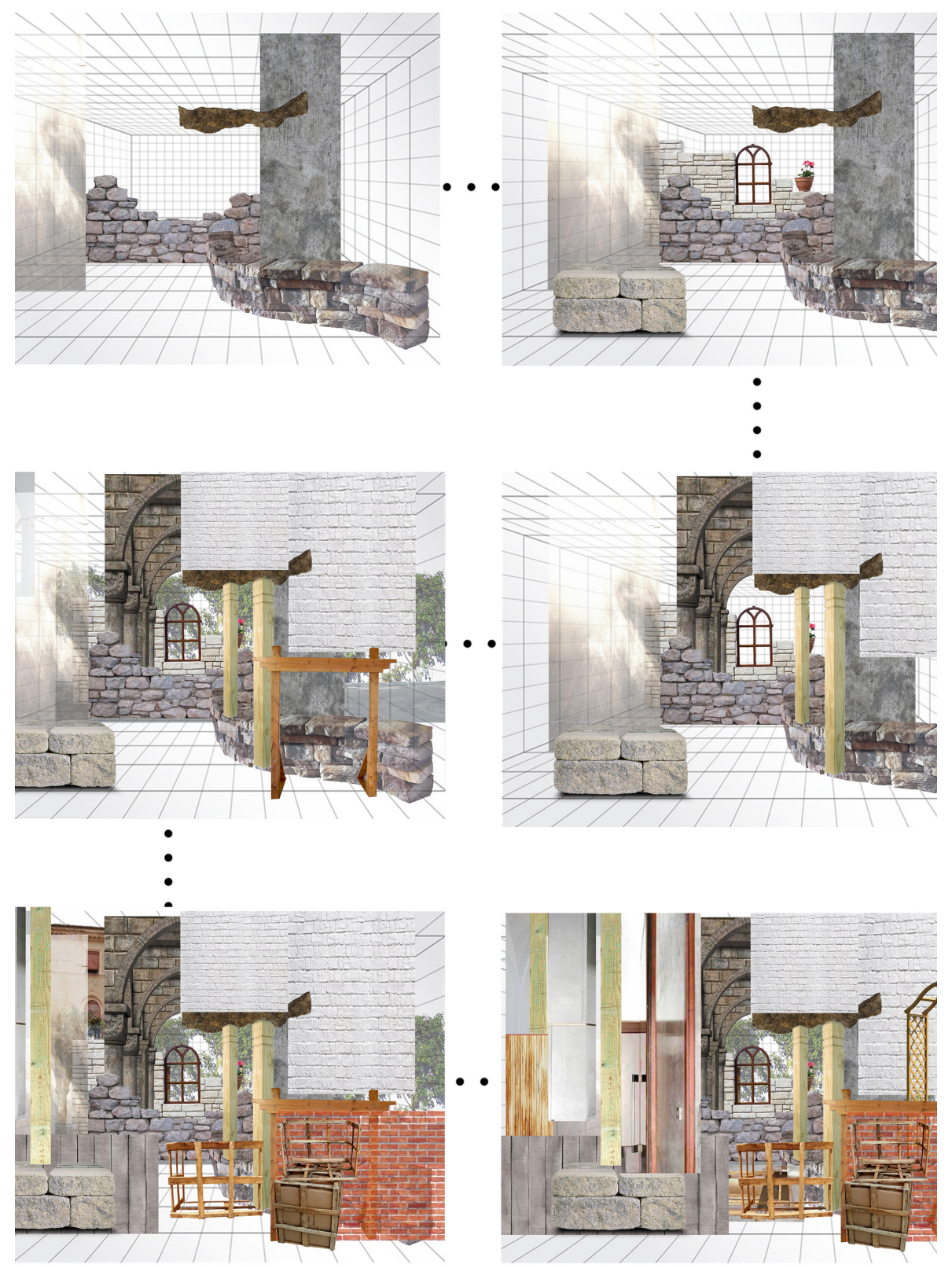

\subsubsection{Domination and Appropriation}

fig 8. Spatialisation. A textured multi-layered association of objects that come into being as an expression of inhabitation
Henri Lefebvre in the 'Production of Space', posits two notions of production regarding the dialectics of social space. Production can be read as an industrial process, where a product as a commodity is produced as a result of repetitive actions, gestures, and habits (Lefebvre, 1991). The mechanism of the modernist forces has commodified social space. Like an object or a container, the language of the contemporary 
corridor space can be identified as such product of such modernist forces: a restricted narrowed down notion of threshold space, an object produced and reproduced as a result of repetitive acts and actions in spatial organization. The corridor space in the contemporary dialogue is a dominated space, a mechanism that dominates space prior to the activities in the space. A space that is closed, sterilized and emptied out and similar to how Lefebvre describes motorways as brutalizers of the countryside, the corridor space disrupts, de-humanizes and forcibly ensures a spatial consensus.

In contrast, a social space is also a production in the sense of a work, a creative activity (Lefebvre, 1991). A work of art, as defined by Walter Benjamin, possessing an aura or uniqueness, transcending the industrial repetitiveness of a product. Lefebvre looks at the organic growth of European cities like Venice to illustrate this concept. Most of the spaces in such cities have come into being as an expression of everyday life of the inhabitants in a particular period in the city's history (fig 9). There is a spontaneous texture to the architecture, expressing the space as it is lived (Lefebvre, 1991). Appropriated space falls under such definition of space as a work of art. In appropriated space, space is individually or collectively appropriated and through lived experiences and spatial practices, spontaneously produces a new space.

Constructing a place is a creative process involving appropriated space that goes against functionalism. Lefebvre theory on social space revolved around how inhabitants go against pre-assigned functions and appropriated space that introduced a sense of spontaneity and naturalness in relation to the concept of dwelling. Appropriation becomes a way to grasp dwelling as a poetic practice, the possibility of shaping space as an individual work within an overarching cultural and social reality (Staneck, 2011). This concept reflects Heidegger's concept of dwelling and Bachelard's poetics of space. 


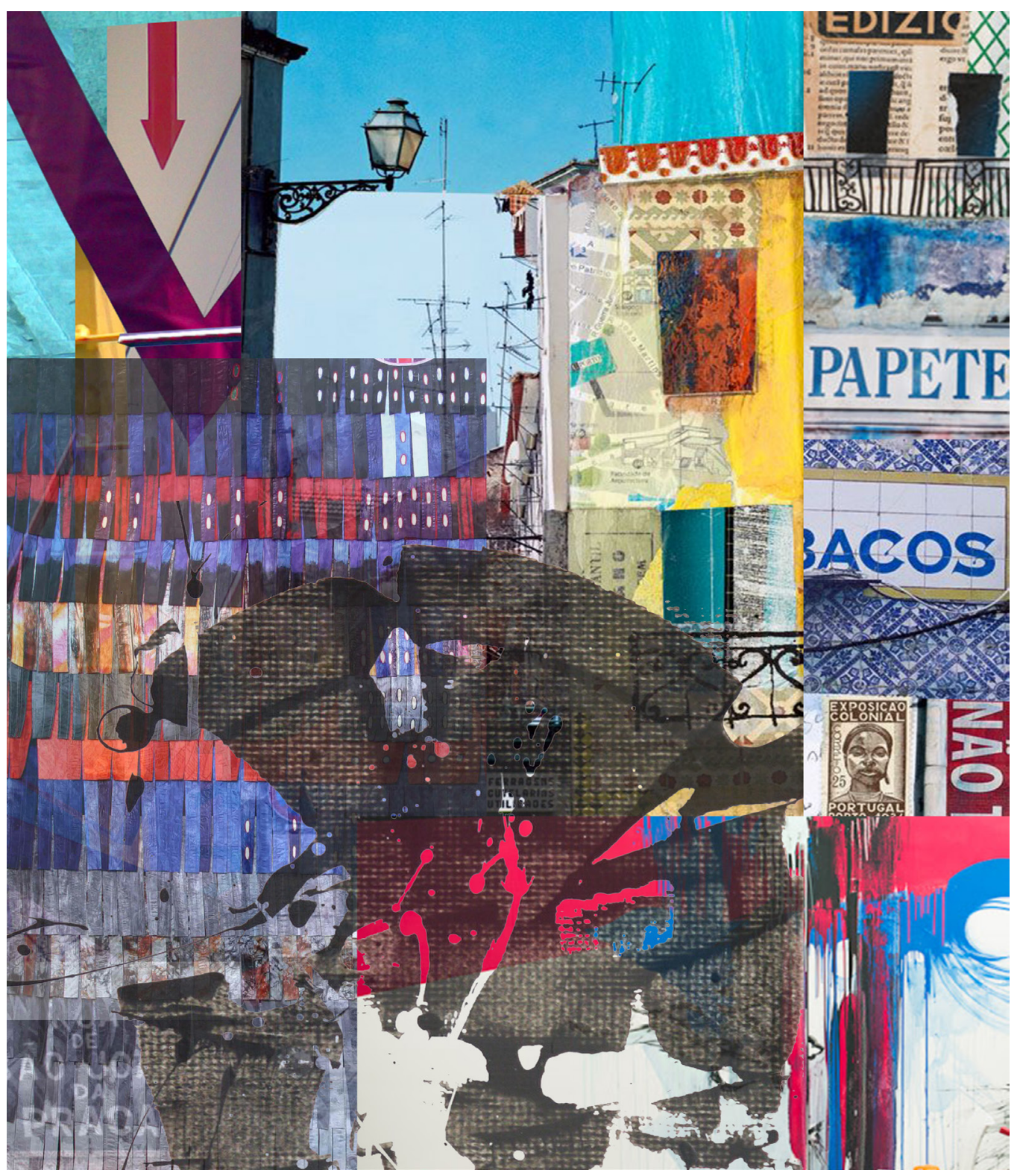




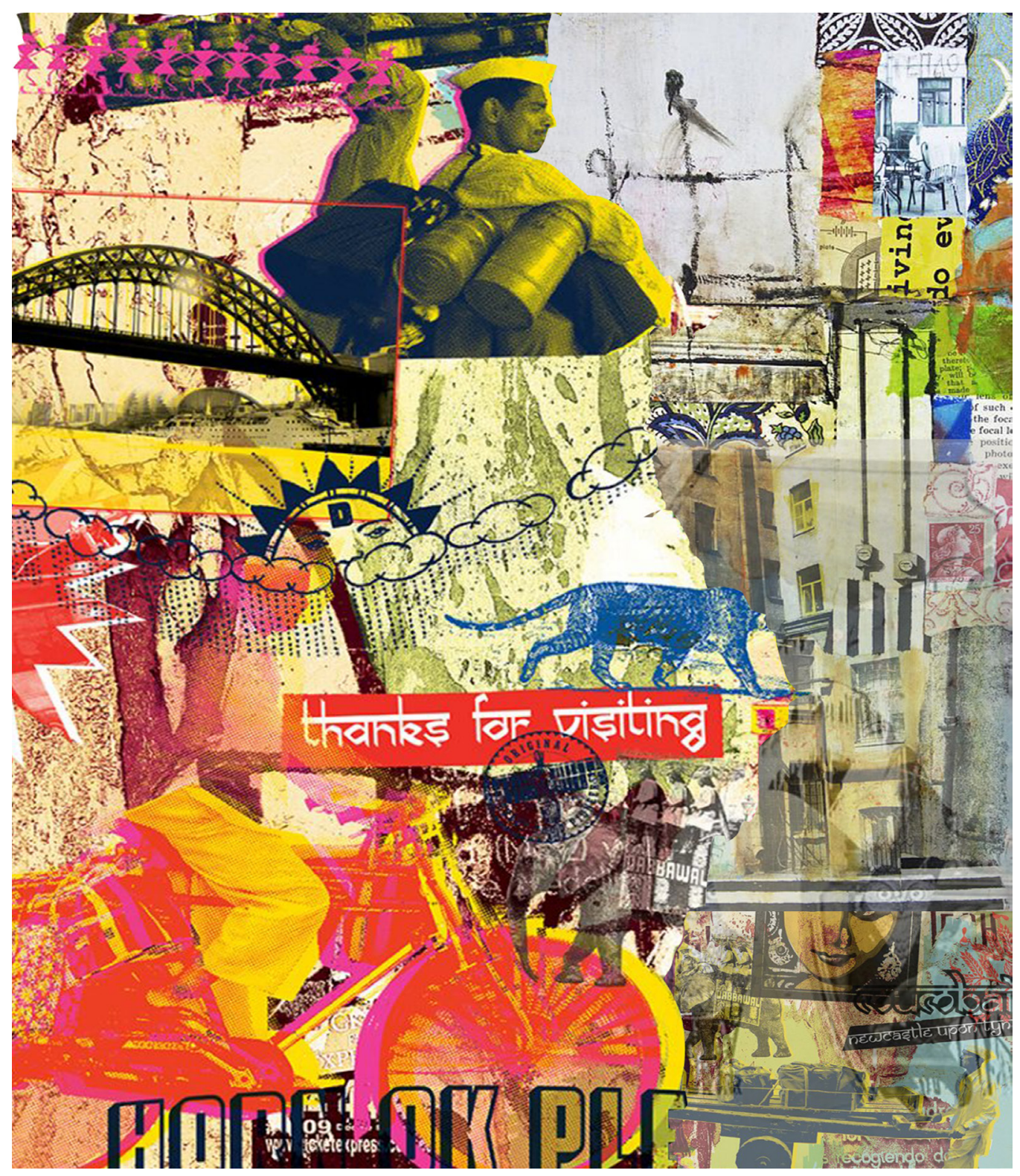

fig 9. Material and haptic sequences we encounter when we stroll through an urban space that has emerged organically as an expression of its inhabitant's lived experience. Like Lefebvre's description of walking through old European towns we find ourselves in dialogue with a spatial language constructed through layers of meaning, textures and other haptic elements that has come into being as an expression of human dwelling. 


\subsubsection{Place building}

'Dwelling relates to the manner in which we exist. It is to remain in place and be situated in a certain relationship with existence, a relationship which is characterized by nurturing' (Heidegger, 1971).

According to Heidegger, a building provides for a sense of 'place' in which dwelling occurs. This sense of place is what grounds Heidegger's existential notion of spatiality and dwelling. Being as appropriation. To elucidate, where one dwells is where one has a place, 'dasein' or 'being there' is located within a set of sense making practices and structures with which one is familiar (Heidegger, 1971).

Heidegger goes ahead to theorize on 'fourfold"2 being a central aspect of dwelling. This thesis moves away from the 'fourfold' and aims to construct another perspective on the dialectics of place-making.

Yi-Fu Tuan's poetic writings about space, place, and identity focuses on how people dwell by creating worlds of meanings. In Tuan's 'Space, Place and Identity', the humanistic concept of place, largely drawn from phenomenology, revolves around the individual's attachment to the symbolic quality of popular concepts of place which link events, attitudes and inter-subjectivity, creating a fused whole (Tuan, 2001). Yi-Fu Tuan locates place as a center of meaning constructed by lived experience, both at a concrete and abstract level. Place is constructed not only through the eyes and mind but also by employing passive and direct modes of experience that resists objectification (fig 10).

'To know a place fully means both to understand it in an abstract way and to know it as one person knows another. At a high theoretical level, places are points in a spatial system. At the opposite extreme, they are

2. Fourfold- A unity of four elements; earth, sky, mortal and divinities that consolidate man as a dwelling being in the world. A symbolic understanding of these elements establish the fertile grounds for dwelling to occur. According to Heidegger, dwelling is done right by existing while not exploiting the earth, understanding the spiritual connotation of the sky and the divine and being aware of the mortal existence 
strong visceral feelings. Places are seldom known at either extreme: the one is too remote from sensory experience to be real, and the other presupposes rootedness in a locality and an emotional commitment to it that are increasingly rare' (Tuan, 2001)

\subsubsection{Placeless-ness}

The prevalent existence of relatively homogenous and standardized architectural landscape diminish spatial meaning and variety that is conducive to a sense of attachment to a space. Arising from the modernist era, certain spatial attitude had taken root in the architectural discourse that had led to the purposeful elimination of place. Humanistic geographer Edward Relph argues that an 'inauthentic' attitude towards a sense of place has replaced an 'authentic' attitude that was crucial towards constructing a sense of place (Seamon \& Sowers, 2008). Authenticity in lived experience, Relph argues, posit a direct and genuine experience of the entire complex of the identity of place- not mediated and distorted through a series of arbitrary conventions about how an experience should be (Seamon \& Sowers, 2008). Individuals and groups create a sense of place by association, appropriation, constant use, familiarization by adding layers of meaning that construct an authentic lived experience in a dwelling space. Standardized spatial conventions and homogeneity eradicate the distinctiveness and sensitivity that construct the significance of place. Relph suggests that placeless-ness originate from an uncritical acceptance of mass values or technique, the overriding concern with efficiency as an end in itself that undermines the significance of a place and replaces it with anonymous and exchangeable environments (Relph, 1993). 


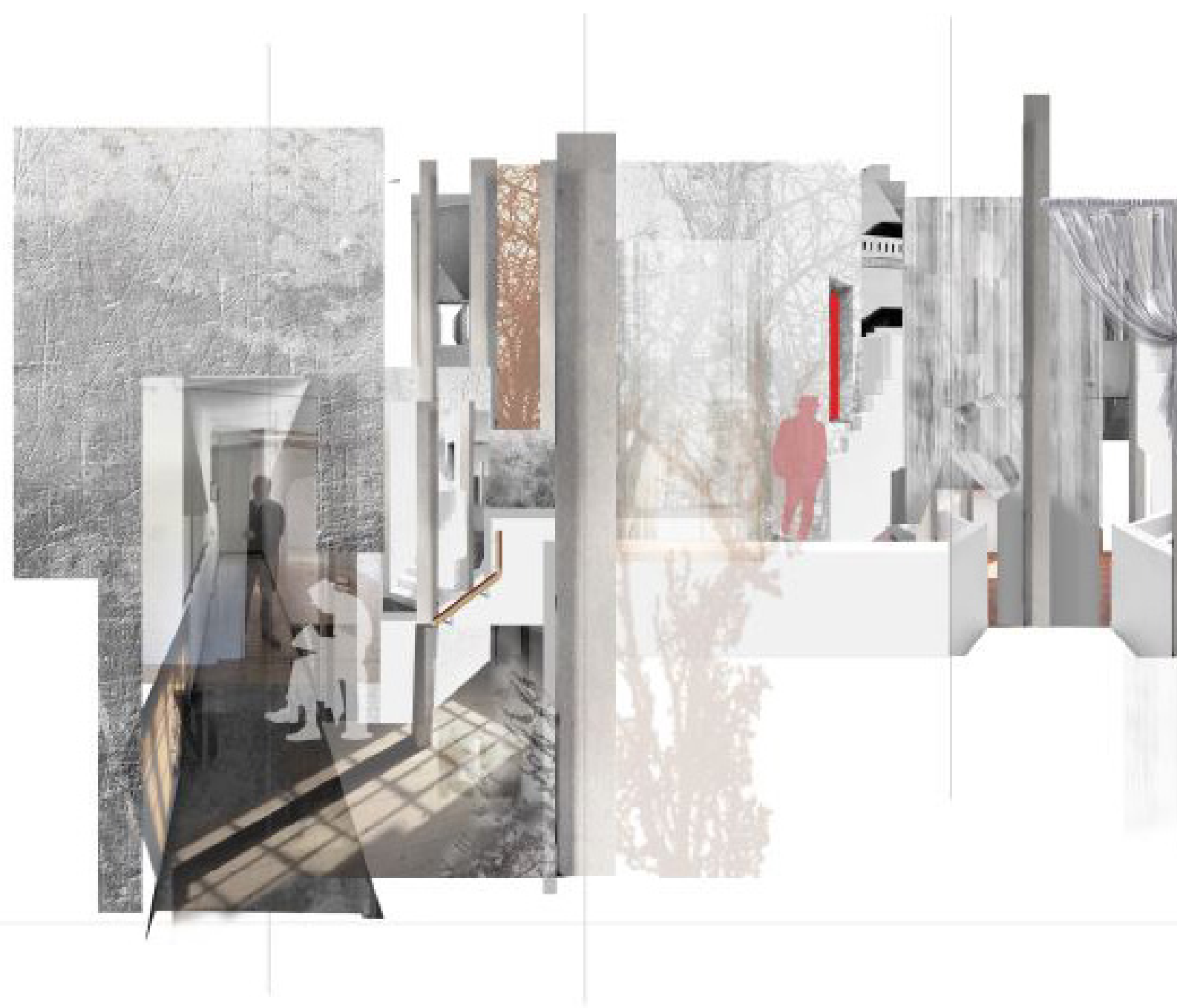




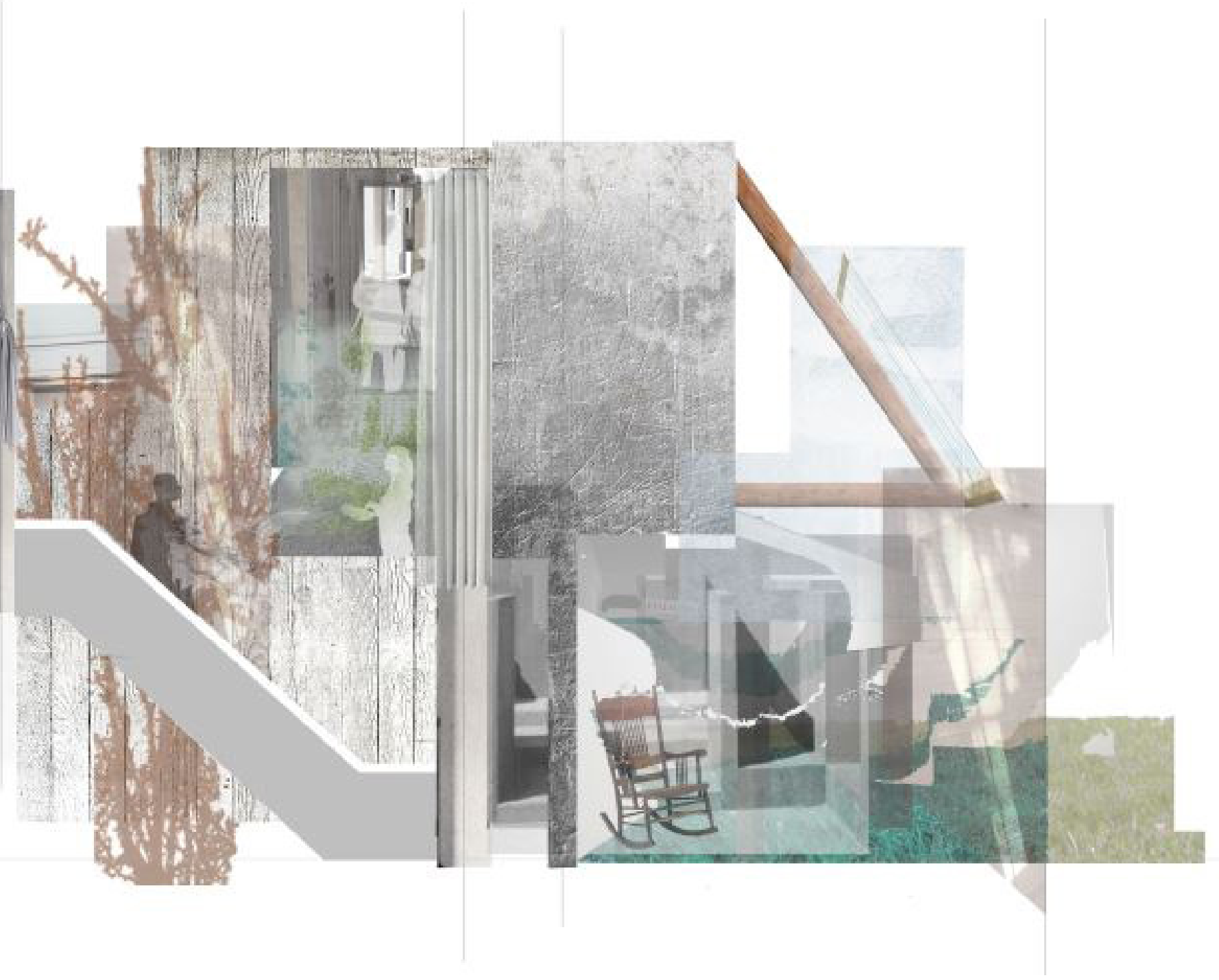

fig 10. Sequential construction of a house through experience and sensations. A Place is constructed not only through the eyes but also by employing passive and direct modes of experience 


\subsection{Creating Humanistic Topographies in a Corridic Place}

To discuss the phenomena of a corridic place as a dwelling place, the structure of the space could be described in terms of a 'Iandscape' constructed by means of a comprehensive concept of 'lived space'. 'Lived space' or 'experienced space' is the amalgamation of spatial elements that make up a space, and the atmosphere that denotes the character of the space (Schulz, 1980). Constructing such a perspective posits a shift from a classical definition of a bounded place.

The primary meaning of dwelling is nurturing shelter. It is devoted to the sustenance of the body. Gaston Bachelard accords a poetic ideal to the concept of dwelling.

"To dwell is to be at home. Home is given over to the hidden processes of life. It protects life, not only from inclement weather and predators but also from the glare of the public eye. In the home we go when we are tired or sick, that is, when we can no longer maintain a brave front before the world. In the home, not the hospital, we recover from illness." (Bachelard, 1969)

Classical antiquity locates the idea of a home as a private and concealed space from which one venture into the light of public life. The hidden processes that Bachelard accords to the idea of dwelling romanticizes the concealed and introspective atmosphere of a home which is perceived uncritically through the passive modes of smell, taste and touch. Such passive modes of experience associated with the idea of home, as Yi-Fu Tuan suggests, cannot be made public as the associated feelings wither under the public glare (Tuan, 1975). The modern home in a high-rise apartment in an extreme sense exemplify the concealed phenomena of a dwelling as a bounded place. The idea of home in this context is that of an enclosed entity. The notion of dwelling as 


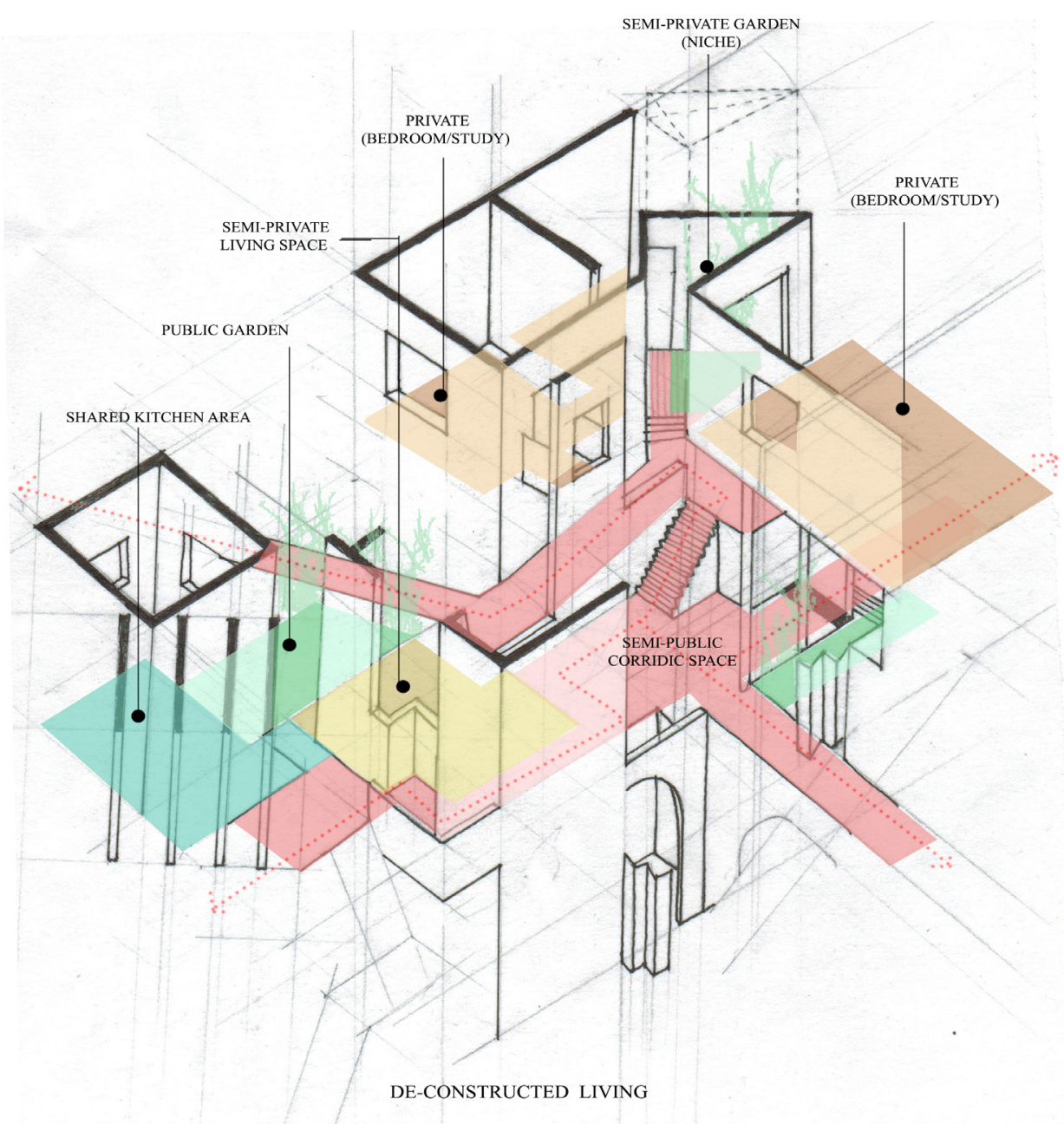

fig 11. De-constructing the dwelling space. The

a processual space deconstructs the enclosed entity and accords the idea of home shifts away from an enclosed entity to a hidden processes varying degrees of enclosure and extension (fig 11). processual incremental space of differing layers in privacy The notion re-evaluates the relation of the inside and outside and aims to construct a multi-layered, varied landscape for dwelling to occur. Dwelling ceases to be a concealed hidden process and becomes a character-defining process in a corridic place. It becomes a presence with the spatial delineations adding character to this presence. Just as a character of a place is a function of time similar to the character of a landscape being a function of time (changing with seasons, time of the day), the processual aspect of dwelling varying with time gives character to a corridic place. The character of the corridic place 
acquire unique signatures in the course of time through its fluidic spatial delineations and modifications brought about by appropriative practices of human inhabitation. Yi-Fu Tuan, in his poetic writings describes how the humanistic process of giving character to a place evokes affection and a sense of attachment to a place.

"The character of a raincoat is imparted by the person who wears it and grows fond of it. The raincoat is for use, and yet in time it acquires a personality, a certain wayward shape and smell that is uniquely its own. So too a place, through long association with human beings, can take on the familiar contours of a nurturing personality” (Tuan, 2001)

\subsection{Hapticity in a Corridic Place}

Constructing a sense of place has two meanings in a corridic place: one is visual that actively helps formulate an explicit knowledge or awareness of a place, the other deploys a more subconscious, passive way of experiencing. Other than the all-important eye, sense of place is also constructed without any attempt at explicit formulation, through the senses of hearing, smell, and touch (Tuan, 1975). The corridic place is a sensuous place that bounds the inhabitant in a subconscious awareness of their material environment. A corridic place de-constructs the uniformity of experience by moving away from the flatness of surface, materials, uniformity of illumination and creating a varying sense of opacity and depth, sensory invitation and discovery as one moves through the place (fig 12). The tactile values of a corridic place re-enforce the authenticity of the lived experience in that space by enabling the space to be a haptic continuity of the self. Moving away from the utilitarian aspect of a corridor revolving around speed and efficiency, the hapticity of a corridic place promotes 
slowness and intimacy. The haptic surfaces instill a sensory essence rather than remaining mute, it employs a presence of matter rather than aspiring for geometric purity or reductive aesthetics (Pallasmaa, 2000). Tactile sensibility evoke what Gaston Bachelard called 'material imagination' in his phenomenological investigations. He considered spatial memory, association or mental images arising from matter project deeper and more profound experiences, than form (Bachelard, 1969). The architecture of a corridic place grows through separate architectural scenes and material episodes that is held together by the constancy of an evocative atmosphere (fig 13). The architectural scenes and material episodes articulating experiential situations add a sense of poetic imagery to the notion of dwelling that characterizes the corridic place. The material imagination that construct a sense of place that one associates with the idea of home extends inside outwards into the corridic place, eventually turning into the entity of the building.

\subsubsection{Fragile Ontology of a corridic place}

The material sensibility and tactile aesthetics characterizing a corridic place reflect the philosophy of 'fragile thought' in architecture. Inspired by the notion of 'weak thought' by the Italian philosopher Gianni Vattimo, the idea of fragile architecture evolved in the 1980s; a notion of architecture that is contextual and responsive, concerned with sensory interaction instead of focusing solely on impressing through an idealized and conceptual manifestation of form (Pallasmaa, 2000).

A corridic place grows, it conceals and opens up. When Lefebvre talks about spontaneous texture and the sense of naturalness in the growth of European towns, he refers to the fragile principles that help construct a haptic landscape of intimacy and a sense of emotional attachment to a place. The corridic space with its multitude of parallel, intertwining spatializations fused with material subtlety construct the episodic 


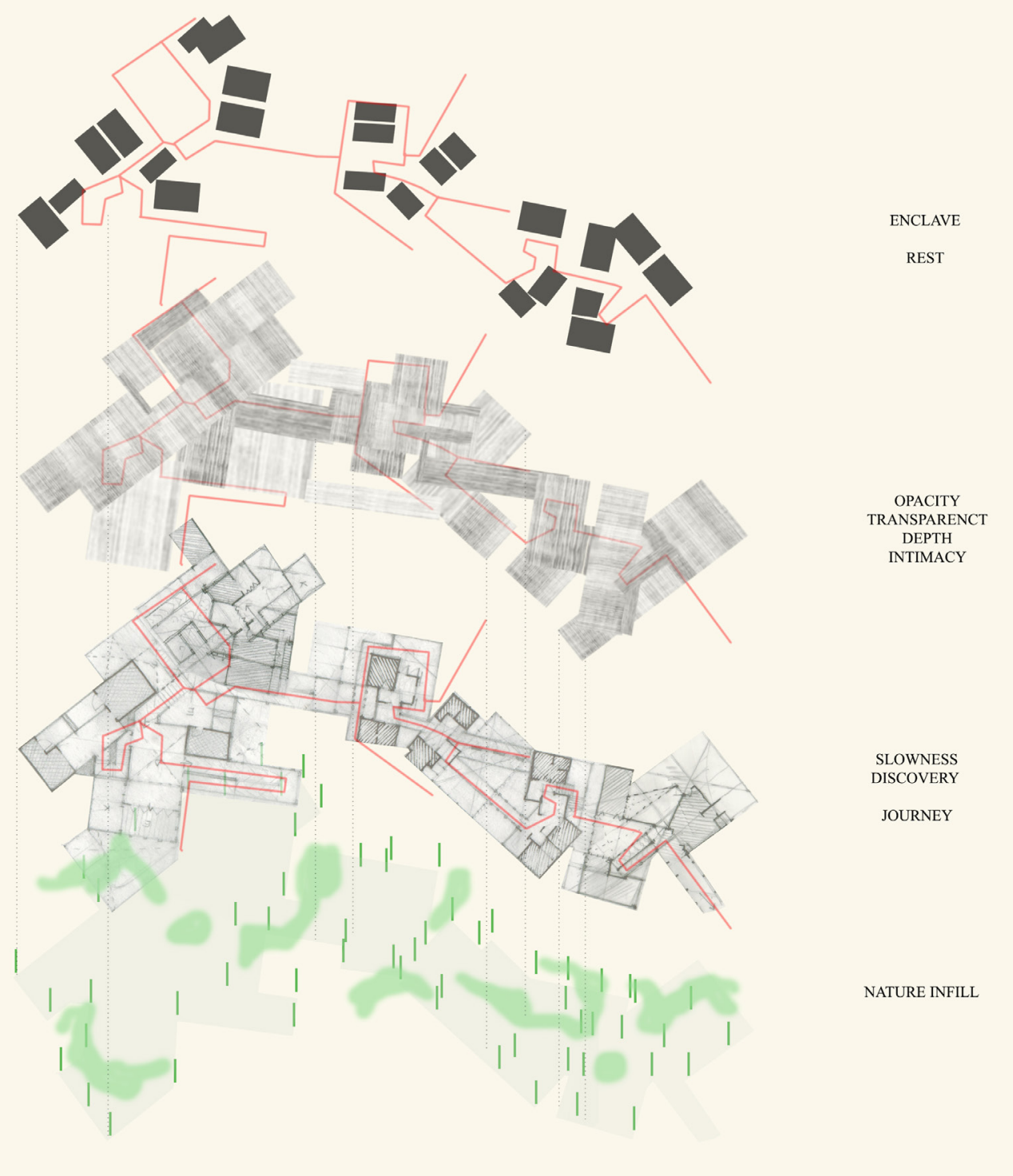

fig 12. Haptic Mapping of a Corridic Space

architecture of the corridic place. Pallasmaa in his poetic writings draw an analogy between the sequence of parts in the episodic architecture of fragile ontology and the composition of acts and movement of music in a theatrical play (Pallasmaa, 2000). Much like a composition, the corridic place aims to create ambient episodes and evoke a sense of natural duration. The music composer John Cage explains the importance of silence in a musical composition: a carefully inserted pause having as much a psychological impact as a well-structured note (Cage, 1973). Similarly, there are moments of pause accorded to the episodic architecture of a corridic place where the space with its tactile sensuality arrests the inhabitant in a moment of receptive attention. 


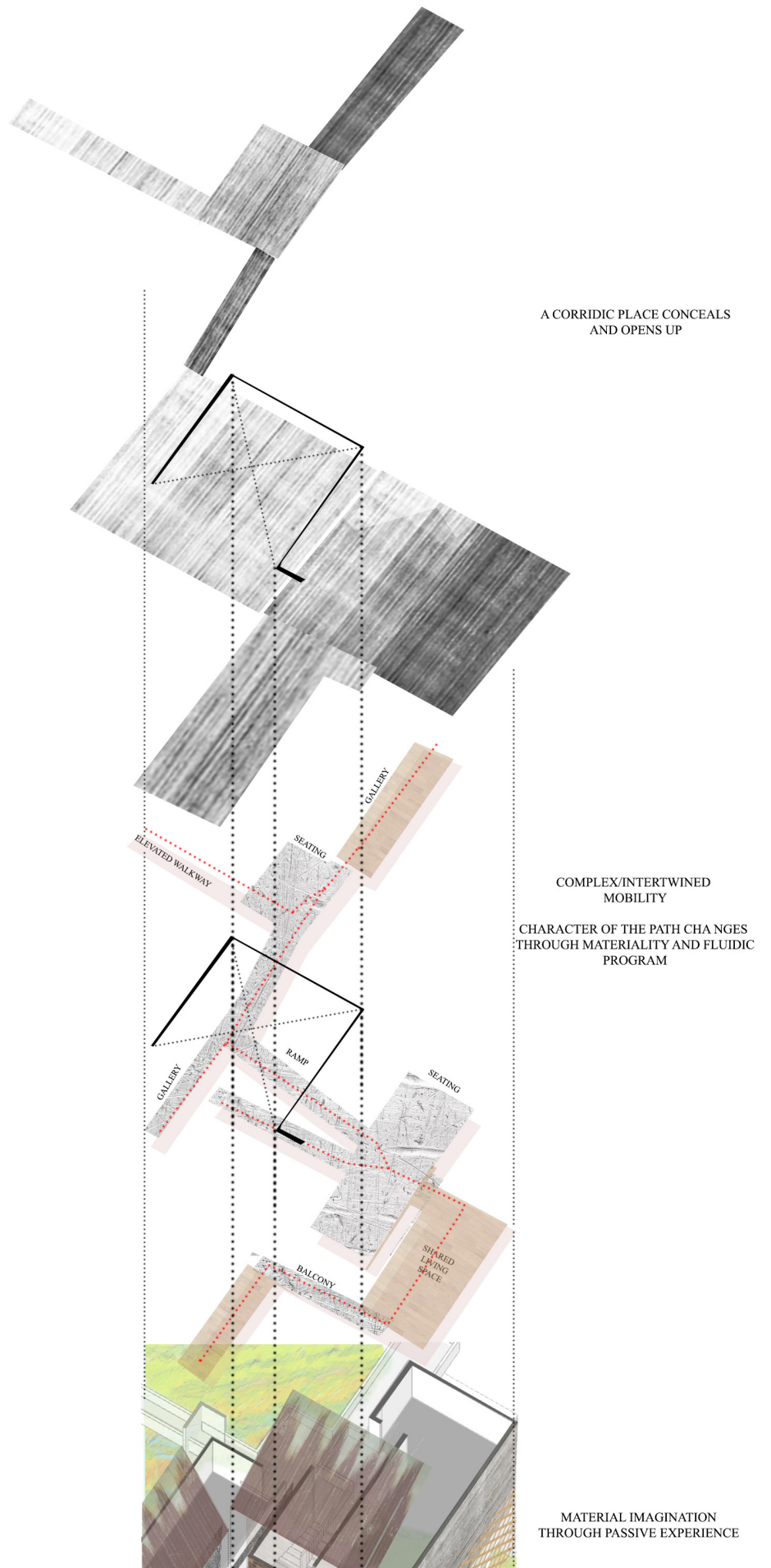

fig 13. Ambient episode

Tactility and experiential layering in a corridic space 


\subsubsection{The Aesthetic ideal in an Imperfect Space}

'Imperfection is in some sort essential to all that we know of life. It is the sign of life in a mortal body, that is to say, of a state of process and change. Nothing that lives is, or can be, rigidly perfect; part of it is decaying, part nascent [...]. And in all things that live there are certain irregularities and deficiencies, which are not only signs of life but sources of beauty'- John Ruskin

The fragile ontology of a corridic space embodies the aforementioned notion of imperfection when it comes to the question of perceiving its aesthetic ideal. Reflecting on Walter Benjamin's definition of a work of art, Lefebvre argued that a social space (in this case, the corridic space) acquires a texture of spontaneity and naturalness as a result of a relaxed structure fused with layered spatializations. Like a creative process or a work of art, the structure of such a space possess a certain level of aesthetic tolerance that allows additions and alterations, a margin for change (fig 14).

The episodic nature of the corridic architecture seeks deliberate discontinuities instead of a unifying logic to its aesthetic ideal, and it seeks to juxtapose variations to create unique 'assemblages'. These variations arise out of a relaxed sense of appropriation, contextuality rather than any deliberate aspiration for preconceived beauty. Reflecting on the third component of Vitruvius' triad; aesthetic delight, the architecture of the corridic space strives to engage the senses by expanding beyond the ocular-centric perception to a multi-perspectival and simultaneous perception. By expanding the perceptual realm, the corridic space engages the peripheral senses and creates a supportive background for human activities and perceptions. It embodies a new Gestalt principle where the inhabitant perceives the individual aspects of the corridic space before perceiving the whole in entirety and in doing so, realizes that 'the whole is other than the sum of its parts'. 


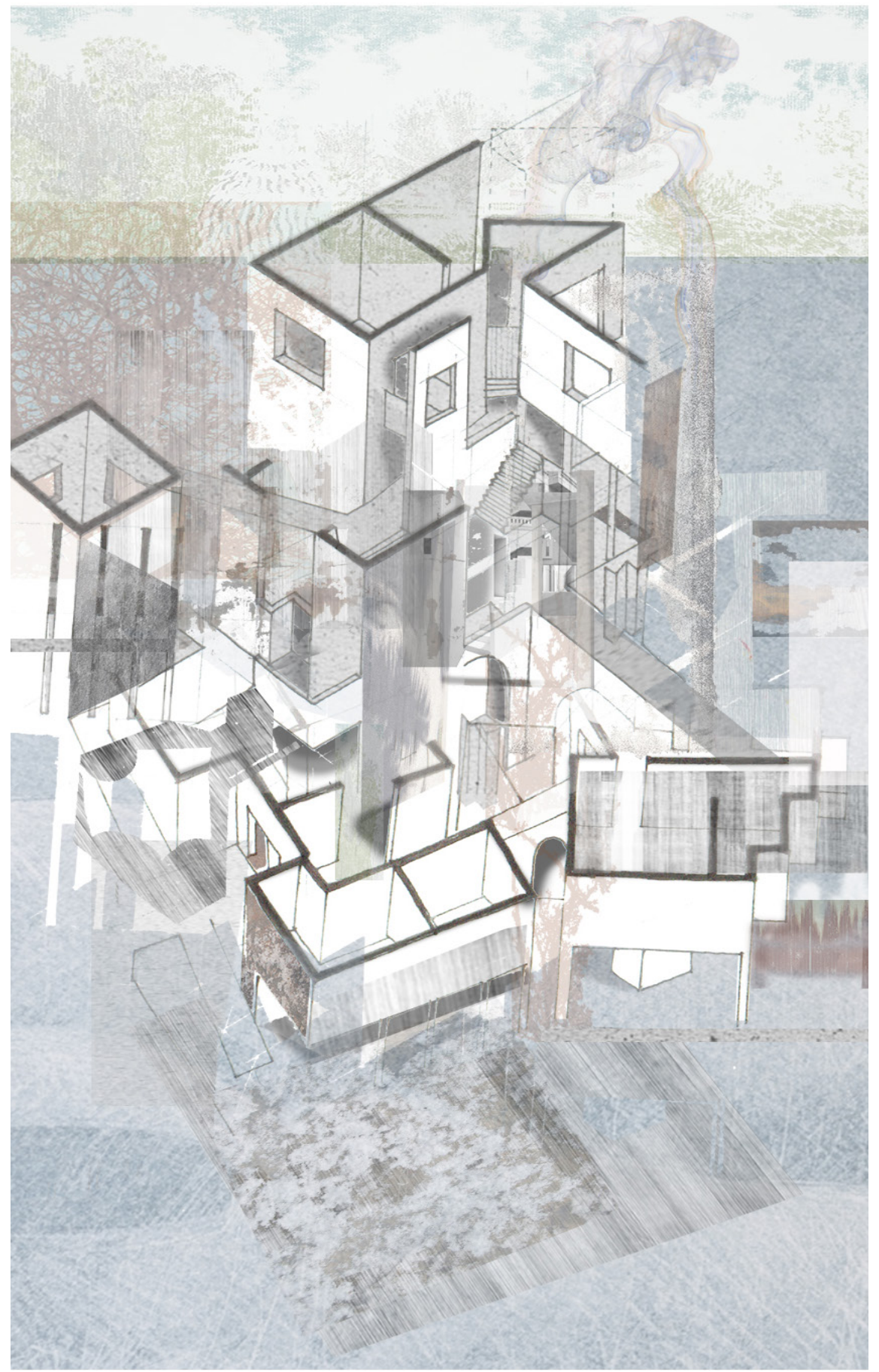

fig 14. The imperfect ideal of the corridic place acquire texture and character through natural duration and over the course of inhabitation. 
Living In-Between 


\section{0}

\subsection{Language of the Corridic place}

\subsubsection{Street-scaping}

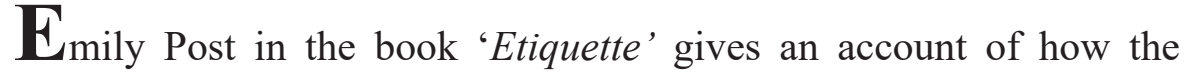
corridor spaces in a building are suggestive of a street in a city whereas elevators are suggestive of a room (Post, 2004). Drawing an analogy could help investigate into the commonalities that both the spaces share as well as determine the transformative possibilities embedded in the corridic threshold space. The thesis also aims to draw analogies from various cultures where abstraction of the rigid interior, exterior dialogue at street level creates a transformative space for community.

"The street is a room by agreement, a community room, the walls of which belong to the donors, dedicated to the city for common use. Its ceiling is the sky. Today, streets are disinterested movements not at all belonging to the houses that front them. So you have no streets. You have roads, but you have no streets." (Kahn L. , 1973) 
Louis Kahn in the aforementioned excerpt defines how streets are the fundamental public spaces but its architectural meaning is increasingly becoming overlooked and diminished to maximize its automotive functionality. The street is increasingly becoming the space for movement and logistics rather than a place for community. Throughout history and across many cultures, this has not always been the case and the dialectics of inside and outside at street level had always led to a transformative space for shaping our physical and mental landscapes. Streets once functioned as multiple-use town centers, as places where children could play and where neighbors and strangers would stop for conversation, today they have become the primary and near-exclusive domain of cars (Mackenzie, 2015). Similar to the 'motor-centric' mindset of the modernists viewing the street as a machine for maximizing efficiency in vehicular movement and eliminating pedestrian association, the modernist fallout of corridor spaces resulted in the diminishing of its function as a social space and becoming a purely utilitarian element for optimizing movement in a building (fig 15).

Le Corbusier envisioned the urban street as a 'machine for traffic' and championed the modernist way of designing the street solely around the car instead of public spaces (Corbusier, 1929). This led to cities and communities being designed to meet mobility needs rather than human needs like social interaction and connection to a place. Similarly, corridor spaces in dwelling systems became a necessary but invisible structure, a mobility device defining the shape and program of the entire building. Like the 'motor-centric' city being an ensemble of isolated public spaces linked by car-dominated placeless streets, a residential system can be viewed as an ensemble of dominant yet isolated social spaces linked by placeless corridors. 

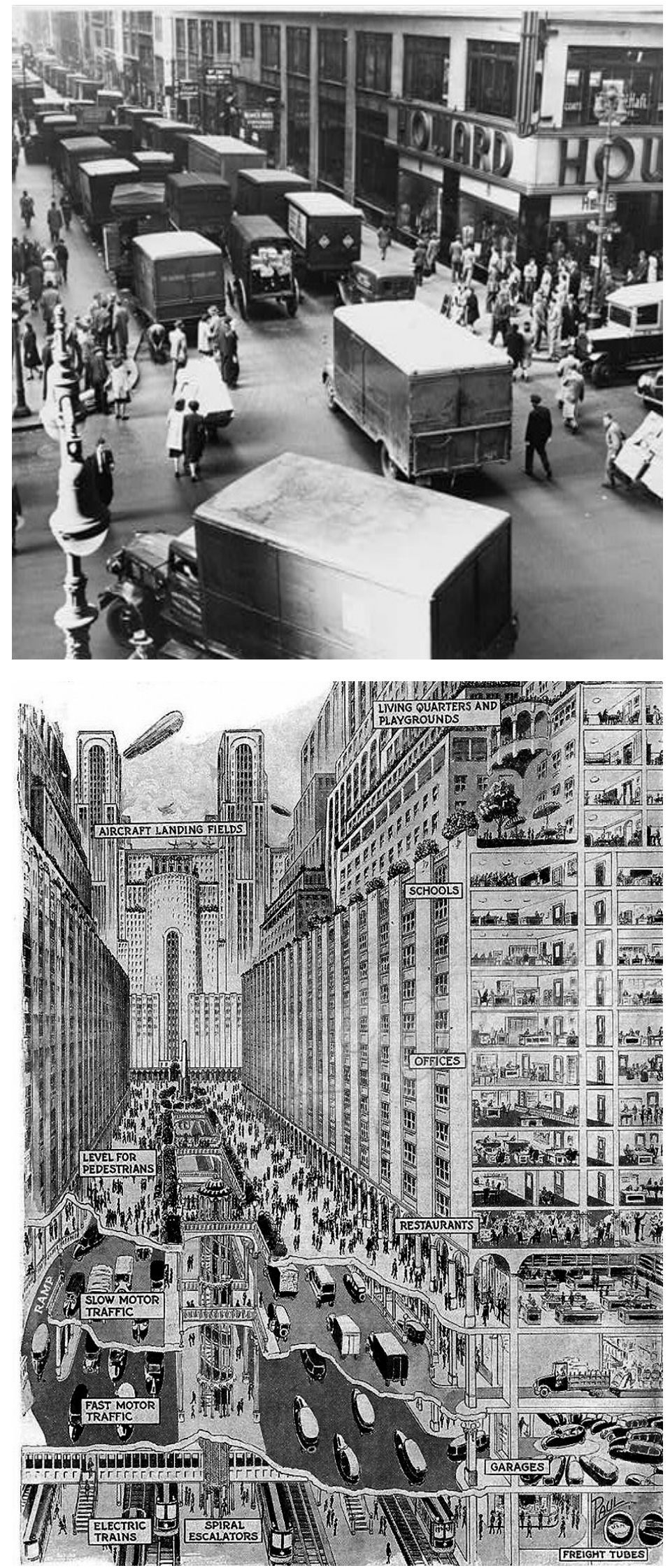

fig 15. Motor-centric city

Top- emergence of the street as a space for auto-centric movement and diminishing pedestrian sensitivity

Bottom- Urban Machine. Parallel can be drawn between the street and the utilitarian consolidation of the building corridor 
The thesis aims to draw principles from how various cultures have abstracted the dialectics of inside and outside to create a transformative space to nurture the sense of community. The Aranya Housing Project designed by Bal Krishna Doshi in India is designed with sensitivity towards community building by taking into consideration how inhabitants require flexibility in their dwelling environment as they start identifying themselves with their dwelling space.

"Doshi's design for the housing varied considerably in size from accommodating several hundred to a few thousand families, and yet he conceived of each as a coherent, self-sufficient community in which common amenities and services were shared. Doshi facilitated this idea by adding clusters of homes together to create low-rise (mostly two- or three-story), high-density townscapes" (Bhatt, n.d.) (fig 16).

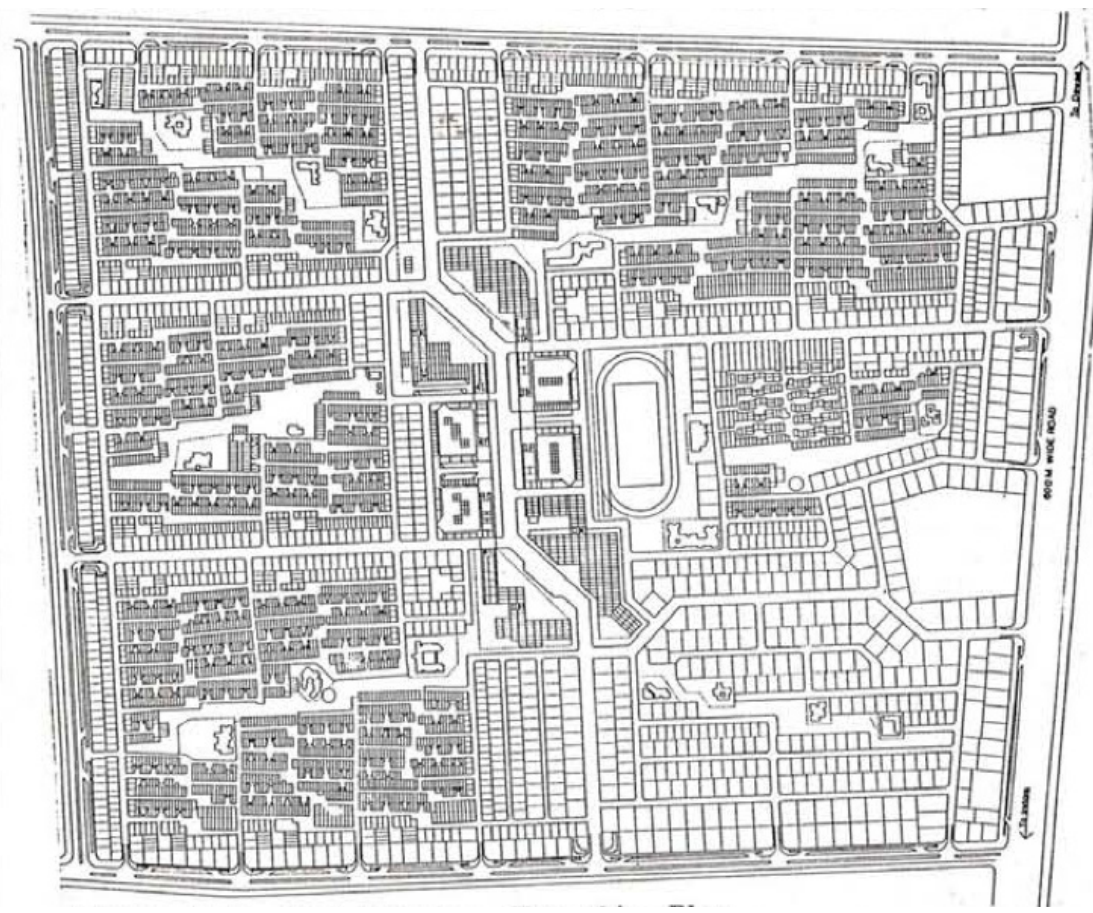

fig 16. Aranya Housing layout, B.V. Doshi.

Designing communities around streetscapes. Branching from the central spine, each community is a self sustained unit organised around a secondary street which acts as a community space 


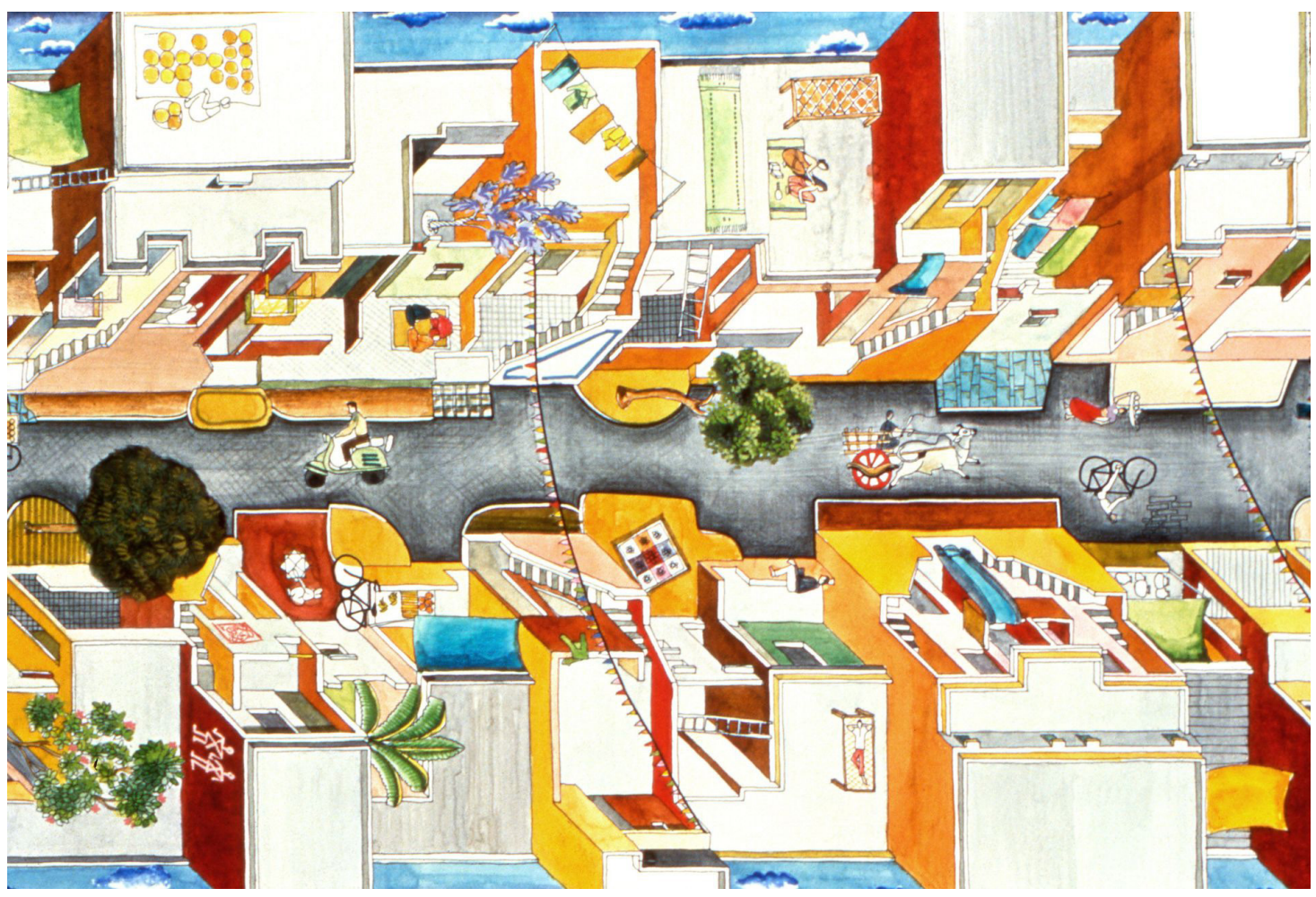

The design responds to the idiosyncrasies and appropriative capacity of its inhabitants by relaxing the rigid inside-outside dialectics at the street level (fig 17). Walls act as doors which open up to the street and fig 17. Aranya Housing Street. Miniature drawing by B.V.Doshi.

Doshi imagined the threshold between the street and the living spaces as a transformative space for community building expands the living space onto the grade level as a flexible porch. Apart from shops, there are dwelling spaces that extend the kitchen space to the street and neighbors congregate in semi-public dining spaces to socialize. Most shops on the ground floor open inwards, so the corridic space in between residential units become a make-shift porch for the shopkeepers and the inhabitants to interact with one another. Doshi had intended for such flexibility to be adopted and the liminality of the discreet spaces to be transformed into thriving spaces for community. 
The architecture of the Kyojima district in Tokyo, Japan exemplifies the abstraction of the threshold spaces at street level. The traditional wooden tenement houses open up in pockets which enables the inhabitants to spill out their dwelling space onto the streets (fig 18). These spaces are used as shops or niches for congregation. The indoor outdoor spaces are well integrated through the transparent façade.

"Because the alleys are usually used as intimate outdoor rooms, passerby would feel comfortable and safe. Most of the area remains walkable. In Kyojima, the function of the intermediate space between public and private is very important. For instance in Tachibana Ginza, about five meters wide, more than 100 shops open up to the street. Doorways are usually open, and at any time it is a lively environment" (Mackenzie, 2015).

Similar to the Aranya project, the human scale in Kyojima is emphasized through the construction of mid-rise dwelling units and alleys focused around casual encounters of the inhabitants. This principle was drawn for the conceptualization of the Moriyama House designed by Ryue Nishizawa (SANAA). The residential project comprises of one to three levels of dwelling spaces dispersed throughout a 'corridic' garden space (fig 19). The organization of the spaces in this project redefines public and private space by abstracting the liminal elements like the corridor between different functional spaces. The architect had intended the flexibility in design so that dwelling units are adaptable to the inhabitant's needs, which consequently also changes the circulation within the site (Eldin, 2017). The use of glass facades and large fenestrations integrates the in- and outdoor spaces while being oriented in a fashion that preserves the privacy in all the spaces. The lack of physical barriers makes the dwelling space integrated with its context. Circulation is relaxed within the site which enables casual encounters of its inhabitants. The garden patches at its threshold 

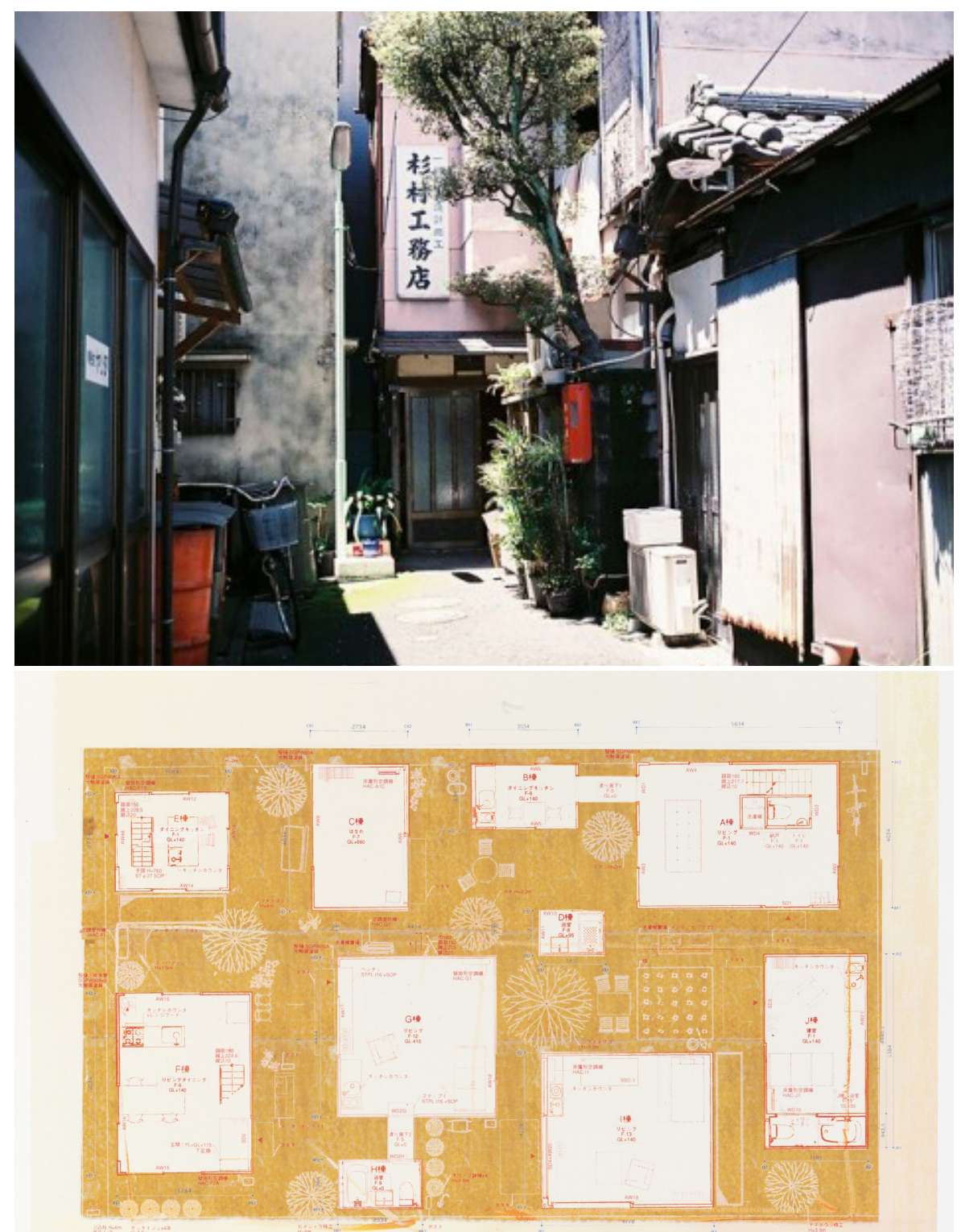

creates an ambiguous space allowing flexibility for its private spaces to become communal spaces. Similarities between the Aranya Project and Moriyama House delineates the conditions where implementing flexibility in the dialectics of in- and outdoor spaces transcends the liminal aspects of threshold spaces. The architectural language of the corridic space can build upon such principles to re-structure the inhabitant's liminal experience and create a transformative space conducive to the phenomenon of communitas.
Top-fig 18. Kyojima district

Bottom- fig 19.

Organization of living spaces around a liminal garden space in Moriyama House deconstructs the idea of indoor-outdoor in a dwelling space 


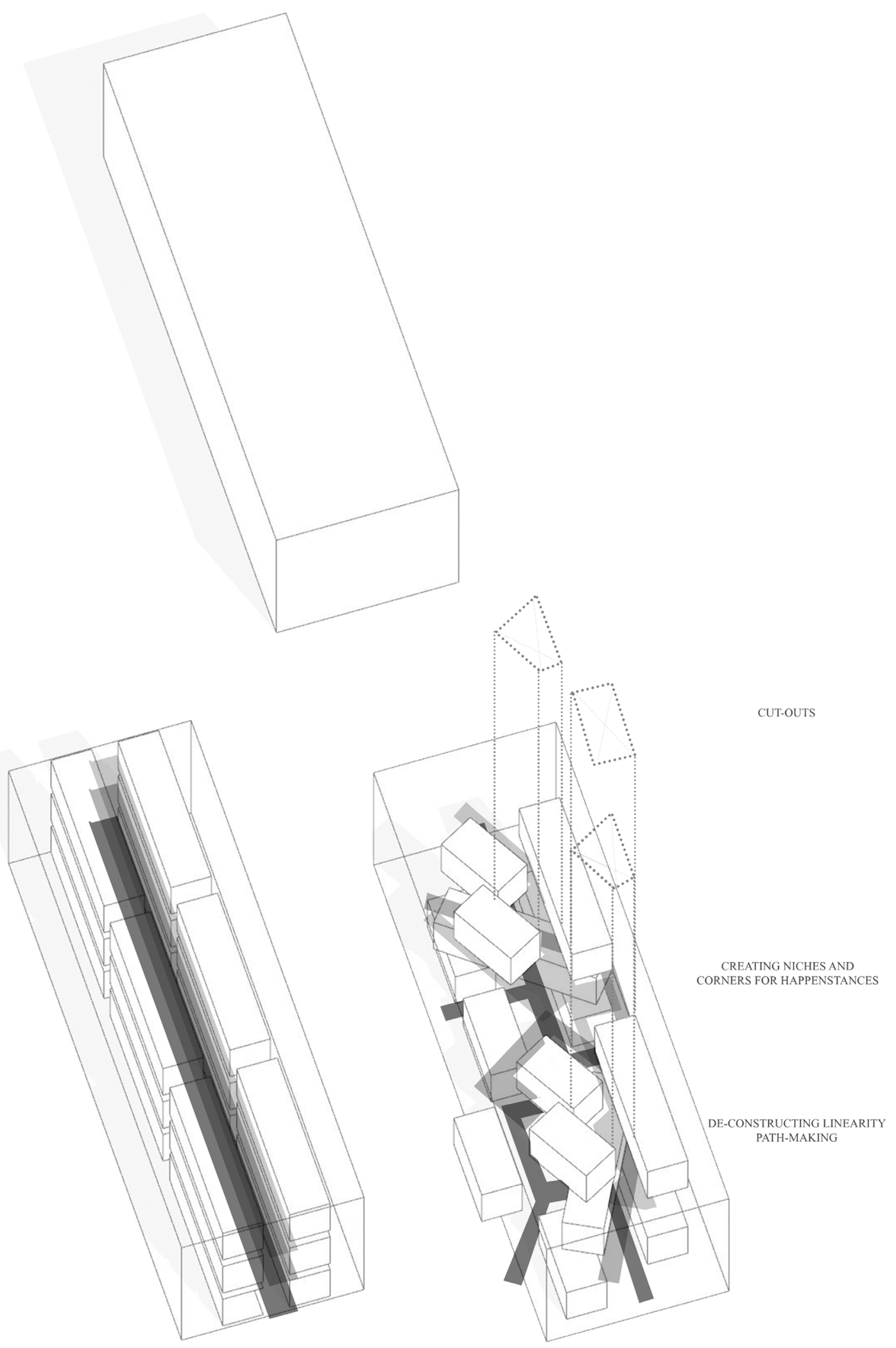




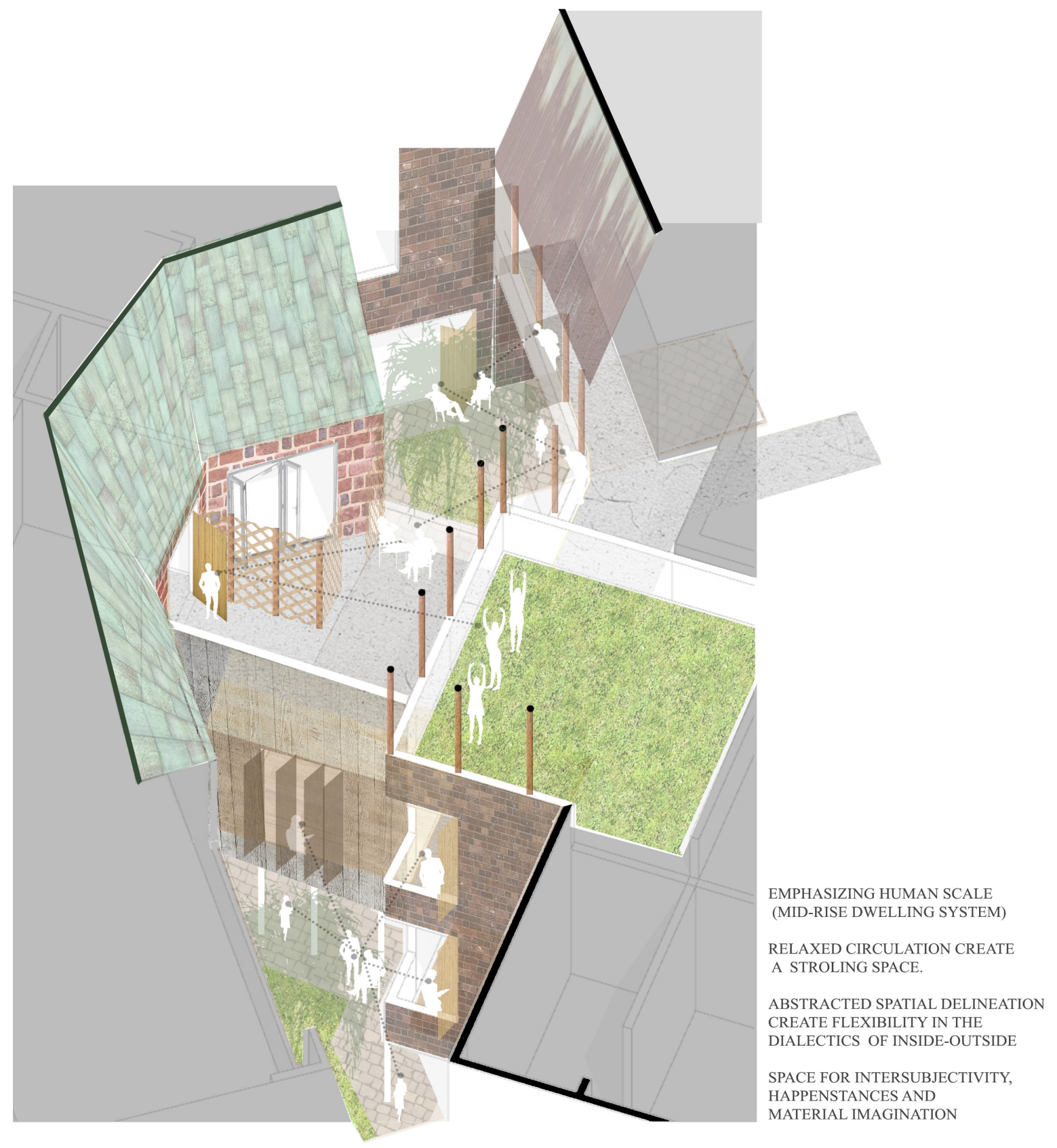

Left- fig 20. Street-scaping the residential corridor

Top- fig 21. Street dialectics of a corridic space in a residential system 


\subsubsection{Porch in Be-twixt}

Ernest Pickering in 'The Homes of America' elaborates on the innate connection of the idea of dwelling to the front porch, stating 'the history of the front porch is itself the history of American life' (Pickering, 1951). The evolution of the front porch came with a cultural significance that connected the idea of a dwelling space with respect to the surrounding nature. The porch evolved out a compromise between the idealization of nature and the ideal of appropriating nature or attempting to 'control' or 'civilize' land for human needs. It formed an essential transitional realm between the uncontrollable out-of-doors and the cherished interiors of the idea of 'home' (Dowell, 1992).

As an architectural concept, the porch existed in the dialectics of the inside-outside since the ancient Greeks. Its stylistic development and socio-cultural significance occurred throughout history, revealing itself at specific points in time in history, disappearing and reappearing again (Kahn \& Meagher, 1990). From the ancient Greek 'portico', 'vestibule' in the Middle Ages, 'loggia' and 'piazza' in Renaissance, Italy, the idea of the domestic porch amalgamated in the Victorian period combining the individual meanings connoted by each of the preceding architectural concepts. From the Victorian definition of the porch as a 'small, enclosed vestibule', evolved the contemporary American definition of a 'roofed, semi-covered living area' contiguously attached to the frame of the house (McAlester, 1984). This semi-open living space was a hybridization of the European architectural traditions and native traditions of a diverse cultural group that settled in America in the 18th century. The cultural significance of the front porch did not gain foothold till well into the 18th century when African immigrants built houses inspired by the shotgun houses of West Africa (Cook, 2009). Such hybridization acted as an impetus to an architectural language that in its ubiquity defined how communities developed in the American context (fig 23). 

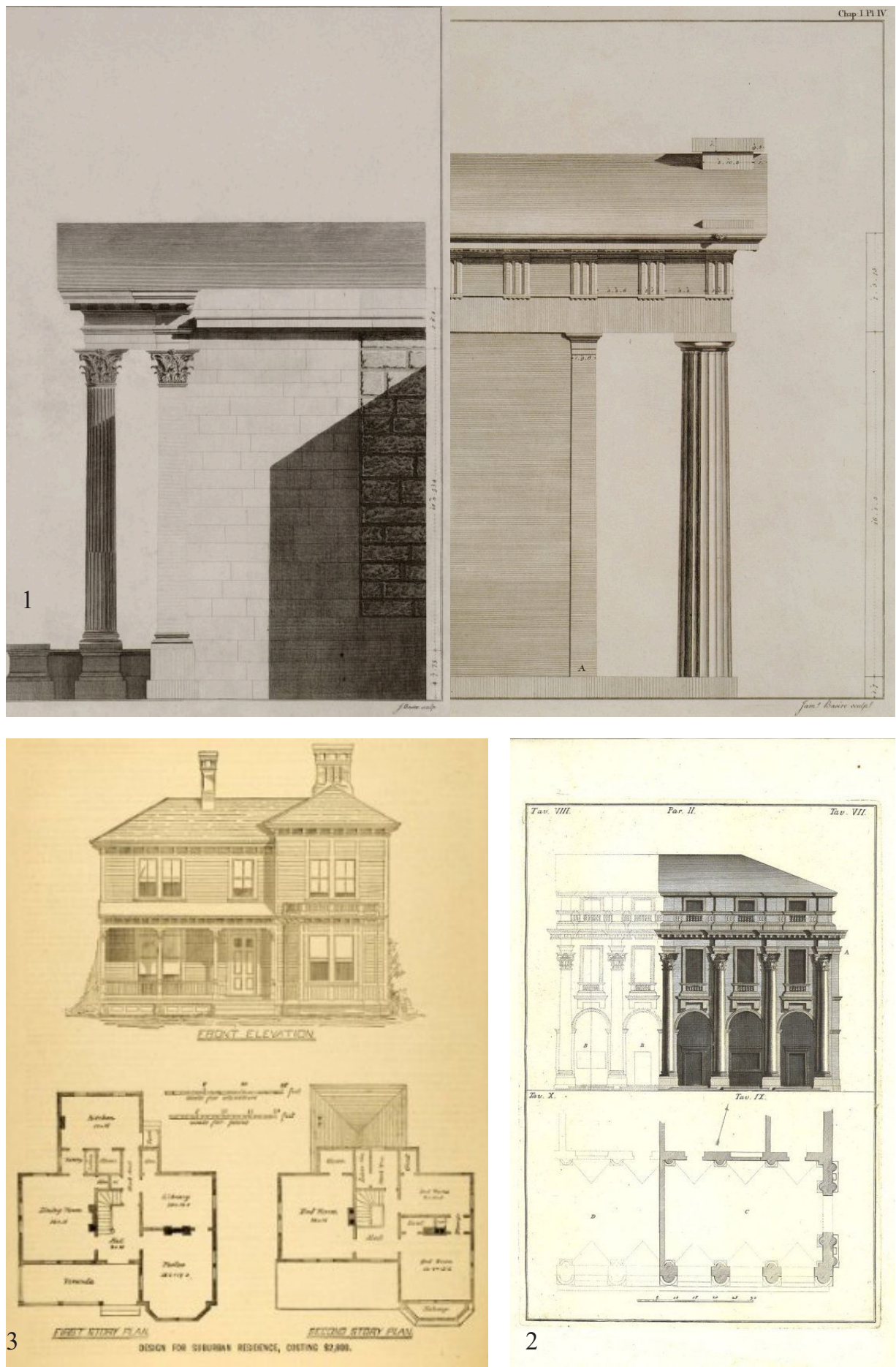

fig 22. From portico to porch. Mediating the indoor-outdoor dynamics

(Clock wise from Top) 1. Ancient Greek portico

2. Loggia in a Renaissance villa

3. The porch in a Victorian house 

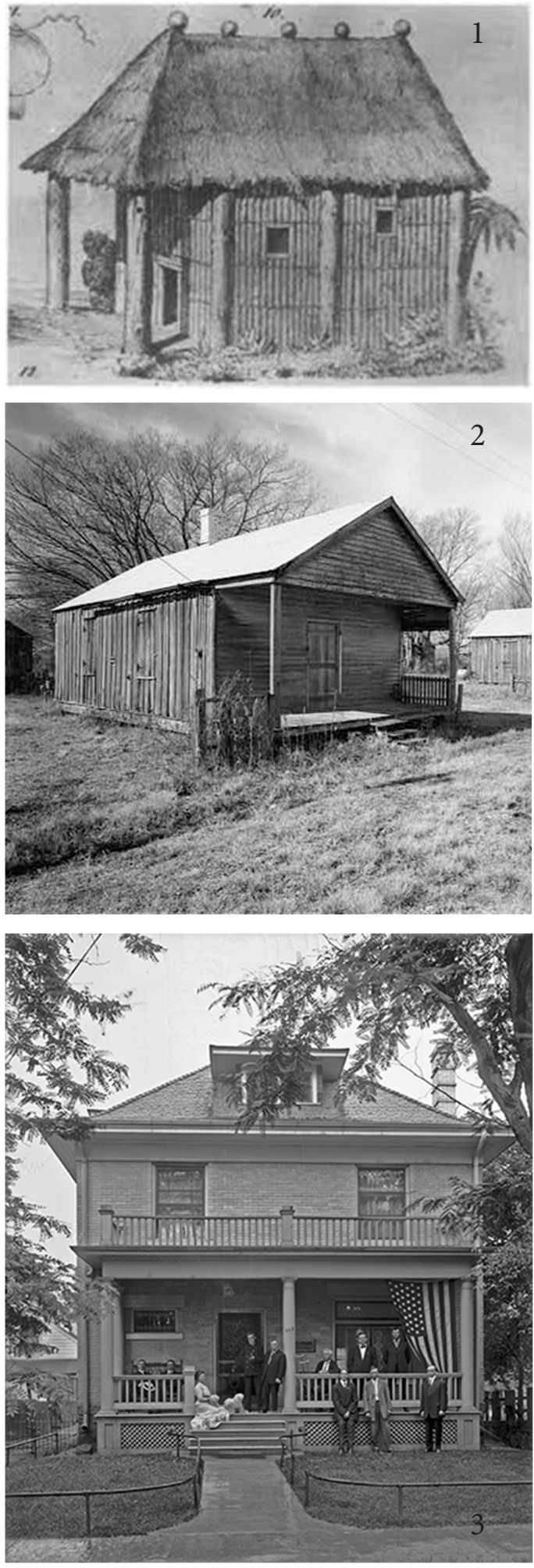

fig 23. Hybridization of the Victorian porch and the African Shotgun houses consolidated into the dialectics of the American porch 
The sense of place that the porch affords is intrinsically linked to the phenomenological reverberations created by the material imagination of the inhabitant inhabiting the threshold space. The porch exists as a transitional space between the public and the private, an area that can be shared between the sanctity and interiority of the home and the exteriority of the community outside (Cook, 2009). Gaston Bachelard's poetic account of the sensual qualities of a dwelling space can be extended to the transitional realm of the front porch. The threshold space is a blurred delineation of a dwelling space, a place that exists as the haptic continuity of the self. The lived experience of the porch is constructed by passive modes of experiences that amalgamate into a heightened sense of awareness, enabling the inhabitant to situate their dwelling space with respect to its natural surroundings. Furthermore, this heightened sense enable the creation of a sense of place in that threshold space which lingers on in memory through 'moments'.

"The twilight was blurred and soft. Supper was almost ready and the smell of cabbage floated to them from the open hall. All of them were together except Hazel, who had not come home from work, and Etta, who still lay sick in bed. Their Dad leaned back in the chair with his sock-feet on the bannisters. Bill was on the steps with the kids. Their Mama sat on the swing fanning herself with the newspaper. Across the street a girl in the neighborhood skated up and down the sidewalk on one roller skate. The lights on the block were just beginning to be turned on, and far away a man was calling someone." (McCullers, 1940)

The aforementioned excerpt from Carson McCullers novel elaborate on such 'moments' that construct a sense of place in that threshold space of the front porch. Such moments are fragmented haptic episodes and architectural scenes that coalesce into an evocative atmosphere. The architecture of the porch is constructed by the assemblage of such evocative atmospheres. 
The civic potency of the porch lies in the layered opportunities it presents for social intercourse (Thomas, 1973). A certain duality can be accorded to the architecture of porches that enable such layered interaction ( $f$ g 24). The spatial delineation in a porch provides a sense of security, but also increases the willingness to engage with others, it allows for a sense of control over the immediate environment of the dwelling space while also being ready to entertain new circumstances (Krivens, 2017). This concept is called 'prospect and refuge', widely explored in landscape design theory. This concept lends the duality to the architecture of the porch which taps into the primal desire of an individual to reside at an elevated surveillance point and spot opportunities and threats, to be in a position of physical and personal safety while taking on the uncertainty inherent in extending ourselves to understand the other in terms of sociality (Krivens, 2017).

Another aspect of its civic potency lies in the organization and orientation of the front porch. The front porch is a spatial condition for creating familiarity where higher the frequency of inhabitants in a neighborhood seeing each other on the porch, the greater the chances are of wanting to socially interact (Jones, 2018). Such an approach employs the social psychological concept of 'the propinquity effect'. Studies of interpersonal relations in neighborhoods reveal that location of housing units, orientation and availability of entranceways are critical determinants of communication patterns that develop among inhabitants living in the neighborhood (Merton, 1948). Residential Propinquity effect in housing aims to explore the degrees to which physical and psychological proximity between inhabitants can be exploited to establish a kinship. An effective application of the concept involves designing movement patterns in a residential system that maximize visual space and the amount of time that when inhabitants are traversing through a sequence of spaces, they are in proximity to spatial conditions that facilitate interactions (fig 25). 

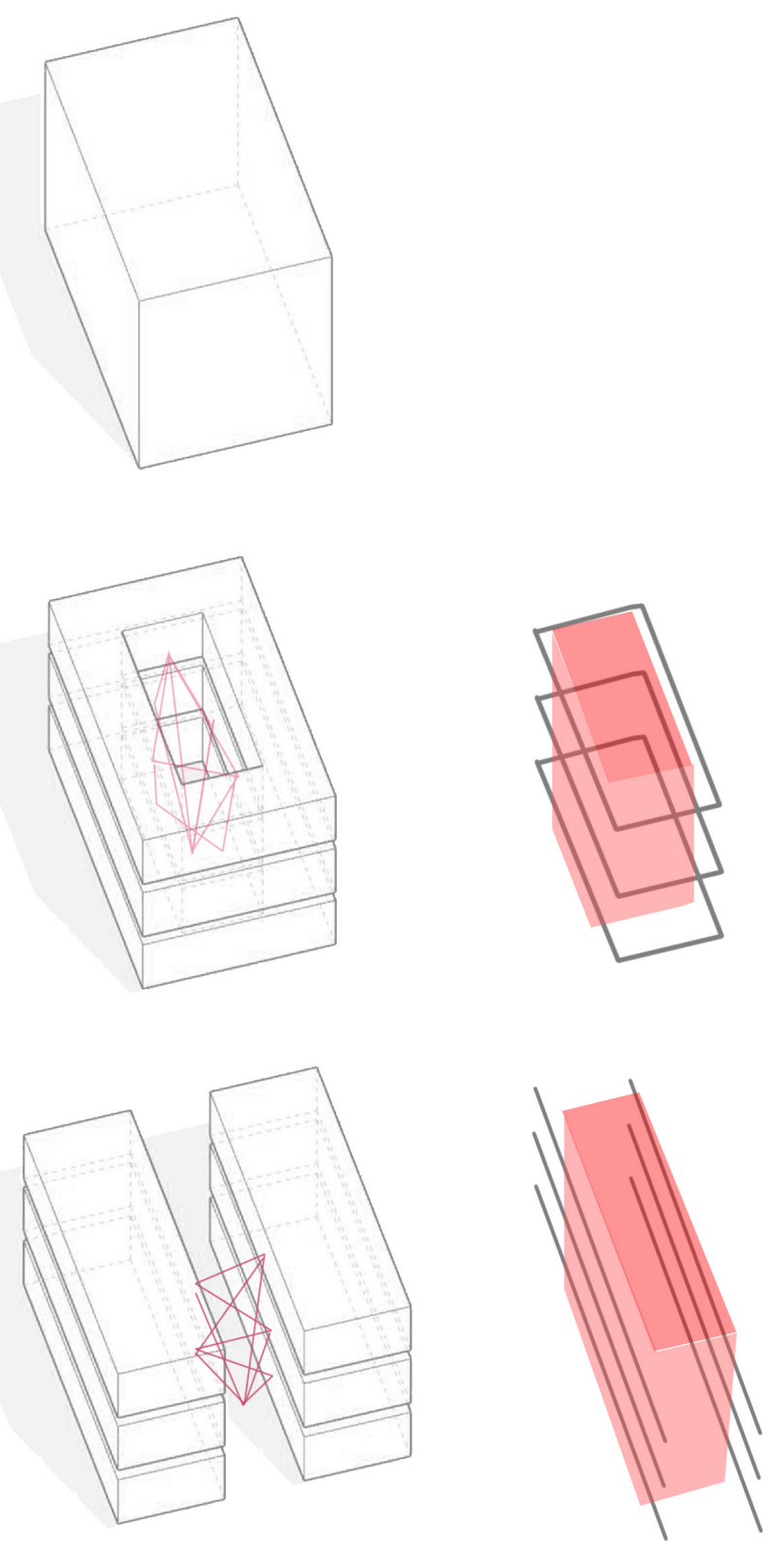

SINGLE VISUAL SPACE
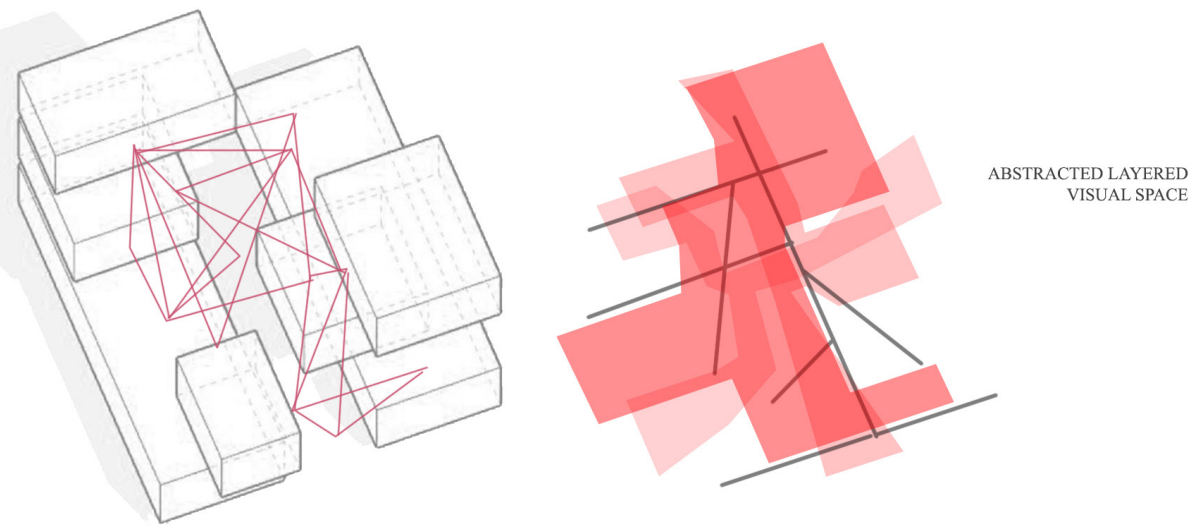

fig 24. De-constructing Visual and Physical proximity for layered interaction 


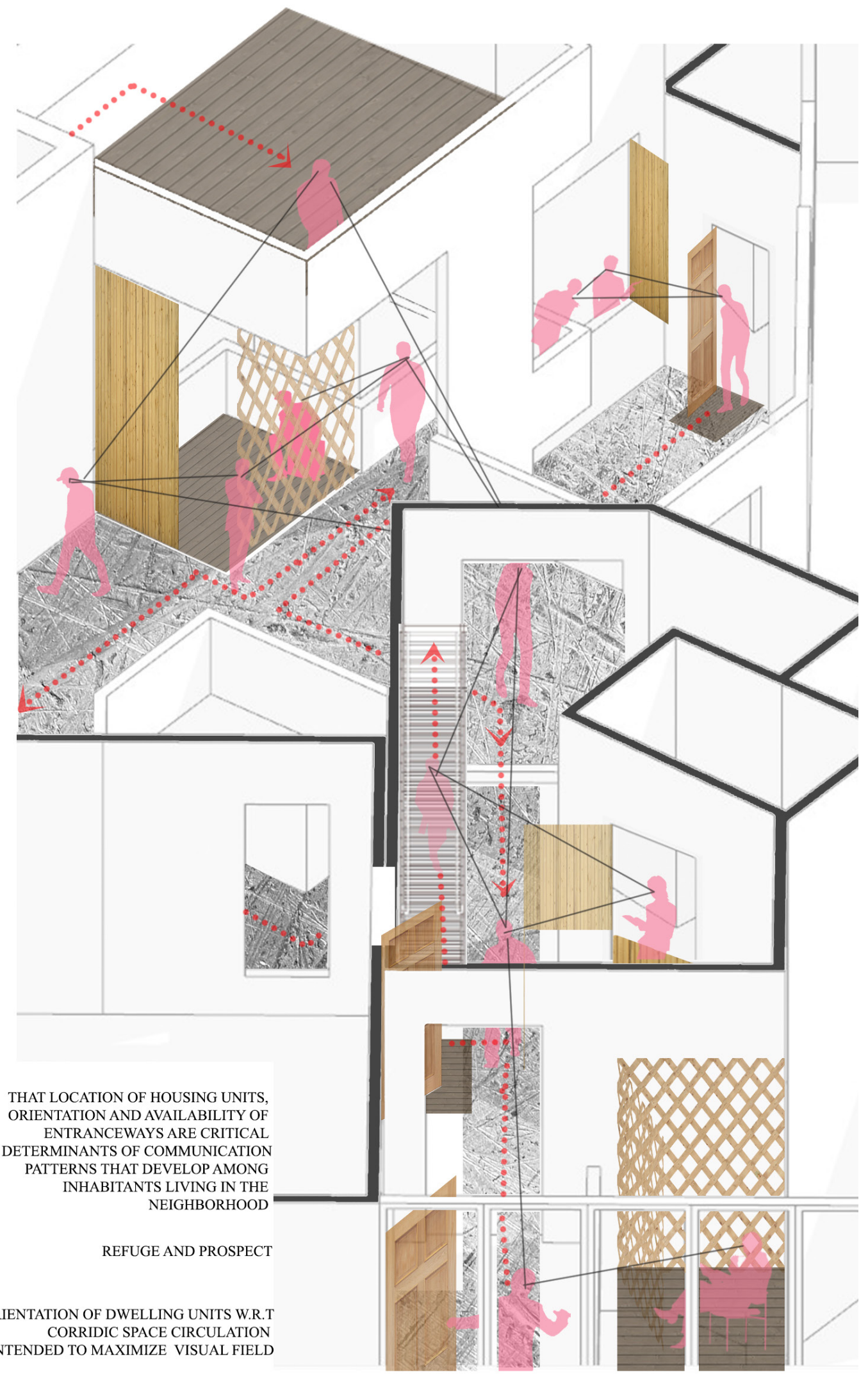

fig 25. Propinquity principles in a corridic configuration in a residential space 
Though porches are a simple, cost-effective solution for community building on the neighborhood level, the concepts they embody haven't gained traction with the rise of modernism. Changes in technological and social forces brought about a change in paradigm. The primacy of automobiles on streets spurred a developing abandonment of the inclusive front porch for an exclusive backyard patio. The automobile further created a new enclave and setting of towns and cities: suburbia. Automobiles allowed for Americans to move further distances from their workplace to build homes on less expensive property. The "automobile-dependent suburbs" did not feature front porches, due to the omnipresence of the automobile (Kahn \& Meagher, 1990). The idyllic setting of the front porch diminished as housing styles changed. The arrangement of the interior of the house with more informal rooms toward the back of the house seamlessly lead the inhabitant to the less formal backyard for recreation (Rowe, 1991)

To create humanistic topographies in a corridic space, the understanding of the aforementioned underlying concept of the conventional front porch provide a precedent to the notion of a dwelling as a processual abstract spatial condition. It supports the deconstruction of the enclosed idea of dwelling to create a multi-layered, haptic, varied landscape for dwelling to occur. Furthermore, the study of the porch as an abstract threshold space which accords various degrees of enclosure and extension to the idea of dwelling, provides a precedent for the spatial delineations that define the threshold between an informal corridic space and an enclosed formal living space. 


\subsubsection{Architecture of change}

"Everything that is static is condemned to death; nothing that lives can exist without transformation..." (Kwinter, 2002)

The growing commodification of architecture encourages the design of buildings which resist change and nurture such obsolescence. In the contemporary scenario, most buildings are constructed with little regard to the notion that the way one operates within a space change as needs and desires evolve.

Keeping that in mind, the design approach to a corridic space has as its underlying core the principle of adaptability and flexibility that enables the unlocking of the potentiality of the corridic space to re-describe the conditions of interactions between the building, its inhabitants and the environment. The corridic space goes against the basic dictum in the notion of obsolescence which states that architectural function and worth were quantifiable and necessarily decreased over time due to its prescribed inability to changing habits and desires (Abrahamson, 2016).

The corridic approach to building design shifts away from the hitherto ignorance of the static architecture of the residential building and takes into account the dynamic complexity of inhabitation. In acknowledging the creative agencies of inhabitation, the corridic place incorporates programmatic flexibility in its abstract processual threshold space that adapts with the changing needs of the dwelling space. It incorporates in its architectural thought the necessity to consider that an architectural project is not finished upon completion of construction. Not only does a programmatic shift occurs in a building with the shifting cultural and socio-economic structure of the society, but the way one uses and operates within a space changes over time with evolving needs and desire. As a result, in the contemporary consumerist societal structure, 

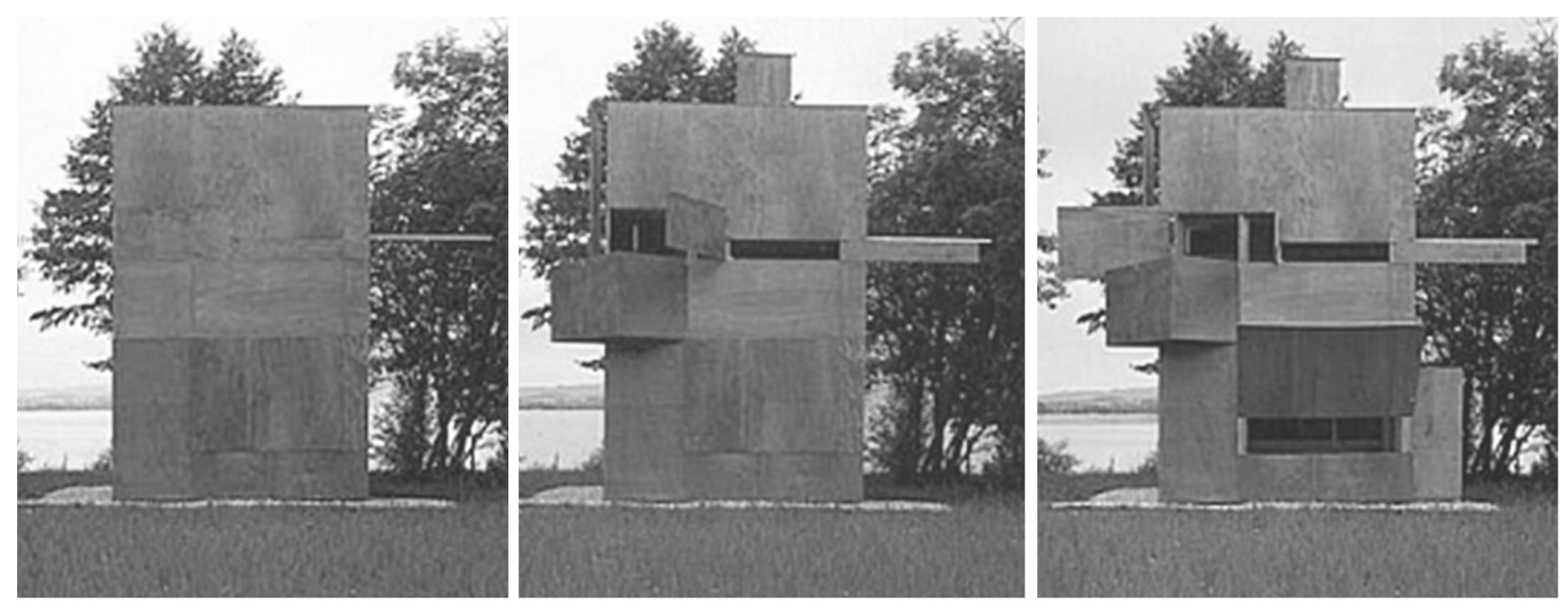

fig 26. Gucklhupf House. Spatial play

the successfulness of a residential building becomes a function of the degree of flexibility to engage several programmatic elements and the ability to facilitate any inevitable change over an extended period of time.

The introduction of programmatic flexibility in a corridic space can be brought about through myriad architectural approaches. The introduction of the dimension of mobility in a simple structural lattice could enable the generation of a variety of permeable and/or intimate spaces according to the dwelling needs. The architect Hans Peter Worndl in the experimental design of the Gucklhupf House explores programmatic flexibility by introducing three assembled squares which move around in a simple structural system (fig 26). Through a system of automated kinetic panels, the building is able to transform and facilitate different programmatic needs during different times of the year. Drawing on similar principles, the corridic space takes on the metaphor of what Hans Peter Worndl calls a perpetual 'workin-progress', as the structure of the space does not tend towards an absolute final state but allows a progressive deviation from its initial state of a stereo-metric object. 

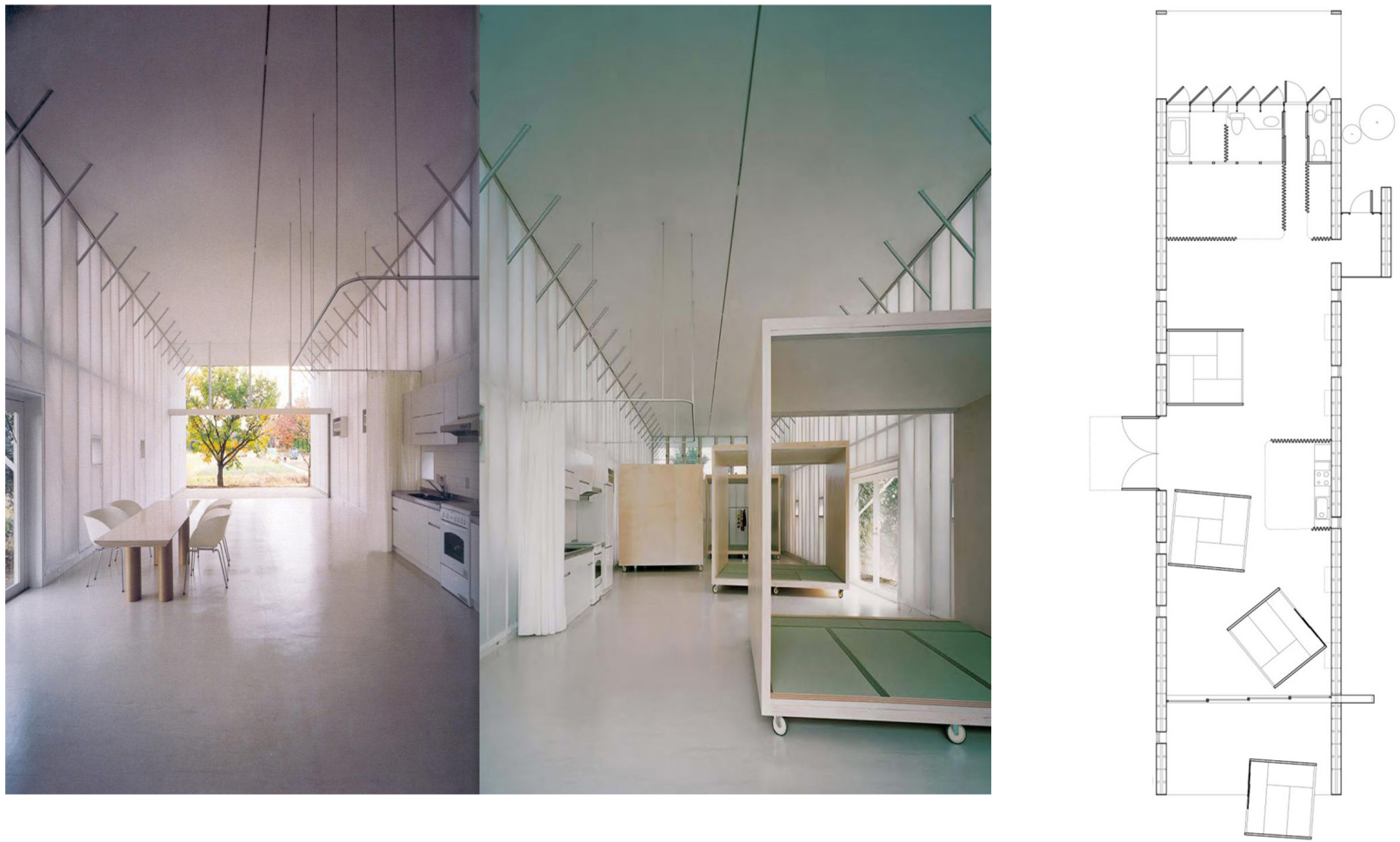

fig 27. Naked House. Mobility
The Naked House by the architect Shigeru Ban is an interesting example of adaptability and flexibility in building design inspired from vernacular architectural traditions. The open plan of the house can be re-organised and transformed according to the needs and desires of the inhabitants. This is achieved by incorporating changeable modular structures in the building which can be moved around to suit various spatial needs (fig 27). The building design can be studied as a constantly evolving system that emulate the fluidity of space present in the vernacular architecture of many cultures. Similarly, the corridic space interjects in it spatial complexity a sequence of open plans that create a paradigm of flexible programmatic networks. This recomposes the nature of dwelling in that corridic space over time.

The notion of programmatic freedom coupled with the introduction of the dimension of mobility of the corridic space finds its precedent in the conceptual projects of the British architect, Cedric Price. Price's works revolved around an innovative investigation into the concept of flexibility and adaptability that gave primacy to flexible programmatic 


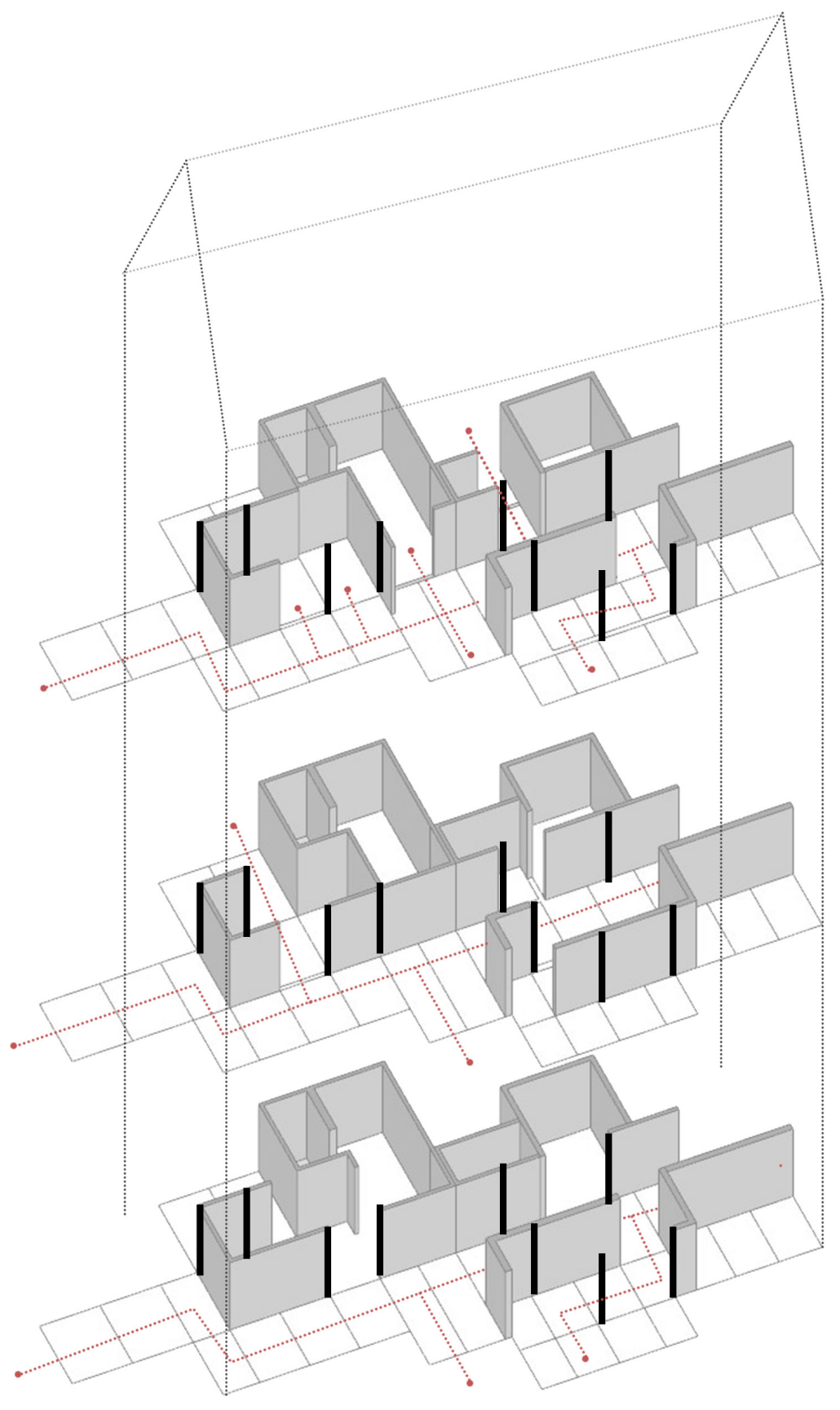

fig 28. Flexible spatial delineations articulate adaptable programmatic spaces in a corridic space 


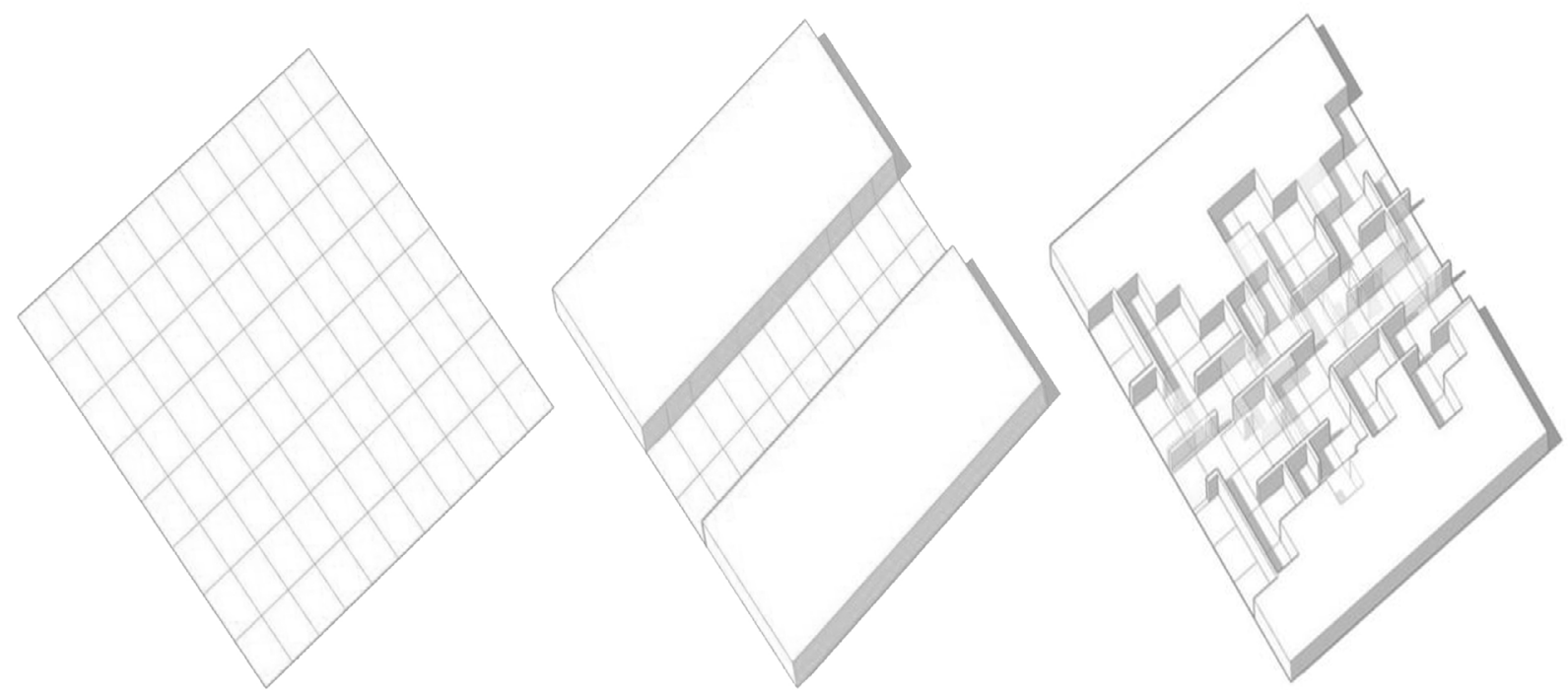

fig 29. Fluid spatial delineation in a corridic space. Plugging/ Un-plugging program

structure rather than a static structure (Hardingham, 2016). Price's proposal for the 'Potteries Think-belt' was an 'enabling' educational facility that consists of a series of programs and functions placed on tracks that can recompose the learning environment as changes in number of students and pedagogies occurred over time. It was designed to be an infinitely extendable network centered on mobility and flexibility instead of a centralised campus. Another visionary project where Price talks about flexibility and adaptability is the 'Fun Palace for Joan Littlewood Project' (fig 30). The facility was designed as a flexible framework into which programmable spaces can be plugged and the structure was envisioned to facilitate change at the behest of its users (Hardingham, 2016).

The architecture of the corridic space employs the dissolution of static structure into a system of processual programmatic spaces (fig 31). The fluidic structure of the space negotiates architecture's propensity for obsolescence by conceiving layers of programs that transcend beyond the physical and psychological constraints of a static structure by acknowledging the dynamism of human dwelling. 


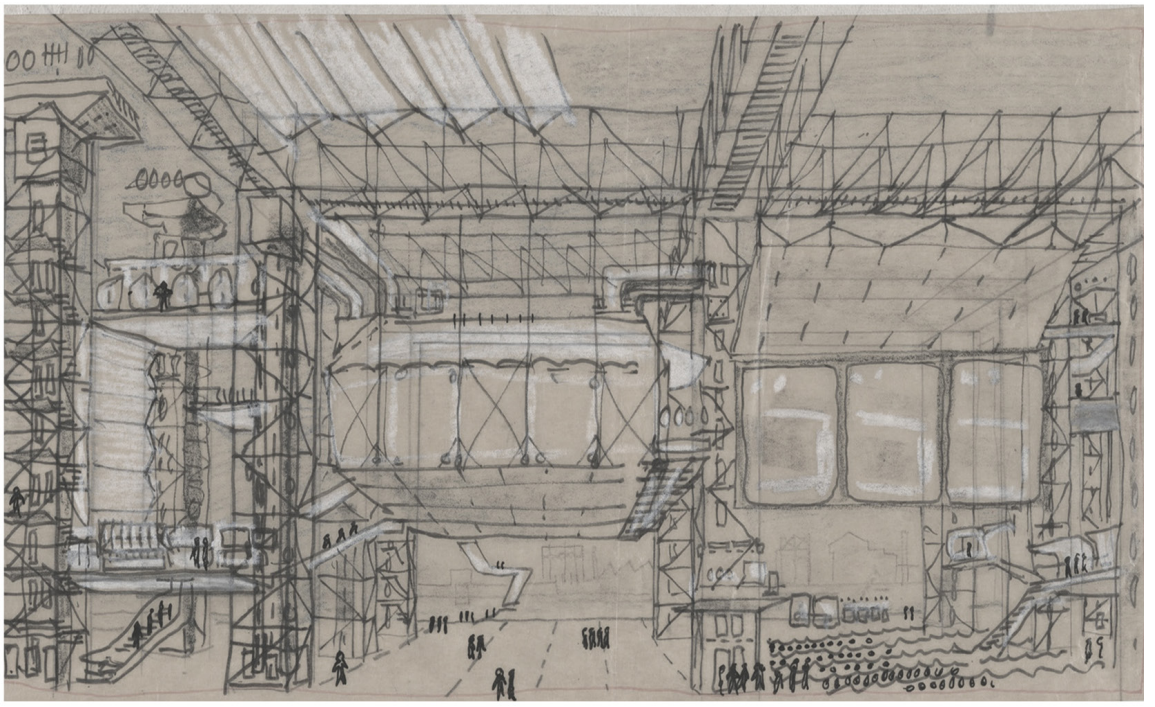

fig 30. Fun Palace, Cedric Price

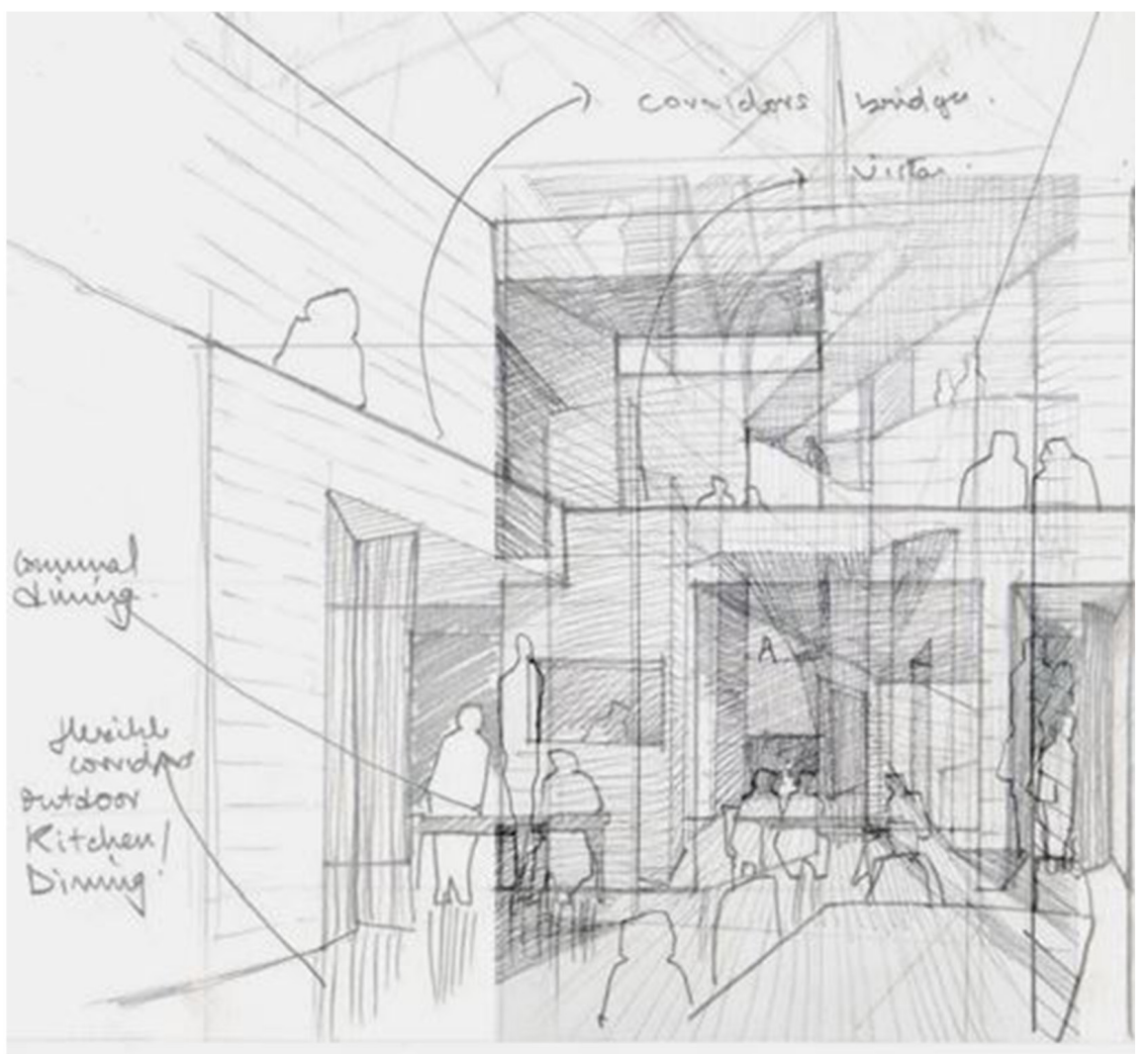

fig 31. Taking inspiration from the Fun Palace project (top), the corridic space employs a framework of "plugging and unplugging" adaptable programmatic spaces in its threshold configurations 


\subsection{Threshold transitions in a Corridic Space}

In a corridic place, the idea of space is defined by the idea of 'betweenness'. The perception of its architectural space lies in the understanding of the inter-relationship between the space defining elements in relationship to the inhabitant existing in that space. The between-ness of a corridic space is articulated through spatial delimiters that construct its haptic spatial body, which the inhabitant traverses and experiences. Jürgen Joedicke creates a distinction when it comes to understanding an architectural space; the presented and the experienced space (Boettger, 2014). Understanding the idea of corridic space requires investigating and analyzing the inter-relation between the abstract and poetic nature of an experienced space with the purely geometrical presented space. This thesis explores one of the possible routes of constructing such interrelationship; through exploring movement in a corridic space.

"An architecture must be walked through and traversed. [...] Thus, equipped with his own two eyes and looking straight ahead, our man walks about and changes position, applies himself to his pursuits, moving in the midst of a succession of architectural realities. He reexperiences the intense feeling that has come from that sequence of movements. This is so true that architecture can be judged as dead or living by the degree to which the rule of movement has been disregarded or brilliantly exploited." (Corbusier, 1929)

Le Corbusier in the aforementioned passage, points out movement in an architectural space as one of the important mechanisms for spatial perception in the Modern Movement (Boettger, 2014).

Exploring movement becomes a key element in constructing the spatial dialogue of the corridic space and its associated atmosphere. In the course of movement through a corridic space, the inter-relationship between spatial delimiters and the sequential spatial experience of 
the inhabitant in that space construct a positive interplay between the inhabitant's sense of space and creation of place. Movement provide spatial depth and enables the perception for comprehending and experiencing the complexity of the corridic space. Unlike the closed body of the traditional corridor, the corridic place is an open spatial body that offer an ensemble of threshold transitions that are sequentially and progressively experienced in various degrees of motion. The analysis of various degrees of motion through the threshold transitions in a corridic space forms the basis for constructing the phenomenological investigation of the space. In a corridic space, the inhabitant traverses in between-ness, between spatial delimiters which in its inter-relationship open up the inhabitant's spheres of perception. Through such mode of perception in the architectural space, the inhabitant is enabled to construct a positive interplay between their sense of space and creation of place.

\subsubsection{The enfilade of the senses}

While traversing through a corridic space, the percipient inhabitant finds themselves in spatial between-ness, a between-ness facilitated by the sequential architectural realities constructed by the interplay of its spatial delimiters. The between-ness or the interstitial nature of the corridic place is essentially a spatial body that is experienced through exploiting various degrees of transition.

"The idea of space in this context becomes more than a static system dealing with the proportions of the human body and strives to create a connection to human perception through motion... Perception occurs via the senses which introduces a system of basic orientation necessary to comprehend the complexity of an architectural space” (Boettger, 2014). 
In the course of movement through the sequence of architectural realities within the corridic space, the interplay of spatial delimiters consciously activate the sensory organs of the inhabitant that construct a coherent perception of the complexity of the space. To explore the interplay of spatial delimiters, the thesis seeks to analyze some of the threshold conditions existing throughout the history of architectural dialogue and create a phenomenological framework that would construct the sequences for the architectural realities of the corridic space.

\subsubsection{Importance of the Theshold}

Before analyzing the different transitional conditions in the framework of the corridic space, it becomes necessary to discuss the significance of a threshold space in terms of transition. Threshold is many things and complex. It symbolizes crossing but also pause, end but also beginning, a brief moment but also extended duration (Stephen, 2014). In addition to being a fundamental structural element, the concept of the threshold adds symbolic depth to the phenomenological discussion of the corridic place. Symbolically, the threshold is linked to the concept of transition between two different states of existence and throughout the history of various cultures, it has found its articulation in various forms of spatial elements and motifs. The importance of threshold in the examination of transitions can be found in the vernacular approach to designing traditional dwelling spaces in numerous cultures. From the flexibility and subtle level difference of the entrance in a traditional Japanese house to the sequential arrangement of the atrium space and the peristyle in the traditional Roman home, the threshold has mediated a layered transition from the exterior to the interior (fig 32). This sensitive gradation in transition is further accentuated by the use of spatial elements that define the ambivalent character of its between- 

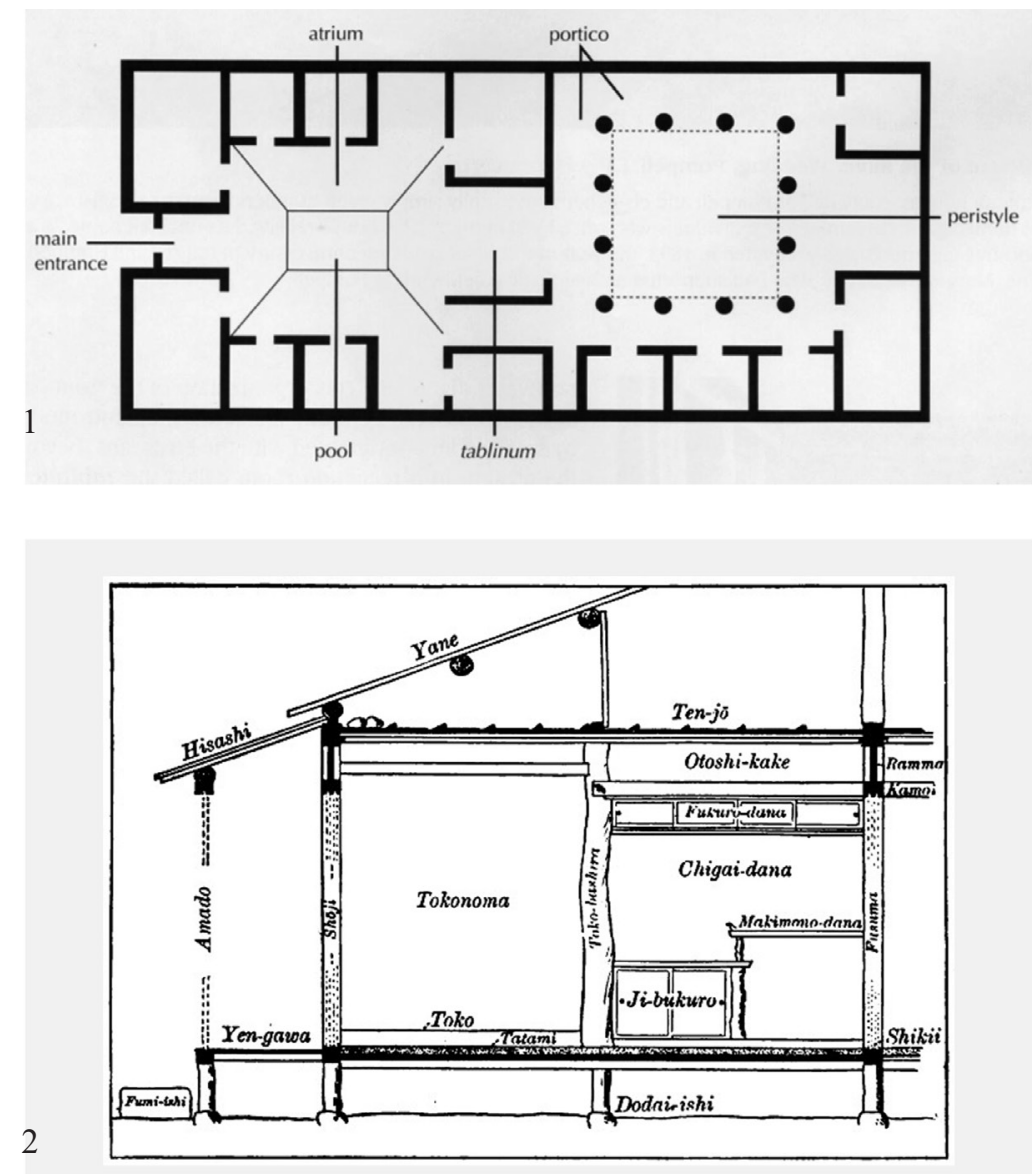

ness (the flexible wall or fusuma and shoji doors in a Japanese home or a columned portico in a Roman house). Furthermore, each transition in such dwelling spaces corresponds to a particular ritualistic process of inhabiting that space.

The use of symbolism and motifs to demarcate threshold spaces is a practice that has survived in many cultures throughout history. In the Indian culture, the threshold has a deep spiritual and symbolic meaning and plays an essential role in linking the inner sanctums of the dwelling spaces. In traditional Indian dwelling spaces, the threshold spaces plays a guiding role in how remaining dwelling spaces are organized, it determines the orientation of spaces, distribution of architectural weight, scale and circulation (Pegrum, 2002). It has a strong ritualistic connotation that has guided and shaped an individual's dwelling practices. fig 32 1. Sequential space in a typical Roman house. The tablinum was the most important threshold mediating the private and the public

2. Japanese house section showing layered transition 
The concept of the threshold is symbolically linked to the ritualistic process cited by Victor Turner and Arnold Van Gennep. In Van Gennep's 'The Rites of Passage', the threshold is the essential element facilitating the three phases of existence; separation, transition and incorporation. In drawing a parallel in the liminal existence of the individual, the thesis links the ontological connotation of the phases to the phenomenological examination of the corridic space. In the sequence of architectural realities constructed by the corridic space, the threshold plays an essential role determining how the transition in space through each sequence is carried out. The threshold space exists as an important node; it shifts the architectural weight of the spatial delimiters, facilitate various degrees of motion, enable continuity and discontinuity of spatial language and materiality, mediate between two very different experiential conditions etc. In a sequence of architectural realities, the threshold is not only a preface to an architectural space that facilitates transition but it is an architectural space by itself. Overall, it serves as an essential element in guiding the perception of the individual in transition. The threshold makes the percipient inhabitant cognizant of the carefully sequenced architectural realities playing out in the course of moving through the corridic space.

\subsubsection{The Spatial Delimiters}

The study of transitional threshold conditions in architectural discourse would enable the determination of the spatial delimiters in the open volume of the corridic space. The outcome of the positive interplay of these elements is the construction of the spatial body where the sequences of architectural realities would determine the phenomenological conditions of the corridic space. These spatial delimiters are threshold elements that would determine the degree of motion for the perception of its architectural space. For the purpose of 

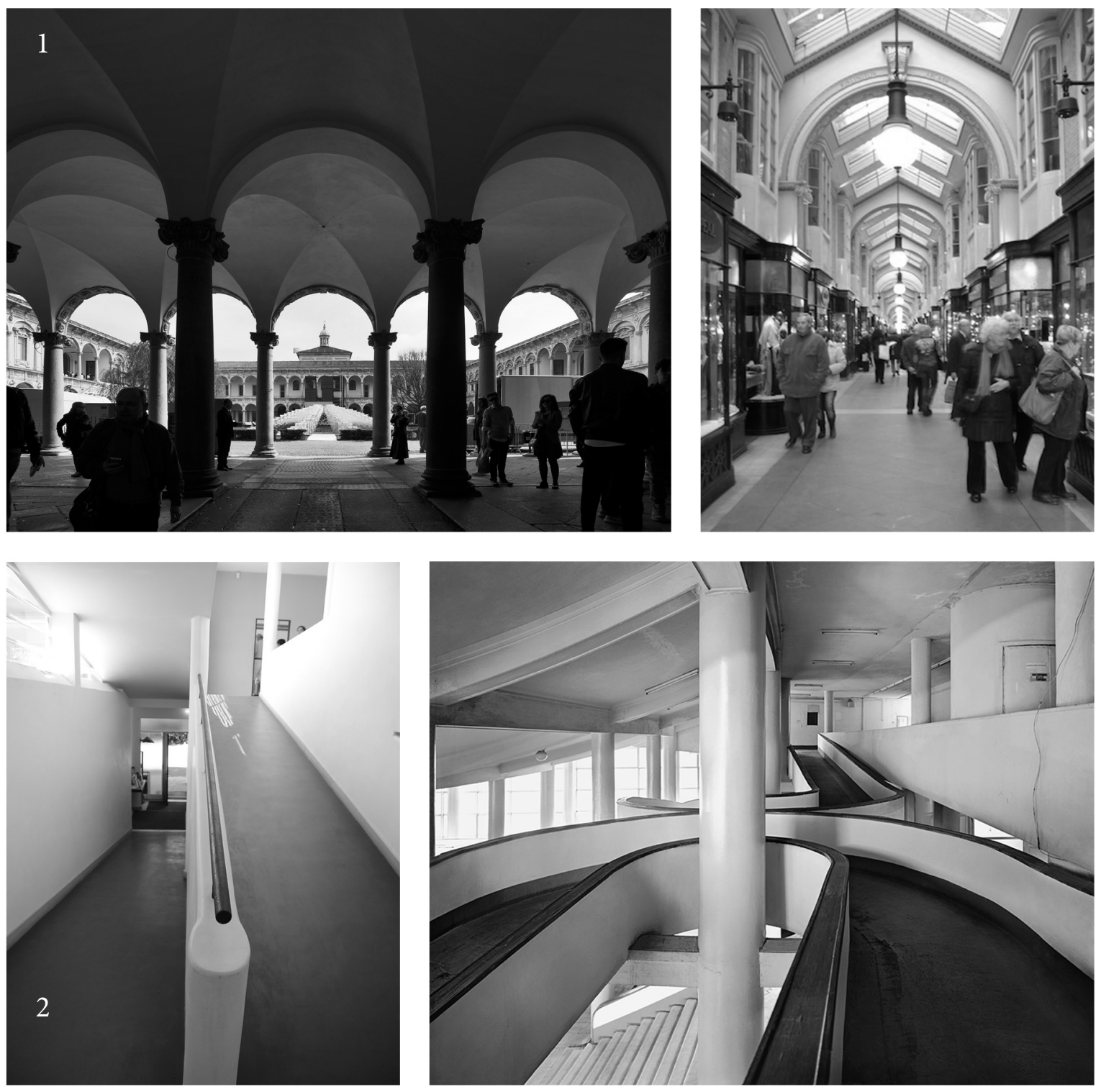

fig 33

this research, some of the threshold conditions looked into are-

\section{Arcades/Colonnades and change in Architectural scale, weight}

2. Ramps and Architectural Promenades (fig 33) 


\subsubsection{Arcades/Colonnades and change in Architctural scale, weight}

One of the oldest architectural element, this threshold space, over centuries of architectural discourse has mediated a sensitive transition between the inside and the outside of an architectural space. Arcades evince an atmosphere of between-ness, a space neither inside nor outside but characterized by an interplay of spatial elements and materiality that creates an illusion. Johann Friedrich Geist locates its illusionist element in its function as a passage area; imaginary exterior space as interior space that enables a natural drift of movement- by creating a façade with exterior architecture pulled inward (Boettger, 2014).

" The high, long passages, illuminated from above thanks to glass roofing, give you the feeling of an interior; thus they are 'inside' and 'outside' at the same time. Inside and outside are so strongly relativized vis à vis each other that you cannot tell whether you are inside one building or in the space connecting two separate buildings." (Boettger, 2014) .

The aforementioned quote elaborates on the inherent ambiguity of arcade spaces as a threshold space and points out the inter-relationship of the spatial elements that constructs its between-ness. From the change in scale, materiality to the careful manipulation of light and positive interplay of other haptic elements, such threshold conditions elicit a very specific perceptive response from the inhabitants of the space as well as movement pattern within that architectural space (fig 34). 

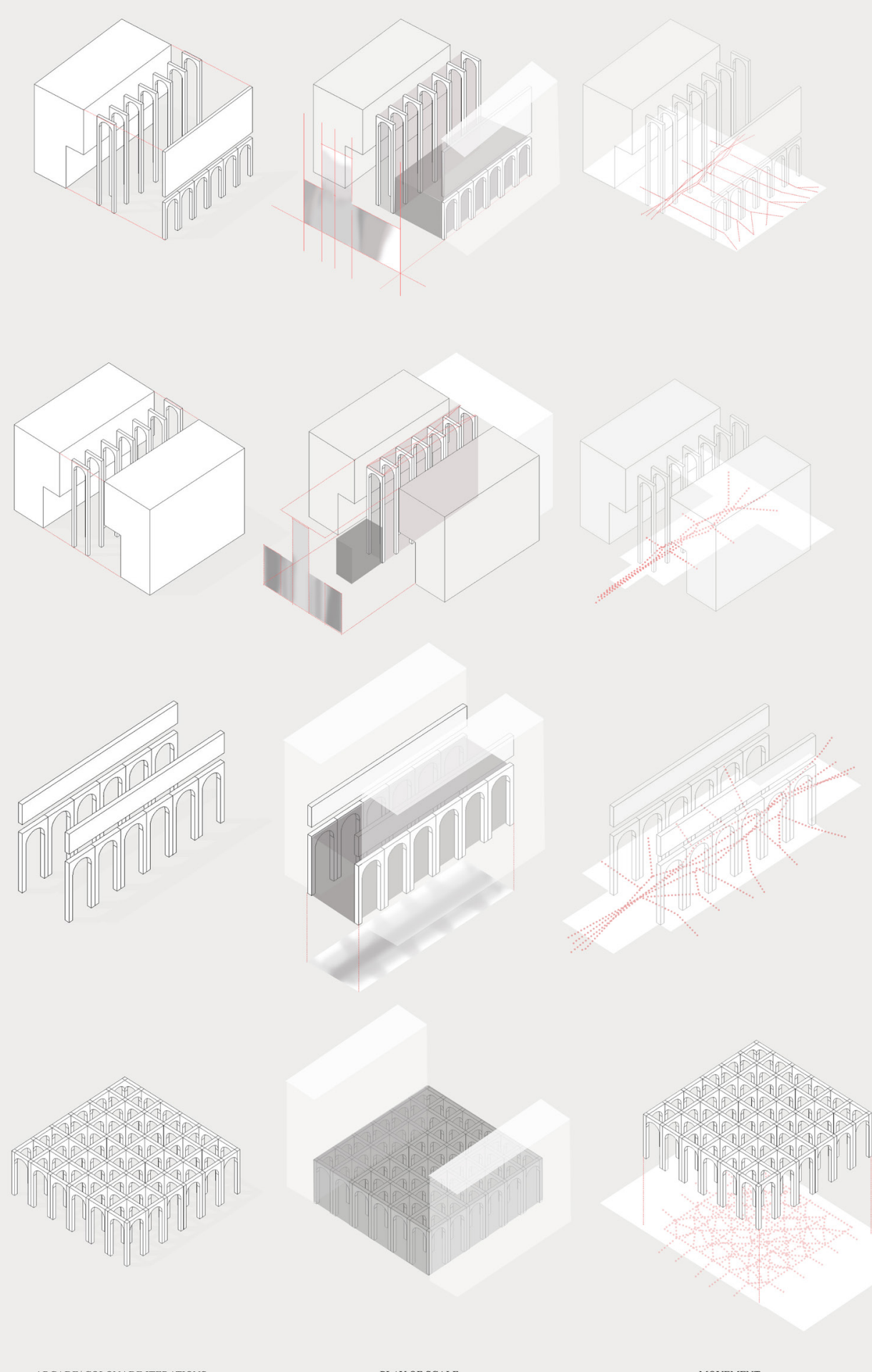

ARCADE/ COLONADE ITERATIONS

PLAY OF SCALE

MOVEMENT

fig 34 Threshold conditions analysis in an arcade/colonnade 


\subsubsection{Ramps and Architectural Promenades}

Le Corbusier in 1942 defined a concept of the architectural promenade in terms of transitioning through an architectural space. He focused on the observer's path as a central element for experiencing an architectural reality through a built space. Similarly, constructing a direction of movement through a sequence of spaces creating accidental views, vistas and spatial experiences is one of the key function of the threshold elements in a corridic space. The Modernist utilization of ramps for the transitioning of spaces acquires the role of a threshold element for facilitating the sequential progression of architectural realities in a corridic space. The use of ramps in projects like the Carpenter Center or Villa Savoye by Le Corbusier or Richard Meier's High Museum of Art and Oscar Niemeyer's Niterói Contemporary Art Museum establish a sequential pattern of a circulation system that orient and reorient the inhabitant and enable the perception of progressive spatial experiences around the architectural space. This nature of progression through sequential architectural spaces is what Le Corbusier termed as

\section{'architectural promenade'.}

The phenomenological experienc of the ramp is articulated through an essence of natural duration in its structural expression. Unlike the stair which reinforces the distinction between two levels, the ramp offers a subtle transition which elicits a unique visual and bodily experience in the user. The ramp prolongs the spatial experience of an architectural space while slowly exaggerating the separateness between spaces at different levels. The corridic space offers the possibility of exploiting the formal characteristics of a ramp, juxtaposed with other spatial elements to accentuate the experiential quality of its architectural expression (fig 35). 


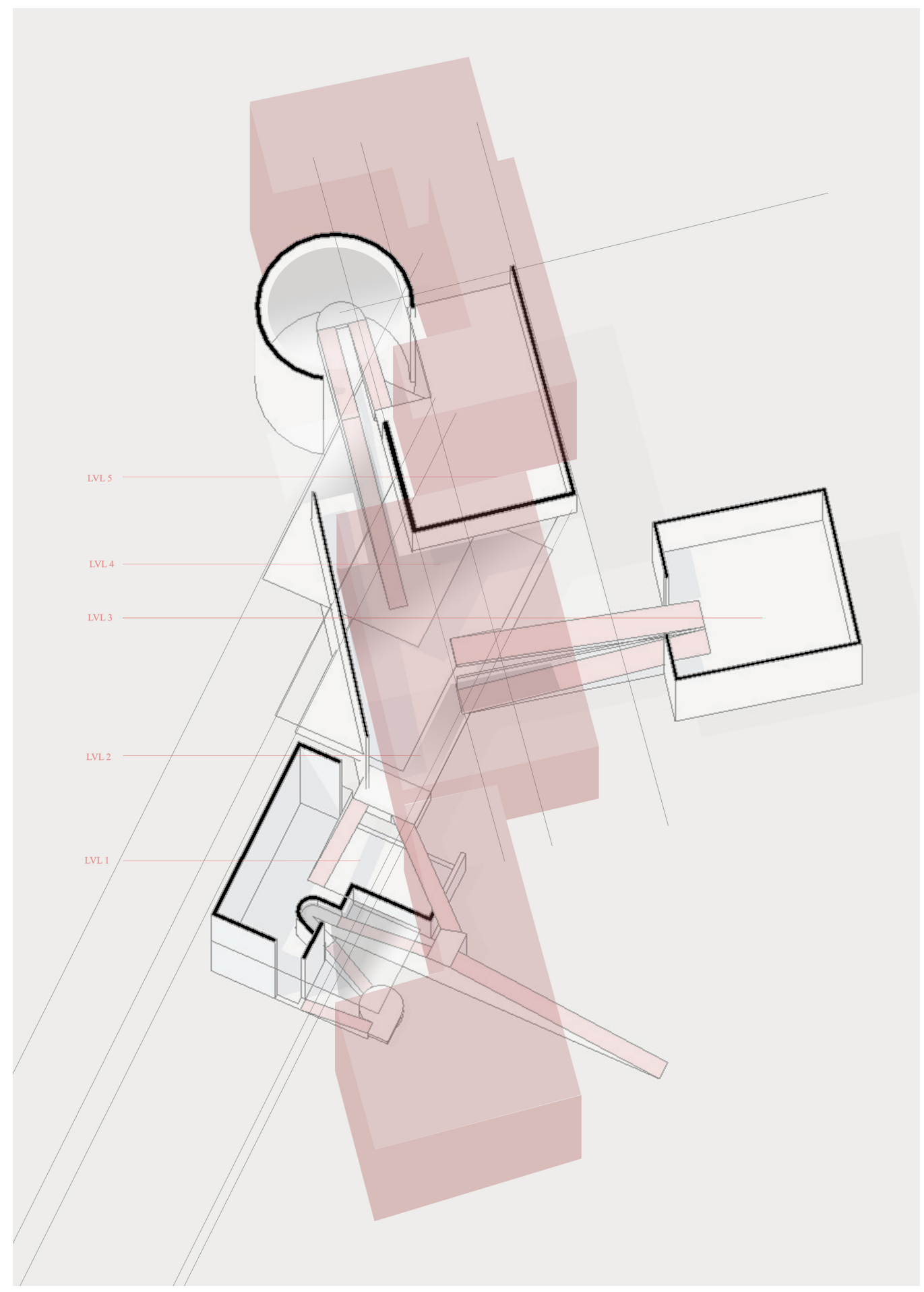

fig 35 Exaggerating seperate-ness by inserting unique interstitial spatial configurations 
Living In-Between 
The concept of thresholds in a corridic space expands upon its meaning as a complex spatial language that orchestrates the progression and sequencing of architectural realities. The threshold in this context encompasses multiple spatial dimensions; it is an in-between space, a duration and an experience. In the course of movement through a corridic space, the threshold is a moment which pauses or prolongates the experiential journey.

It regulates and gives meaning to the act of crossing (Stephen, 2014). In a corridic space, the threshold becomes a spatial tool that adds a distinctive perceptual, behavioral, social and symbolic connotation to the concept of dwelling. 
Living In-Between 


\section{0}

\subsection{Corridic Iterations of Thresholds and Movement Spaces: Constructing Atmospheres}

\footnotetext{
The spatial language of the corridic space orchestrates a progression of architectural realities with distinct experiential qualities in the course of movement through its sequence of threshold conditions. The positive and negative interplay of massing in its threshold delineations create spatial conditions where compression and expansion of space guide the movement through the space (fig 36a). The corridic space reveals and conceals the architecture of its transitional dwelling space. At the point where the space reveals, it engages in a dialogue with haptic elements, which further pauses and prolongates the duration of the lived experience in its architectural space (fig 36b). These moments of pause are intended to produce a distinct perceptual behavior in its transitional inhabitant which further reinforce their orientation within the architectural space.
} 

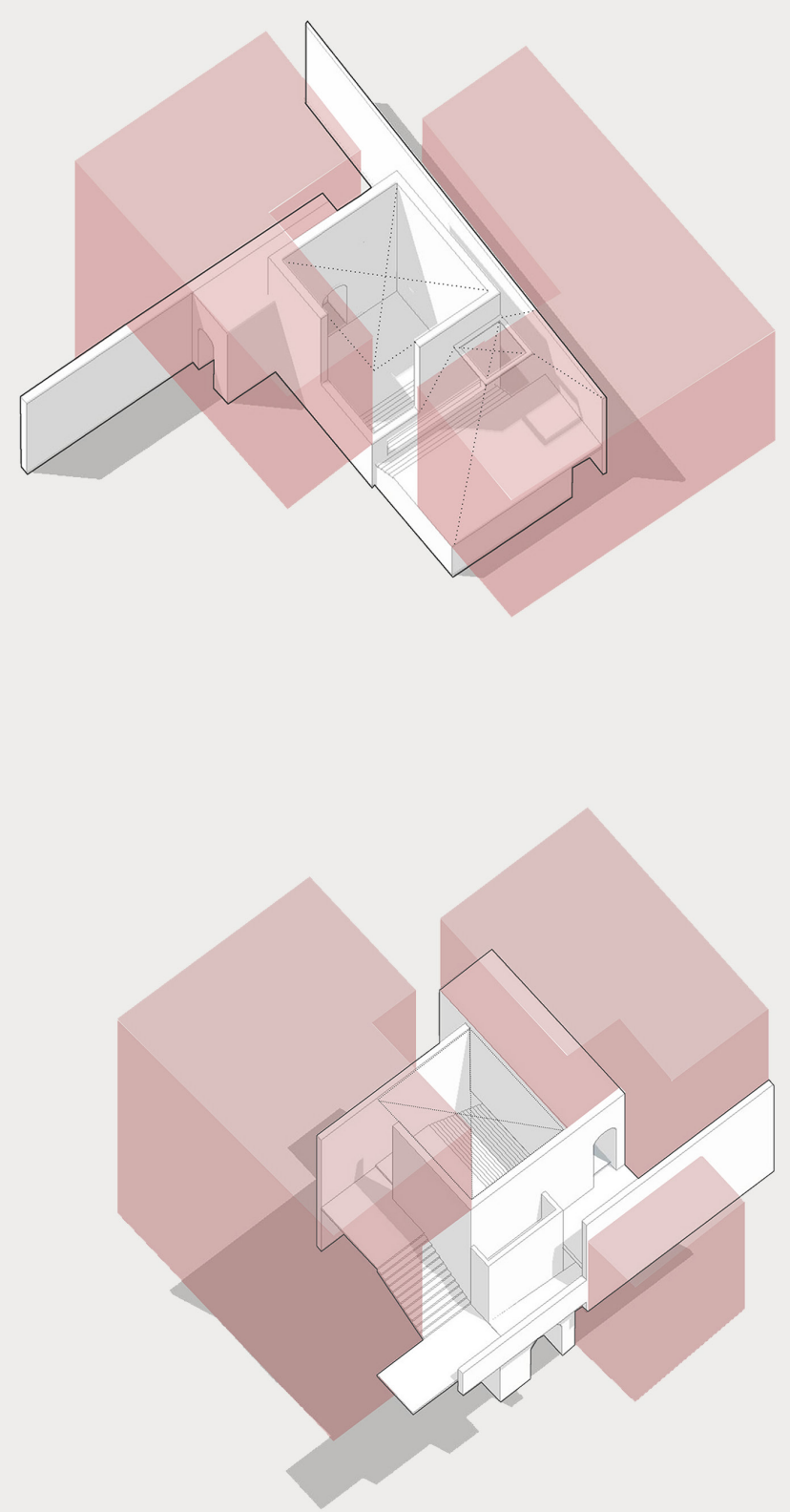

fig 36 a Study diagram: Compression and Decompression in corridic space 

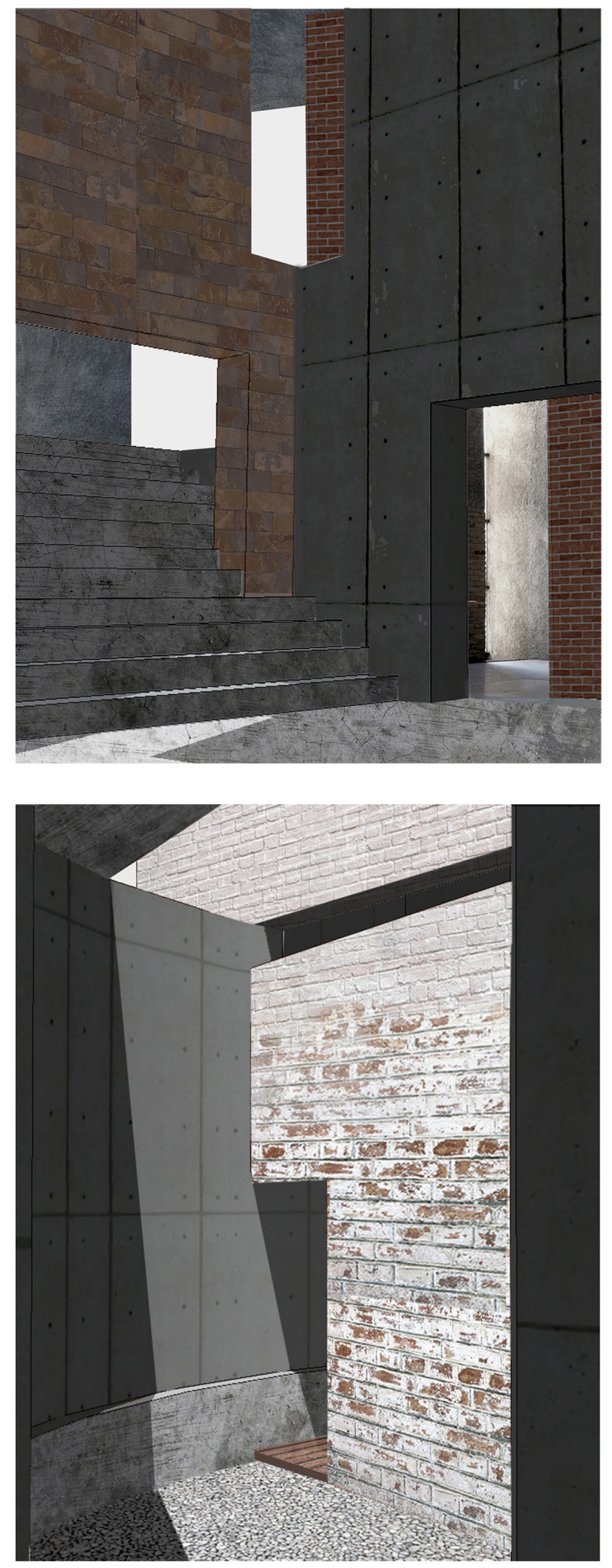

fig 36 b Constructing Atmospheres: Compression and Decompression in corridic space 

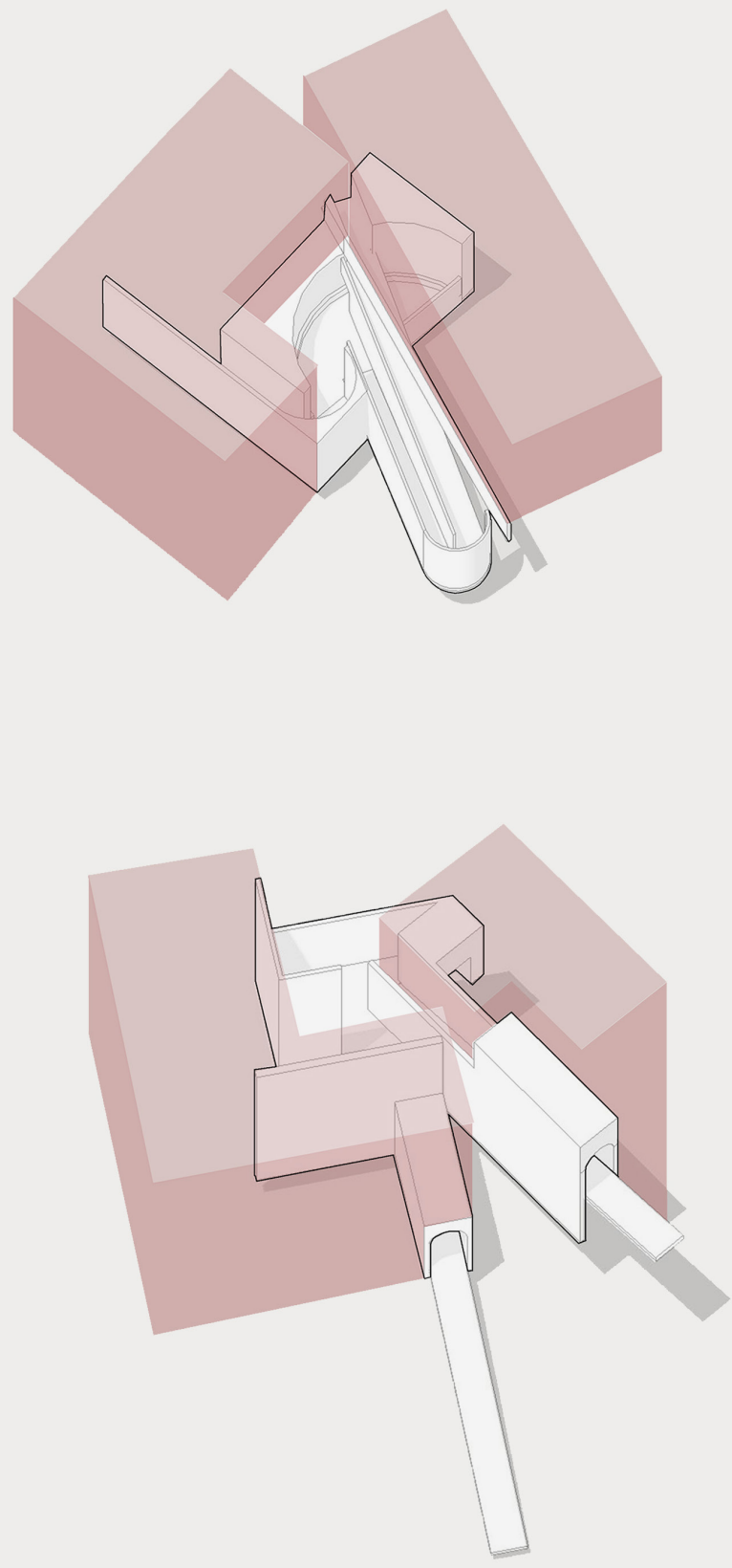

fig 37 a Study diagram: Ramps and shift in Architectural weight and Mass 


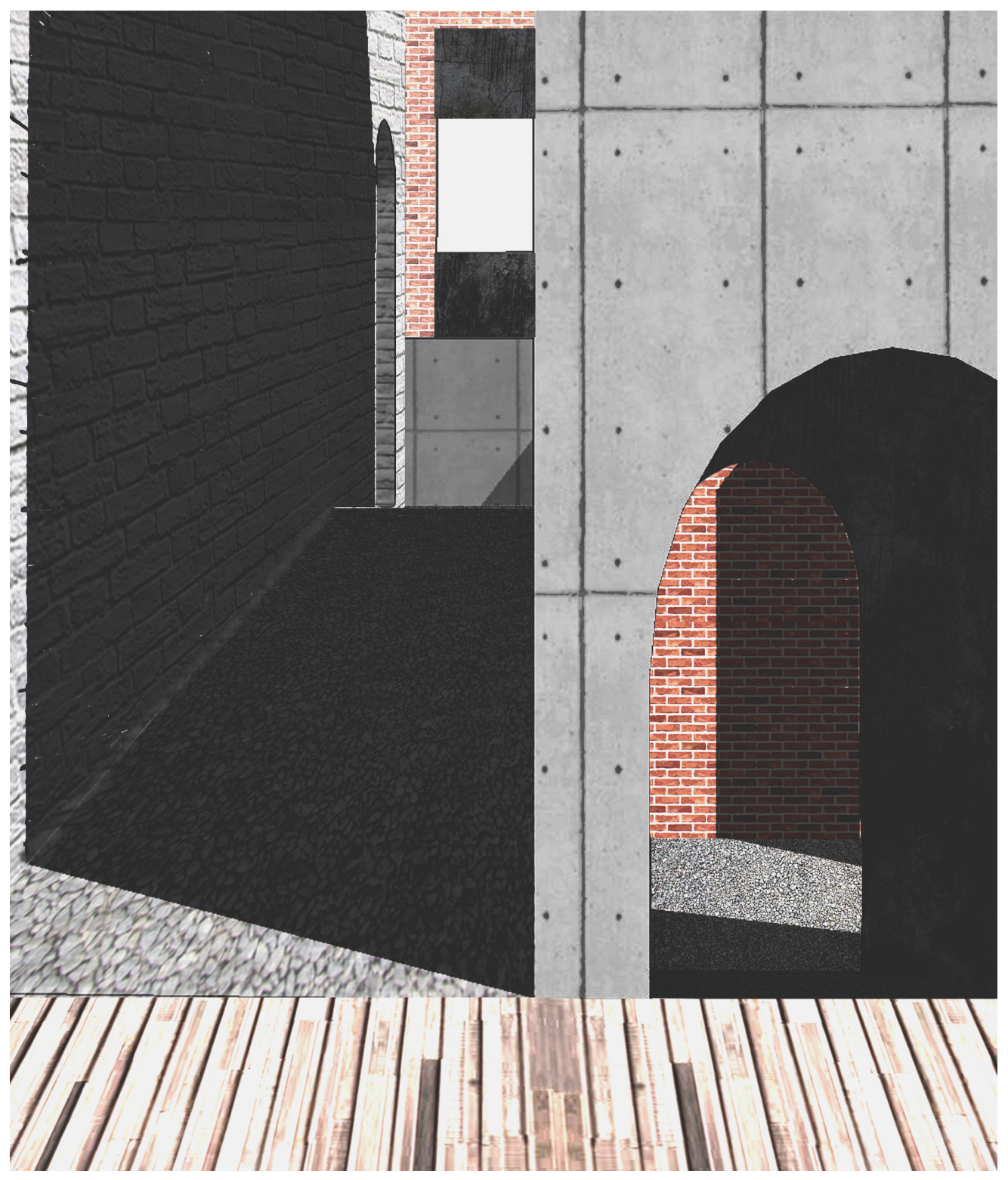

fig 37 b Constructing Atmosphere: Ramps and shift in Architectural weight and Mass

Ramps play an essential role in elaborating and prolonging the lived experience of a corridic space. The gradual duration of its structural expression is exploited to enrich the experiential quality of each architectural space (fig 37 b). The ramp is the essential element of movement that traverses through the play of architectural realities. Apart from guiding the orientation of movement, it orchestrates the shift in architectural weight and scale (fig 37a). 


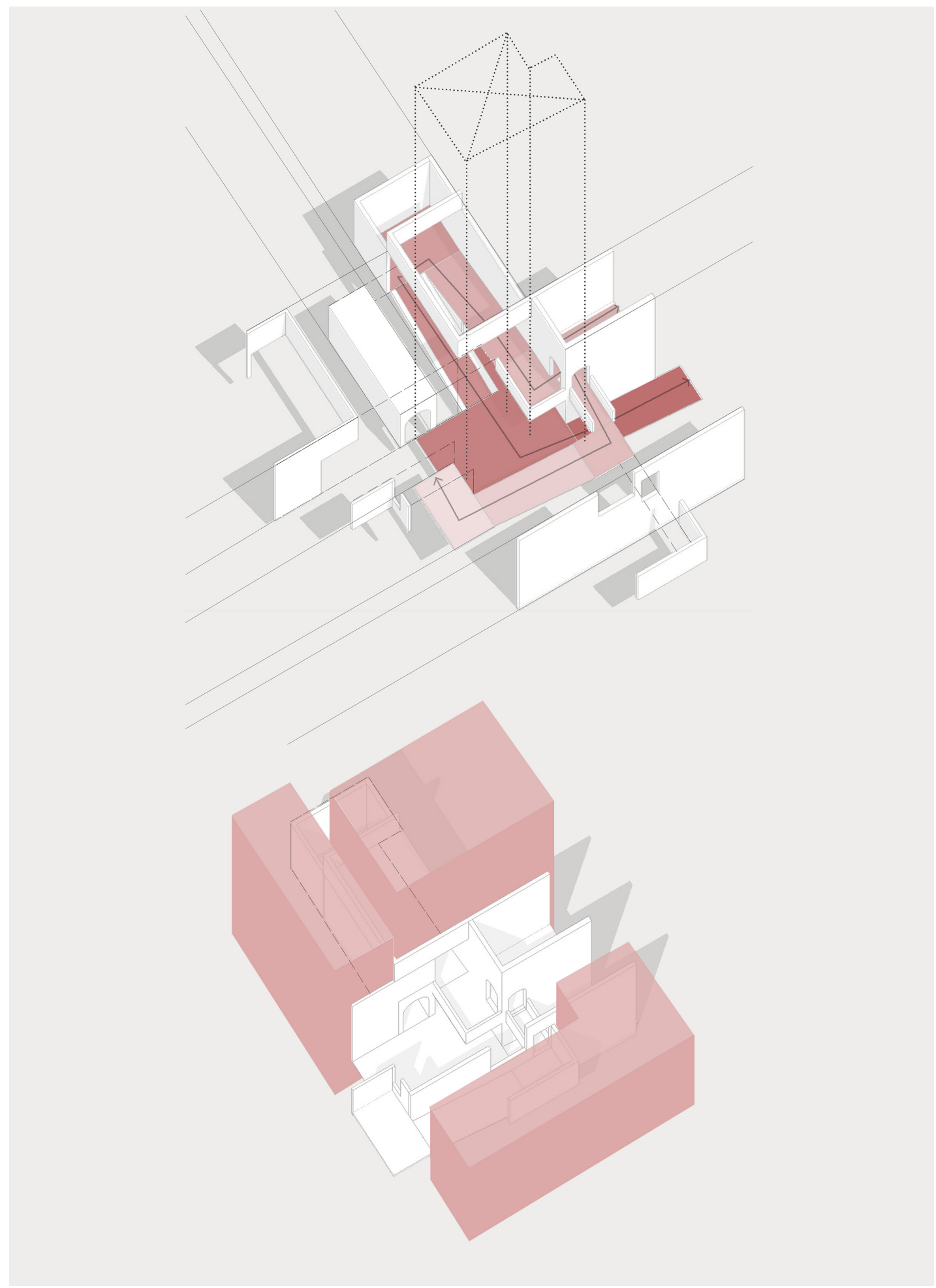

fig 38 a Study diagram: Spatial layers in a corridic promenade 

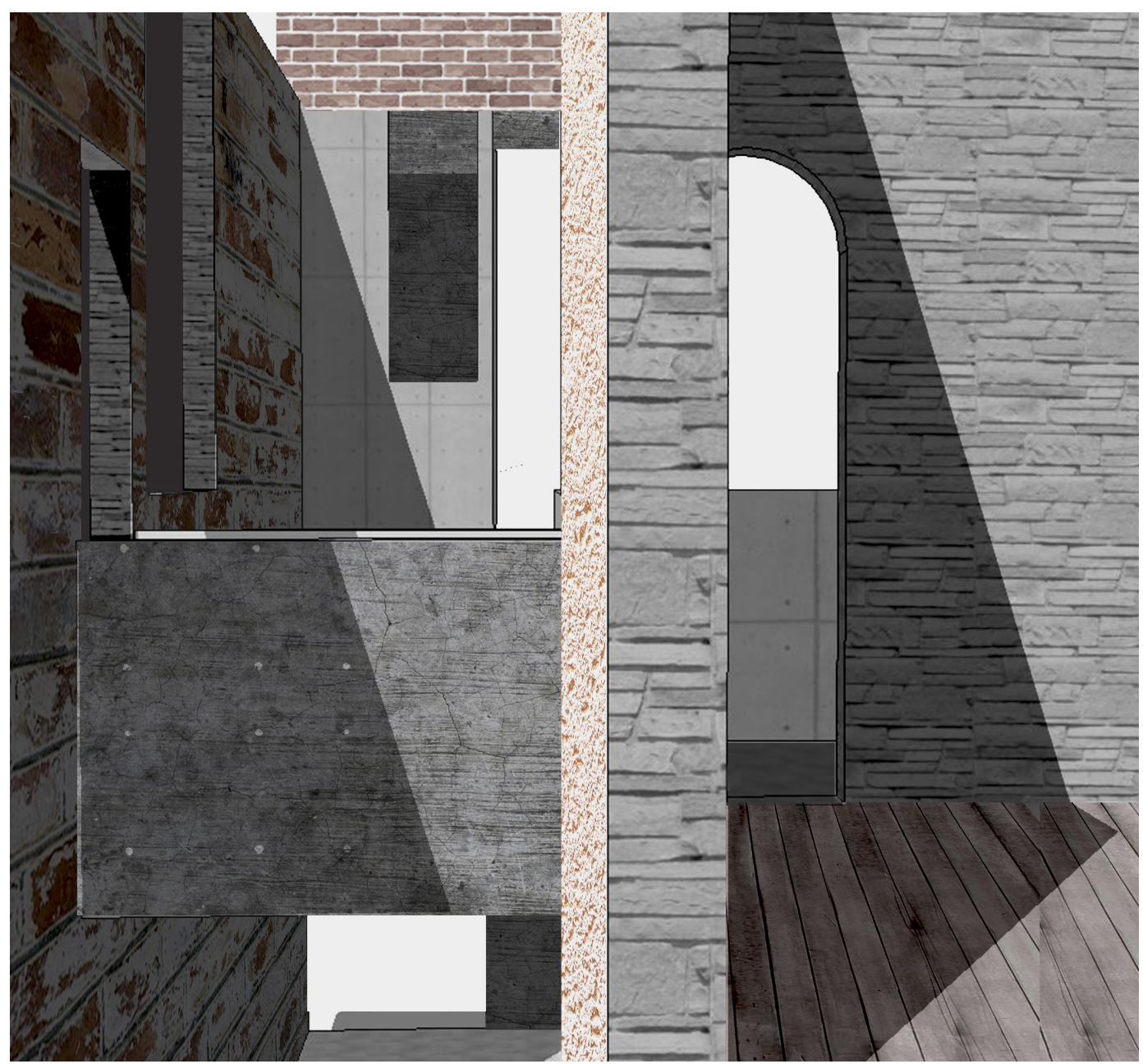

Enabling a sense of exploration through a sequence of spaces creating accidental views, vistas and spatial experiences is one of the key function of the ramp in a corridic space. Drawing on Le Corbusier's idea of the architectural promenade, the ramp in a corridic space expands the inhabitant's spatial perception of an architectural space. This is done through employing and enabling various degrees of movement and tying in a sequence of spatial conditions that allow the inhabitant to receive and engage the architectural space in different perspectives (both visual and haptic) in a single course of movement through that space (fig 38a). By engaging with a space in a multitude of manner, the ramp further adds to the spatial depth of the architectural space while accentuating the experiential journey through its threshold conditions (fig 38b). fig 38 b Constructing Atmosphere: Spatial depth in a corridic promenade 

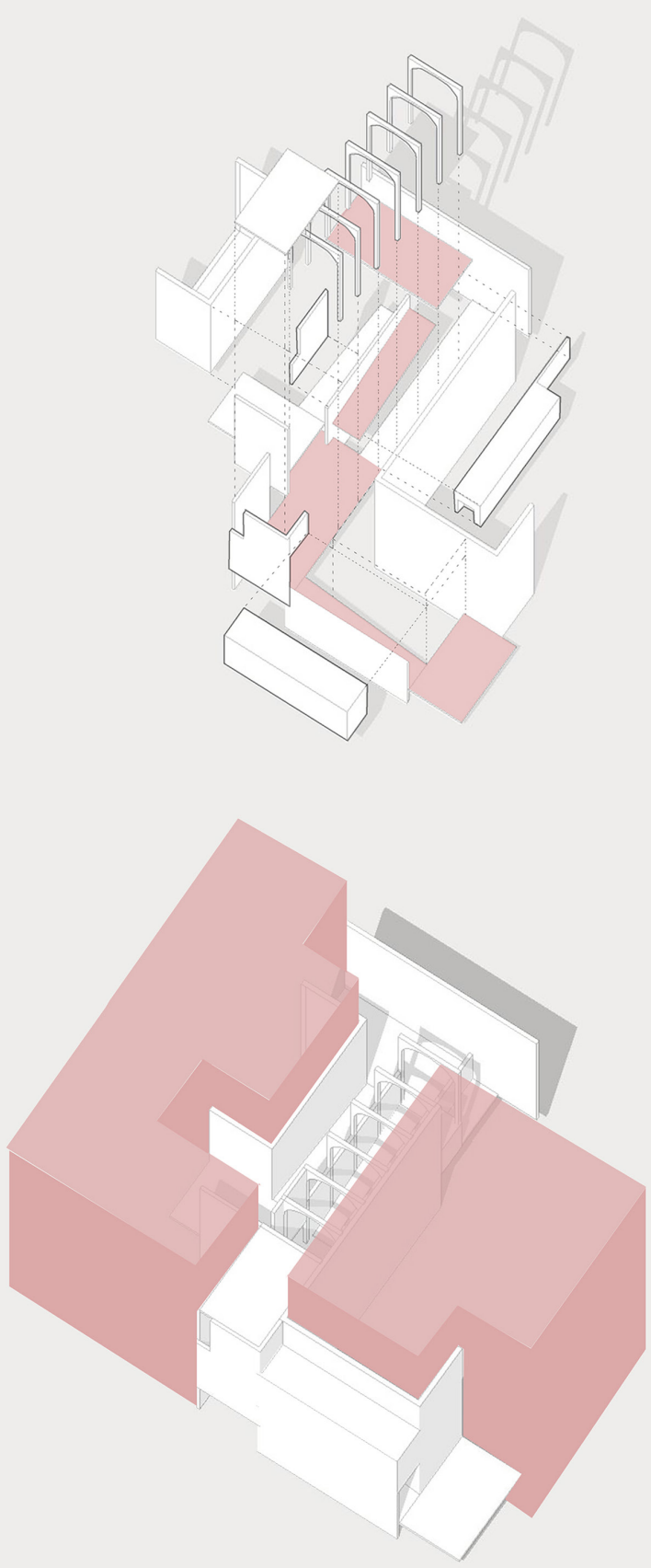

fig 39 a Study diagram: Spatial delimiters mediating indoor-outdoor dialectics and creating different threshold variations in a corridic space 

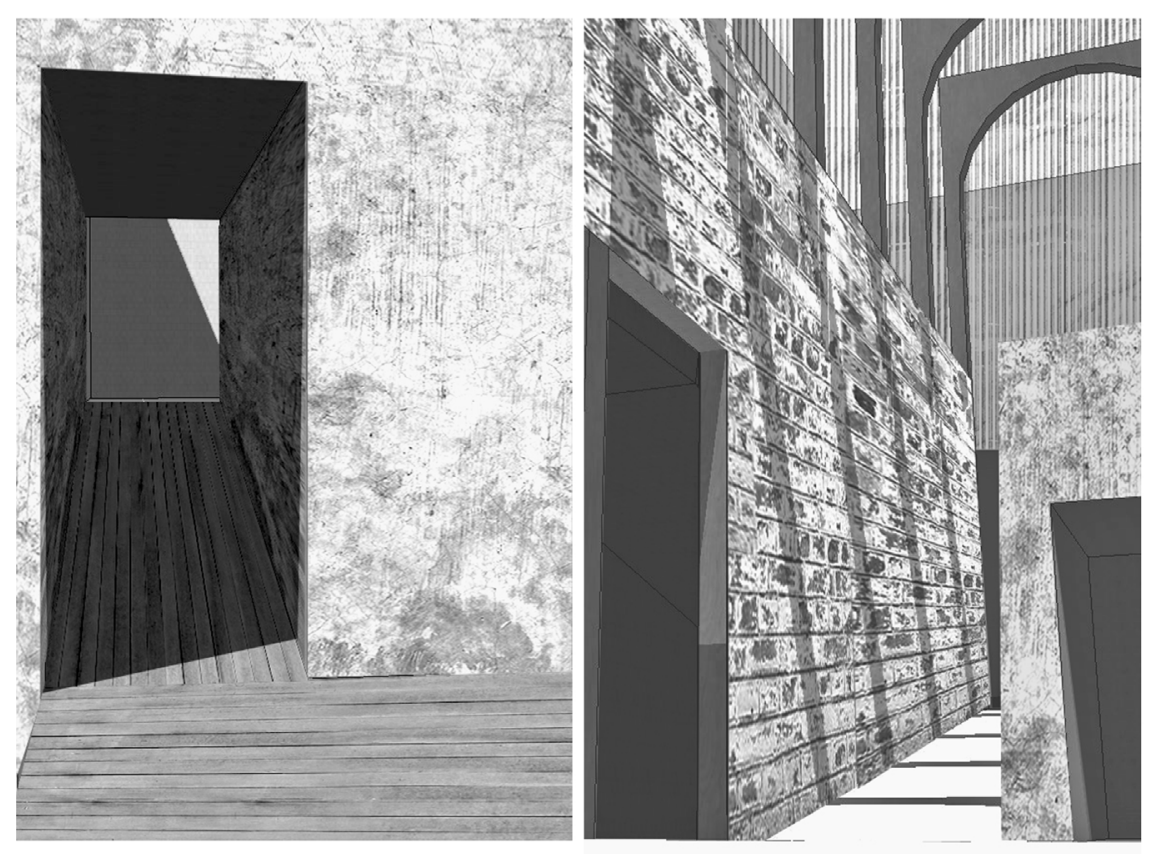

Reinforcing the experience of gradual transition of the ramp are spatial delimiters that focus on the transition of space as one moves through the corridic place. These spatial delimiters are threshold elements which in its positive and negative interplay elicit specific perceptual behavior from the transitional inhabitant. Moreover, these elements directly influence the continuity or discontinuity of the architectural language of the corridic space by facilitating the shift in scale and volume and abstracting the dialectics of the inside and outside (fig 39a). The spatial delimiters mediate a careful transition between the inside and the outside of an architectural space, often creating the illusion of an outdoor condition in the between-ness of the threshold space.

These elements confront the inhabitant in transition, offers a moment of pause and experiential snippet of the corridic space, further delaying the expediency of transition through a corridic space (fig 39b). Along with the corridic application of a ramped passage space, these threshold delineations add a spatial and haptic depth that enables the inhabitant to immerse and stroll about in the experiential space of the corridic place.

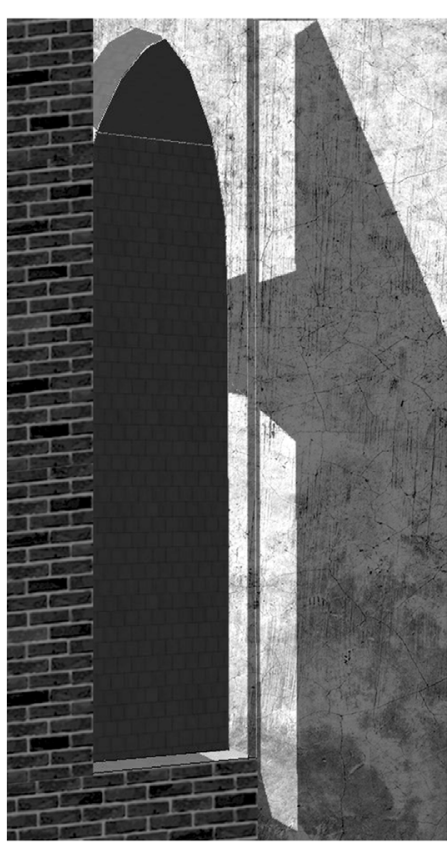

fig 39 b Constructing Atmospheres: Creating conditions for experiential snippets and moments of pause through the interplay of spatial delimiters 
Living In-Between 


\section{0}

\subsection{The Case for Co-housing}

The concept of the corridic space brings the question of dwelling to the corridor configuration of a residential system. The theoretical discussion of the corridic space began with identifying the liminal characteristics and passivity of a residential corridor and advocating a new threshold dialectic that adds material and dynamism to the concept of human dwelling in a residential system. To contextualize this thesis, the corridic notion of dwelling finds its application as a co-housing model where its potentiality to advocate a new spatial dialogue conducive to place building and foster an alternative social dialectics can be explored. 


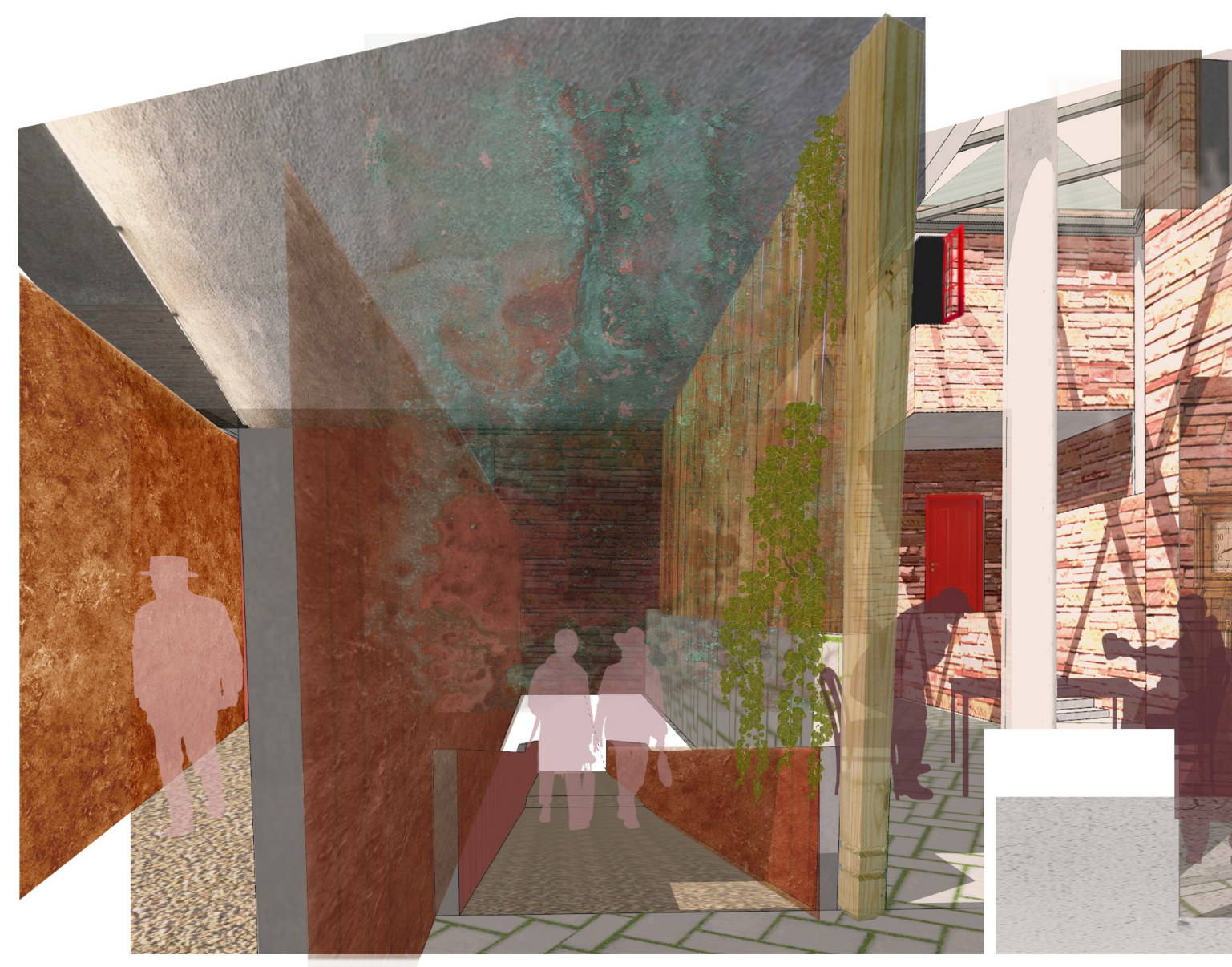


Co-housing is a fairly recent model that has been introduced in the West in the 1980s which implemented design guidelines to form intentional communities. The core concept of a co-housing model is to create a sense of neighborhood of participation and shared operation where individuals optimize private ownership while contributing to shared facilities. A typical co-housing configuration has several defining characteristics. Its focuses on a configuration of clustered units around a shared common utility space or pedestrian area (a garden, courtyard) with circulation restrained to the periphery (Schacher, 2006). It programmatically defines a separate community space (a commons) which accommodate common facilities where activities are shared (community dining, childcare and other social endeavors).

The case for co-housing lies in the way its design is approached. Profit driven developments that shape the housing market in most cities often, in its strict pursuit of optimization, tend to standardize the approach to the design of co-housing projects which desensitizes the notion of dwelling and fosters homogeneity. A co-housing project in a strictly urban context then tend to gravitate towards a standardized apartment configuration which compartmentalizes the various aspects of dwelling. However, recent interventions in the co-housing model are breaking ground that are looking towards exploring the notion of dwelling and co-inhabitation. A more contemporary take on cohousing, Germany's Baugruppen model of designing co-living spaces foster cohesive neighborhood designing and enable adaptable solutions for designing shared spaces (Ring, 2016). The baugruppe (German for 'building group') model has no typical model format since it primarily focuses on customizing the social space configuration in a co-inhabiting space. This adds a spatial depth to the flexible notion of dwelling as spaces can be adapted to suit changing dwelling needs. The baugruppen model is the architecture of change. The flexible character of its dwelling conditions builds upon a skeletal structure 


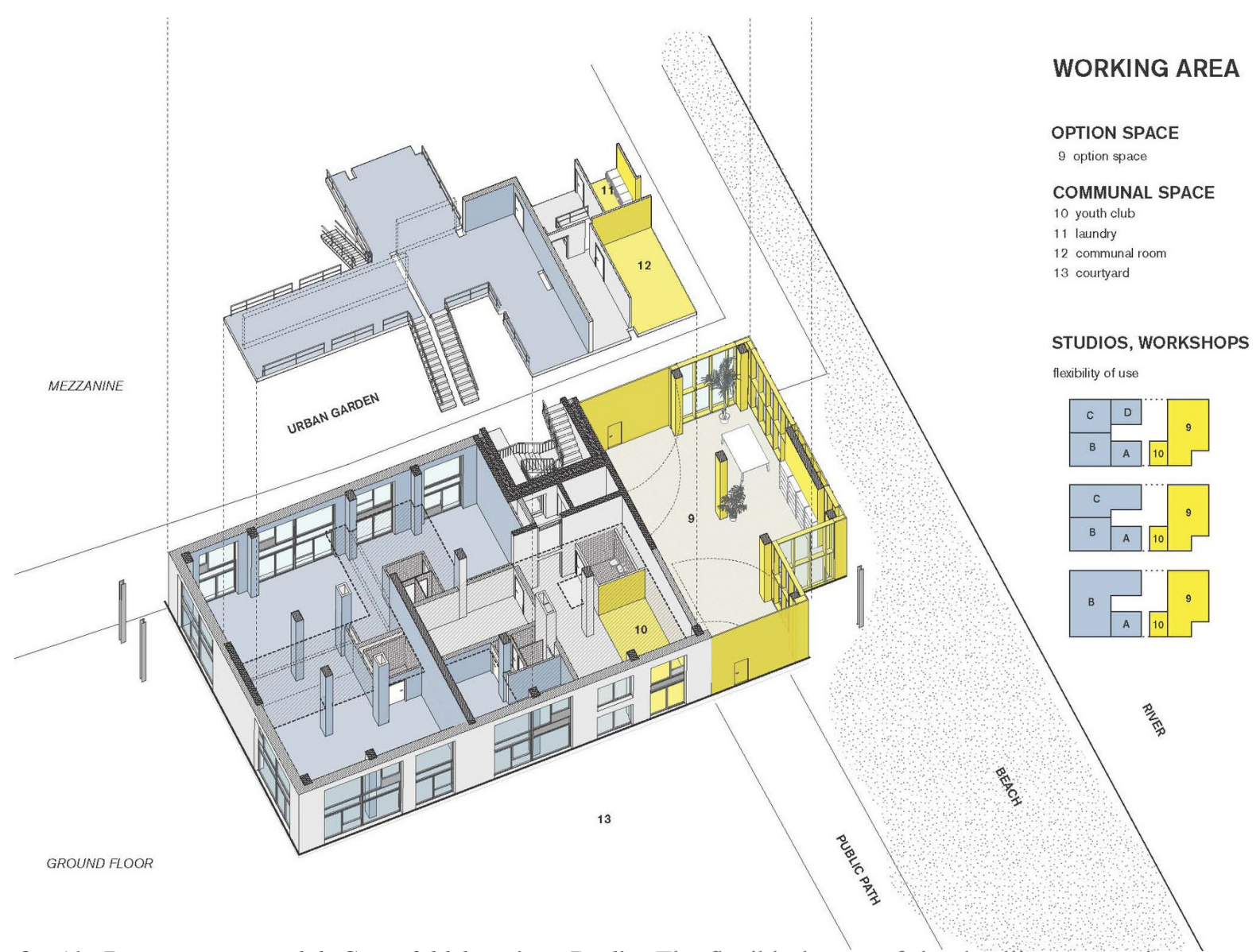

fig 41 Baugruppen model: Spreefeld housing, Berlin. The flexible layout of the dwelling spaces incorporate an 'option space' (marked in yellow), a non programmatic open space adaptable for varying functional needs and open accessibility

which enables the inhabitant to exercise greater freedom to configure and re-configure their own dwelling spaces.

Furthermore, moving beyond the basic co-housing structure, baugruppen projects adds to urban vitality by incorporating elements that foster urban interaction between the housing project and its surrounding context. Most co-housing models incorporates mixed use elements and garden spaces accessible to the public which enable the residential system to be a part of a larger urban fabric and consequently profit from its surrounding urban spaces. The experience helps foster a sense of community identity and place building which encourages the inhabitants to take responsibility for the place they live in (Ring, 2016). 

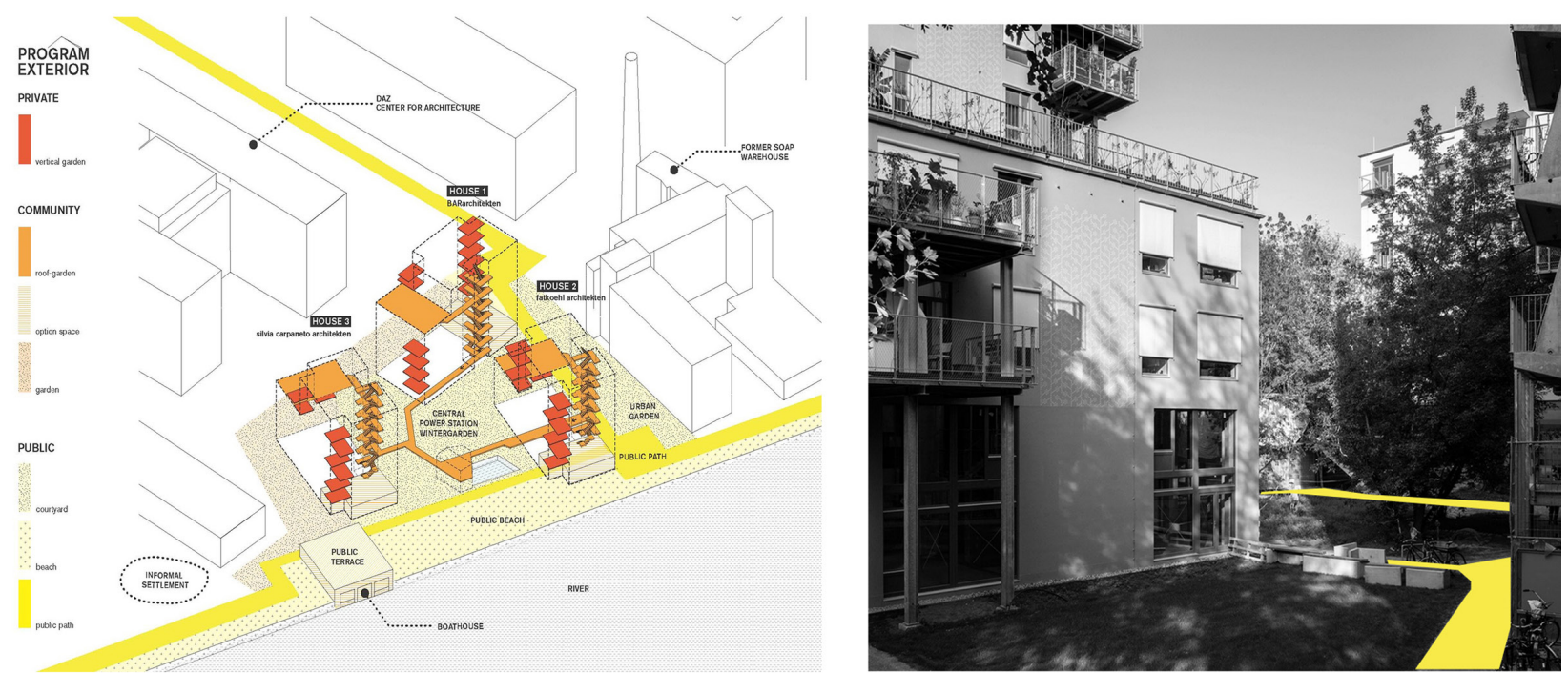

fig 42 Baugruppen model: Spreefeld housing, Berlin. In addition to incorporating accessible and shared green spaces between dwelling units, the project fosters urban interaction by bringing the context into the site and creating public spaces
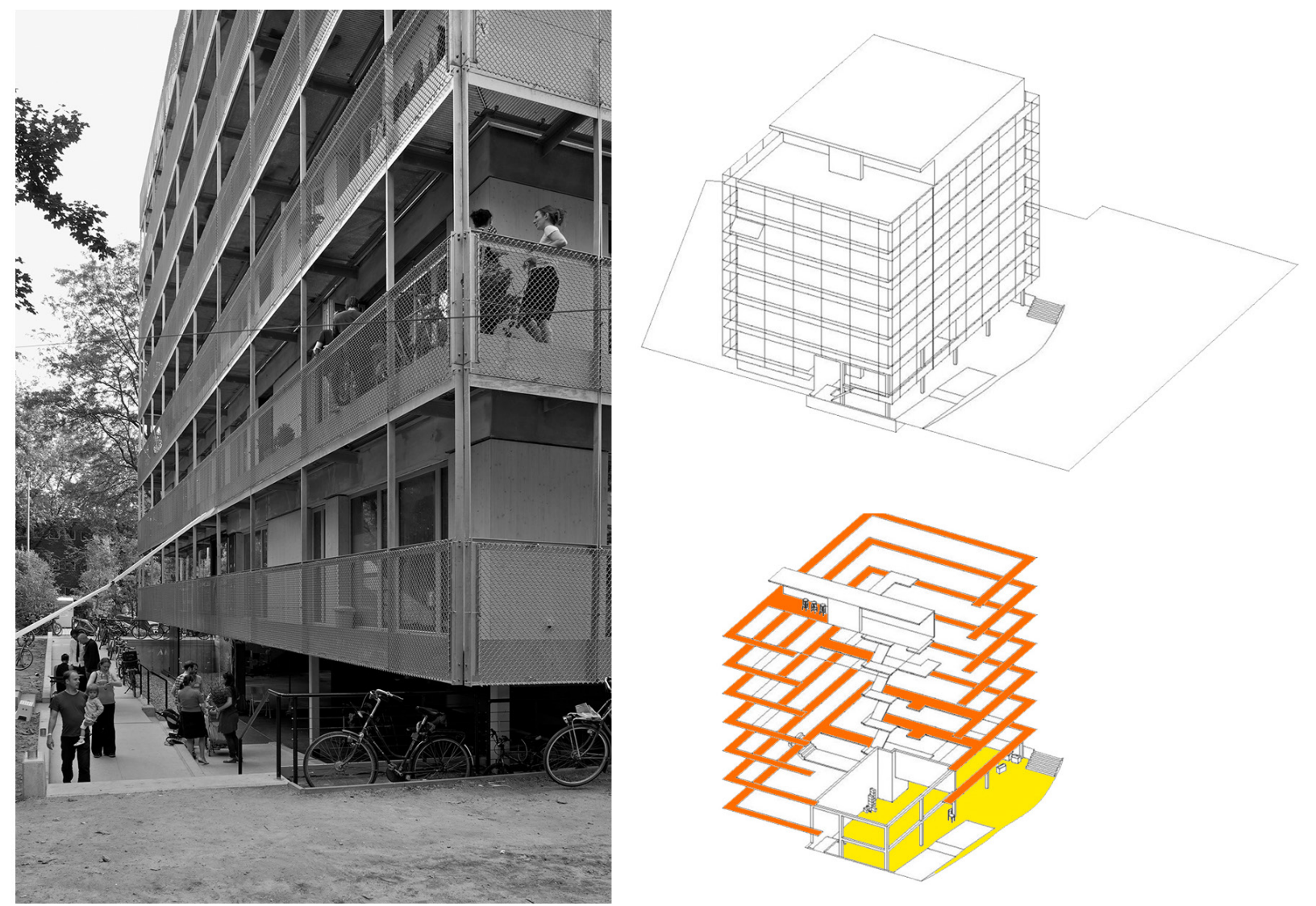

fig 43 Baugruppen model: R50, Berlin. The project shifts the social space to a peripheral continuous balcony where the residential units open up, acting as a porch. the building also opens up at the basement level to public use with a flexible, non-programmatic space. 
In its design principles, a corridic model of co-housing is a slight deviation with regard to its spatial language. By amalgamating the baugruppen notion of co- housing with its own set of design principles drawn out in the structure of its phenomenological investigation, the corridic model aims to formulate an alternate approach to the notion of dwelling and co-inhabiting in a residential system. The corridic notion of co-inhabiting a residential system focuses on the transformation of the residential corridor into non-programmatic dwelling spaces adaptable to the changing needs of inhabitation. It delegates the role of a social space onto the interstitial spaces of the corridor transforming it into a sequence of unique spatial conditions which moves away from the compartmentalized and homogenized notion of a common space to a freely accessible ambiguous spatial entity adaptable to the dynamism of human dwelling. The corridor loses its placeless structural identity and becomes assimilated as a social space within the sequences of corridic spatial conditions. The corridic notion of co-inhabitation focuses on incorporating various degrees of motion that permeates through its sequences of social spaces, hence deconstructing the threshold between dwelling units and shared spaces.

Similar to the baugruppen model, the corridic model of co-inhabitation, reserve a mix of private living spaces for the inhabitants which are optimized yet varying to accommodate a wider demographics. This model includes a variety of compact and flexible unit types for families, couples, singles and seniors clustered around the sequences of a semi-private corridic space. It is essentially a hybrid model that incorporates planned spatial intervention with participatory building process. In a single corridic cluster, multiple families get together to configure and re-configure their dwelling conditions around a skeletal corridic structure. As a result, it diversifies the co-housing formats in a mid-rise, high density residential system. 
Living In-Between 


\section{0}

\subsection{The Corridic Model}

\subsubsection{Site. Location and Approach}

$\mathbf{T}_{\mathrm{o}}$ contextualize the idea of a corridic model of co-housing, a site is chosen as an experimental ground for the project to materialize as an architectural space. Contrary to most co-housing projects, but not all, the location of site has a symbolic connotation that resonates with the guiding principles of the co-housing model. The site is a threshold condition by itself. Situated at the junction of Keele Street, St. Clair Avenue West and Weston road, the location is a construction site of a de-commissioned re-development project lying at the threshold of different housing conditions (fig 44). Landlocked by heavy industrial, commercial and residential systems, the site provides the opportunity to be treated as an urban infill or a transition place for different urban conditions. 

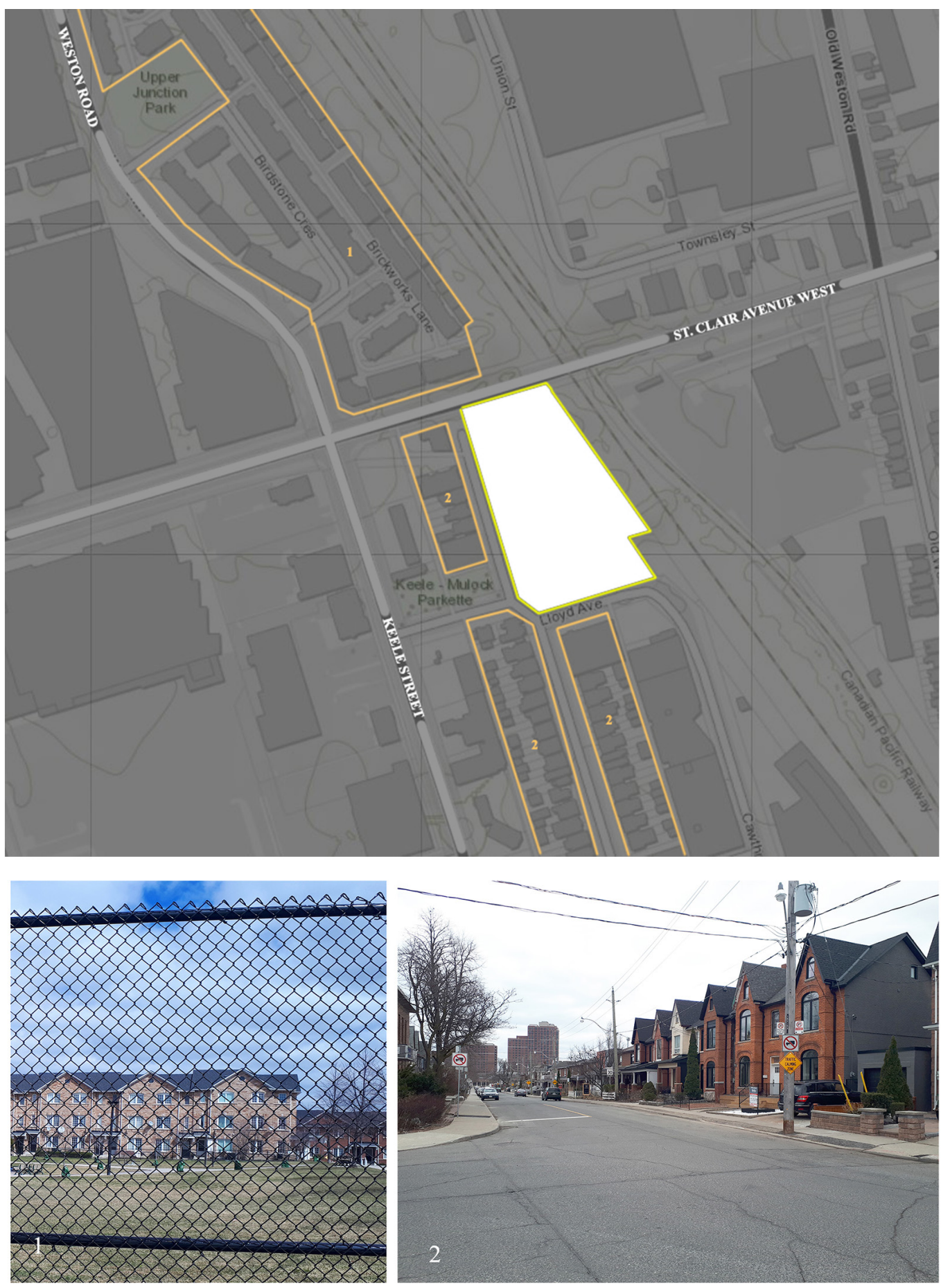

fig 44The site at the threshold of two different housing conditions. Detached housing to the south (2) and a more recent row housing project to the north (1). 

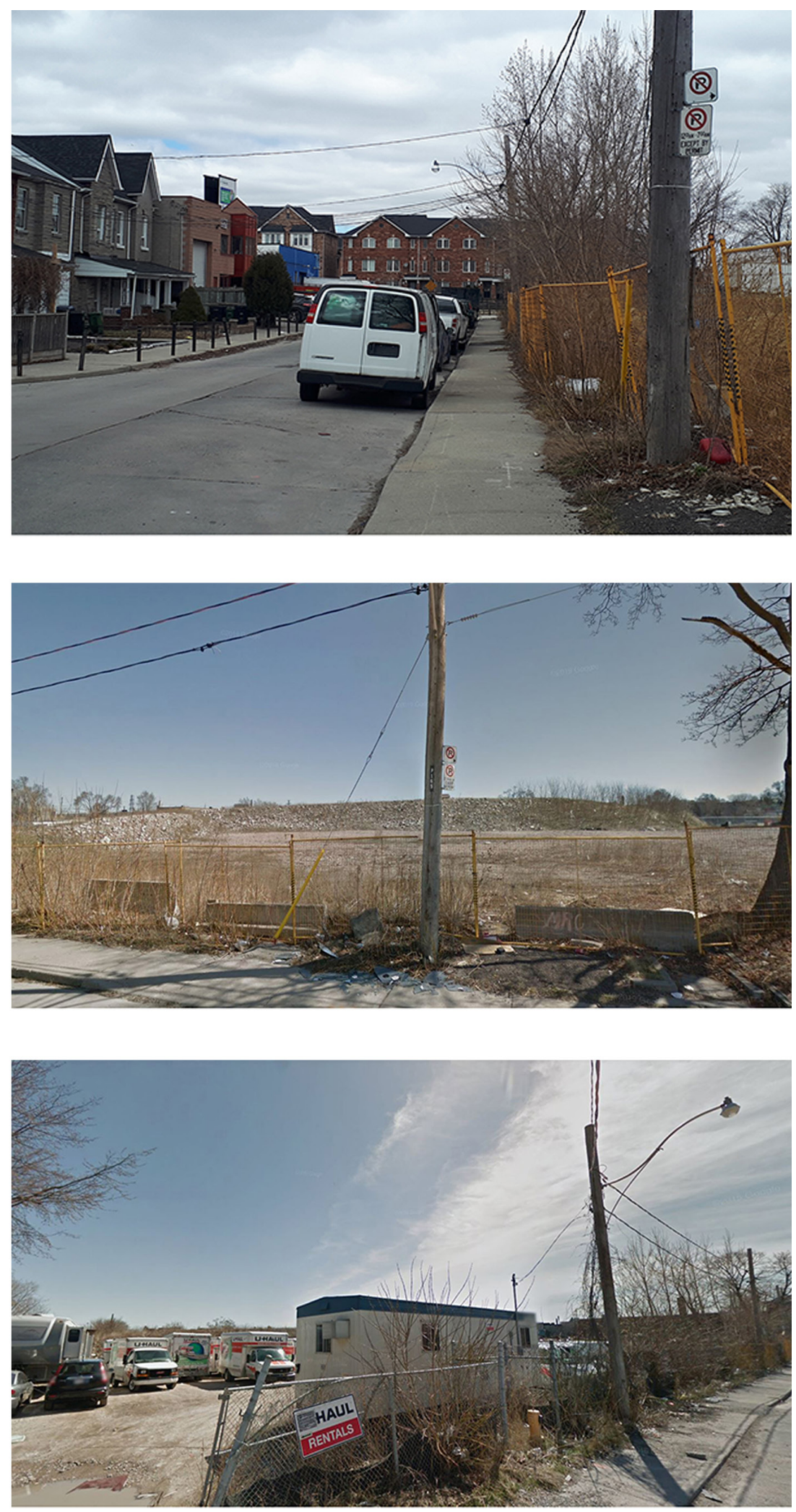

fig 45 Site edge conditions 

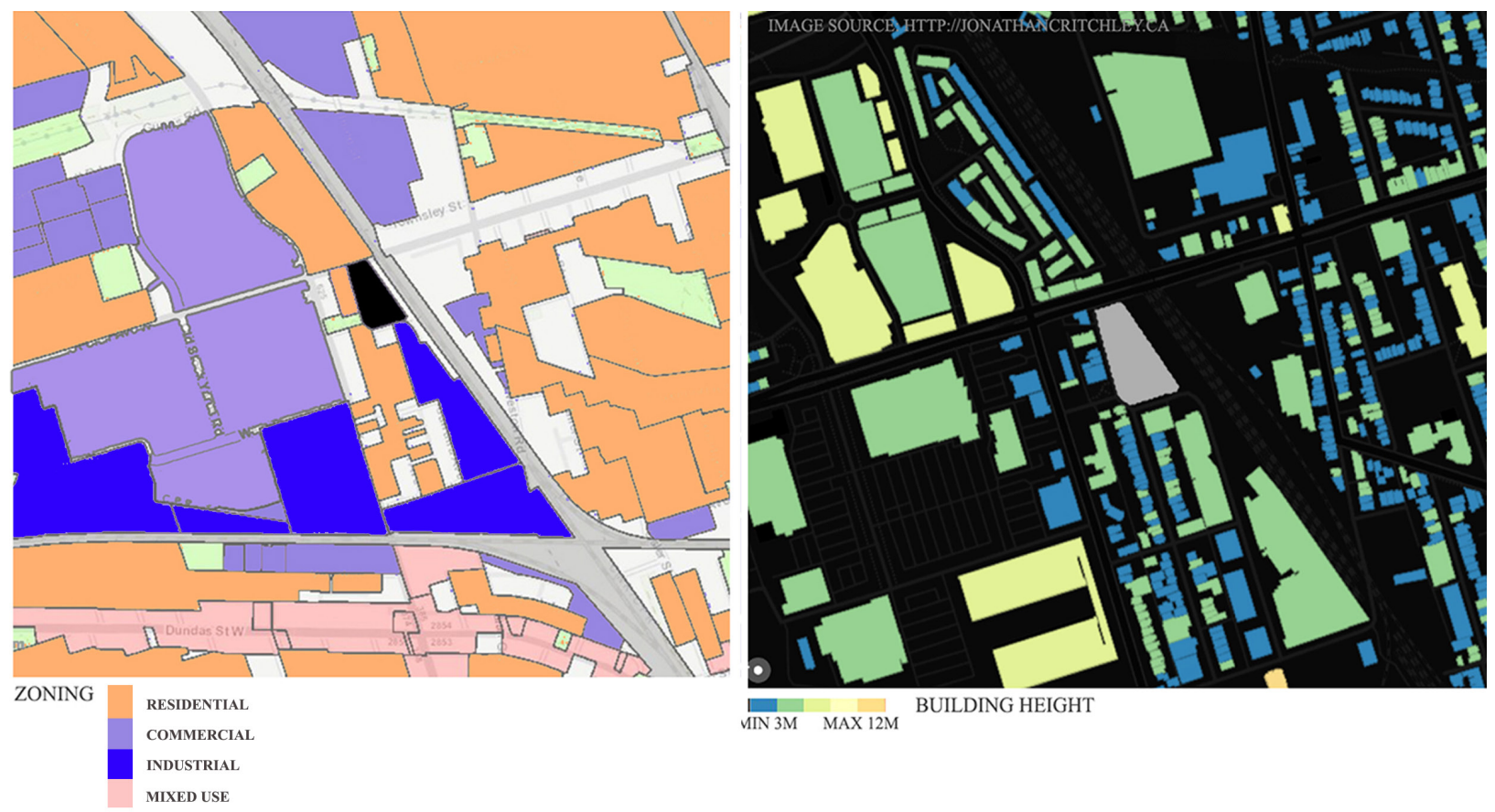

fig 46 Context study. Zoning and building height specification place the project in a mid-rise residential area with close proximity to heavy industrial and big box stores. To create a successful transition space for pedestrian movement, the project opts for a mid-rise mixed use development.

To characterize the site as a transition space, it becomes essential to identify the existing urban conditions like the degree of pedestrian movement and transit points and the possible 'magnets' that could guide the rerouted pedestrian footprint in the site (fig 47). 'Magnets' are the existing commercial zones that have the potential to influence pedestrian activity along a selected site. The stockyards village to the west and the Toronto Weston Flea market and commercial strip to the east of the site are potential 'magnets' that could determine pedestrian density through the site. Currently, the pedestrian connection between these two commercial zones passes through a railway underpass (the Canadian Pacific Railway connection) along St. Clair Avenue West. The site looks towards creating an alternate route by creating a connecting urban park trail that shifts the pedestrian activity along the street and densifies it within site (fig 48). 


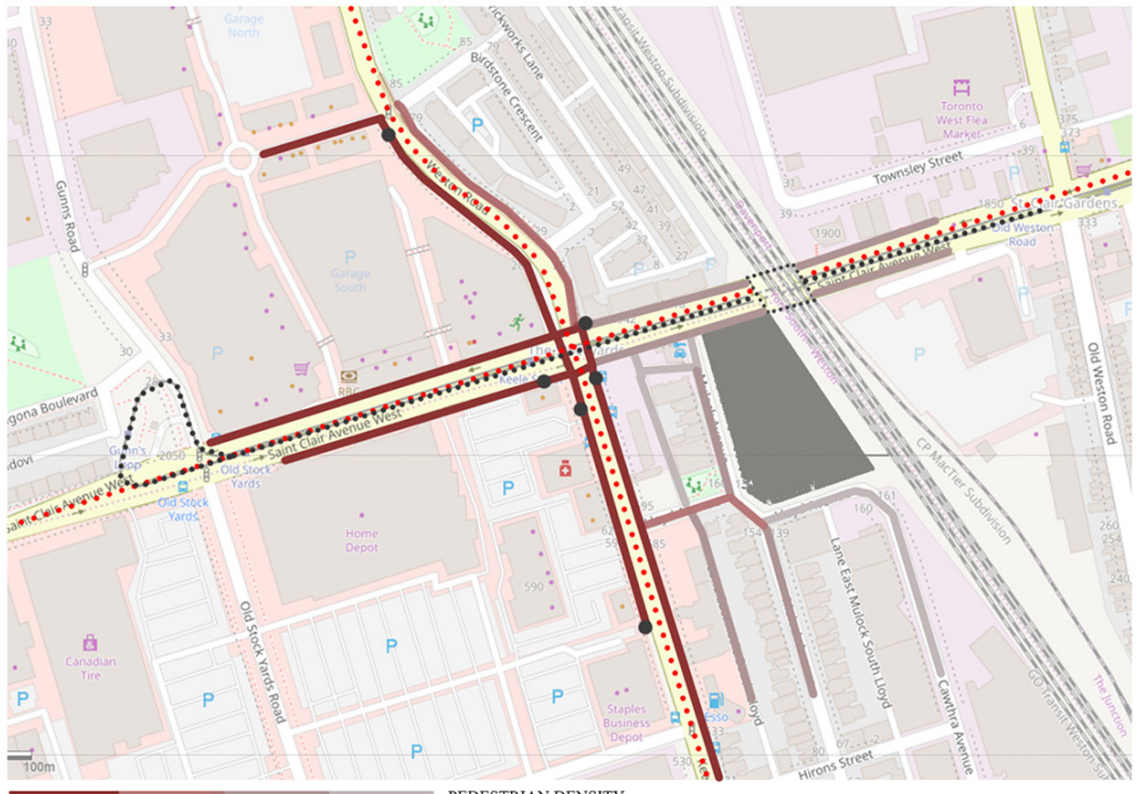

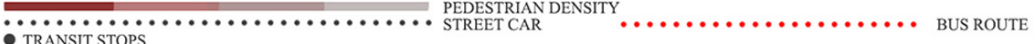

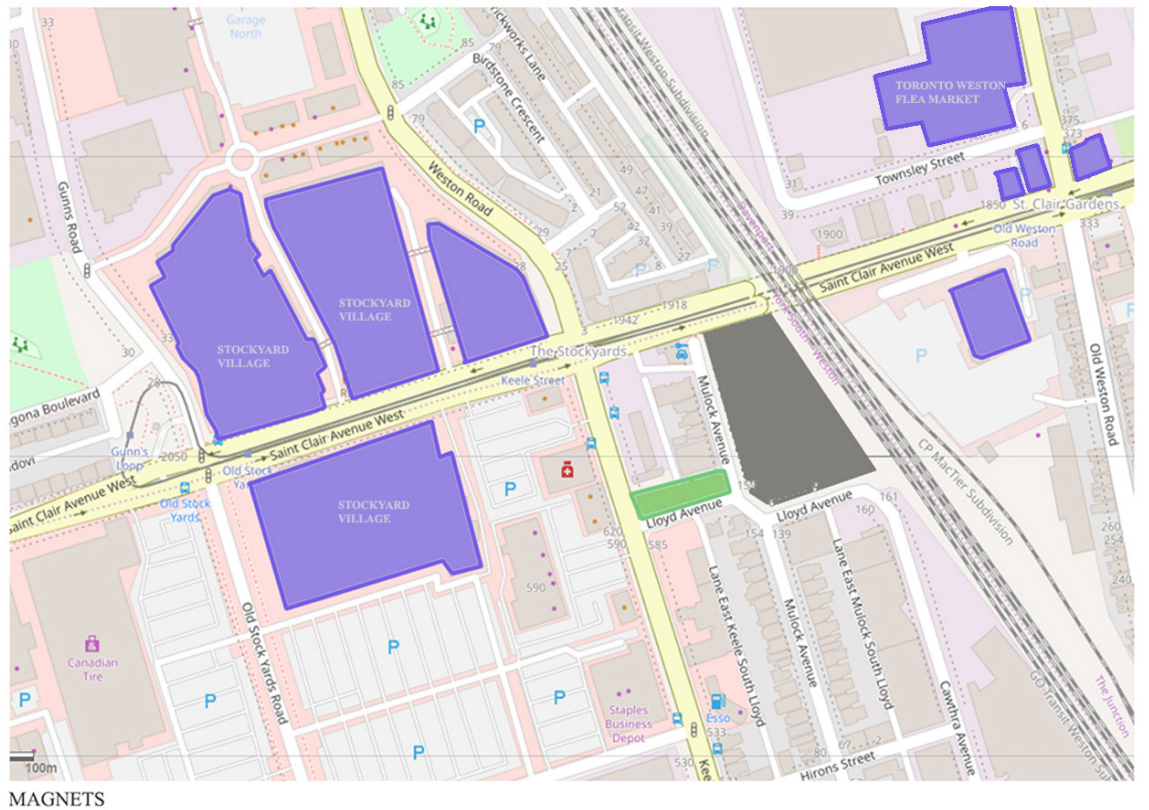

fig 47 Context study. ) Identifying existing pedestrian route and point of entry to connect the commercial magnets 


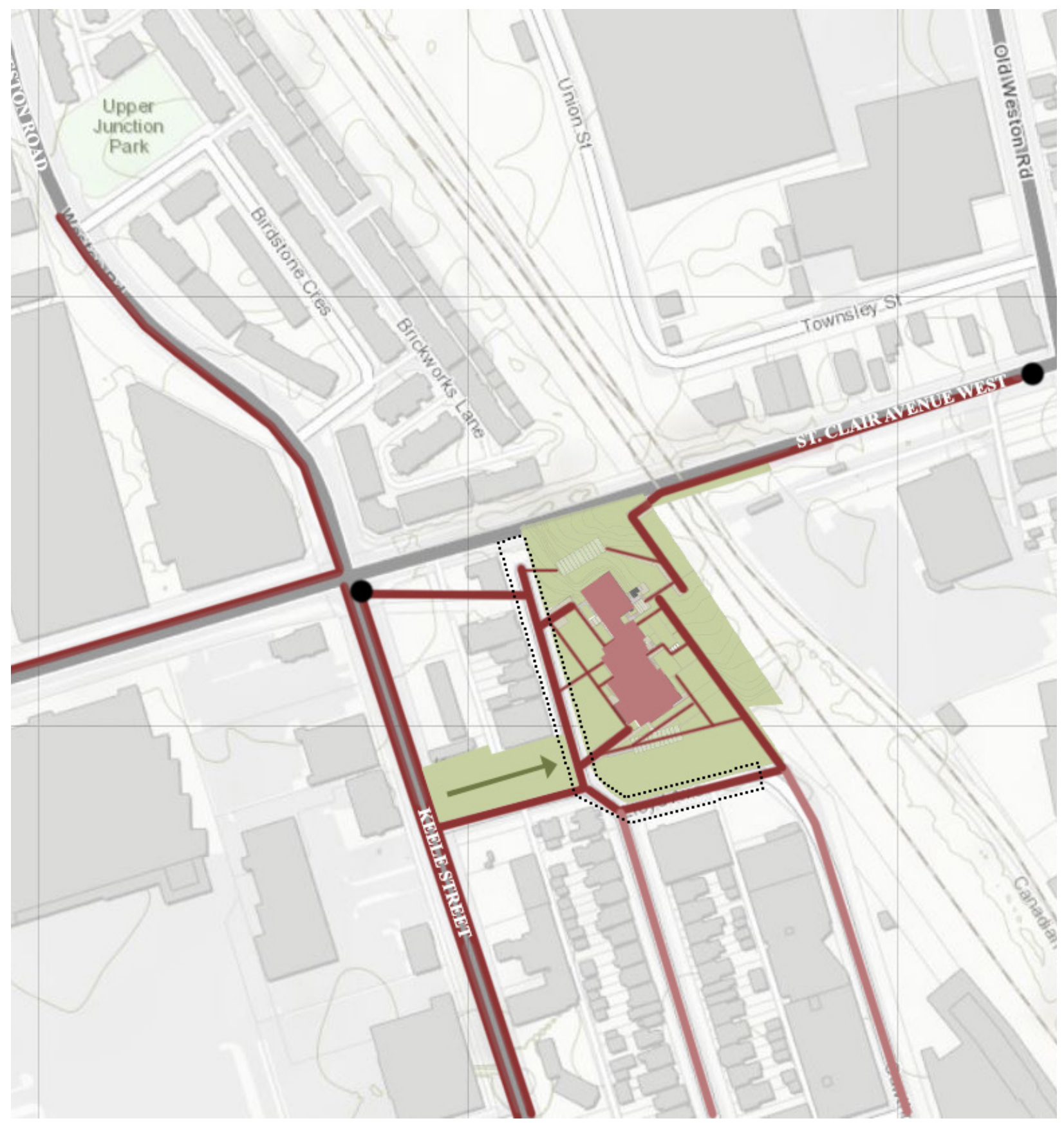

fig 48 Shifting pedestrian footprint within the site by creating an urban park.

This enables the transfomation of the secondary streets into pedestrian zones 


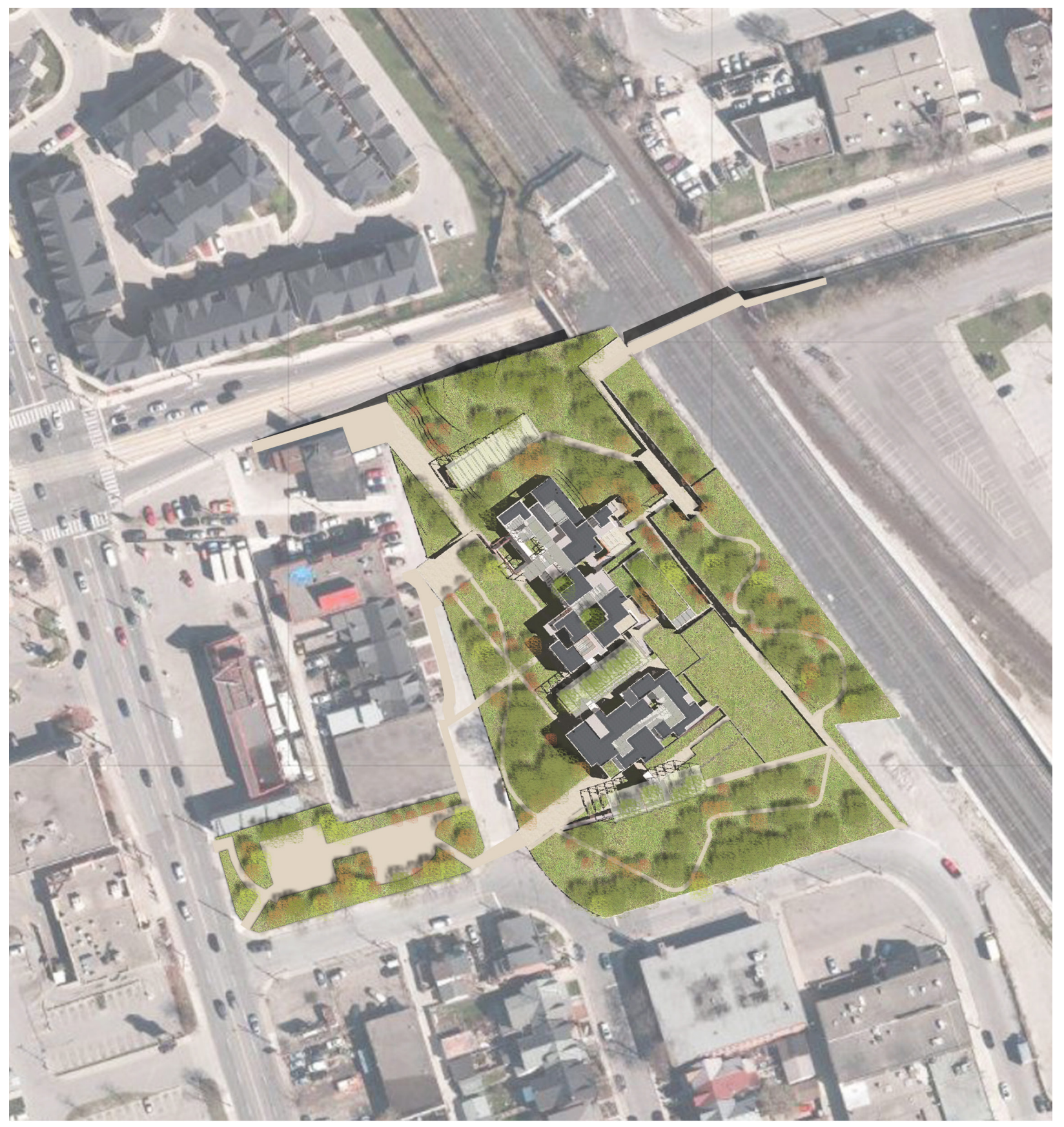

fig 49. Arial view of the proposed model and connection to context 


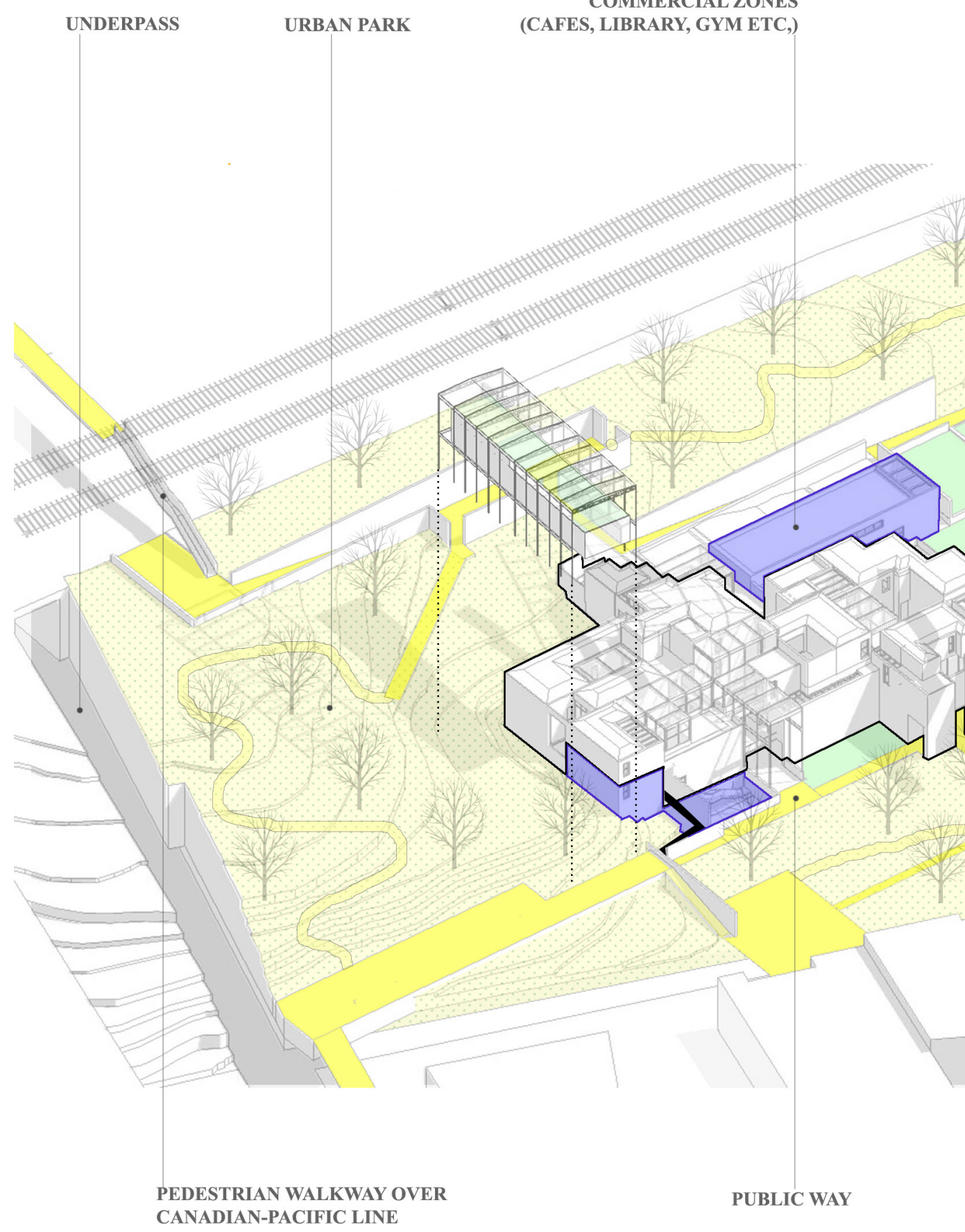

Instead of being envisioned as an object in the field, the co-housing model is visualized as part of its landscape with a direct relation with its context. The site is visualized as an open urban park that acts as a green connector and a transition space for the residential and commercial zones in its context. By extending an existing parkette, the site extend a public way to direct pedestrian traffic into the site. The strong delineation of a boundary is replaced with a green buffer that invites the public into the site through a park trail. The topography to the east is accentuated to 


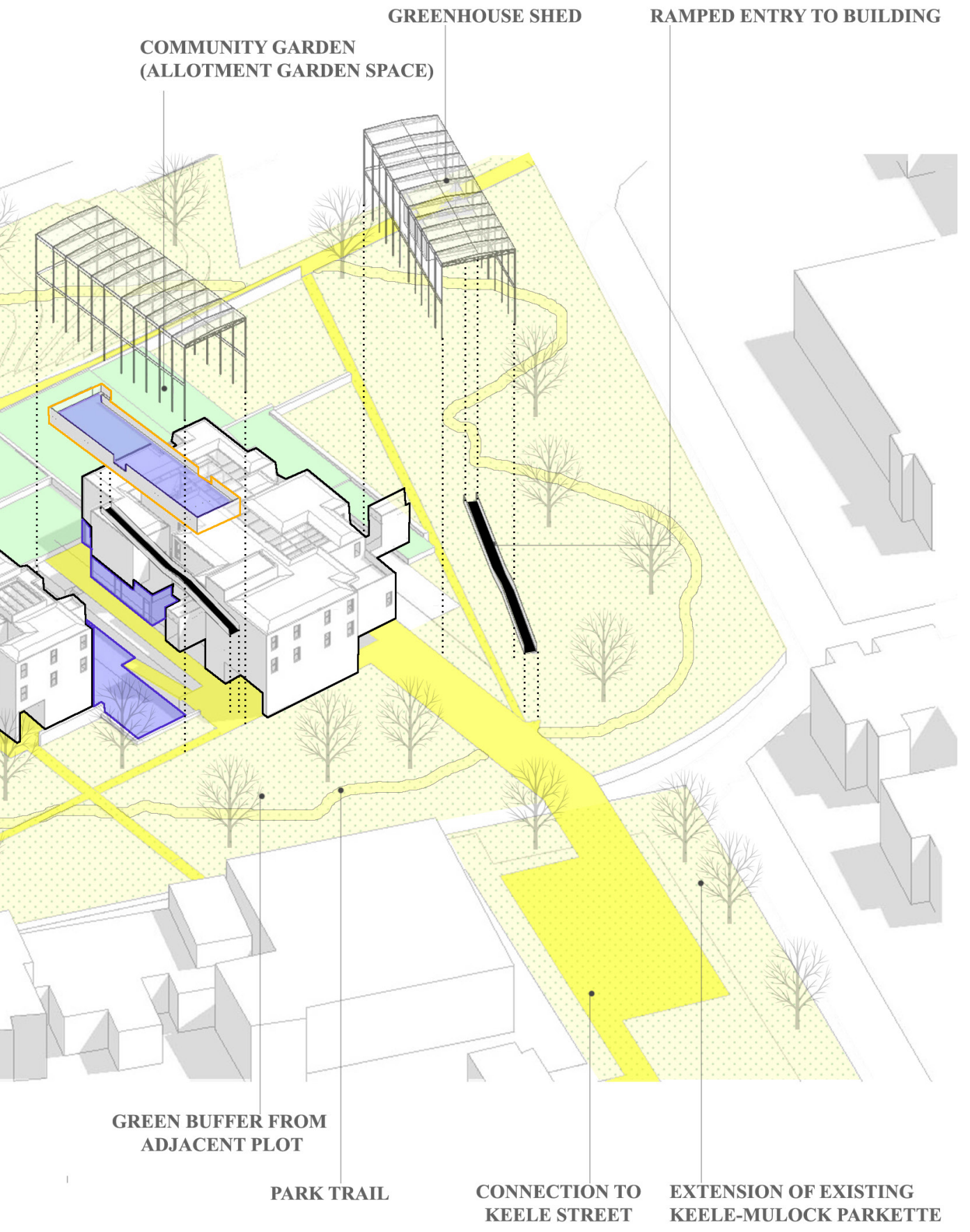

fig 50. Site schematics. The co-housing model in a spatial dialogue with the urban context. Surrounded by an urban park, the site transforms into a space accessible by the public.

create a difference in elevation to separate the site from the railway line. The building instead of obstructing the flow of pedestrian movement, acts as a spatial intervention in the park which directs movement within the site. The building is raised at places to provide spaces for commercial use which acts as 'magnets' within the site to influence pedestrian movement. By implementing such design principles, the co-housing becomes a part of a larger urban fabric and add to urban vitality by becoming a social place. 


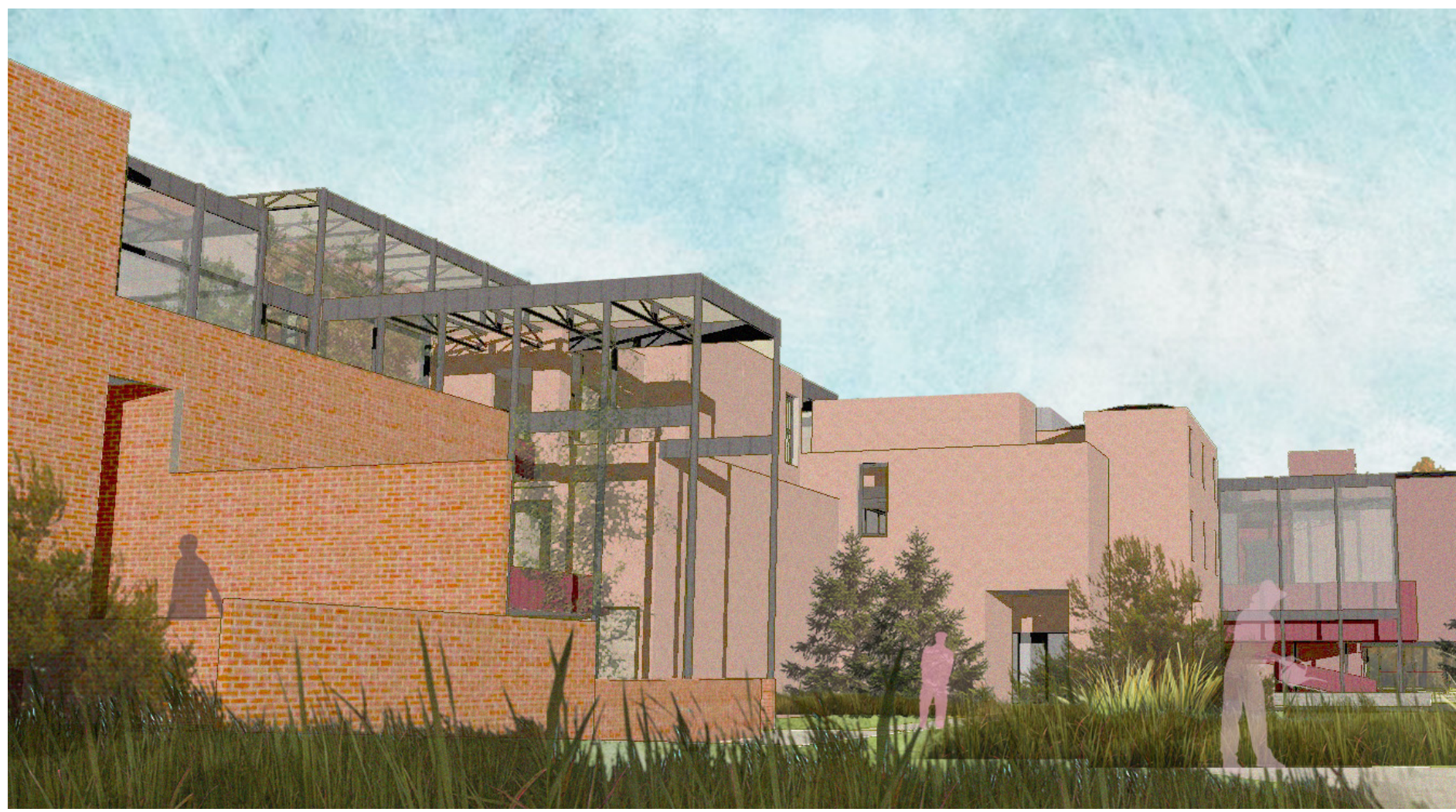

fig 51. Threshold 1- The green buffer defining the edge conditions of the site is a space for passive strolling. Characterized by features like allotment garden space, jogging trails, greenhouses, nurseries and covered re-creational spaces, this buffer area is a space shared by the residents and the public 


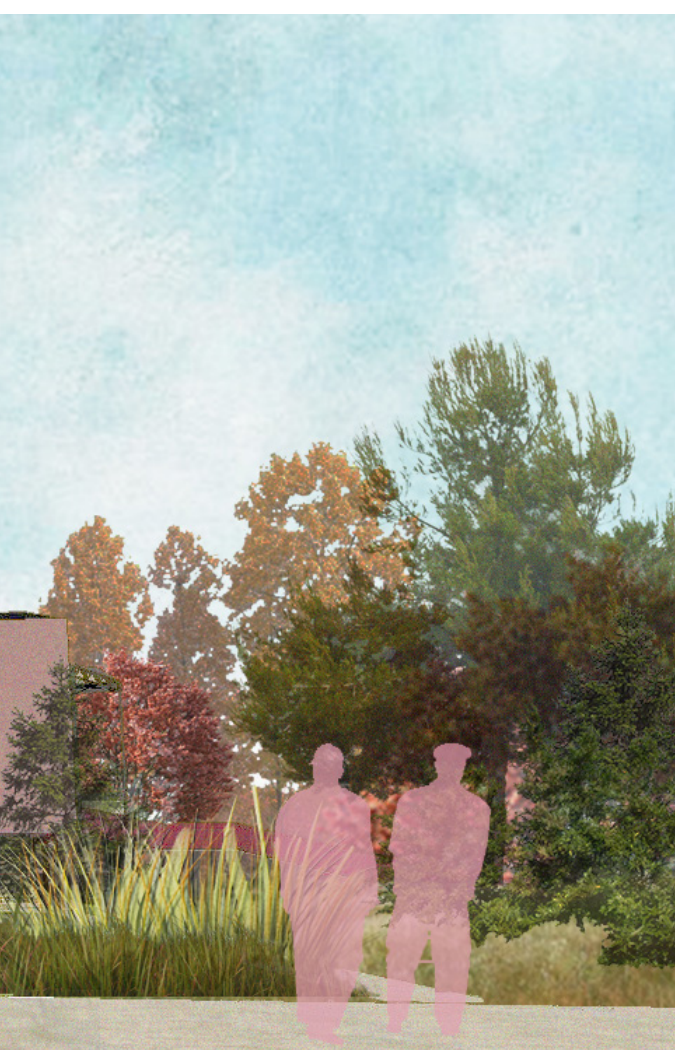

The significance of the green buffer lies in its reflection of the fragile ontology of the corridic place. The notion of its architecture being contextual and responsive and concerned with sensory interaction is reflected in the space the green buffer creates as a threshold element within the site. It creates the sensation of a haptic approach, a sensory prelude and de-constructs the monotony and flatness of moving in and out of the site (fig 52a,b).

Furthermore, this green buffer creates a soft boundary where a person in transit is invited to take a stroll. The natural duration of this strolling space is an intentional spatial intervention because it enables the notion of separation the building embodies. Instead of confronting its inhabitant with a sudden change in scale and a stark sense of separation, the building builds upon the natural duration of taking a stroll and puts into place a gradual transition of space and scale as the inhabitant moves into the building from the park. 


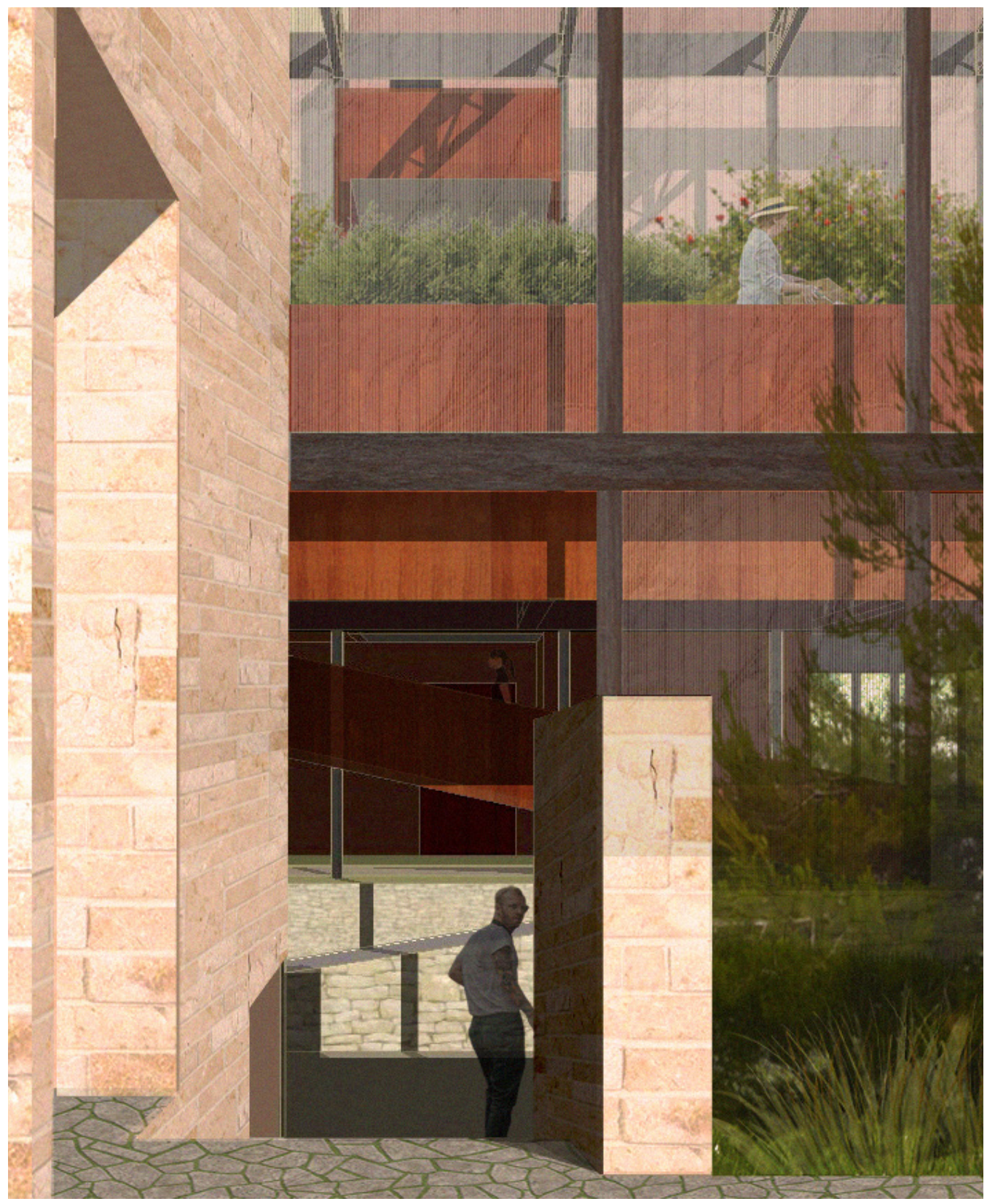

fig 52 (a). Transitioning from the buffer space to the building is a sequential, gradual process through a play of levels and manipulation in directionality. 


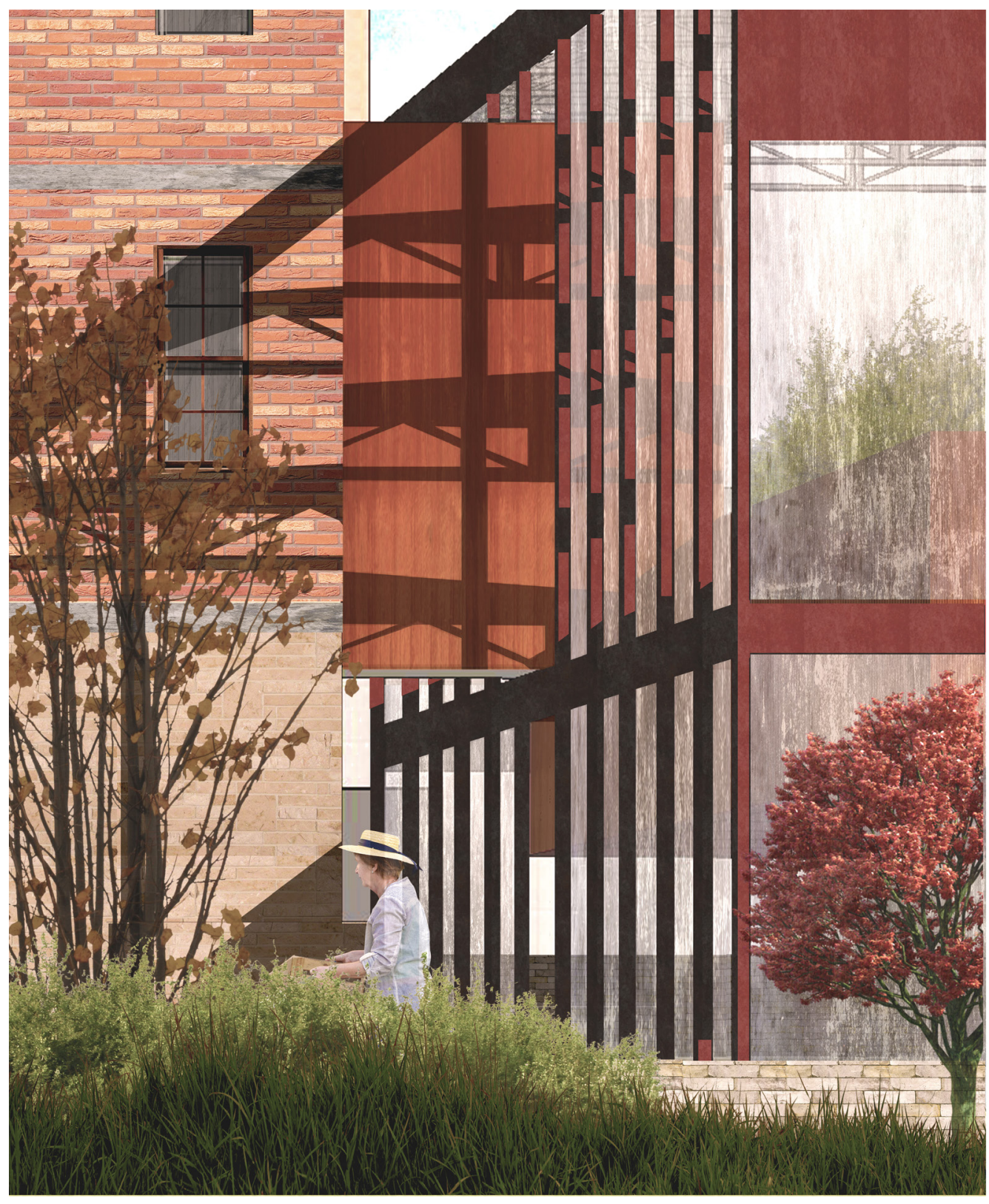

fig 52 (b). Transitioning from the buffer space to the building is a sequential, gradual haptic process that breaks the monotony and flatness of moving in and around the building 


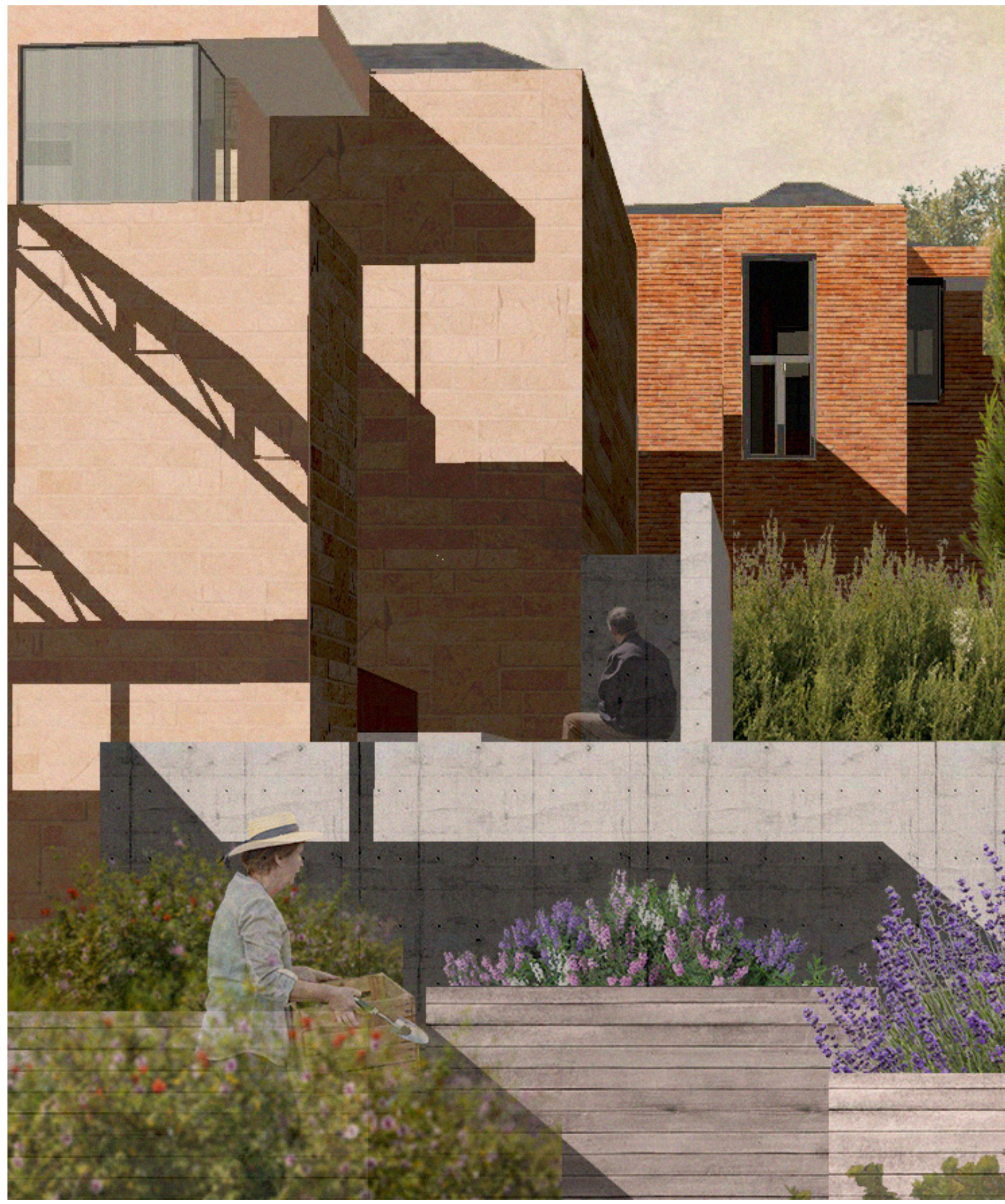




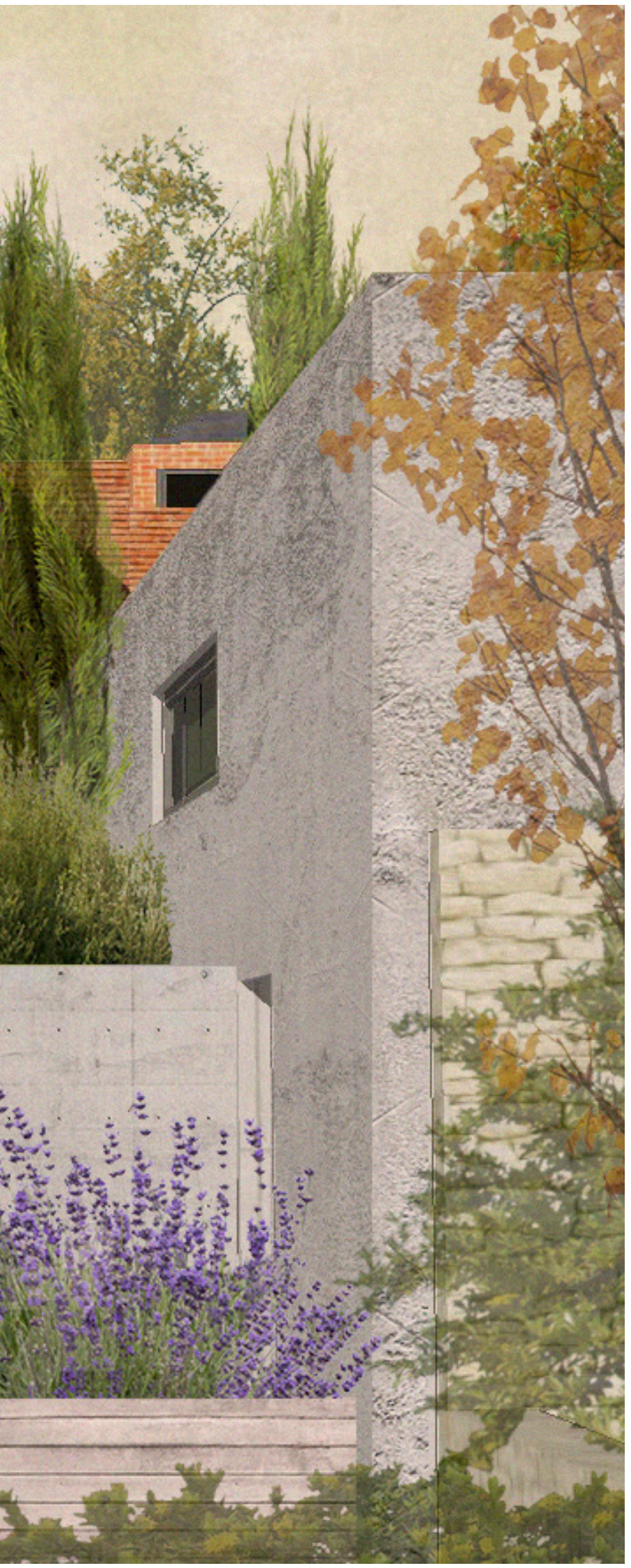

fig 53. View from the allotment garden space.

Continuing on the ground floor, the public paths converges to a community allotment garden space. The building form opens inward into this space and creates a layered space for social interaction. 


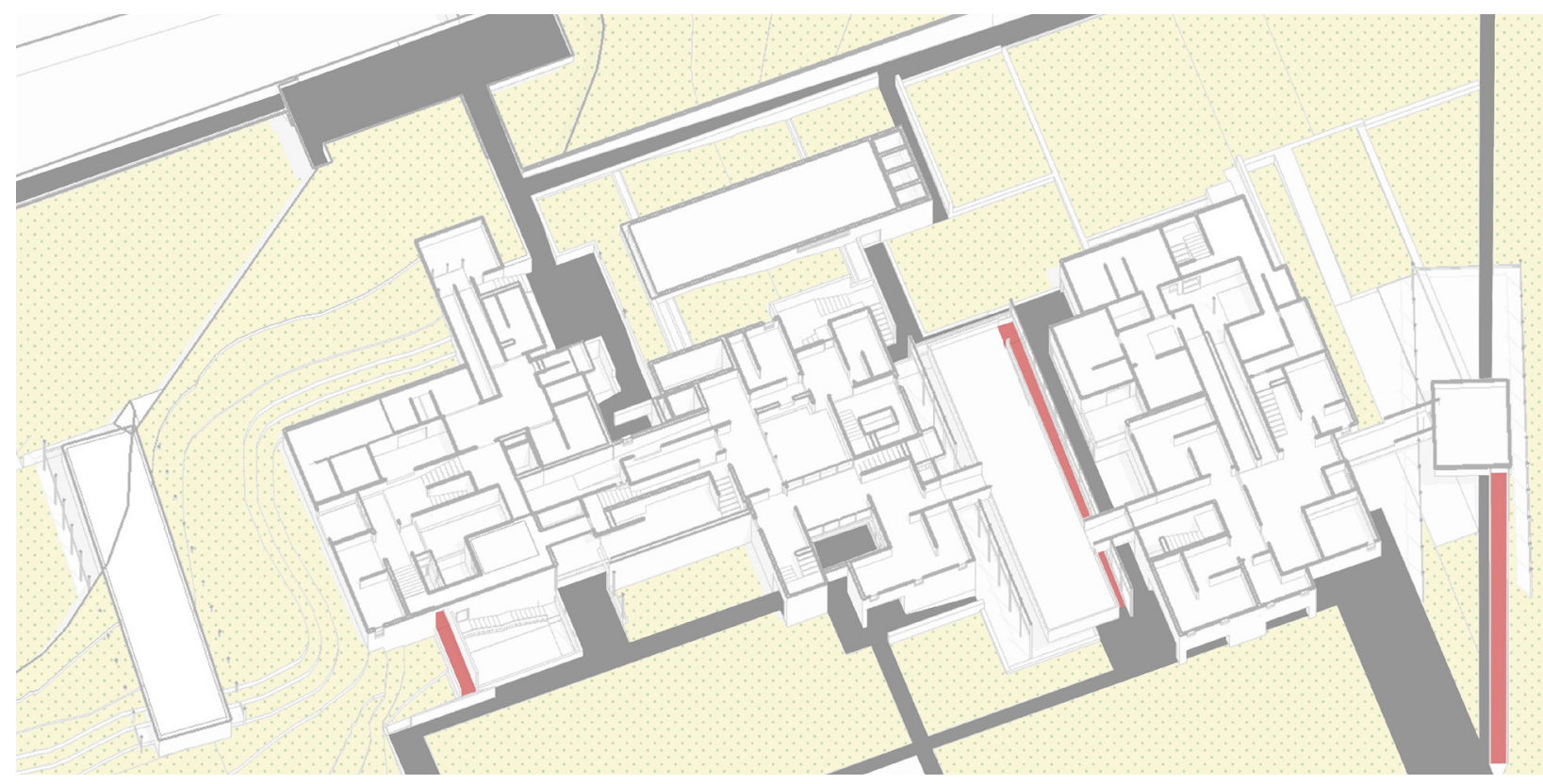

fig 54. Threshold 2 -

ramped entrances

This gradual transition of space and scale while extending the natural duration of taking a stroll is achieved through the design of ramped entrances to the building. The ramped walkways compliment the haptic approach outside the building and adds another vector to movement. Instead of taking the person directly to the building, the ramps also prolong the lived experience of the person in the threshold of the site and the building. In this corridic model, the ramps enter the building through a greenhouse and semi-public zones (fig 55), thus creating a sequence of spatial conditions that the inhabitants explores and traverses through before entering the building. 

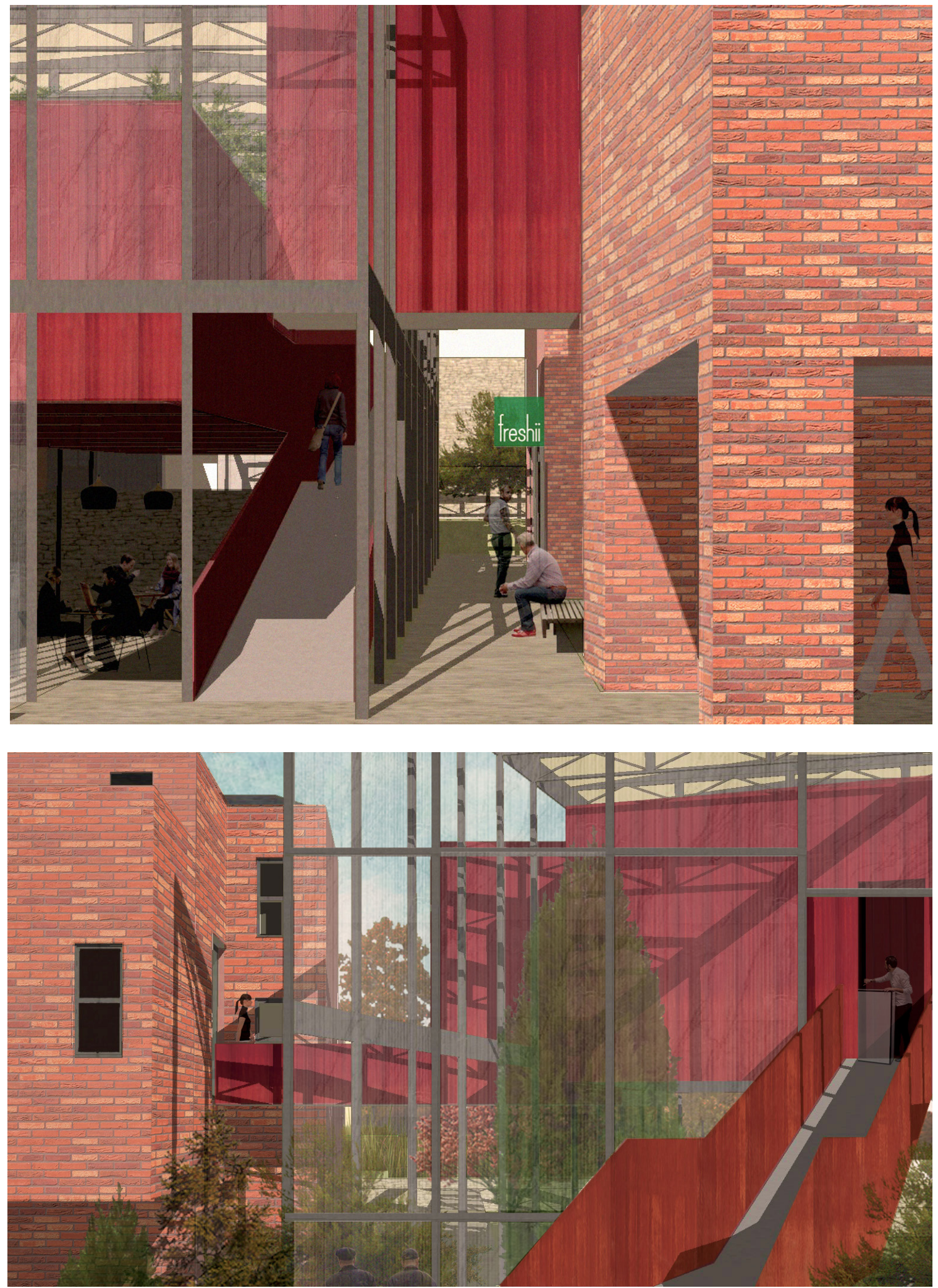

fig 55. Ramped entrances to the building. There is a careful construction of a gradual sense of separation from a public space to the resiential structure as the ramps build upon the processual nature of movement of the green stroling space 


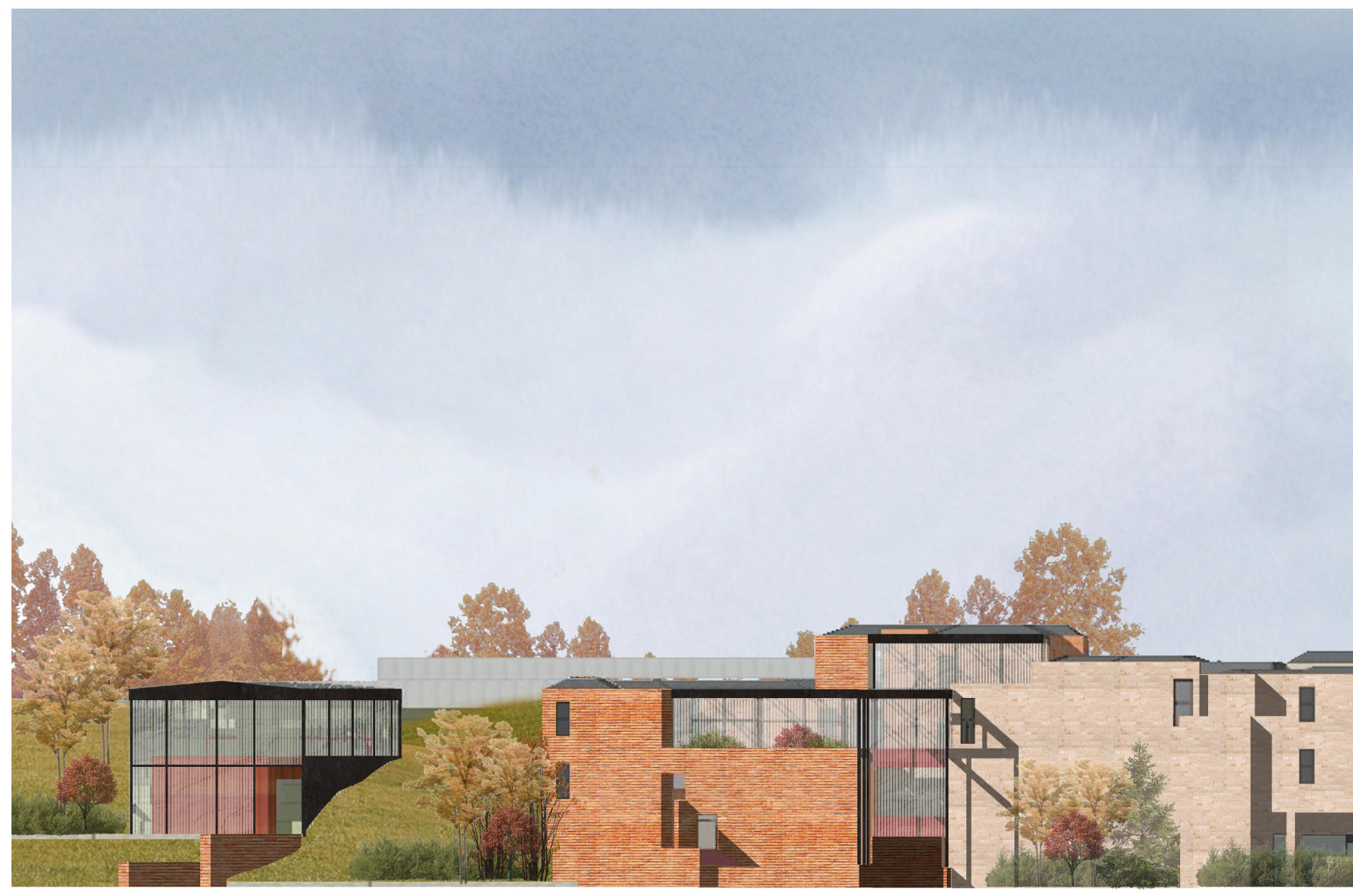



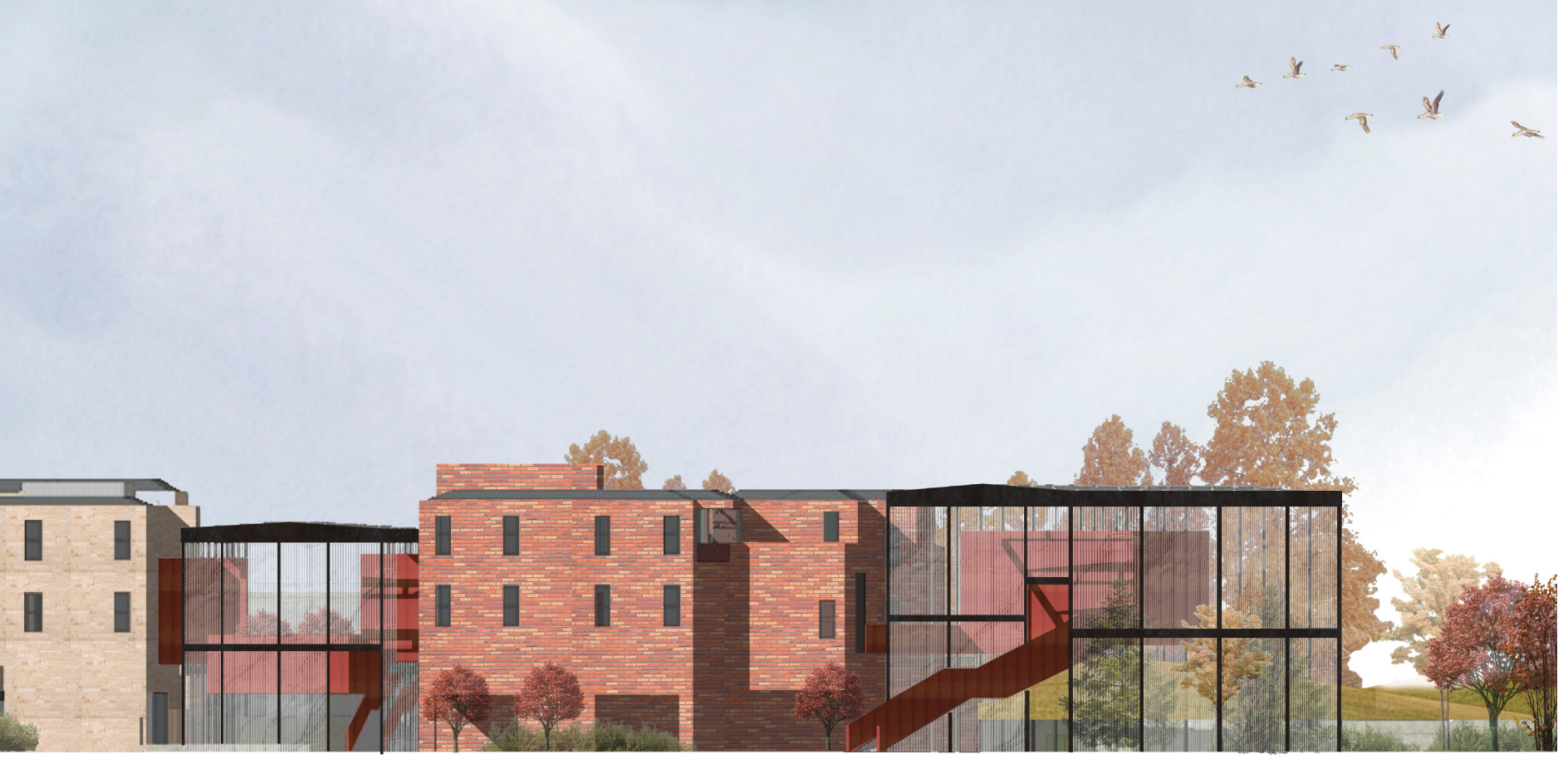

fig 56. Elevation. De-constructing the monotony and flatness of the residential built form 


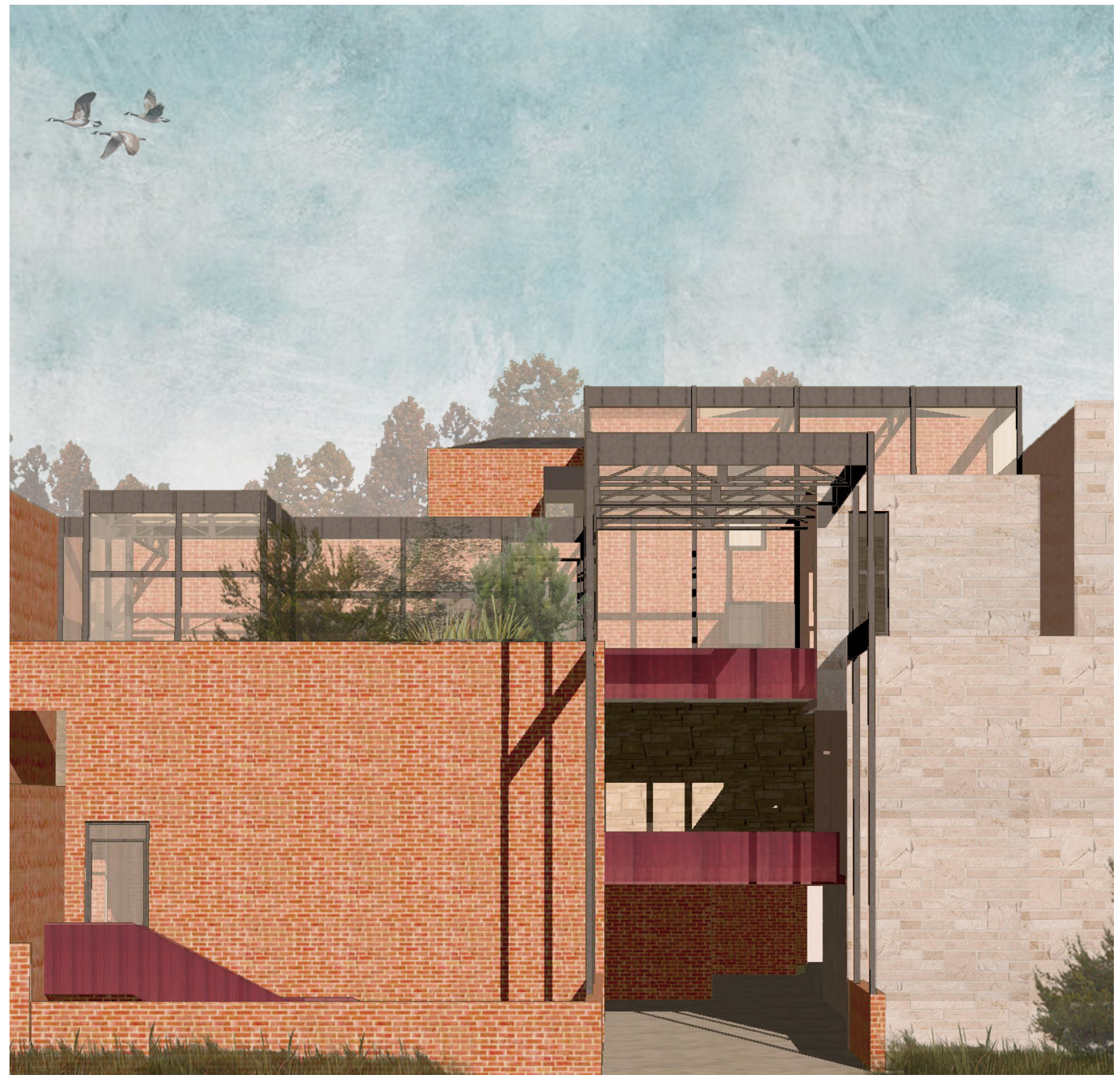

fig 57. Episodic architecture. Varying layers of opacity and depth coupled with the de-construction in the uniformity of surface exposes the haptic character of the corridic space to the outside

While approaching the building, the sensuous qualities of the corridic space reveals itself in the episodic nature of its architectural language. The de-construction of spatial experience by the corridic space is observed in the varying layers of opacity and depth that shifts away from the flatness of surface, materiality and uniformity of illumination further revealing the building's haptic layers. These haptic surfaces 


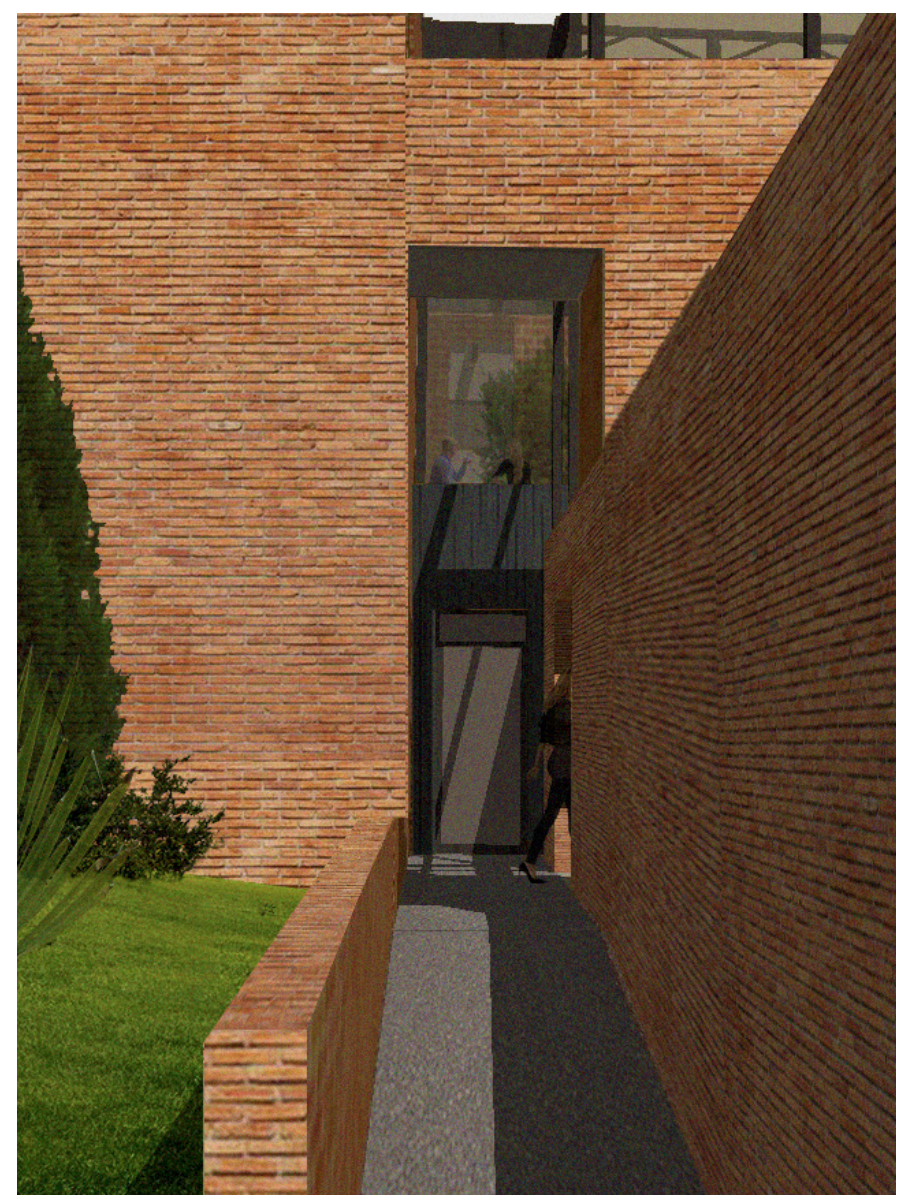

fig 58. Play of surfaces influence the pattern of movement from the outside to the inside

impregnates the architectural space with a sensory essence and a presence of matter which brings out the evocative qualities of the corridic place. The building appears to conceal and open up (fig 57). In the act of opening up, it reveals elements which act as identifying markers to help navigate a person exploring the corridic sequences in the building. For example, revealing the material of the ramped walkways and footbridges (corten steel cladding in this case) at places help the inhabitant to anticipate the sequence of spaces as they transition in and out of the building. The notion that a corridic architectural space is a space of exploration and curiosity is revealed in these exposed play of surfaces. 


\subsubsection{The Corridic House}

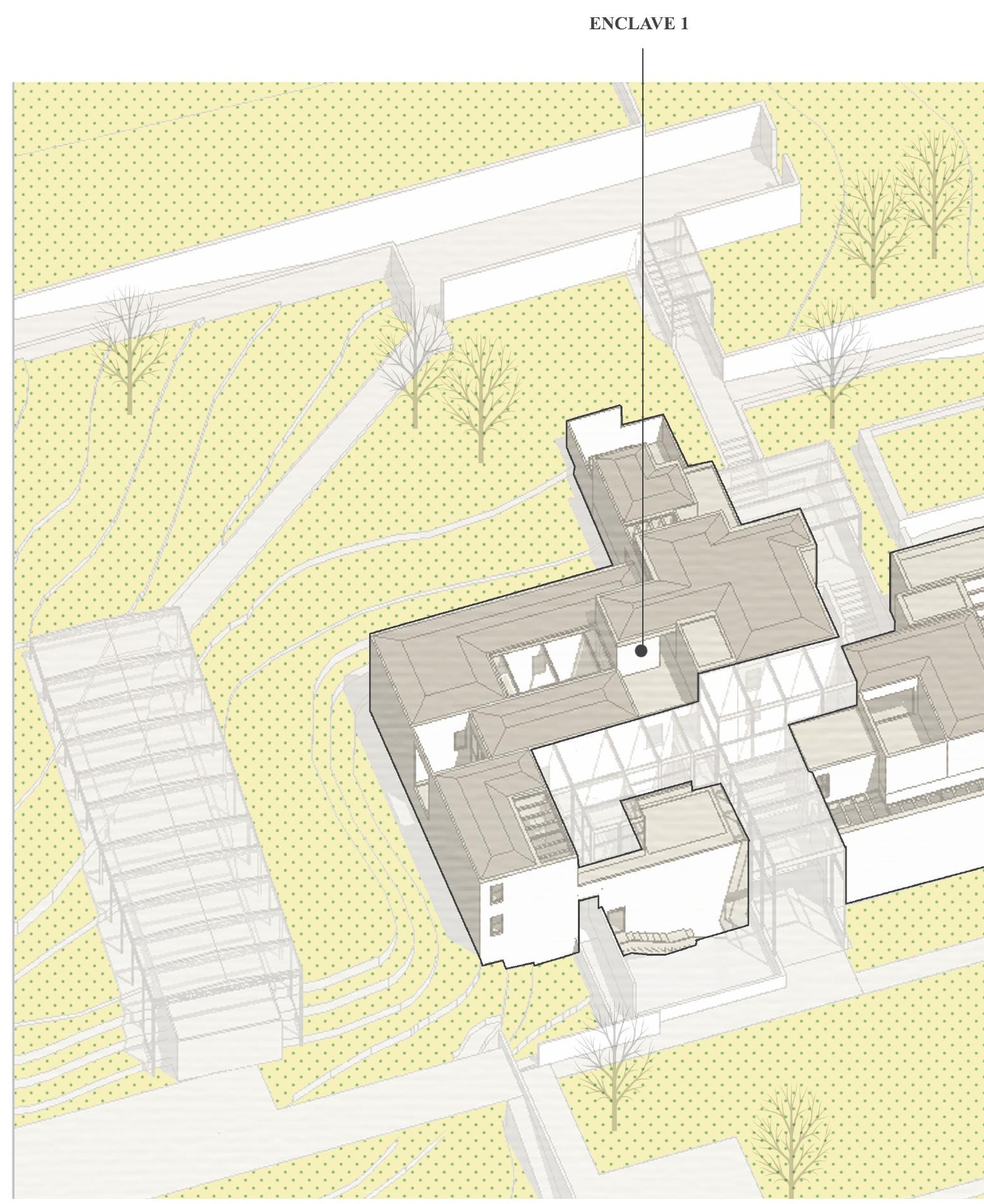




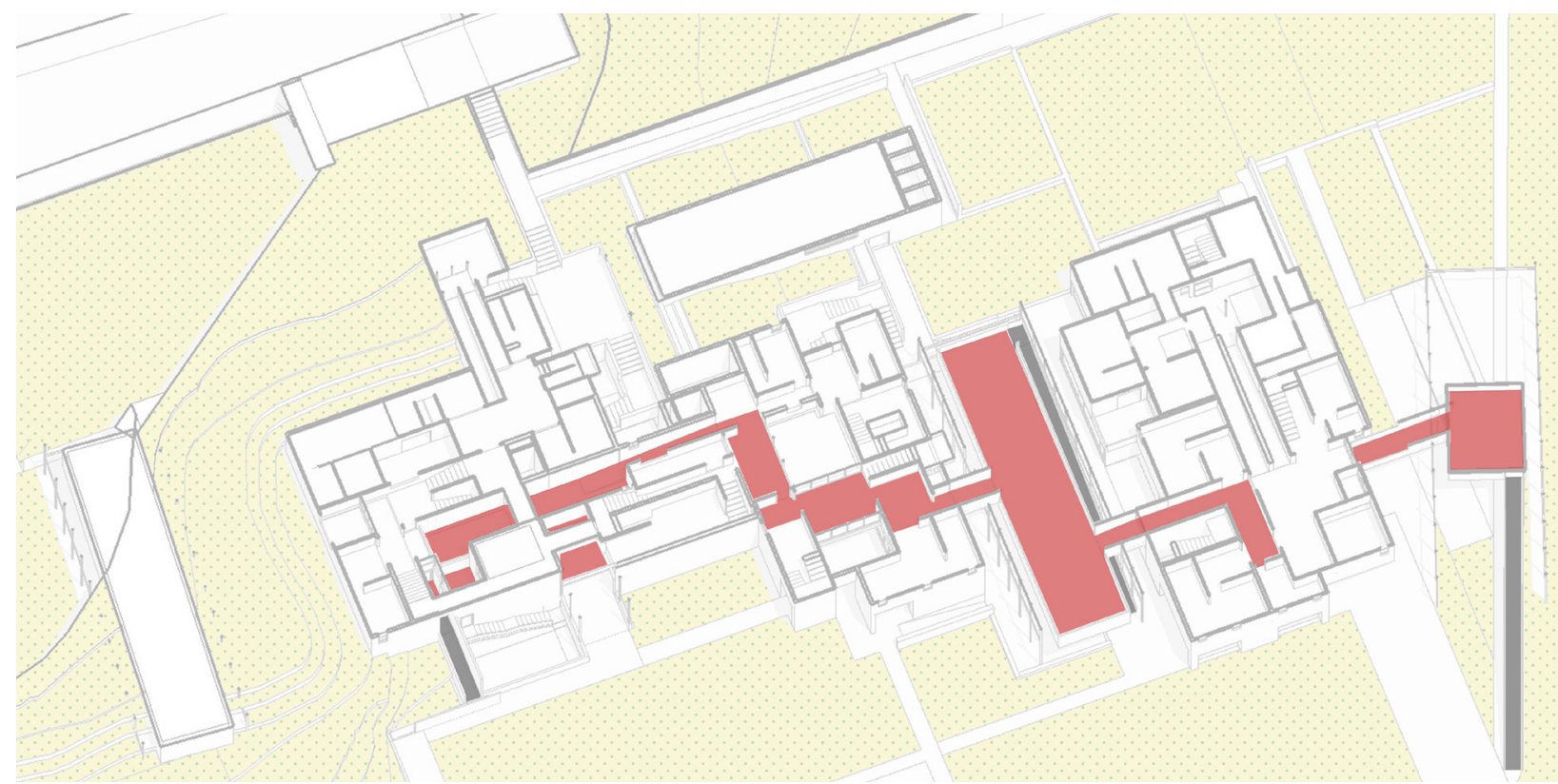

fig 60. Threshold 3-

The Spine

The sequential movement in the green buffer zone transitions into a series of indoor-outdoor spatial conditions inside the building which act as a central dwelling spine in the corridic co-housing model. This architectural sequence of spaces (spine) is a programmatically ambiguous zone adaptable for a set of variable dwelling conditions. Such a threshold space can be appropriated as a 'common' that the inhabitant traverses through in the course of transitioning in and out of the building. The spatial language of this dwelling spine emulates that of a streetscape and as an appropriated dwelling space, the architectural language of this streetscape comes into being as an expression of everyday life of its residents over a period of its inhabitation. Through collective appropriation, the space acquires a texture and presence over time and becomes a haptic landscape for dwelling to occur. Accentuated by its added haptic sensibilities, the relaxed structure of this architectural space with its layered spatializations constructs a social space imbued with a material imagination that helps in place building. 


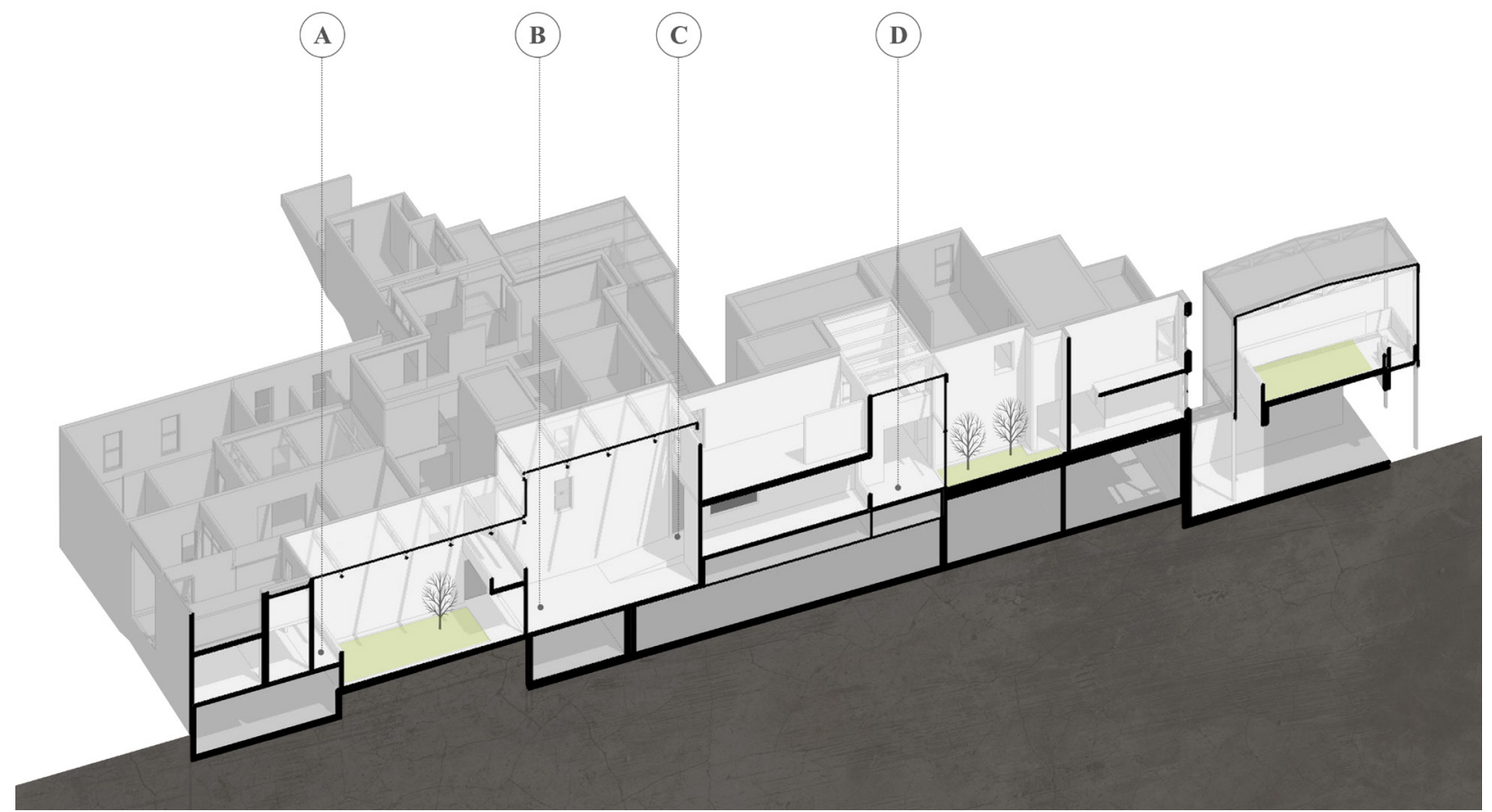

Furthermore, this corridic common is also a passage space. Perforating the built form with a series of threshold conditions of varying scale and The Spine in enclave 1 and 2 directionality, this central spine guides the transition from one dwelling space to the other. It orchestrates the progression of movement through the episodic architecture of the corridic space. It guides the inhabitant through varying architectural realities with distinct experiential qualities which it constructs through the compression and expansion of its spatial delineations (fig 61). It periodically opens up in a spatial dialogue with haptic elements with the intention of creating moments of pause in the course of movement through its architectural space. These moments of pause reflect the fragile ontology of the corridic place where the space with its tactile sensuality arrests the inhabitant in a moment of receptive attention. In this corridic model, as the inhabitant traverses through the spine from one part of the building to another, they are confronted by pockets of atrium spaces, niches or portals opening into courtyards (fig 62). These pockets, where the visual space of the inhabitant momentarily changes, one becomes cognizant of the communal life playing out at different levels inside the building. 


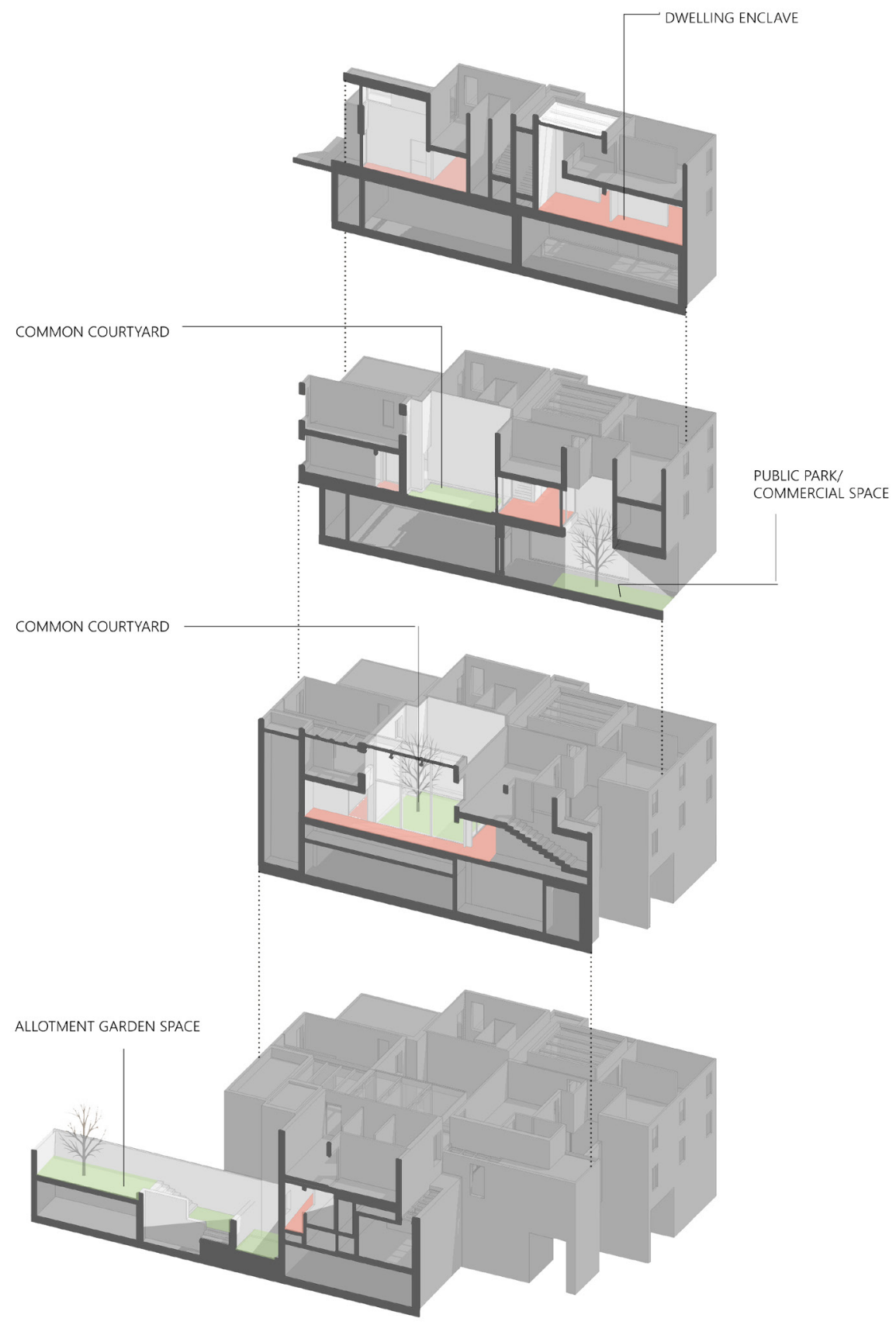

fig 62. Section through enclave 2 illustrates the sequential vistas and opportunities for spatial dialogue and moments of pause as an inhabitant moves between two points in the building through the corridic spine.
This 'common' corridic space connects the three dwelling enclaves in the co-housing model and therefore, can be viewed as the primary thoroughfare within the building. As its spatial flexibility offers the possibility of being appropriated for different programmatic configuration shared by all the three enclaves, this passage space becomes a place for community and moves beyond the placeless-ness of a residential corridor. 


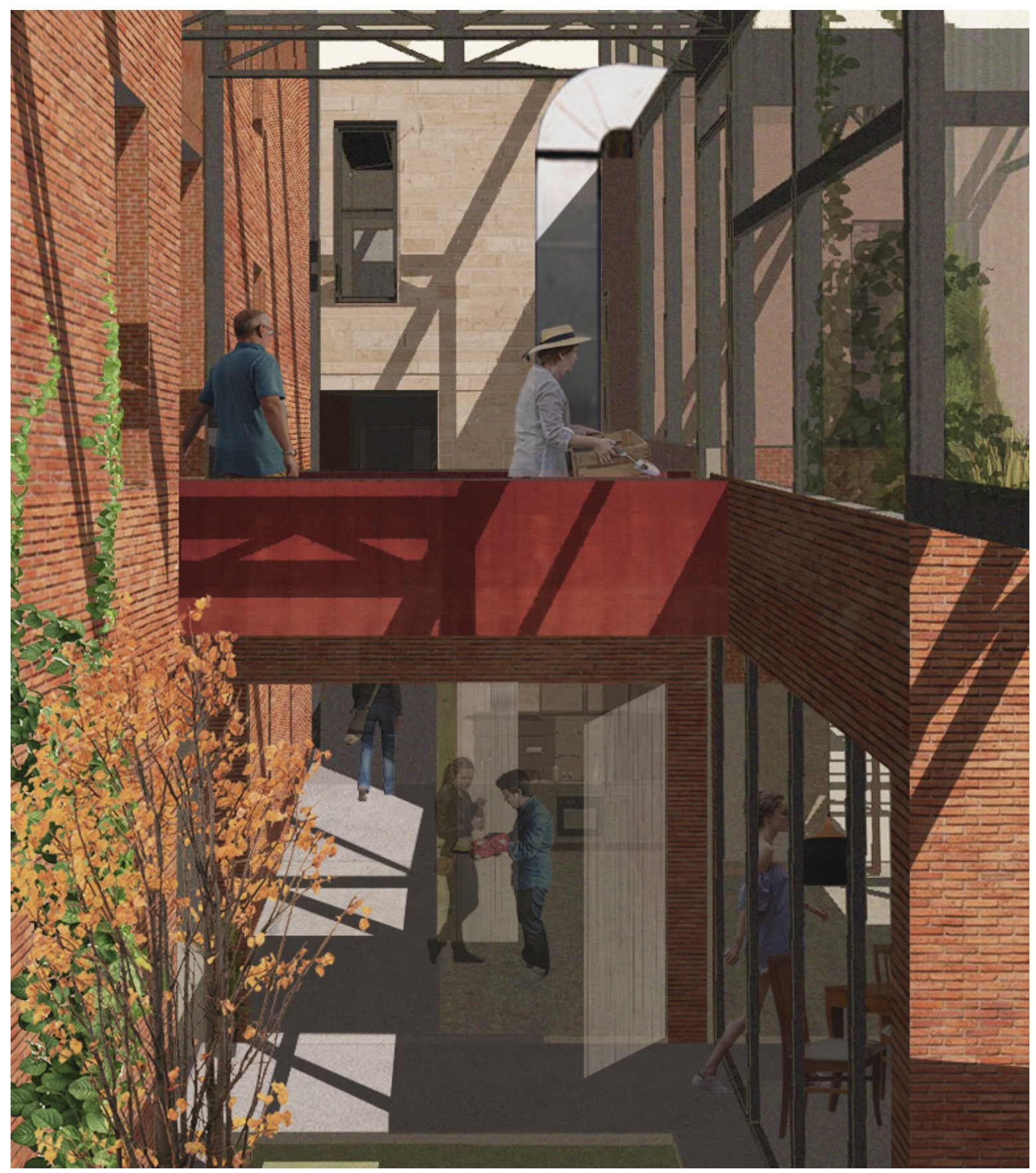

fig 63. View A. The spatial layering and play of levels through the corridic spine. This is a space shared by the entire cluster of enclaves. The architectural space of this common spine is intersected by walkways that connect the promenade spaces of each enclave at the first floor level. These walkways frame the visual space of the

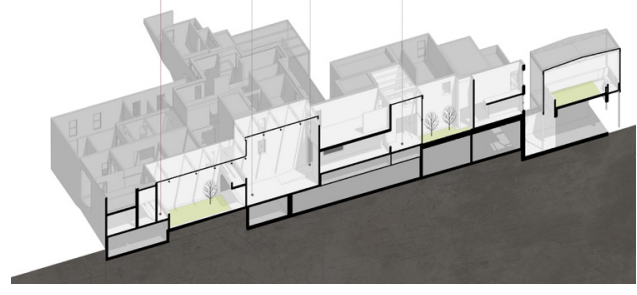
spine and also adds another layer for social interaction to occur. In a subtle way, these bridges delineate the spatial separation between the semi-public and the public realm within the corridic spine while promoting inter-subjectivity within the social space 

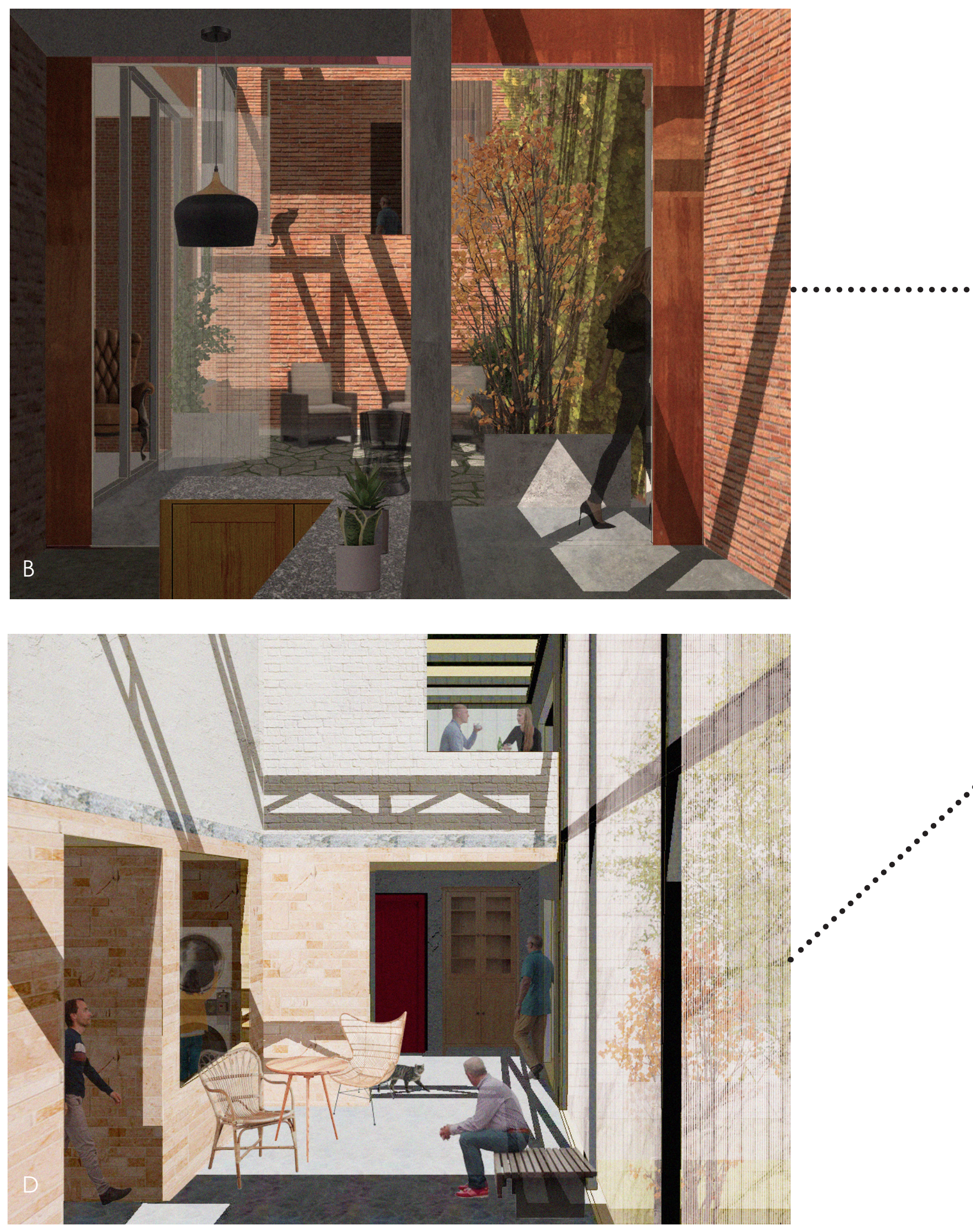


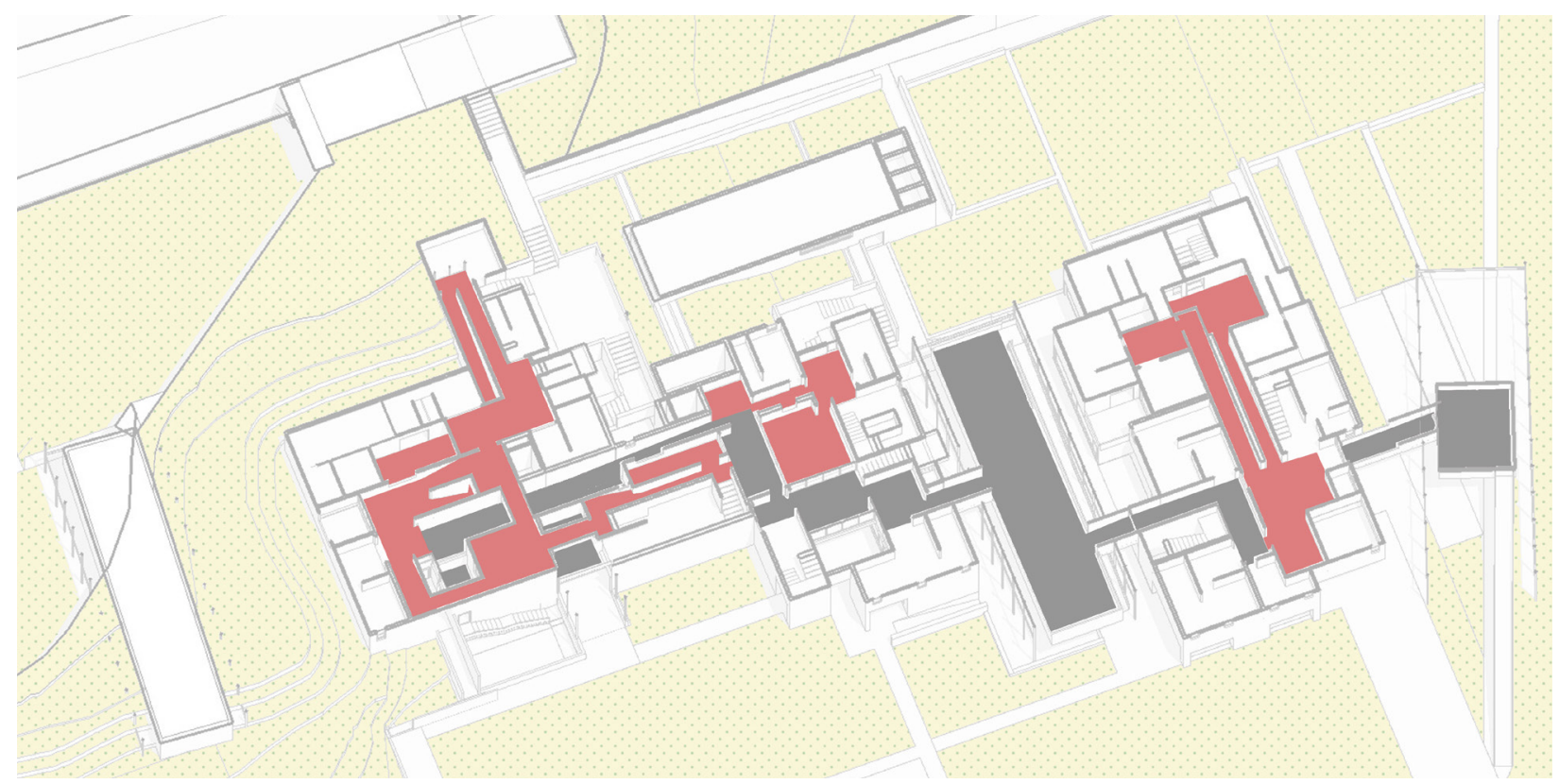

fig 65. Threshold 4The Promenade
Branching from the central 'common' spine, the spatial organization of the corridic space transitions into a series of spatial promenades that guide the inhabitant towards the private dwelling enclaves. The spatial promenade organizes a series of programmatically flexible dwelling spaces around a central element (a common atrium space or a shared garden in this co-housing model) and allows for a progression of architectural realities that elicit a unique visual and bodily experience in the inhabitant traversing through its sequential spaces. This nature of organization puts the inhabitant in a spatial between-ness which by the virtue of being programmatically flexible deconstructs the notion of a dwelling space as a closed entity.

Dwelling occurs in a processual space that is multi-layered and collectively appropriated over time to create a varied landscape conducive to place building (fig 67). This spatial deconstruction of the notion of dwelling reflects what Yi-Fu Tuan categorized as a humanistic topography. Through the various degrees of appropriation, these layered configuration of spaces acquire a texture and presence over time and transforms into the character defining entity of corridic co-living. 


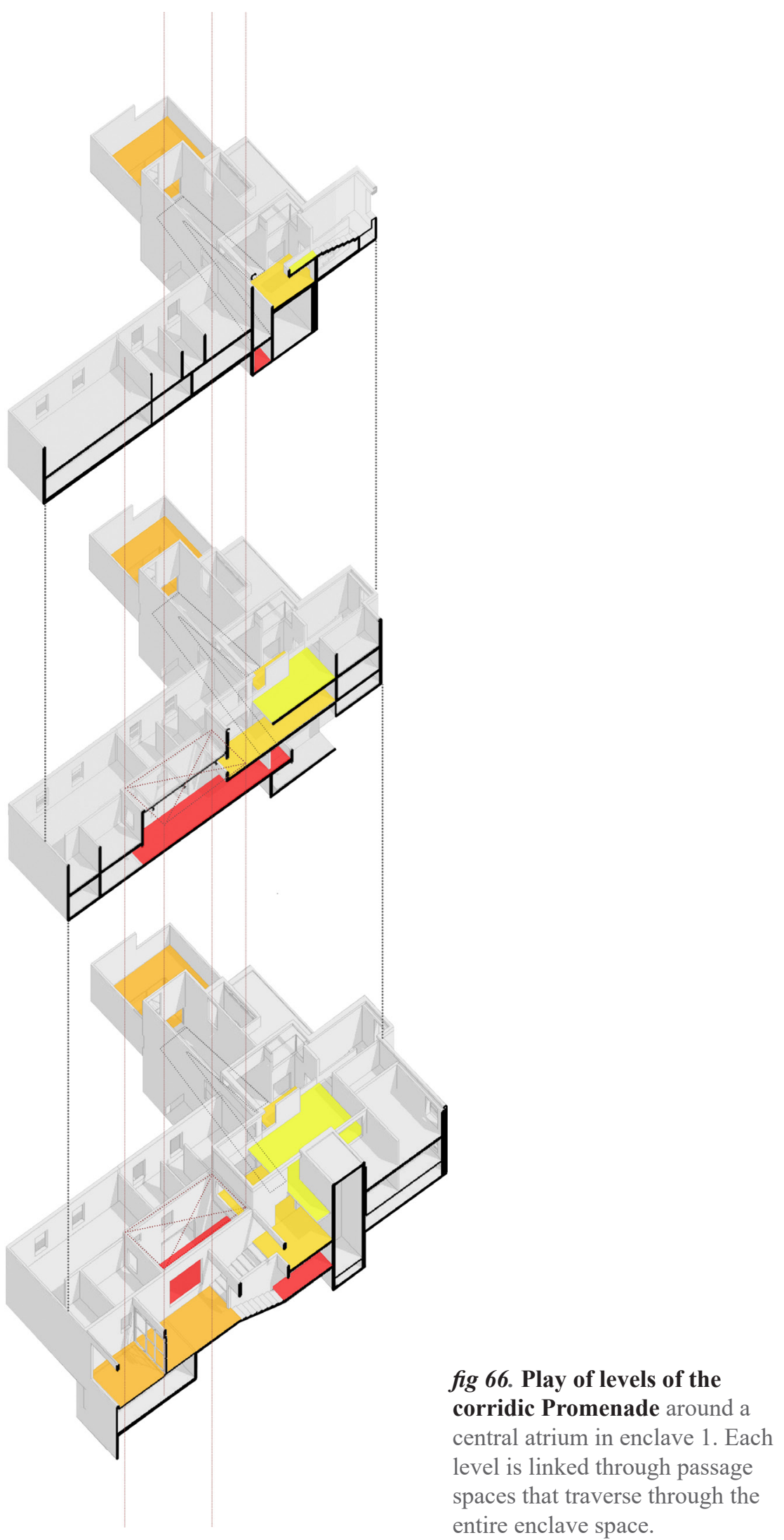




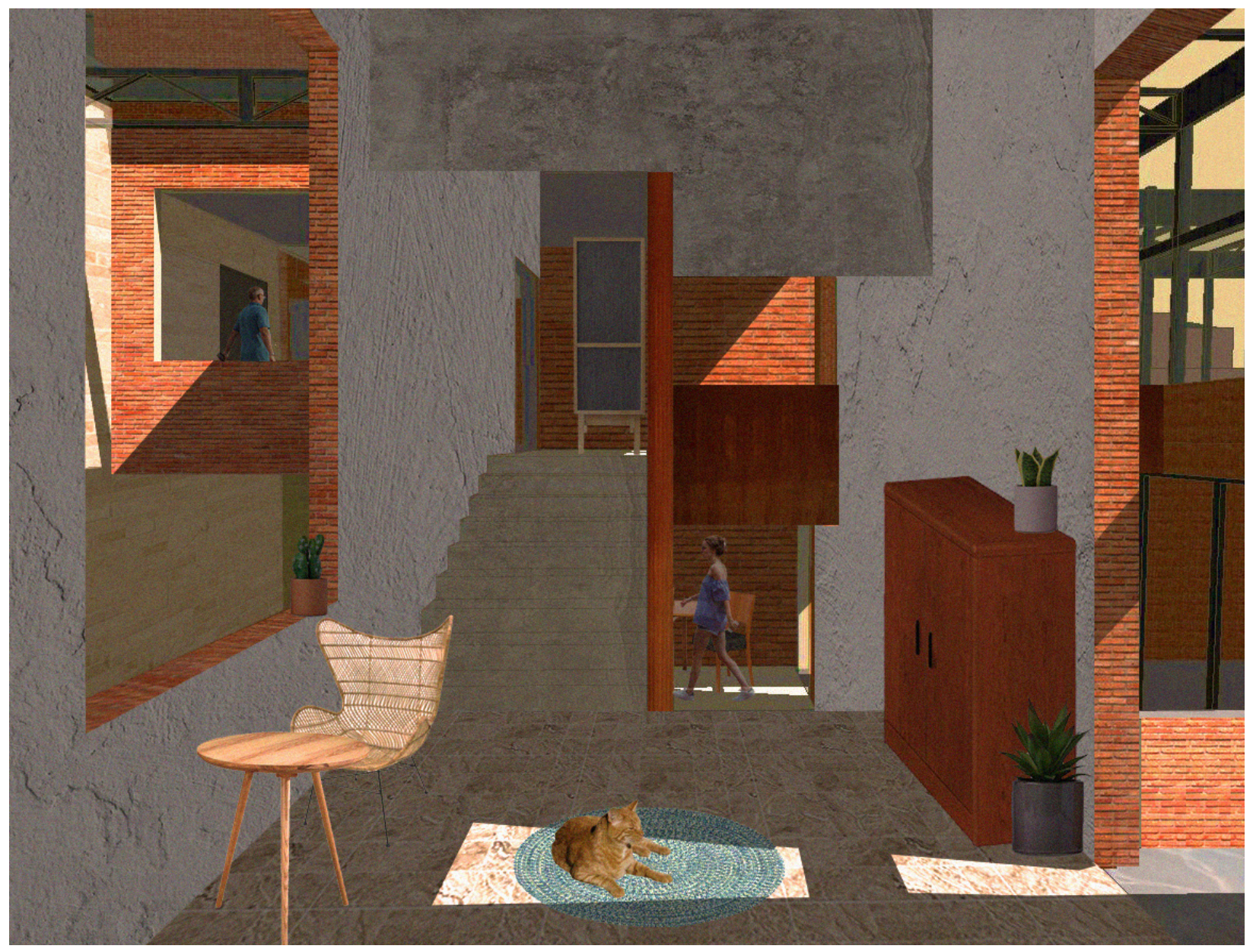

fig 67. Play of levels,

movement and

appropriating a corridic promenade
Another defining character of the corridic promenade in this co-housing model is the varying degrees of movement integrated into its spatial organization as a tool to prolong the lived experience of the inhabitant in its architectural space. As a passage space, this corridic promenade exploit various degrees of movement to orchestrate an ensemble of spatial conditions resonant with the episodic nature of its fragile ontology. This is intended to create moments of pause as the inhabitant comes into a spatial dialogue with the haptic character of the corridic space. In this co-housing model, the promenade infuses each enclaves with an enfilade of experiential pause that arrests the inhabitants in a receptive attention in the course of traversing through the layered dwelling spaces. This compliments the nature of progression of the central dwelling spine but introduces it in a new spatial dimension. 

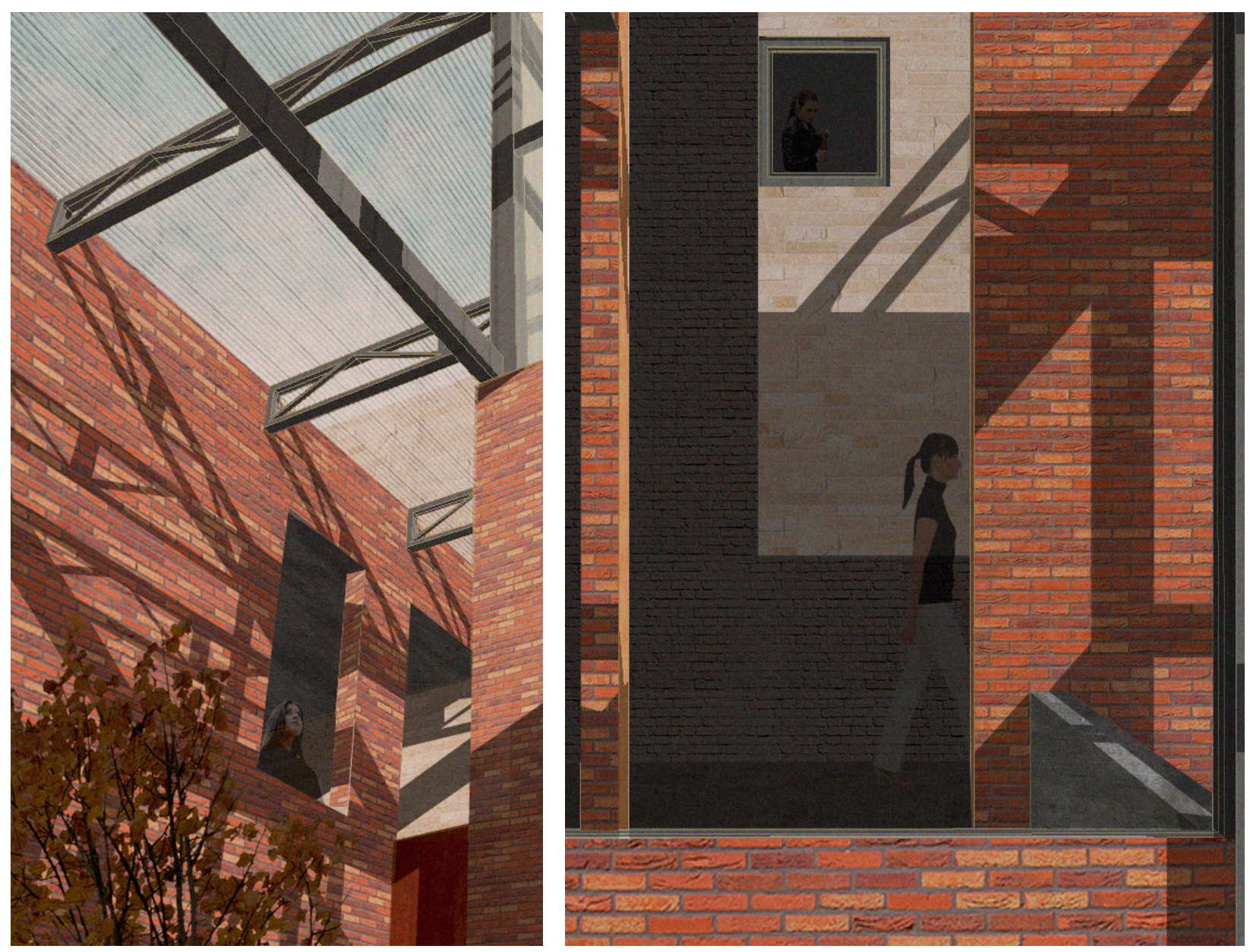

Furthermore, the promenade in this model is a device to break the uniformity and monotony of circulation and evoke a desire for exploration while traversing through the building. The spatial delineation of the de-constructed promenade spaces accentuate the sense of exploration by constructing spatial conditions for chance meetings and happenstances while navigating through the complexity of the corridic space. The spatial delimiters of the promenade is further punctured by large openings and narrow slits that manipulate the visual space of the inhabitant and enables a layered spatial interaction at any given location. This expansion and contraction in visual space while navigating through the dwelling spaces add to the spatial depth of exploring the corridic promenade. fig 68. Large

Openings create vistas and connect visual spaces across different levels in the promenade that arrest the inhabitant in a receptive attention, enabling them to notice and pay attention to the spatial dynamics, textures, light and shadow and other haptic elements that impregnates the corridic space 


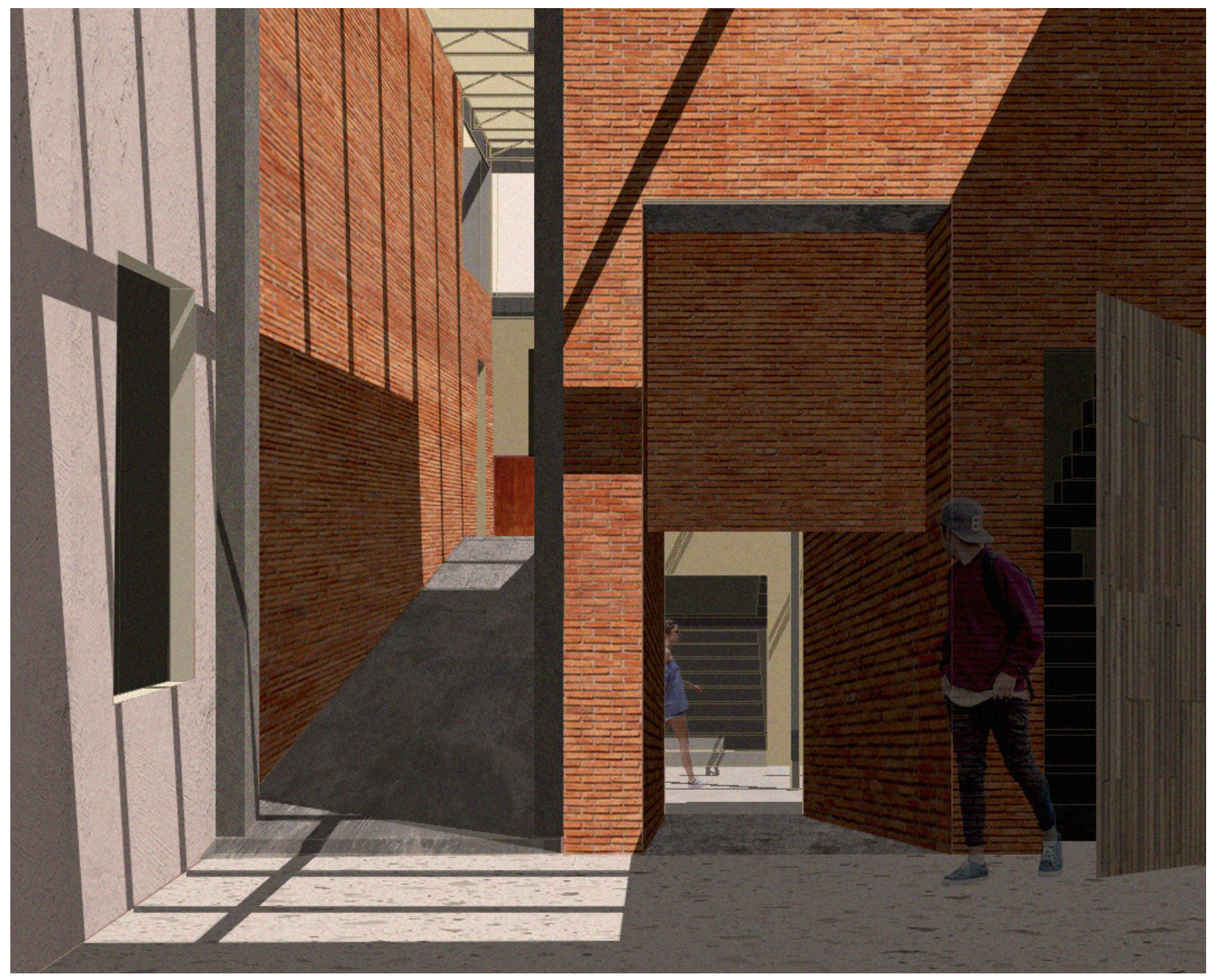

fig 69. Ontology of ramps in the promenade

Mediating levels while de-constructing visual uniformity creates conditions for chance meetings and happenstances. View of ramp in enclave 3
The expansion and contraction of the corridic promenade in this cohousing model is further accentuated by the use of ramps as a threshold passage space. The spatial delimiters expand around a central open courtyard or a shared garden space in a dwelling enclave and each open space is connected and separated at different levels by the use of ramps. The ramps compliment the openness of the central open space by acting as spaces of contraction that influence the course of movement through a corridic promenade. Each dwelling units open inwards into the atrium creating a centralized visual space while the narrowness of the ramps further accentuated by blank walls flanking it, create a more linear visual space. The narrowness of the ramps further reinforce the slowness and experiential quality of a corridic transition 


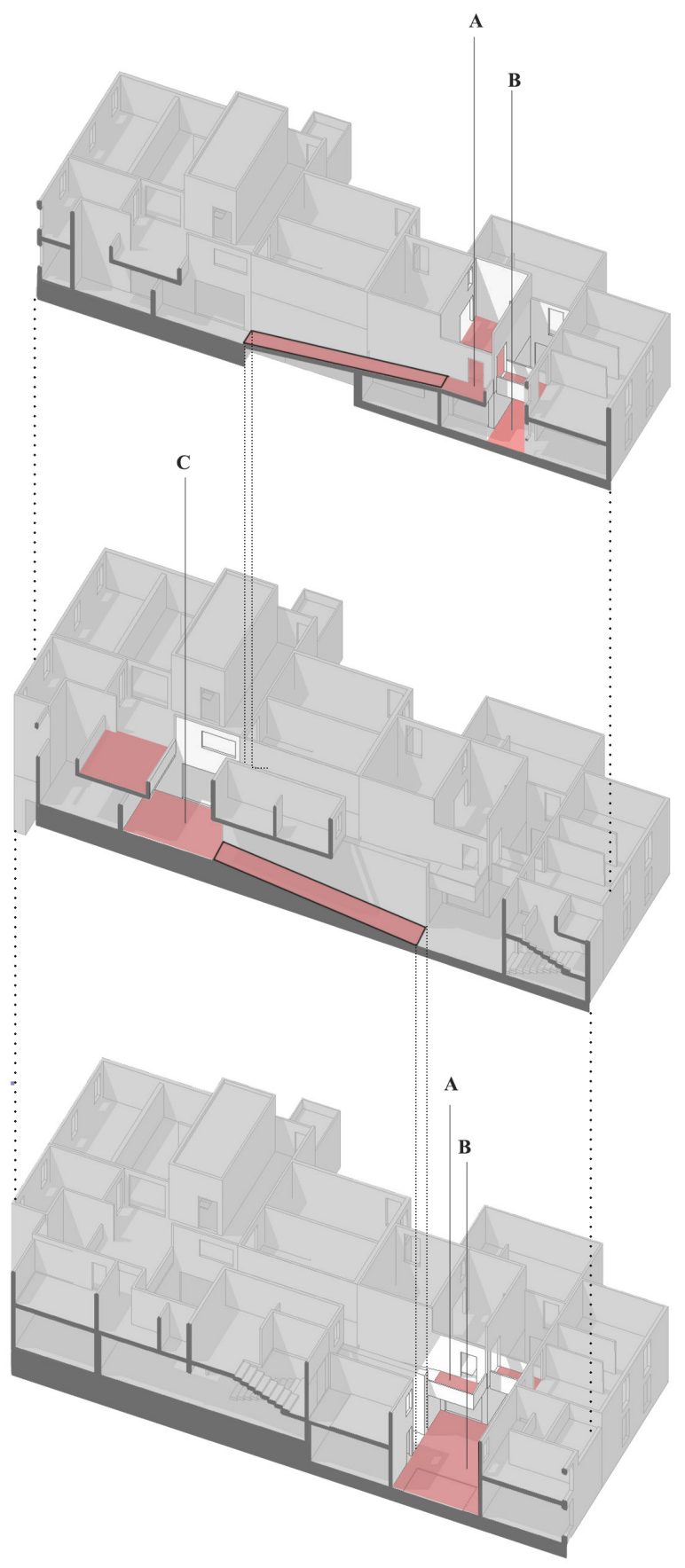

by de-constructing the uniformity of movement and visual connection between different levels in a promenade (fig 70). It creates a sense of approach and journey in the spatial between-ness of the dwelling fig 70. In enclave 3 , as an inhabitant proceeds between A,B the ramp disrupts the visual and spatial connection between point $\mathrm{A}$ and $\mathrm{B}$ by introducing a seperate space $\mathrm{C}$ that reorients the person within the same corridic space enclaves. 


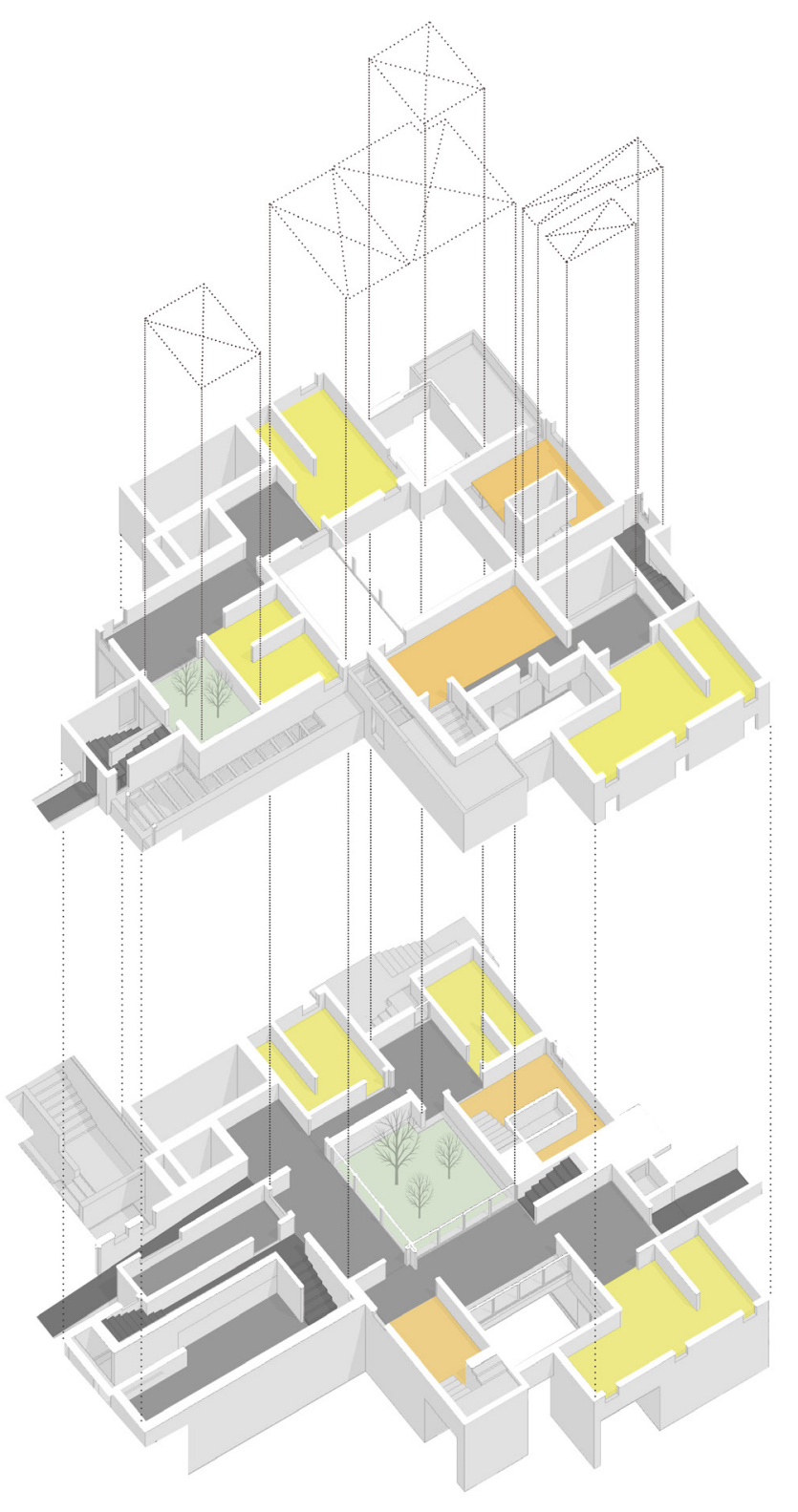

fig 71. Organization of dwelling units around flexible corridic promenade space in enclave 2

The deconstruction of the promenade becomes more articulate around a cluster of private dwelling units in each enclave. This free flowing space in close proximity to each dwelling unit becomes a layered extension of each living space and is collectively appropriated on a smaller, intimate scale. Depending on the degree of occupation and the demographics of each cluster, each intimate flexible spaces acquire its own idiosyncratic character. The adaptability of this interstitial space shared by a cluster provide the opportunity to make modification to the space over time (fig 73). In essence, these relatively unadorned flexible spaces connecting each dwelling unit acts as blank canvases to 


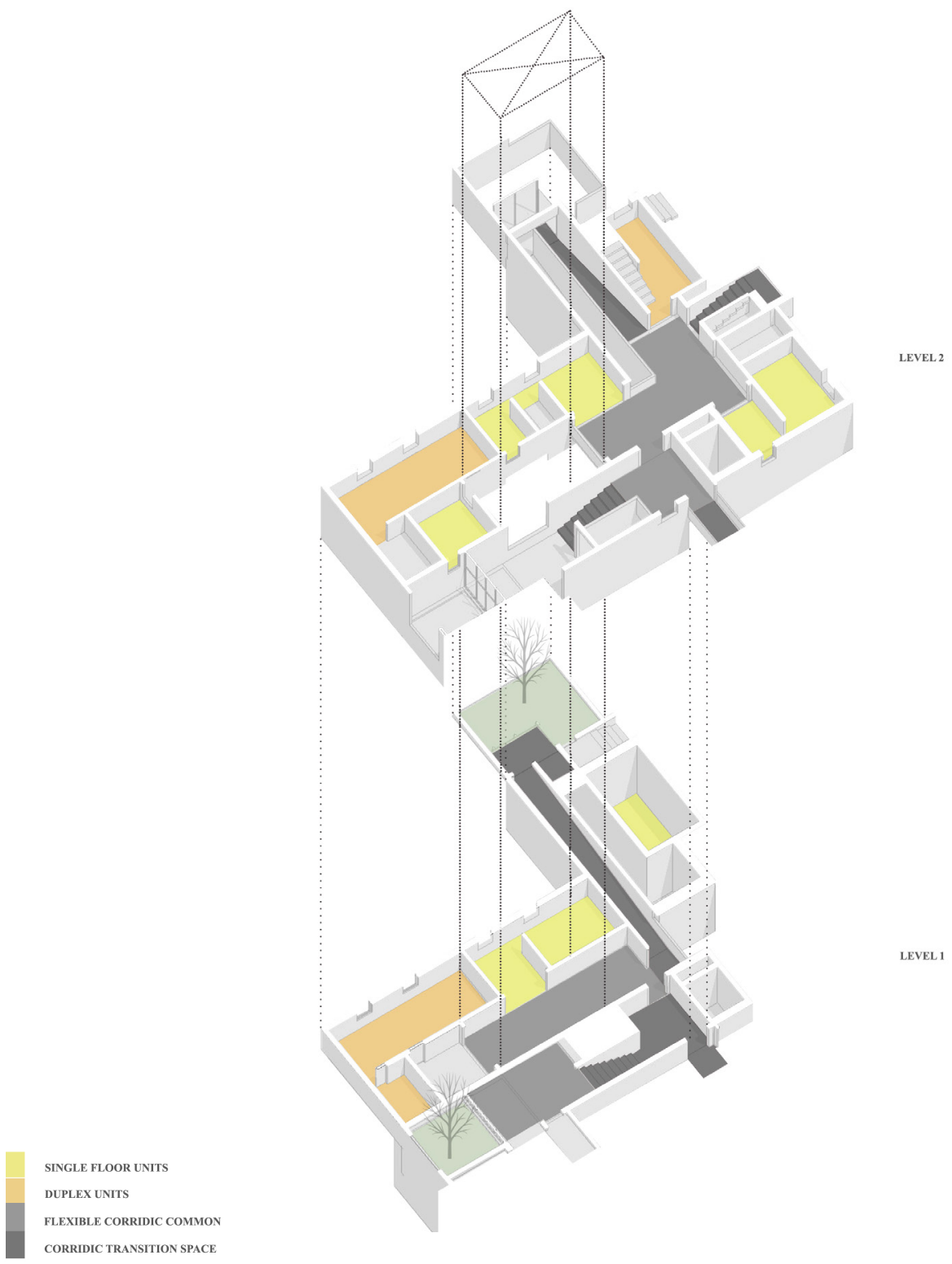

fig 72. Organization of dwelling units around flexible corridic promenade space in enclave 1

accommodate the flexibility of human inhabitation. In the incipient stages of inhabitation, certain structural elements are kept bare in an open corridic space which can be utilized according to the changing needs of the inhabitants. The freedom of modifying this immediate threshold space opens up a multitude of programmatic possibility where maximum spatial control by an individual dwelling unit can be exercised. By according various degrees of spatial delineation, these localized promenade spaces can transform into a multitude of threshold conditions for a dwelling unit like a porch or private parlor or even a common living space between two units, etc $(f i g 74 a, b, c)$. 

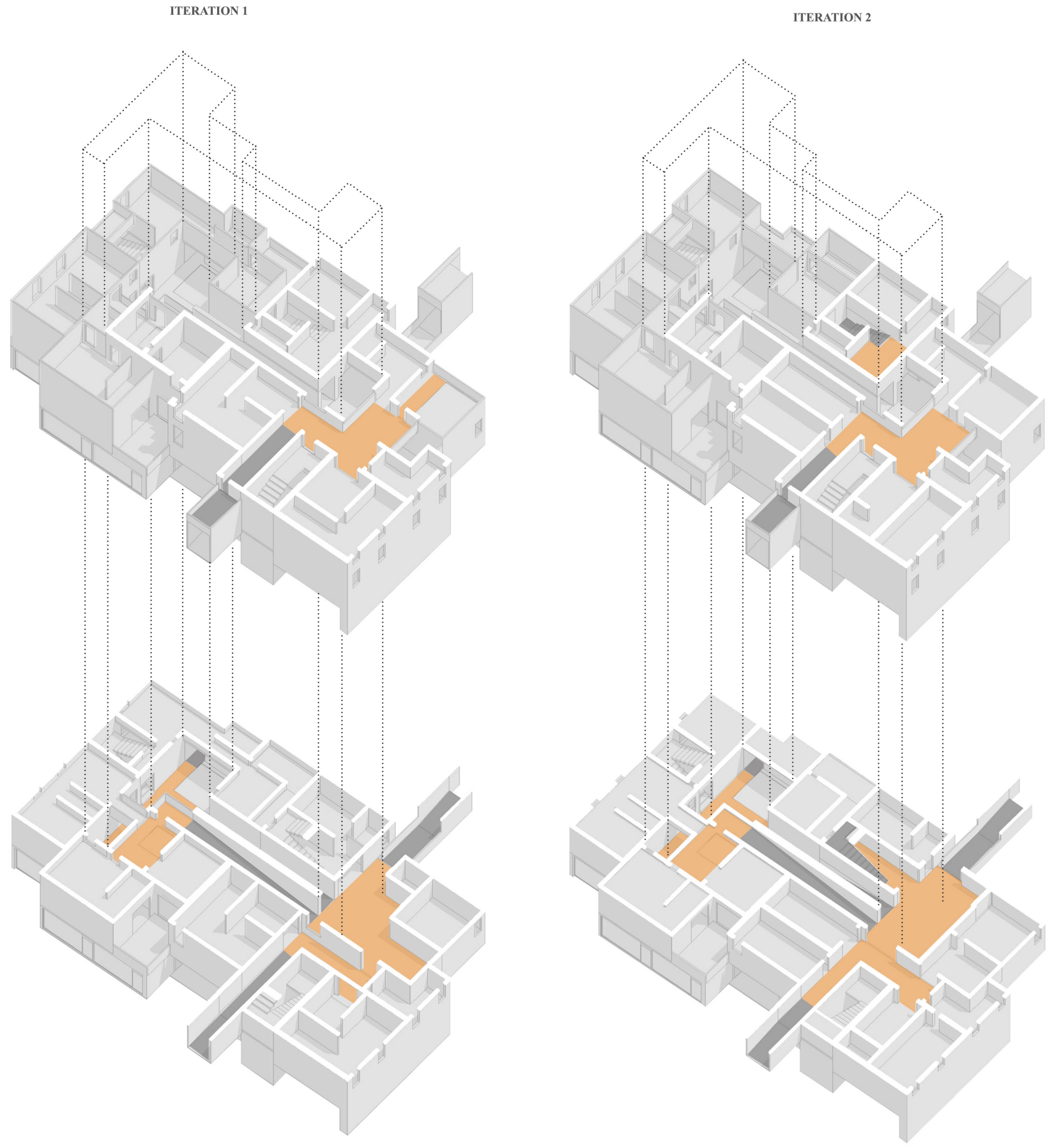

fig 73. Flexibility of the interstitial space in a corridic

promenade facilitates different spatial configurations. Iterations in enclave 3 


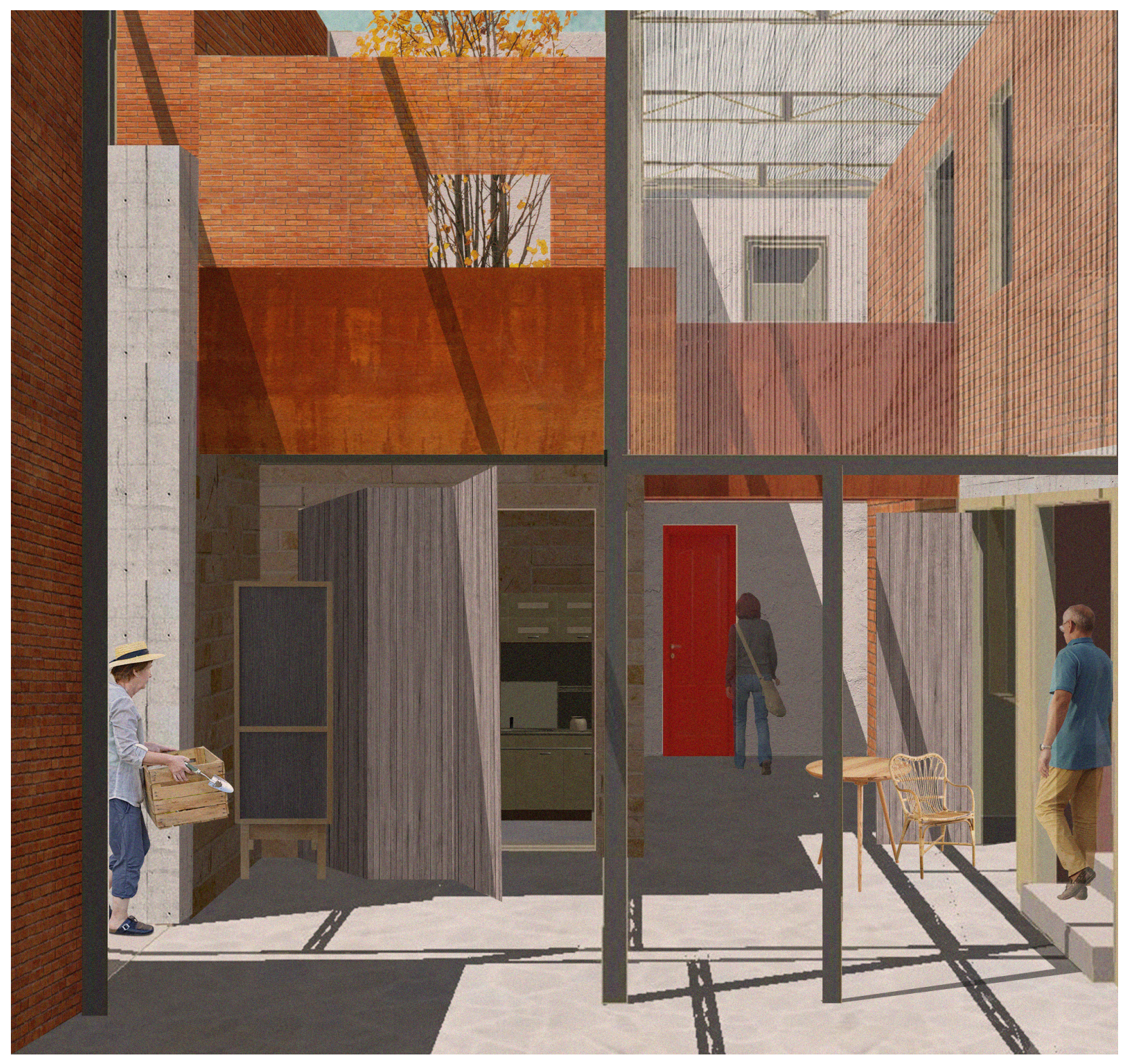

fig 74a. Architecture of change 


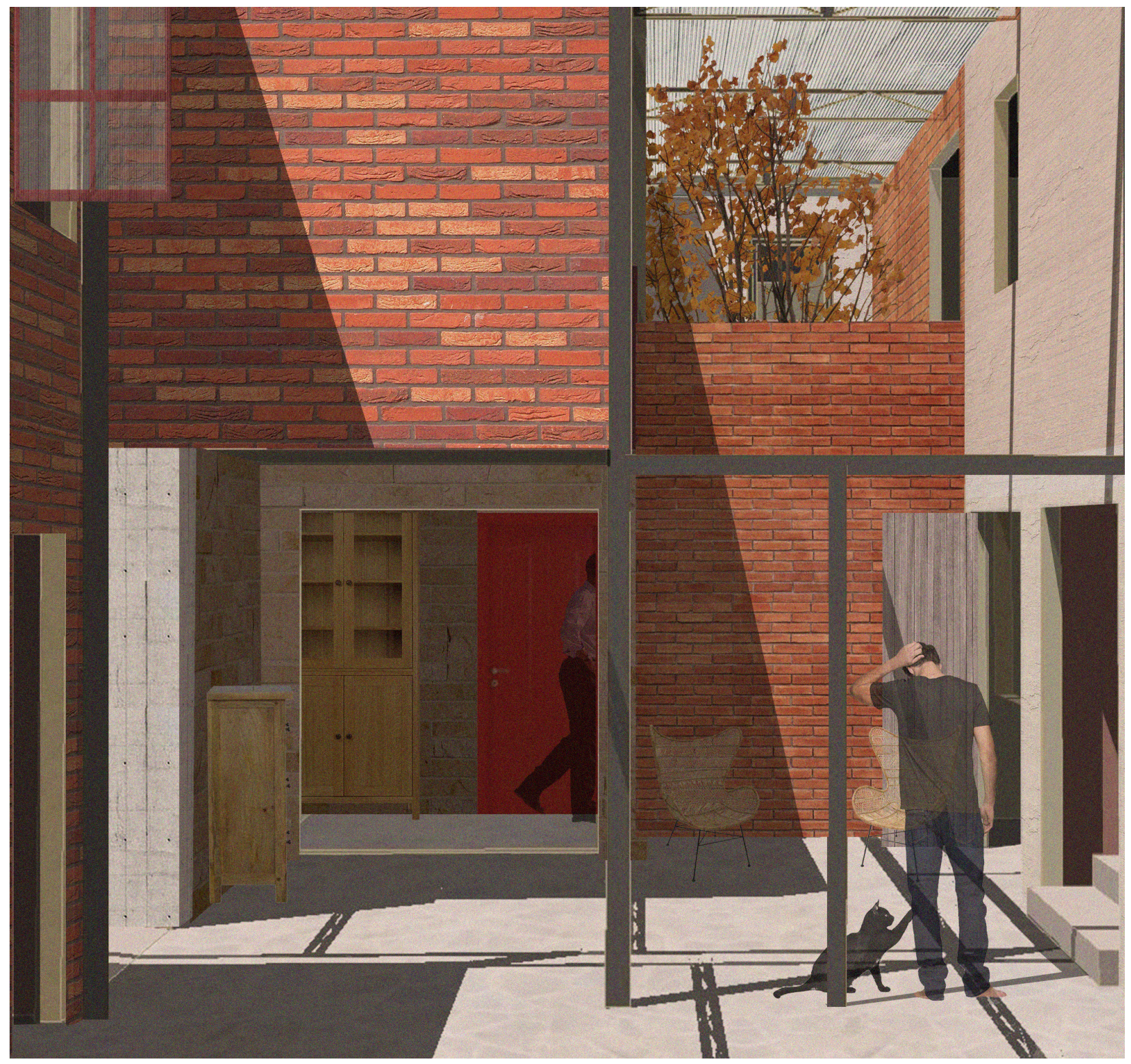

fig 74b. Architecture of change 


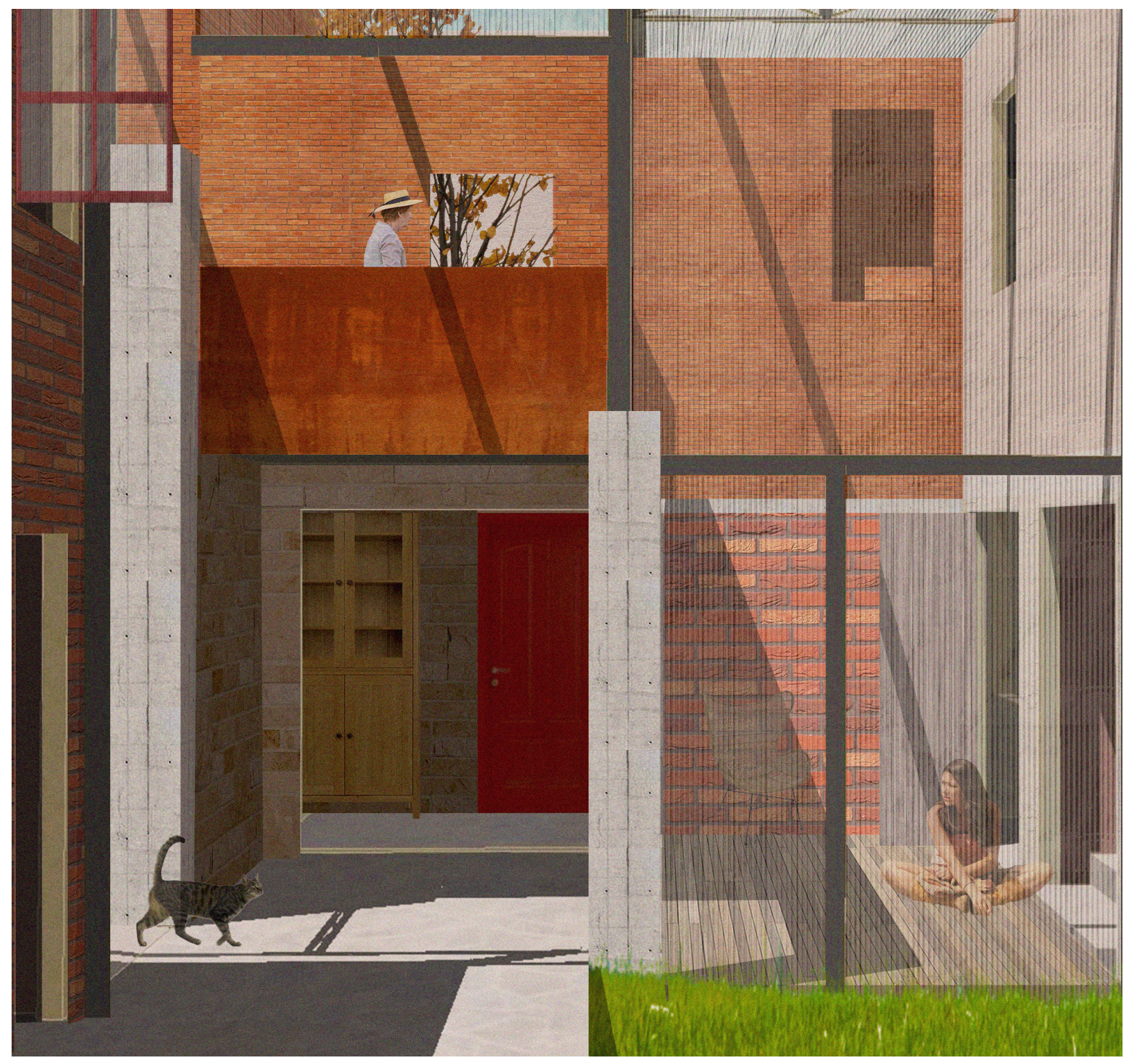

fig 74c. Architecture of change 


\subsection{Corridic Speculations}

The development of the corridic form is a vision that enables long term adaptability as a means of creating and sustaining stable neighborhoods that are organized around co-housing models. Moving away from the isolating and rigid notion of dwelling in high-rise apartments, this idea seeks to engender a tradition of appropriating a fluid space for dwelling in a layered mid-rise residential system. Appropriation of space by adding textures and individual meanings is a powerful tool that defines how the idea of home manifests. In the course of inhabiting a space, various degrees of appropriation is accorded to a space. This act fosters sensual association, familiarity and place-building that creates a place out of space. In a contemporary residential system, this act is a concealed process defined within the closed spatial entity of the apartment space. In a more profound phenomenological sense, the feeling of being home manifests solely upon entering one's appropriated dwelling space. The notion of home remains on the margin of the conscious mind while traversing through a multitude of threshold conditions that exist as an invisible, but dominant liminal spaces within the building. These liminal spaces separates and isolates the idea of home and diminishes the essence of a community that could exist within the building. On that note, this thesis was an investigation into one of those dominant spaces: the residential corridor, and the social dynamics around it.

The corridic notion of dwelling aims to deconstruct that spatial dialogue that exists in the strong delineation between a dwelling space and the corridor. It seeks to formulate a new dialectics where the process of appropriation or place-building extends beyond the closed entity of the apartment space and gain material and presence in the threshold spaces. The corridic notion of dwelling is no longer a concealed rigid concept, but a layered process that define the architectural language of the entire residential space. 
The model for co-housing illustrated as a product of this phenomenological investigation of the corridic dwelling is an idea exploring how future shared dwelling spaces can be conceptualized. This model aims to create a new communal dialectics in light of the current trajectory of social dynamics in metropolitan cities where retaining communities is a growing issue. Moving away from the homogeneity of residential development created in the 20th and 21 st century Toronto, the corridic model can serve as a precedent for future conceptualizations where a housing project is conceived in resonance with the multi-layered nuances of human dwelling. These projects could aim to shirk away from the race for the heights and profit-driven developments and opt for a space that is self-initiated, adaptable and community-driven with shared responsibility for defining and redefining the place of dwelling. Instead of opting for verticality, the spatial organization in the co-housing model can be perceived with a more horizontal modularity where different configuration of dwelling spaces can be linked in a corridic sense and create an eclectic collage of texture and spatial conditions that foster social interactions. A dwelling using corridic form could be a place for a sensitive transformation between two different modes of existence inside and outside the building, it could be a space for phenomenological experiences where living is a sequence of sensory experiences that construct a place for interiority. On a conclusive note, the corridic model of dwelling is a vision for a residential space that is layered, human-scaled, contemplative, and imbued with the material imagination of a cultural place. 
Living In-Between 


\section{Appendices}

The following drawings which did not find a place in the main body of research, remained a critical part of the design process and contributed immensely to the understanding of a layered corridic space within an enclosed residential system. The diagrams focus purely of the nature of the layered shared spaces in a corridic common and includes sectional illustrations of the organisation of these layered space throughout the corridic model 


\section{Appendix A}

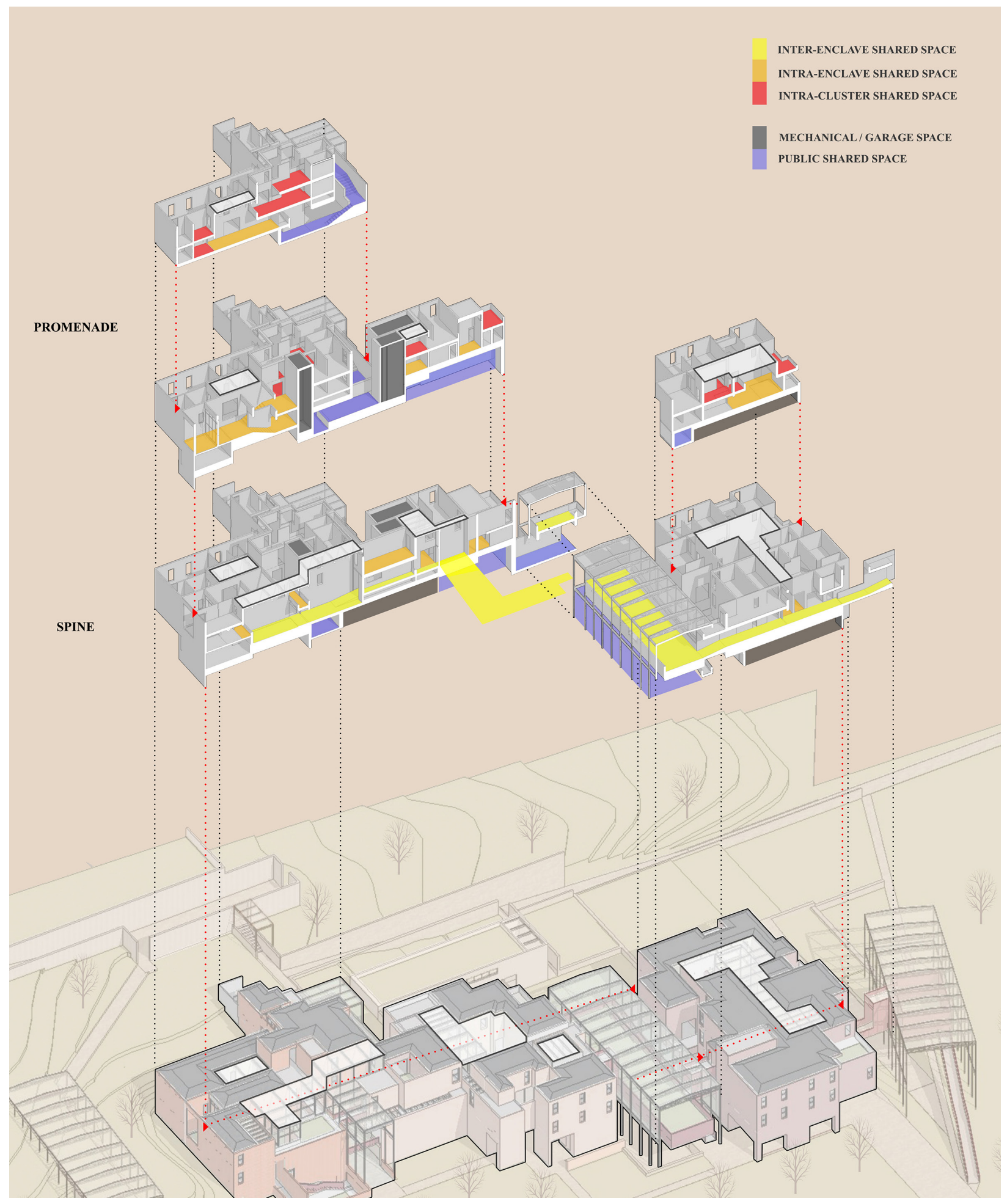

A1. Heirarchy in shared space 
Appendices

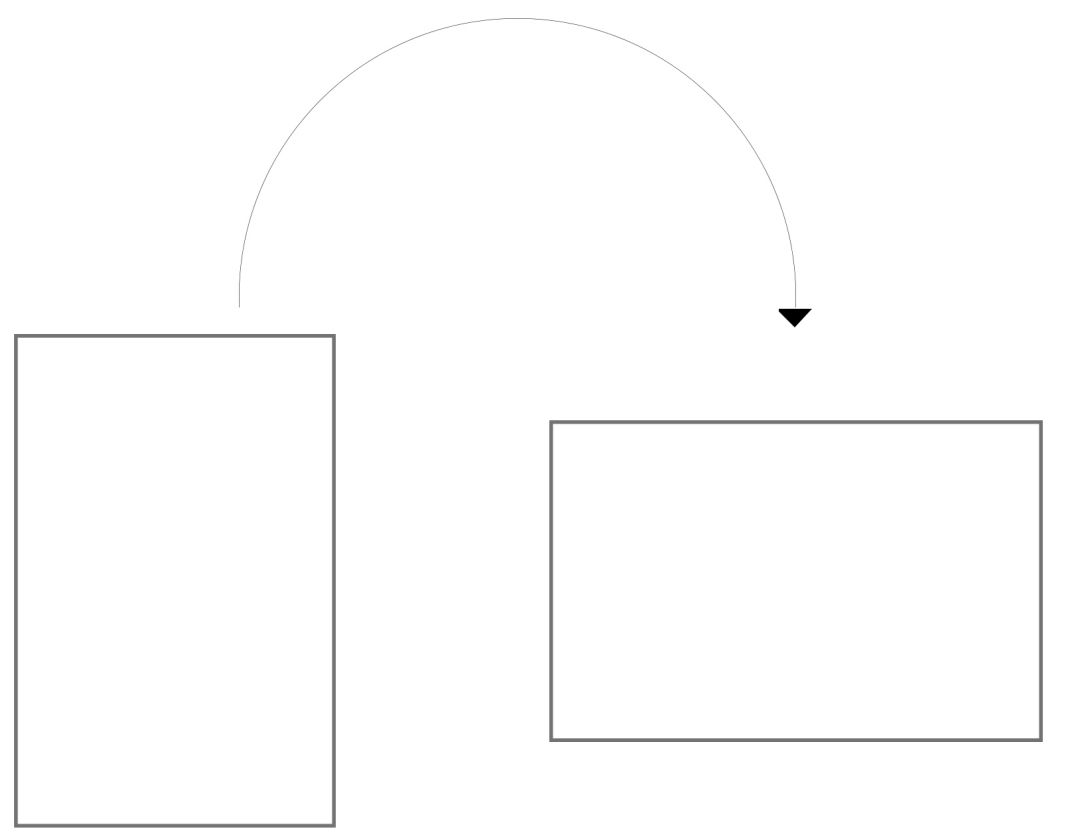



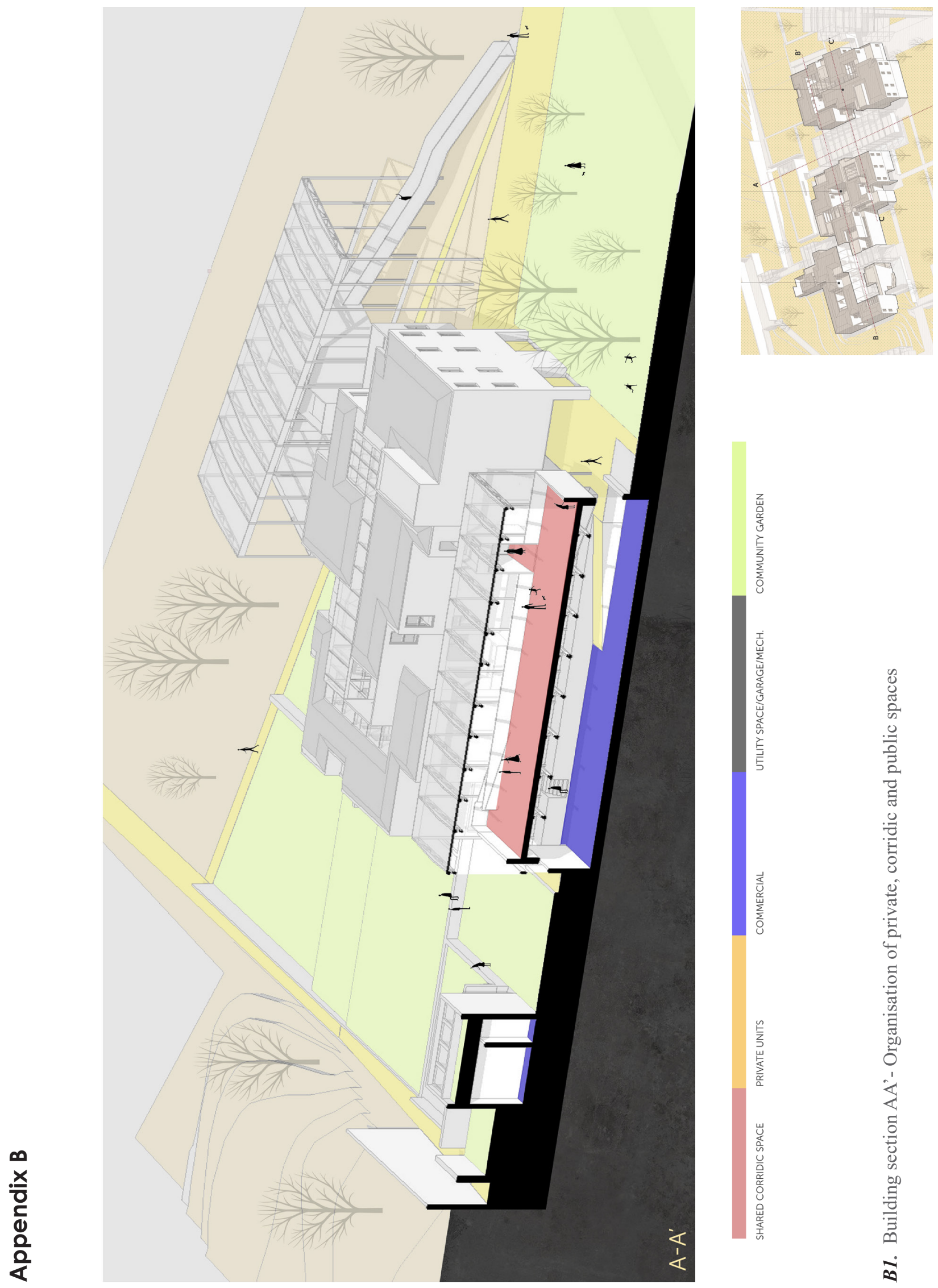

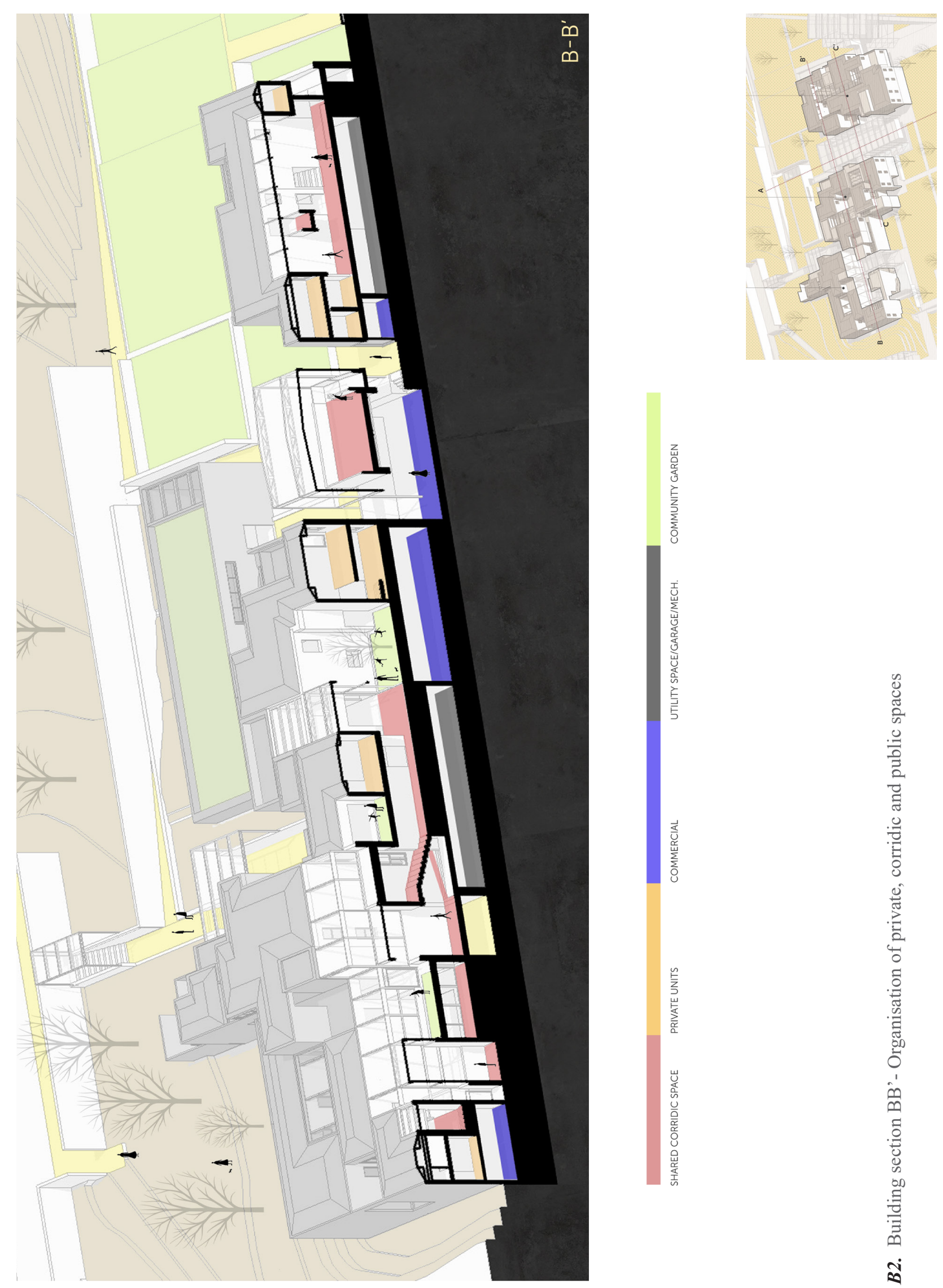

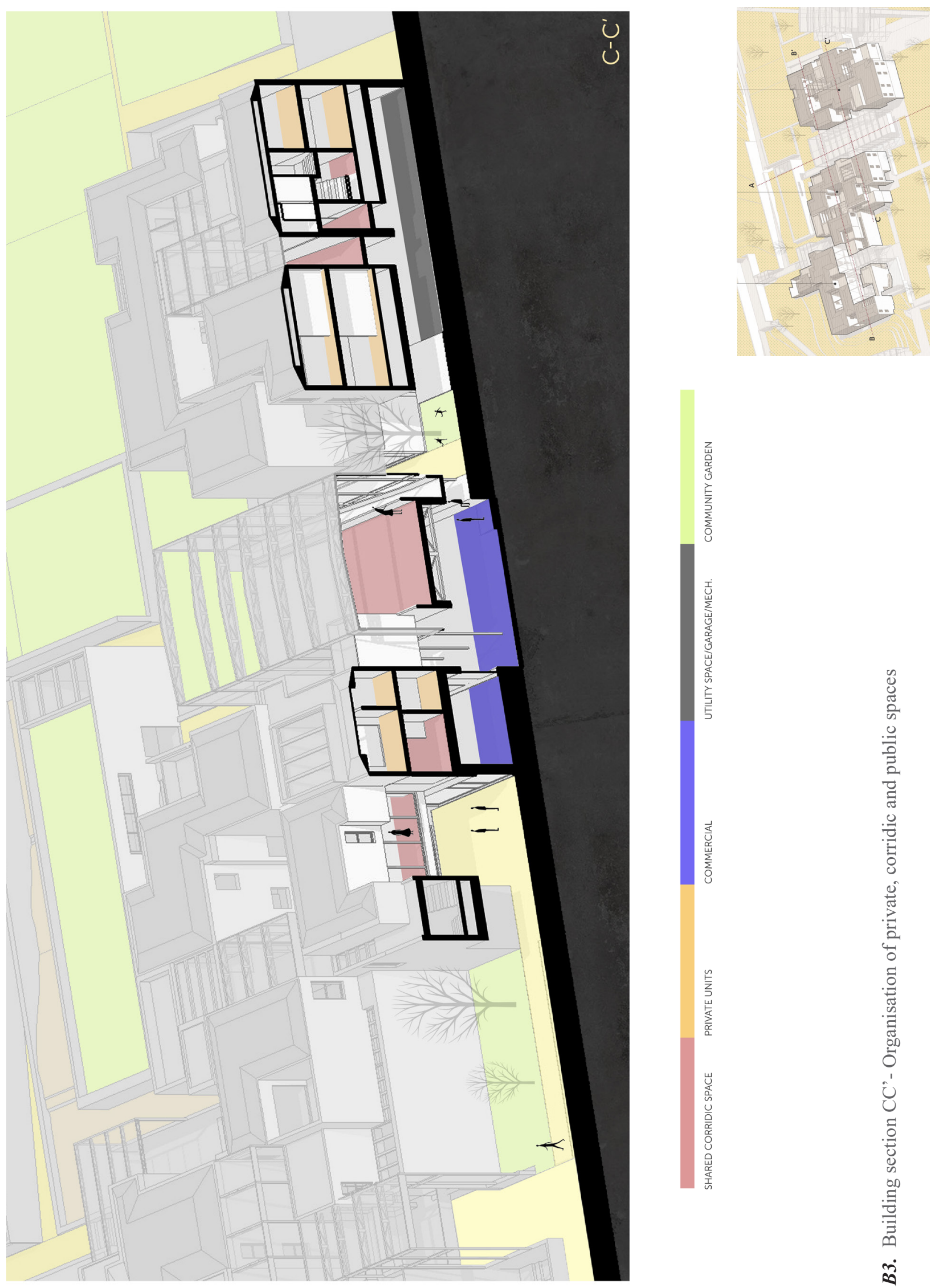

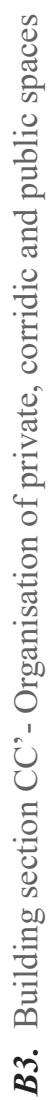


Appendices

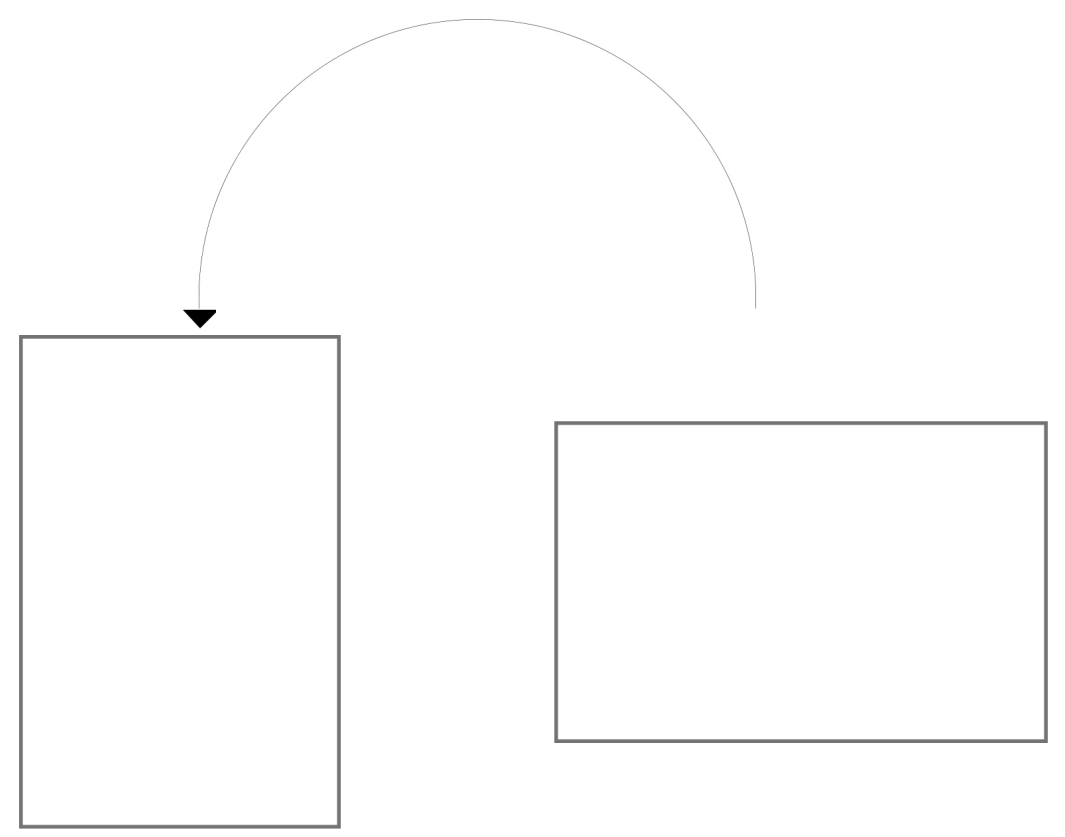




\section{Bibliography}

Abrahamson, D. (2016). Obsolescence: An Architectural History. Chicago: University of Chicago Press.

Alexander, B. (1991). Victor Turner Revisited: Ritual as Social Change. Michigan: Scholars Press.

Bachelard, G. (1969). The Poetics of Space. Boston: Beacon Press.

Bhatt, V. (n.d.). Balkrishna Doshi's Aranya. Retrieved from Canadian Centre for Architecture: www.cca.qc.ca

Bly, R. (1990). Iron John: A Book About Men. Addison-Wesley.

Boettger, T. (2014). Threshold Spaces: Transitions in Architecture Design and Analysis tools. Basel: Birkhauser.

Cage, J. (1973). Silence: Lectures and Writings by John Cage. Hanover: University Press of New England.

Cook, S. (2009). The Evolution of the American Front Porch: The Study of an American Cultural Object. Retrieved from American Studies at the University of Virginia: http://xroads.virginia.edu

Corbusier, L. (1929). The City of To-morrow and Its Planning. Dover Publication; Reissue edition 1987.

Dowell, C. (1992). Out on the Porch. New York: Algonquin Books of Chapel Hill.

Eldin, C. (2017, November 21). Moriyama House by Ryue Nishizawa. Retrieved from More With Less: https://morewithlessdesign.com

Evans, R. (1997). Figures, Doors and Passages. In Translations from Drawing to Building and Other Essays (pp. 70-71). MIT Press.

Hardingham, S. (2016). Cedric Price Works 1953 - 2003. A ForwardMinded Retrospective. Architectural Association.

Hardingham, S. (2016). Cedric Price Works 1953-2003. A Forward minded Retrospective. Architectural Associatin. 
Heidegger, M. (1971). Poetry, Language, Thought. (A. Hofstadter, Trans.) New York: Harper Colophon Books.

Hurdley, R. (2010). The Power of Corridors: Connecting Doors, Mobilising Materials, Plotting Openness. The Sociological Review, 45-64.

Hurdley, R. (2017, September 29). The Hidden History of the Corridor. (B. R. 4, Interviewer)

Jarzombeck, M. (2010). Corridor Spaces. Critical Inquiry, 732-733.

Jones, B. (2018, April 20). The Civic Character of a Front Porch. Retrieved from Strong Town: https://www.strongtowns.org

Kahn, L. (1973). The Room, The Street and the Human Agreement. A + U-Architecture and Urbanism.

Kahn, R., \& Meagher, E. (1990). Preserving porches. New York: Henry Holt \& Co.

Koetter, F. (1980). Notes on the In-Between. Harvard Architectural Review.

Krivens, D. (2017, July 4). "Building bridges" has failed to unite us. America needs to embrace the front porch instead. Retrieved from Quartz: https://qz.com

Kwinter, S. (2002). Architecture of Time. Cambridge: MIT Press.

Lefebvre, H. (1991). The Production of Space. (D. N. Smith, Trans.) Cambridge: Basil Blackwell Ltd.

Mackenzie, A. (2015, March 2). Reimagining our Streets as Places from Transit Routes to Community roots. Retrieved from Project for Public Spaces: www.pps.org

McAlester, V. (1984). A Field Guide to American Houses. New York: Knopf.

McCullers, C. (1940). The heart is a lonely Hunter. Houghton Mifflin Harcourt.

Merton, R. (1948). The Social Psychology of Housing. Current Trends in Social Psychology, 163-217. 
Pallasmaa, J. (2000). Hapticity and Time: Notes on Fragile Architecture. The Architectural Review, 78.

Pegrum, J. (2002). The Vaastu Home. Ulysses Press.

Pickering, E. (1951). The Homes of America. New York: Thomas Y. Cromwell Company.

Post, E. (2004, December 10). Etiquette. Retrieved from The Project Gutenberg: http://www.gutenberg.org

Relph, E. (1993). Modernity and the Reclamation of Place. In D. Seamon, \& D. Seamon (Ed.), Dwelling, Seeing and Designing: Toward a Phenomenological Ecology (pp. 25-40). New York: SUNY Press.

Ring, K. (2016, November 21). Reinventing density: how baugruppen are pioneering the self-made city. Retrieved June 23, 2019, from The Conversation: theconversation.com

Rowe, P. (1991). Making a middle Landscape. Boston: MIT Press.

Schacher, C. (2006, October). The Good and the Bad of Cohousing. Retrieved june 10, 2019, from ALA-APA: http://ala-apa.org

Schmid, C., Milgrom, R., \& Kipfer, S. (2008). Space, Difference, Everyday life: Reading Henri Lefebvre. New York: Routledge.

Schulz, C. N. (1980). Genius loci: towards a phenomenology of architecture. Academy Editions.

Seamon, D., \& Sowers, J. (2008). Place and Placelessness, Edward Relph. Key Texts in Human Geography, 43-51.

Staneck, L. (2011). Henri Lefebvre on Space: Architecture, Urban Research and the Production of Theory. University of Minnesota Press.

Stephen, A. (2014). User Experience in the Threshold Matrix of Public: Design Intervention in a Complex Environment. Texas: Texas State University.

Thomas, R. H. (1973). From Porch To Patio. The Palimpsest, 122-123.

Tuan, Y.-F. (1975, April). Place: An Experiential Perspective. Geographical review, 65, 151-165. 
Tuan, Y.-F. (2001). Space And Place: The Perspective of Experience . University of Minnesota Press.

Turner, V. (1995). The Ritual Process: Structure and Anti-structure. Transaction Publishers.

Van Gennep, A. (1960). The Rites of Passage. Chicago : The University of Chicago Press.

Welten, R. (2016). Community from the Perspective of Life. Analecta Hermeneutica, 132-133. 